FABIANO MORENO PERES

DESENVOLVIMENTO DE MÉTODOS ALTERNATIVOS PARA A AVALIAÇÃO DA RESISTÊNCIA À FRATURA POR FLUÊNCIA DE RESINAS DE POLIETILENO UTILIZADAS PARA A EXTRUSÃO DE TUBOS DE ÁGUA

Dissertação apresentada à Escola Politécnica da Universidade de São Paulo para obtenção do Título de Mestre em Engenharia 
FABIANO MORENO PERES

\section{DESENVOLVIMENTO DE MÉTODOS ALTERNATIVOS PARA A AVALIAÇÃO DA RESISTÊNCIA À FRATURA POR FLUÊNCIA DE RESINAS DE POLIETILENO UTILIZADAS PARA A EXTRUSÃO DE TUBOS DE ÁGUA}

Dissertação apresentada à Escola Politécnica da Universidade de São Paulo para obtenção do Título de Mestre em Engenharia Área de Concentração:

Engenharia Metalúrgica e de Materiais

Orientador:

Prof. Livre-Docente

Cláudio Geraldo Schön 
FICHA CATALOGRÁFICA

Peres, Fabiano Moreno

Desenvolvimento de métodos alternativos para a avaliação da resistência à fratura por fluência de resinas de polietileno utilizadas para a extrusão de tubos de água / F.M. Peres. -- São Paulo, 2005.

$168 \mathrm{p}$.

Dissertação (Mestrado) - Escola Politécnica da Universidade de São Paulo. Departamento de Engenharia Metalúrgica e de Materiais.

1.Tubos de polietileno 2.Distribuição de água (Sistemas) 3.Mecânica da fratura I.Universidade de São Paulo. Escola Politécnica. Departamento de Engenharia Metalúrgica e de Materiais II.t. 
Com carinho e amor:

Aos meus pais Jordão e Aurélia

À minha esposa Luciana

Aos meus filhos Natália, Diego, Lívia, Fabiana e Joana Aos meus irmãos Luciana, Jordão, Laureano e Fernanda. 


\section{AGRADECIMENTOS}

Agradeço a todas as pessoas que contribuíram neste trabalho, especialmente:

Ao amigo e orientador Prof. Dr. Cláudio Geraldo Schön pelo permanente incentivo, pelo incansável apoio, pela segura orientação, pela confiança e pela fraterna convivência.

Ao inestimável Leonardo Nino pela colaboração dedicada e pela convivência fraterna.

Aos amigos Wanderson, Márcio, Joelmir, Alessandra, Cláudia e demais colegas da pós-graduação do PMT/EPUSP pela convivência fraterna e pela colaboração.

Aos amigos Clélia, Gilberto, Lívio, Danilo, Rubens e demais funcionários do PMT/EPUSP pela valiosa colaboração.

Ao Prof. Dr. Eduardo Ioshimoto e ao Prof. Dr. Jan Vatavuk pelas valiosas contribuições.

Aos amigos Nicolai Duboc, Antonio Rodolfo Jr., Renato Di Thommazo, Jonadabe de S. Santos, Saul Costa, Rosina Coimbra, Luciana P. Panza e Eliton J. da Silva, pelo apoio.

Às empresas Braskem S.A., Dow Brasil S.A., Ipiranga Petroquímica S.A., Solvay Indupa do Brasil S.A., Cromex S/A e Brashidro S.A. pelo fornecimento de materiais, pelo apoio e pelo uso de laboratórios.

À SABESP pela liberação para cursar as disciplinas e para o desenvolvimento do trabalho.

Ao meu sogro Dr. Michel, à minha sogra Dna. Lourdes e à minha cunhada Ana Lúcia.

Ao Pierre (bissinho). 


\section{RESUMO}

O polietileno tem sido muito empregado em transmissão de água potável, particularmente em ramais prediais. Este polímero apresenta vantagens em relação a seus concorrentes, como flexibilidade, baixo preço, facilidade de instalação e resistência à corrosão. Os tubos fabricados com polietileno de alta densidade PEAD, como o material é genericamente conhecido na indústria de saneamento básico no Brasil - são suscetíveis de apresentar falhas em serviço por fratura em fluência, as quais provocam vazamentos e perdas de água e incorrem em maiores custos de manutenção. Os principais fatores que influenciam a vida dos tubos de polietileno são: material, meio, condições de carga e técnicas de instalação. A busca de melhores materiais tem levado a indústria petroquímica ao contínuo desenvolvimento de novas resinas, com maior resistência às falhas, que ocorrem através do crescimento lento de trincas. Essa resistência à falha em serviço dos tubos geralmente é avaliada através de ensaios de resistência à pressão hidrostática interna de longa duração, realizados em diferentes temperaturas. Nestes ensaios observa-se que o PEAD apresenta comportamento dúctil (acompanhado de significativa deformação plástica) e falha em menor período de tempo a níveis elevados de tensão, enquanto que em níveis mais baixos de tensão o material apresenta falhas com aparência frágil - sem deformação plástica visível apreciável - após longos períodos de tempo. As falhas em serviço são predominantemente deste último tipo. Esta transição "dúctil-frágil" no comportamento do material, pelo menos ao nível da falha macroscópica, é muito importante e precisa ser bem compreendida pois pode abreviar a vida útil do tubo através de falhas precoces. Dados de tensão circunferencial versus tempo de ruptura dos tubos podem ser plotados em escala bilogarítmica, formando o que se conhece na prática industrial por "curva de regressão", a qual é linear, com inclinação negativa e com maior inclinação (em módulo) na região correspondente às falhas do modo frágil. Dessa forma, a transição “dúctil-frágil" apresenta-se na "curva de regressão" como um ponto de inflexão. A tensão de transição dúctil-frágil é característica de uma dada formulação (composto) e não é facilmente determinada em ensaios conduzidos à temperatura ambiente. Apesar de sua ampla aceitação na indústria os testes de resistência à pressão hidrostática interna de longa duração devem ser criticados pois são muito longos, 
caros e pouco práticos para efeito de controle de qualidade dos tubos de polietileno. Além disso, a maioria dos dados são coletados a altas pressões internas (ou seja, na região "dúctil") para economizar tempo, enquanto que os tubos operam na região “frágil". A filosofia desses testes, como empregados na indústria, também implica que o tempo de falha é uma propriedade do material, enquanto que fatores extrínsecos, como defeitos introduzidos durante a instalação, podem reduzir o tempo de nucleação da fratura, levando à falha precoce. O crescente emprego de tubos de polietileno em sistemas de distribuição de água, além de outras aplicações, como em sistemas de gás, requer o desenvolvimento de novos métodos de avaliação de desempenho, que levem em conta não apenas o tempo de falha como também os mecanismos de fratura. Busca-se desenvolver métodos de laboratório, de curta duração, para se estabelecer o comportamento dos tubos a longo prazo, principalmente para prevenir falhas precoces, do tipo frágil, dentro do período de vida útil esperado. A mecânica da fratura é justamente a disciplina que estuda o comportamento dos materiais na presença de trincas. Neste sentido duas abordagens são propostas no presente trabalho: "Ramp Test" e o método do Trabalho Essencial de Fratura. O método do "ramp test" permite estimar a tensão crítica correspondente à transição dúctil-frágil da "curva de regressão" a partir de ensaios simples de tração. Por outro lado, o método do Trabalho Essencial de Fratura permite estimar diretamente as partes essencial e não essencial do trabalho específico de fratura. São analisadas cinco resinas provenientes de fornecedores tradicionais de matériasprimas para a produção de tubos de polietileno e duas outras resinas, desenvolvidas para outros fins. Os resultados permitem concluir que os ensaios propostos são viáveis como substitutos ou complementares ao ensaios de resistência à pressão hidrostática na avaliação da tendência de tubos de polietileno apresentarem falhas em serviço.

Palavras chave: polietileno; distribuição de água; tubos; ramal predial; mecânica da fratura; trabalho essencial de fratura; "ramp test". 


\section{ABSTRACT}

Polyethylene has been largely used in potable water distribution systems, mainly in service lines. This polymer offers many advantages over its competitors: flexibility, low cost, ease installation and corrosion resistance. Pipes made with high density polyethylene - HDPE, the generic designation of the material in the sanitation industry in Brazil - fail in service by fracture due creep, giving rise to leakage and water losses, resulting in higher maintenance costs. Main factors that affect the service life of polyethylene pipes are: material, environment, load and settlement. The search for improved materials leads the petrochemical industry to the continuous development of new resins, with increased resistance to failure, which occurs via slow crack growth. This resistance to in-service failure is usually measured in longterm hydrostatic strength tests, at different temperatures. In these tests HDPE behaves like ductile material (followed by significant plastic deformation) and fails in lower period of time under high stress levels, whereas under lower stress levels it fails in a brittle-like mode - with no visible permanent plastic deformation - after longer times. Failures in service are mainly brittle-like. This ductile-fragile transition in the behavior of the material at least at macroscopic scale, is very important and must be well understood, because it can abbreviate the service life of the tube, through early failure. Time-stress failure data can be ploted in bi-log scale to form what is known in the industrial praxis as regression curve, which is linear, with negative slopes, and a larger slope in modulus for the brittle-like fracture mode. In this way, the ductile-fragile transition appears as a point of inflection. The "ductileto-brittle" transition stress is claracteristic of a given formulation and is not easily determined in tests conducted at room temperatures. In spite of its widespread acceptance in the industry, the long-term hydrostatic strength test must be criticized because it has long duration, is expensive and not practical for pipes' quality control. Beside that, most of the data are collected at high inner pressures to save time, while the tube is expected to operate in the "brittle-like" region. The philosophy of these tests, as used in the industry, also implies that the time-to-failure is a material property, while extrinsic factors may shorten the fracture nucleation time, leading to a premature failure. The rising use of polyethylene pipes in water distribution systems, beside other applications as in gas systems, requires the development of 
new performance evaluation methods, that take into account not the time to failure but also the fracture mechanisms. It is desirable for developing short-term laboratory tests to establish the long-term behavior of pipes, to prevent premature brittle-like failures in the desired service life. Fracture mechanics is just the subject which studies the behavior of materials in the presence of cracks. In this way, two approaches are suggested for the present work : "ramp test" and the Essential Work of Fracture method. The "ramp test" method allows to estimate the critical stress that corresponds to the ductile-brittle transition in the regression curve using standard tensile test samples. On the other hand, the Essential Work of Fracture allows a direct estimation of the essential and the non-essential parts of the specific work of fracture. Five different resins for production of polyethylene pipes obtained from traditional raw material suppliers and two other resins designed for other purposes are analysed. The results allow to conclude that the suggested tests are feasible as substitutes or complementaries to the long-term hydrostatic stress tests to evaluate the tendency of the polyethylene pipes to present service failures.

Key words: polyethylene; pipes; service line; fracture mechanics; water distribution, fracture mechanics; essential work of fracture; "ramp test". 


\section{OBJETIVOS}

- Desenvolver metodologias de ensaio para duas abordagens alternativas "ramp test" e Trabalho Essencial de Fratura, que podem ser aplicadas para a avaliação comparativa de duas ou mais resinas, sem a necessidade de realização de testes completos padronizados de resistência à pressão hidrostática de longa duração.

- Testar as duas metodologias em cinco diferentes resinas projetadas para a extrusão de tubos de água, cujas curvas de regressão são conhecidas, e duas resinas projetadas para finalidades diferentes, obtidas de quatro tradicionais fabricantes. 


\section{SUMÁRIO}

INTRODUÇÃ

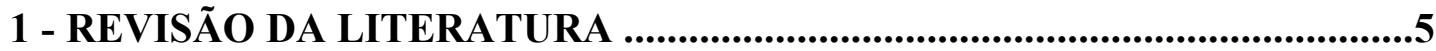

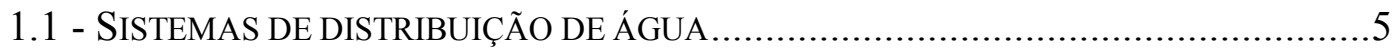

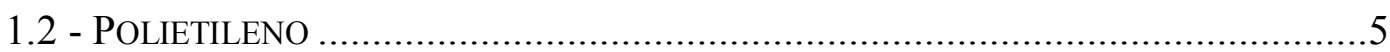

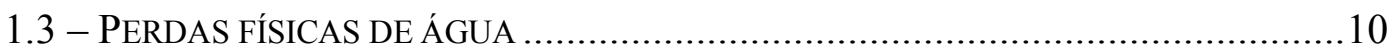

1.4 - A EXPERIÊNCIA DAS COMPANHIAS DE ÁGUA E OS TIPOS DE FALHAS

ENCONTRADOS NA EXPERIÊNCIA OPERACIONAL.................................................. 12

1.5 - A “CURVA DE REGRESSÃO” E O DIMENSIONAMENTO DE TUBOS DE POLIETILENO

1.6 - DEFORMAÇÃO DO PEAD E A TRANSIÇÃO DÚCTIL FRÁGIL .................................27

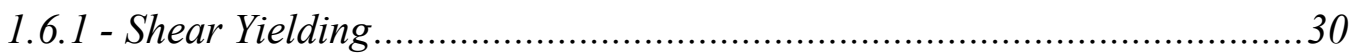

1.6.2 - Crazing ..................................................................................... 32

1.7 - LIMITE DE ESCOAMENTO (YIELD POINT) E ESTIRAMENTO A FRIO (COLD-

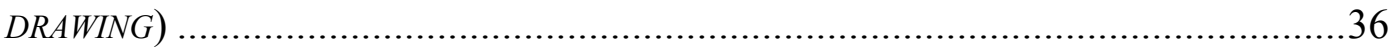

1.8 - Processo DE FRATURA E A FRATURA DO POLIETILENO DE ALTA DENSIDADE..40

1.9 - CRITÉRIOS DE DURABILIDADE E DE PROJETO ...............................................49

1.10 - FUNDAMENTOS DA MECÂNICA DA FRATURA ….........................................54

1.11 - TRABALHO ESSENCIAL DE FRATURA - EWF .............................................59

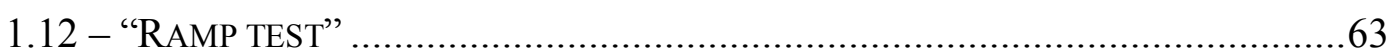

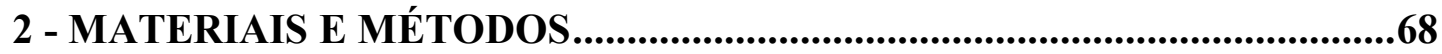

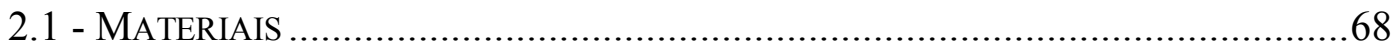

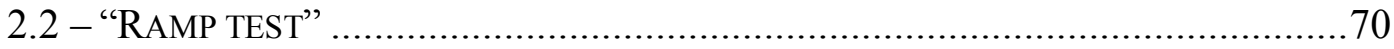

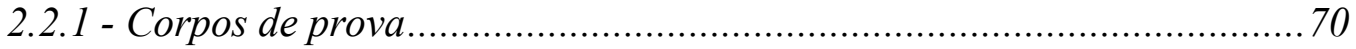

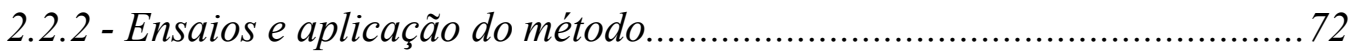

2.3 - TRABALHO ESSENCIAL DE FRATURA (EWF) ............................................74

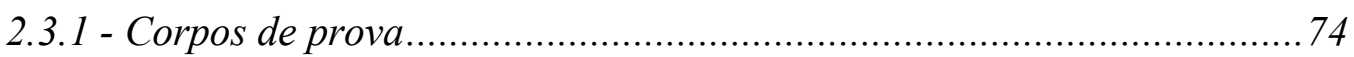

2.3.2 - Ensaios e aplicação do método........................................................ 75

2.4 - MiCROSCOPIA ELETRÔNICA DE VARREDURA ...................................................76 


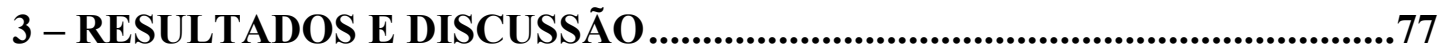

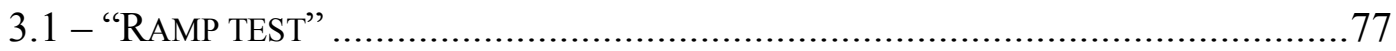

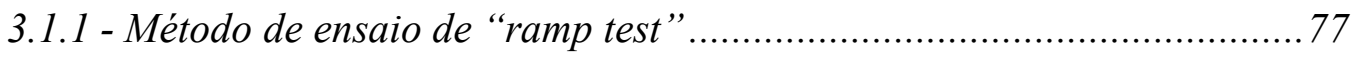

3.1.2 - Curvas carga x deslocamento do "ramp test" ....................................8 80

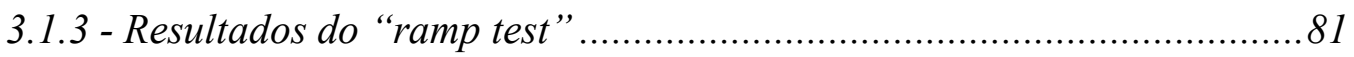

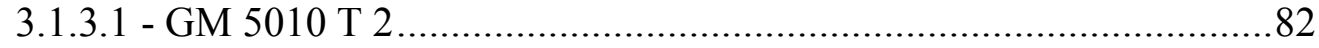

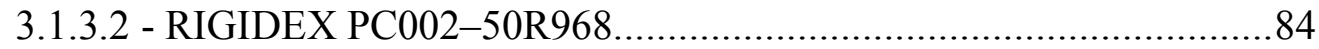

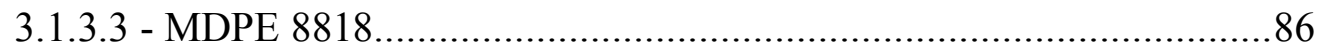

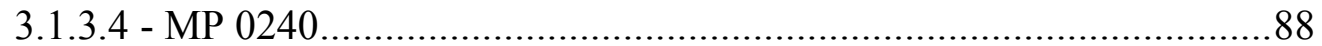

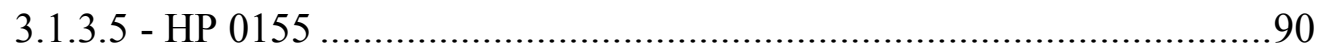

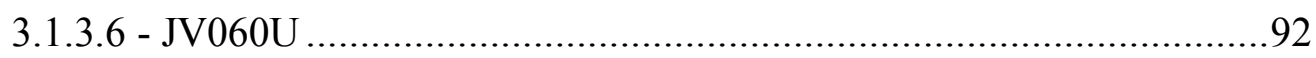

3.1.4 - Resumo dos resultados do "ramp test"...........................................93

3.2 - TRABALHO ESSENCIAL DE FRATURA - EWF............................................ 94

3.2.1 - Método do trabalho essencial de fratura ............................................94

3.2.2 - Curvas carga x deslocamento do método EWF ..................................100

3.2.3 - Resultados do método EWF .............................................................. 101

3.2.3.1 - Efeito da precisão da medida da espessura do corpo de prova ......102

3.2.3.2 - Resumo dos resultados do método EWF .....................................104

3.3 - MICROSCOPIA ELETRÔNICA DE VARREDURA .................................................. 106

4 - CONCLUSÕES .............................................................................109

APÊNDICE A - TABELAS DE DADOS DO "RAMP TEST" ..........................111

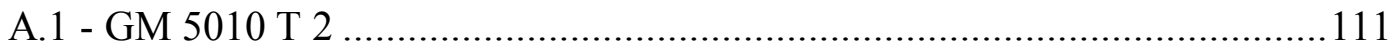

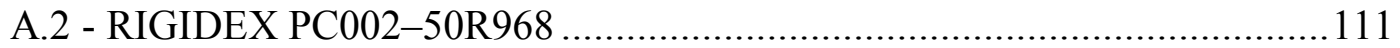

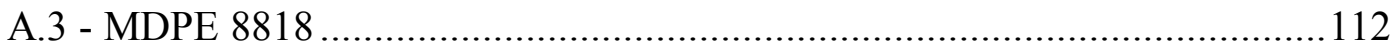

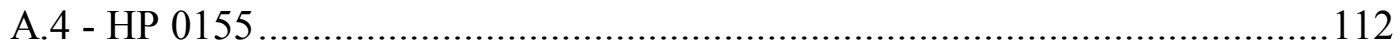

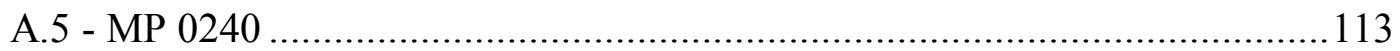

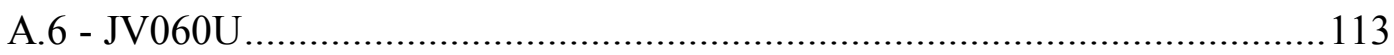

APÊNDICE B - RELATÓRIOS DE ENSAIOS, TABELAS DE DADOS E

CURVAS DO MÉTODO EWF ....................................................................114

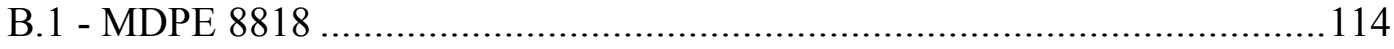


B.1.1.1 - Critério de tensão com limites da faixa de validade de $10 \% \sigma_{\mathrm{m}} . .114$

B.1.1.2 - Critério de tensão com limites da faixa de validade de $11 \% \sigma_{\mathrm{m}} . .117$

B.1.2. Espessura do corpo de prova medida com micrômetro

B.1.2.1 - Critério de tensão com limites da faixa de validade de $10 \% \sigma_{\mathrm{m}} \ldots 120$

B.1.2.2 - Critério de tensão com limites da faixa de validade de $11 \% \sigma_{\mathrm{m}} . .123$

B.2 - BS 002 126

B.2.1 - Espessura do corpo de prova medida com paquímetro 126

B.2.1.1. Critério de tensão com limites da faixa de validade de $10 \% \sigma_{\mathrm{m}} \ldots . .126$

B.2.1.2 - Critério de tensão com limites da faixa de validade de $11 \% \sigma_{\mathrm{m}}$...129

B.2.2 - Espessura do corpo de prova medida com micrômetro. 132

B.2.2.1 - Critério de tensão com limites da faixa de validade de $10 \% \sigma_{\mathrm{m}} . .132$

B.2.2.2 - Critério de tensão com limites da faixa de validade de $11 \% \sigma_{\mathrm{m}}$...135

B.3 - RIGIDEX PC 002-50R968 138

B.4 - MP 0240 . 141

B.5 - HP 0155 . 144

B.6 - GM 5010 T 2 147

B.6.1 - Corpos de prova na direção da extrusão $\left(0^{\circ}\right)$ 147

B.6.2 - Corpos de prova na direção perpendicular à extrusão $\left(90^{\circ}\right)$ 150 


\section{LISTA DE FIGURAS}

Figura 1: Esquema simplificado de polimerização do etileno

Figura 2: Exemplos de estrutura das cadeias de polietileno (Adaptado de PPI, 2003) 8

Figura 3: Falha dúctil de tubo de polietileno (abolamento) .20

Figura 4: Falha dúctil de tubo de polietileno (abolamento seguido de ruptura dúctil)

Figura 5: Falha frágil de tubo de polietileno (slit failure) (Fonte: NTSB, 1998)......20

Figura 6: Falha frágil de tubo de polietileno. (Fonte: BARRETO, 2001) .................21

Figura 7: Falha frágil de tubo de polietileno. (Fonte: BARRETO, 2001) ................21

Figura 8: Vazamento a partir de uma falha frágil de tubo de polietileno. (Fonte: BARRETO, 2001 21

Figura 9: Forma característica da curva de regressão. .25

Figura 10: Forma característica da curva de regressão - influência da temperatura (Fonte: NTS 048). .25

Figura 11: Exemplo de "curva de regressão" (Fonte: PIEROZAN, 2004) 26

Figura 12: (a) Modelo que descreve a transformação de um "pacote" de lamelas paralelas em um "fardo" de feixes empacotados e alinhados. (b) alinhamento de blocos cristalinos em feixes. Exemplos de moléculas de ligação são mostradas em A e B. (Fonte: HERTZBERG, 1995).

Figura 13: Desenho esquemático de um craze. (Fonte: CALLISTER, 2000) ..... 32

Figura 14: Desenho esquemático de craze. Chudnovsky \& Shulkin idealizaram a "zona de processo" (ou process zone - PZ) como uma região formada por uma parte cuja estrutura é a típica de crazing, como descrita acima, e uma parte composta de material com microvazios. A zona de processo integra o sistema crack layer - CL, concebido pelos autores, o qual compreende ainda a trinca. (Adaptado de CHUDNOVSKY \& SHULKIN, 1999)

Figura 15: Conjunto de crazes em polietileno. (Fonte: DUAN \& WILLIANS, 1998)

Figura 16: Estrutura do craze (ampliação da área demarcada na Figura 15). (Fonte: DUAN \& WILLIANS, 1998). 
Figura 17: Morfologia da zona de processo na ponta de um entalhe. (a) iniciação da fratura; (b) após o crescimento da trinca; (c) estrutura detalhada das fibrilas. (Fonte: LU et al, 1994).

Figura 18: Curva tensão-deformação de engenharia típica de vários polímeros cristalinos. B: yield point. C: cold drawing. (Material: MDPE $8818 / 50 \mathrm{~mm} / \mathrm{min}$ )

Figura 19: Yielding, estricção e cold drawing. (Material: MDPE 8818/50 mm/min Adaptado de Nimmer, 1988)

Figura 20: Corpo de prova de ensaio de tração de polietileno de alta densidade (esquerda) e o mesmo corpo de prova após estiramento (cold drawn)

Figura 21: Superior: regiões de fragilidade e de resistência em escala molecular em um polímero, as quais parecem ser importantes na nucleação de crazes e trincas. Inferiores: Etapas sucessivas no desenvolvimento de microvazios, orientação molecular, e crazes como resultado de uma tensão de tração aplicada na direção vertical. (Adaptado de NIELSEN \& LANDEL, 1994)

Figura 22: Gráfico típico de $w_{f}$ x $l$ (Material: Resina GM 5010 T2 - perpendicular à direção de extrusão). .62

Figura 23: Esquema do método EWF (Adaptado de PERES \& SCHÖN, 2004b).....63

Figura 24: "ramp test". $\dot{\varepsilon}_{1}>\dot{\varepsilon}_{2}$ (Fonte: Peres \& Schön, 2004b) ............................64

Figura 25 - Gráfico do "ramp test" da resina GM 5010 T 2 2................................82

Figura 26 - "Curva de regressão" da resina GM 5010 T2 ...................................82

Figura 27 - Gráfico do "ramp test" da resina Rigidex PC002-50R968 ....................84

Figura 28 - "Curva de regressão" da resina Rigidex PC 002-50R968 ......................84

Figura 29 - Gráfico do "ramp test" da resina MDPE 8818 ....................................86

Figura 30 - "Curva de regressão" da resina MDPE 8818 YW. . A Figura é uma adaptação extraída do relatório fornecido à PBBPolisur S.A. pela Gastec N.V. The Netherlands, referente ao material indicado na curva de regressão. ............86

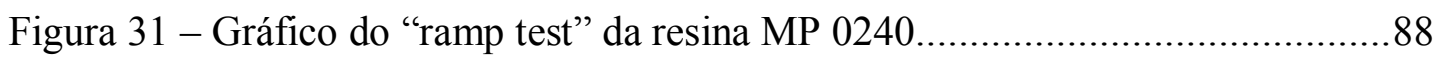

Figura 32 - "Curva de regressão" da resina MP-0240 Yellow ................................88

Figura 33 - Gráfico do "ramp test" da resina HP 0155 .........................................90

Figura 34 - "Curva de regressão" da resina HP-0155 Black ..................................90

Figura 35 - Gráfico do "ramp test" da resina JV 060U .........................................92 
Figura 36 - Esquema de comparação entre duas resinas diferentes com o mesmo valor de $\sigma_{\mathrm{c}}$ mas com diferentes tempos de transição dúctil-frágil

Figura 37: Corpo de prova para ensaio de EWF, sem entalhes em "V". Vista frontal (esquerda) e lateral (direita). 95

Figura 38: Imagens obtidas por MEV da ponta da trinca de corpos de prova de EWF

Figura 39: Fotografia da ponta da trinca durante ensaio de EWF

Figura 40: Conjunto de curvas típicas do método EWF (Resina GM 5010T2 perpendicular à direção da extrusão).

Figura 41: Conjunto de curvas típicas do método EWF (Resina GM 5010T2 direção da extrusão). 101

Figura 42: Imagem MEV da região de fratura do composto MP 0240 106

Figura 43: Imagem MEV da região de fratura do composto HP 0155 107

Figura 44: Imagem MEV da região de fratura do composto JV 060U 107

Figura 45: Imagem MEV da região de fratura do composto Rigidex PC 002-50R968

Figura 46: Imagem MEV da região de fratura do composto MDPE 8818 108

Figura 47: Critério de tensão - MDPE 8818/paquímetro/10\% $\sigma_{\mathrm{m}}$. 116

Figura 48: Curva do método EWF - MDPE 8818/paquímetro/10\% $\sigma_{\mathrm{m}}$. 116

Figura 49: Curva do método EWF - MDPE 8818/paquímetro/11\% $\sigma_{\mathrm{m}}$. 119

Figura 50: Curva do método EWF - MDPE 8818/micrômetro/10\% $\sigma_{\mathrm{m}}$. 122

Figura 51: Curva do método EWF - MDPE 8818/micrômetro/11\% $\sigma_{\mathrm{m}}$. 125

Figura 52: Curva do método EWF - BS 002/paquímetro/10\% $\sigma_{\mathrm{m}}$. 128

Figura 53: Curva do método EWF - BS 002/paquímetro/11\% $\sigma_{\mathrm{m}}$. 131

Figura 54: Curva do método EWF - BS 002/micrômetro/10\% $\sigma_{\mathrm{m}}$. 134

Figura 55: Curva do método EWF - BS 002/micrômetro/11\% $\sigma_{\mathrm{m}}$. 137

Figura 56: Curva do método EWF - Rigidex PC 002 - 50R968 140

Figura 57: Curva do método EWF - MP 0240. 143

Figura 58: Curva do método EWF - HP 0155 146

Figura 59: Curva do método EWF - GM 5010 T 2 - direção da extrusão

Figura 60: Curva do método EWF - GM 5010 T 2 - perpendicular à extrusão 
Figura 61: Contorno arbitrário em torno da ponta de uma trinca (Fonte:

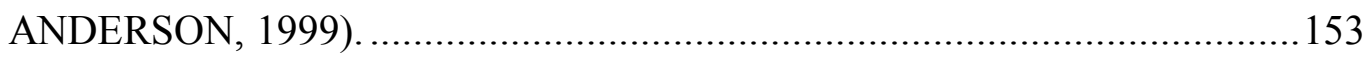

Figura 62: A Integral $J$ (deslocamento controlado). (Adaptado de Kinloch \& Young, 1995) 155

Figura 63: Configurações dos corpos de prova conforme protocolo de ensaio do ESIS. (a) flexão de três pontos (SENB); (b) corpo de prova compacto. (Fonte: HALE \& RAMSTEINER, 2001). 157

Figura 64: Ponta da trinca em um corpo de prova compacto de tração de polietileno de alta densidade (vista lateral) após deformação a $-20^{\circ} \mathrm{C}$ (crazing) e $23^{\circ} \mathrm{C}$ (blunting) (Fonte: HALE \& RAMSTEINER, 2001). 158 


\section{LISTA DE TABELAS}

Tabela 1: Velocidades de ensaio adotadas no "ramp test".....................................73

Tabela 2: Resumo dos resultados do "ramp test"...................................................93

Tabela 3: Resumo dos resultados de EWF com medições da espessura dos corpos de prova realizadas com paquímetro e com micrômetro. 102

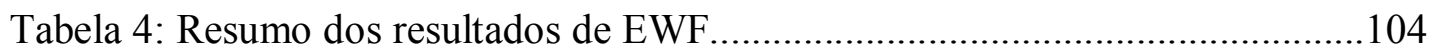

Tabela 5 - Resultados do "ramp test" da resina GM 5010 T 2 2..............................111

Tabela 6 - Resultados do "ramp test" da resina Rigidex PC002-50R968...............111

Tabela 7 - Resultados do "ramp test" da resina MDPE 8818 .................................112

Tabela 8 - Resultados do "ramp test" da resina HP 0155 .......................................112

Tabela 9 - Resultados do "ramp test" da resina MP 0240.....................................113

Tabela 10 - Resultados do "ramp test" da resina JV060U......................................113

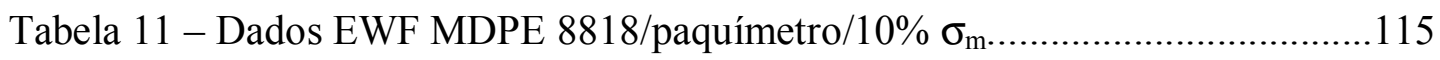

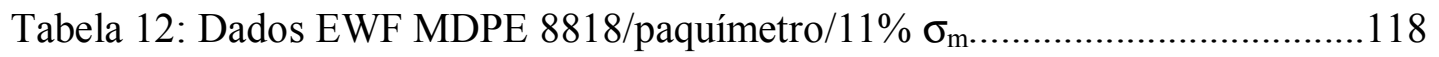

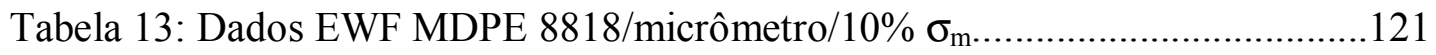

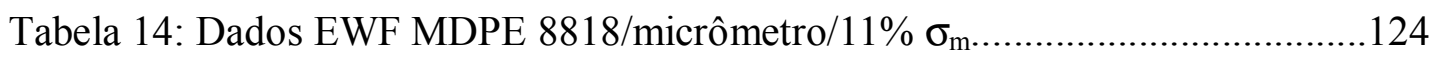

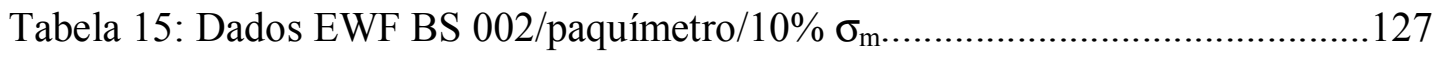

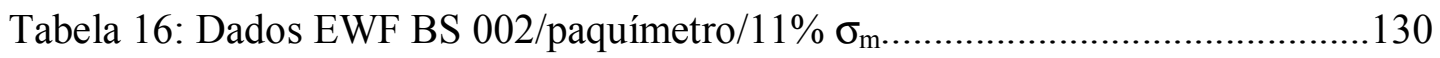

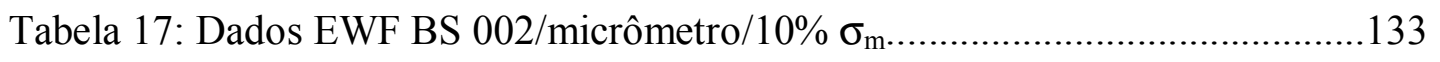

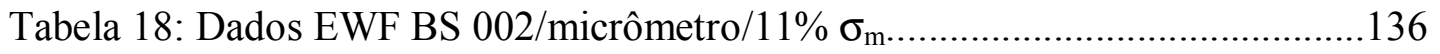

Tabela 19: Dados EWF Rigidex PC 002-50R968 ....................................................139

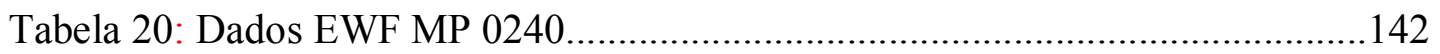

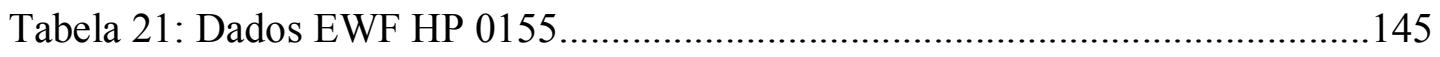

Tabela 22: Dados EWF GM 5010 T 2 - direção da extrusão....................................148

Tabela 23: Dados EWF GM 5010 T 2 - perpendicular à direção de extrusão..........151 
LISTA DE ABREVIATURAS, SIGLAS

ASTM American Society for Testing and Materials (como originalmente conhecida)

AWWA American Water Works Association

AWWARF American Water Works Association Research Foundation

CL Cracklayer

DENT Double edge notched tension

EAC Environment-assisted cracking

EPFM Elastic-plastic fracture mechanics

ESC Environment stress cracking

ESIS European Structural Integrity Society

EWF Essential Work of Fracture (Trabalho Essencial de Fratura)

DF Design factor

HDB Hydrostatic Design Basis

HDS hydrostatic design stress

ISO International Organization for Standadization

LCL lower confidence limit (limite inferior de confiabilidade)

LEFM linear-elastic fracture mechanics

LTHS Long-term hydrostatic strenght (resistência à pressão hidrostática interna de longa duração)

LTHS/LCL Long-term hydrostatic strenght/lower confidence limit (LTHS com limite mínimo inferior de confiabilidade 97,5\%)

MEV Microscopia eletrônica de varredura

MRS Minimum Required Strenght (resitência mínima requerida)

NTS Norma Técnica Sabesp

PE Polietileno

PEAD (HDPE) Polietileno de alta densidade

PMT/EPUSP Departamento de Engenharia Metalúrgica e de Materiais da Escola Politécnica da Universidade de São Paulo

PVC Poli cloreto de vinila 
PZ

RMSP

SABESP

SCG

SNIS
Process zone

Região Metropolitana de São Paulo

Companhia de Saneamento Básico do Estado de São Paulo

Slow crack growth (crescimento lento de trinca)

Sistema Nacional de Informação em Saneamento 


\section{LISTA DE SÍMBOLOS}

a comprimento da trinca

A constante na relação de potência de J

B espessura do corpo de prova (placa)

$\mathrm{B}_{\mathrm{vol}}$ módulo de volume

d diâmetro do tubo

e espessura da parede do tubo

E módulo de rigidez

F força

G taxa de liberação de energia de deformação

$\mathrm{G}_{\mathrm{c}} \quad$ valor crítico da taxa de liberação de energia de deformação

h altura do corpo de prova

$\mathrm{J} \quad$ Integral J

$\mathrm{J}_{\mathrm{IC}}$ Integral $\mathrm{J}$ no modo de abertura $\mathrm{I}$, em estado plano de deformação

K fator de intensidade de tensão

$\mathrm{K}_{\mathrm{B}} \quad$ constante de Boltzmann

$\mathrm{K}_{\mathrm{c}} \quad$ tenacidade à fratura

$\mathrm{K}_{\mathrm{IC}}$ tenacidade à fratura no modo de abertura I, em estado plano de deformação

1 comprimento do ligamento

L comprimento do corpo de prova

$\mathrm{M}_{\mathrm{n}} \quad$ massa molecular numérica média

$\mathrm{M}_{\mathrm{w}} \quad$ massa molecular ponderal média

$\mathrm{M}_{\mathrm{z}} \quad$ massa molecular $\mathrm{Z}$ - média

$\mathrm{N}$ número

p pressão interna

P carga

$\mathrm{P}_{\mathrm{b}} \quad$ probabilidade de ruptura da cadeia polimérica

r distância da ponta da trinca

s comprimento do arco ao longo da linha de integração

S desvio padrão 
t espessura dos corpos de prova EWF

$t_{\mathrm{f}} \quad$ tempo de falha

T vetor de tensão

$\mathrm{T}_{\mathrm{g}} \quad$ temperatura de transição vítrea

$\mathrm{t}_{0}$ fator relacionado com o recíproco da freqüência de oscilação molecular

$\mathrm{u} \quad$ vetor deslocamento

$\mathrm{U}_{\mathrm{t}} \quad$ energia total aplicada

W largura do corpo de prova

w densidade de energia de deformação

$\mathrm{W}_{\mathrm{e}} \quad$ trabalho essencial de fratura

$\mathrm{W}_{\mathrm{f}} \quad$ trabalho específico de fratura

$\mathrm{W}_{\mathrm{f}} \quad$ energia total de fratura

$\mathrm{W}_{\mathrm{p}} \quad$ trabalho plástico não essencial

$\mathrm{W}_{0} \quad$ parâmetro de colisão

$\beta \quad$ fator de forma relacionado com a dimensão da zona plástica

$\beta \mathrm{w}_{\mathrm{p}} \quad$ fator de dissipação de trabalho plástico

$\varepsilon \quad$ deformação

$\dot{\varepsilon} \quad$ taxa de deformação

$\eta \quad$ fator de calibração

$v \quad$ coeficiente de Poisson

$\theta \quad$ ângulo medido a partir do plano da trinca

$\sigma \quad$ tensão

$\sigma_{0} \quad$ tensão característica

$\sigma_{c}$ tensão crítica, correspondente à transição dúctil-frágil

$\sigma_{\text {hoop }}$ tensão circunferencial

$\sigma_{\mathrm{m}} \quad$ média das tensões máximas

$\sigma_{\max }$ tensão máxima no ligamento

$\sigma^{*} \quad$ tensão na cadeia do polímero

$\sigma_{\mathrm{y}} \quad$ limite (ou resistência) de escoamento

$\sigma_{\mathrm{dr}} \quad$ tensão de estiramento

$\Delta \quad$ deslocamento 
$\Delta \mathrm{a} \quad$ crescimento de trinca

$\Delta \mathrm{H} \quad$ energia de ativação

$\Delta \mathrm{G}$ energia de ativação molar

$\Delta \mathrm{U} \quad$ variação de energia potencial

$\Lambda \quad$ volume de ativação

Y fator de forma (parâmetro ou função adimensional)

$\Gamma \quad$ caminho da integral ao redor da trinca 


\section{INTRODUÇÃO}

Vários tipos de materiais podem ser empregados em tubulações de sistemas de água, sendo os principais ferro fundido cinzento, ferro fundido nodular (ferro dúctil), aço, concreto, cimento amianto e plásticos (principalmente PVC e polietileno). O ferro fundido é o material que tem permanecido por mais tempo em serviço, tendo sido usado em todo o mundo desde a segunda metade do século dezessete. A partir de meados dos anos 50 os tubos de ferro fundido nodular foram introduzidos em substituição aos de ferro fundido cinzento, em virtude de suas propriedades superiores. Os tubos de ferro são muito duráveis, mas têm como desvantagens a dificuldade de trabalhar devido seu elevado peso e sua propensão à corrosão. Os tubos de aço são mais leves e fáceis de transportar e instalar do que os tubos de ferro, mas são menos duráveis, e igualmente suscetíveis de sofrer corrosão. Os tubos de concreto são menos empregados do que os tubos de ferro, sendo geralmente usados em sistemas que possuem um baixo gradiente de pressão ou em tubulações de grandes diâmetros. Possuem boa resistência à corrosão e boas propriedades hidráulicas, mas podem romper em solos alcalinos ou ácidos. O cimento amianto foi abandonado em virtude dos riscos ocupacionais existentes na sua fabricação, e devido a dificuldades operacionais.

O uso de tubos plásticos é relativamente recente, tendo sido introduzidos nos sistemas de água há cerca de 40 anos. Apresentam várias vantagens, onde se destacam o baixo preço, a flexibilidade, baixo peso, facilidade de instalação e resistência à corrosão. Entretanto há muitas restrições para seu emprego indiscriminado, sem o suficiente conhecimento. Particularmente em aplicações de responsabilidade estrutural muitas vezes os polímeros adquirem o estigma de materiais inferiores e fracos principalmente devido ao desconhecimento de suas propriedades e ao mau uso (LJUNGBERG, 2003). A engenharia tradicional, mais conservadora em projetos com materiais metálicos e cerâmicos, pode ser muito suscetível de incorrer em erros que levam a falhas prematuras de tubos plásticos. Algumas dessas falhas decorrem de má seleção do material, más condições de processamento, exposição a agentes ambientais, fluência, falhas de instalação e 
operação, entre outras. Um polímero pode, por exemplo, ser processado mais facilmente se possuir menor massa molecular, o que pode parecer atrativo para um fabricante de tubos, entretanto, terá propriedades mecânicas inferiores, principalmente menor resistência ao impacto e à fluência. Tal como os metais, os tubos plásticos podem e provavelmente irão falhar em serviço por várias razões. Entretanto, a falha de um componente de plástico pode ser muito diferente da falha de um componente metálico. Modos de falha muito comuns de tubos plásticos estão associados com a variação de suas propriedades em função do tempo e temperatura, o que é raramente considerado no projeto de tubos metálicos para sistema de água.

As causas de vazamentos acidentais em sistemas de distribuição de água, que provocam perdas físicas de água, estão em grande parte relacionadas às falhas de materiais.

O Polietileno tem sido muito empregado em transmissão de água potável há mais de 30 anos (JANSON, 2003); (SANDSTRUM, 2004). Em particular, esse tipo de material é muito utilizado nos tubos dos ramais prediais (tubulação que liga a rede de distribuição ao dispositivo de medição de consumo).

A Companhia de Saneamento Básico do Estado de São Paulo - SABESP, principal empresa de saneamento básico do Brasil, utiliza desde 1976 nos ramais prediais de água o polietileno de alta densidade, mais conhecido no setor pelas suas iniciais PEAD. Em 1998 73,3\% dos ramais prediais da Região Metropolitana de São Paulo - RMSP eram de PEAD, 26\% de aço galvanizado e 0,7\% de PVC (SABESP, 1998).

Apesar de sua utilização vir se tornando cada vez mais popular nos ramais prediais, os tubos de polietileno instalados podem apresentar falhas inesperadas em serviço, prematuras em relação à sua vida útil prevista, através de um mecanismo conhecido como slow crack growth ou crescimento lento de trincas. Visando prevenir falhas precoces, com graves conseqüências e elevadas perdas, novas resinas e compostos de polietileno para tubos de água e gás têm sido desenvolvidos como resultado de constantes pesquisas e desenvolvimentos ao longo dos anos (ALLMANN, 2004). Os métodos têm envolvido variações na distribuição e na densidade de ramificações ao longo das moléculas, variações na massa molecular e 
na sua distribuição, emprego de comonômeros, como hexeno, etc. (MILLS, 1993); (BROWN et al, 1991); (FAYOLLE \& VERDU, 2005).

Há quatro principais fatores que influenciam a vida útil de um tubo de polietileno: fatores materiais, fatores ambientais e do meio, condições de carga e técnicas de instalação. Testes de curta duração em condições de laboratório geralmente demonstram que o polietileno comporta-se de maneira dúctil, ou seja, em testes de resistência à pressão hidrostática interna ou em testes de tração o material exibe níveis altos de deformação plástica localizada antes de romper-se. As falhas dos tubos de polietileno no campo, entretanto, são geralmente falhas de aparência frágil, com reduzida ou nenhuma deformação plástica aparente, o que sugere que outros fatores do sistema afetam o desempenho do tubo ao longo do tempo. Causas possíveis dessas falhas incluem sobrecargas, fadiga, qualidade do tubo, técnicas de instalação, corrosão sob tensão, procedimentos de terceirização e contratação, e fatores locais, relacionados com o assentamento (SMITH et al, 2000); (THOMPSON et al, 2000).

$\mathrm{O}$ entendimento dos mecanismos que relacionam as falhas precoces com os fatores que atuam sobre os tubos é fundamental para preveni-las. Através das relações estrutura-propriedades-processamento-comportamento/desempenho podese buscar primeiramente a compreensão das propriedades do polietileno que determinam o comportamento dos tubos e a melhoria das técnicas de projeto e aplicação. Posteriormente pode-se alterar seus elementos estruturais e modificar as suas propriedades para superar suas limitações. Oportunidades de melhoria dos ramais prediais de água com tubos de polietileno surgirão com a melhor compreensão da natureza e das propriedades do polietileno, e também das suas limitações, pelas companhias de água.

Ao longo dos últimos anos o comportamento em fratura do polietileno tem sido muito estudado em virtude do seu crescente uso como material estrutural. Diversos trabalhos têm sido publicados à respeito do comportamento em fratura de tipos de polietileno empregados em tubos: Huang \& Brown (1988), Qian \& Brown (1989), Lu et al (1990, 1991, 1994), Brown et al (1991), Chan \& Williams (1993), Rose et al (1994), Duan \& Williamns (1998), Chudnovsky \& Shulkin (1999), Ivankovik et al (2004), Nishimura \& Kawaguchi (2004), Ting et al(2004). 
Os testes usualmente empregados para avaliar o comportamento dos tubos de polietileno a longo prazo são demorados e caros. Busca-se desenvolver métodos de laboratório, de curto prazo, para se estabelecer o comportamento dos tubos a longa duração, principalmente para prevenção de falhas precoces, do tipo frágil, dentro do período de vida útil esperado.

É objetivo desse trabalho situar o problema da ruptura dos tubos de polietileno usados nos ramais prediais dos sistemas de distribuição de água e abordálo na profundidade correta, buscando caracterizar o comportamento mecânico do material em fratura. Essa tarefa contempla a apresentação da abordagem mais comum, que leva em conta a falha macroscópica, mas pretende aprofundar a discussão incluindo a descrição do processo de fratura, dos mecanismos envolvidos e das ferramentas disponíveis para a compreensão do fenômeno. A partir desse entendimento, são propostos novos métodos de ensaio de curta duração para controle de qualidade e apoio a processos de desenvolvimento de produtos, ensaios estes mais práticos, eficazes e econômicos, com foco na questão do desempenho dos tubos a longo prazo.

O assunto é amplo e o objetivo é pretensioso. Portanto, é importante ressalvar que não se pretende neste texto abranger exaustivamente todo o campo do conhecimento sobre o processo de fratura do polietileno e sua implicação nas falhas de tubos fabricados com esse material. Por outro lado, pretende-se abordar sucintamente alguns dos mais importantes aspectos sobre o tema, situando o leitor.

A seguir faz-se uma breve descrição do estado-da-arte deste problema 


\section{1 - REVISÃO DA LITERATURA}

\section{1 - Sistemas de distribuição de água}

Um sistema de suprimento de água consiste basicamente de fontes e mananciais de água, instalações e dispositivos de bombeamento e transferência, estações de tratamento, reservatórios e um sistema de distribuição.

Um sistema de distribuição de água é parte de um sistema de abastecimento de água, e consiste de uma rede de tubulações, dispositivos e acessórios que têm a finalidade básica de conduzir água potável da estação de tratamento e/ou reservatórios e disponibilizá-la ao consumidor final, de forma contínua, em quantidade adequada e pressão suficiente (TSUTIYA, 2004). A rede de tubulações consiste de adutoras, redes de distribuição e ramais prediais (ou de serviço). Os ramais prediais - os tubos de menor diâmetro, são aqueles que transferem a água do ponto de derivação na rede de distribuição local para o usuário final. Na SABESP os diâmetros usuais nos ramais prediais de polietileno são de 20 e $32 \mathrm{~mm}$, conforme a Norma Técnica Interna SABESP 048 (NTS 048).

A maior parte da infra-estrutura dos sistemas de distribuição de água está envelhecendo e este processo está relacionado com o aumento do número de vazamentos. Além disso, restrições de orçamento, comuns nas companhias de água, prejudicam a manutenção adequada dos sistemas e a programação de investimentos futuros em renovação (SMITH et al, 2000). Daí a importância de se compreender os mecanismos que levam às falhas das tubulações para minimizar estes eventos após a instalação do tubo.

\section{2 - Polietileno}

O polietileno comum é um polímero termoplástico, parcialmente cristalino e flexível. É obtido a partir do monômero etileno, num processo de polimerização por adição que envolve a ruptura das ligações duplas carbono-carbono das moléculas de etileno e sua união, formando longas cadeias poliméricas, as quais possuem milhares de átomos de carbono ligados entre si somente por ligações covalentes simples (Figura 1). 


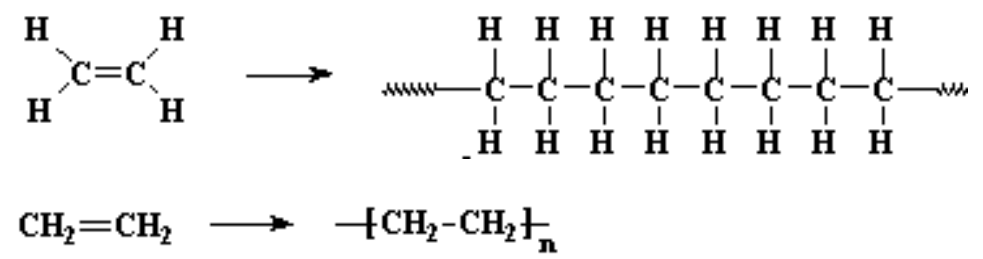

Figura 1: Esquema simplificado de polimerização do etileno

O etileno pode ainda ser copolimerizado com outros tipos de monômeros, com a finalidade de alterar a estrutura do material e conseqüentemente modificar suas propriedades. São exemplos de comonômeros o buteno, o propileno, o hexeno e o octeno.

No passado, o polietileno era classificado principalmente em função de sua densidade e pelo tipo de processo usado em sua fabricação. Atualmente suas características estruturais são mais relevantes, na medida em que a linearidade das cadeias, bem como a quantidade e o comprimento das ramificações, determinam a densidade do polímero e suas propriedades. Assim, os polietilenos podem ser melhor classificados como ramificados ou lineares. Dependendo do sistema de polimerização empregado (condições de reação, catálise, etc.), pode-se obter cinco tipos básicos de polietileno: polietileno (ramificado) de baixa densidade (PEBD ou LDPE), polietileno linear ou polietileno de alta densidade (PEAD ou HDPE), polietileno linear de baixa densidade (PELBD ou LLDPE), polietileno de ultra alto peso molecular (PEUAPM ou UHMWPE) e o polietileno de ultra baixa densidade (PEUBD ou ULDPE) (COUTINHO et al, 2003).

A linearidade das cadeias permite maior eficiência na orientação, acomodação e empacotamento das cadeias, de forma que as ligações secundárias intermoleculares, tipo forças de van der Waals, tornam-se mais eficientes e intensas. O resultado é maior grau de cristalinidade e maior densidade. Por outro lado, quanto mais numerosas e/ou mais longas forem as ramificações, menores serão a cristalinidade e a densidade. Essas variações provocam acentuadas diferenças nas propriedades mecânicas do polímero. Conforme Coutinho et al. (COUTINHO et al, 2003), as menores unidades cristalinas, lamelas, são planares e consistem de cadeias perpendiculares ao plano da cadeia principal e dobradas em zig-zag, para cada 5 a 15 
nm. A Figura 2 apresenta esquematicamente algumas estruturas de arranjos de cadeia na escala molecular.

O polietileno linear - PEAD, por muito tempo o tipo mais empregado nos tubos dos ramais prediais de água, é altamente cristalino (acima de 90\%), possui temperatura de fusão cristalina em torno de $132^{\circ} \mathrm{C}$, temperatura de transição vítrea de cerca de $-90^{\circ} \mathrm{C}$, e densidade entre 0,95 e $0,97 \mathrm{~g} / \mathrm{cm}^{3}$ (CALLISTER, 2000); (COUTINHO et al, 2003).

As propriedades mecânicas do PEAD são muito influenciadas por fatores estruturais como massa molecular, distribuição de massas moleculares, quantidade e extensão das ramificações, densidade das moléculas de união (tie-molecules) cristalinidade, estrutura morfológica e orientação (BOENIG, 1973); (OGORKIEWICZ， 1974); (BILLMEYER, 1975); (MORTON-JONES， 1989); (BROWN et al, 1991); (HERTZBERG, 1995); (KINLOCH \& YOUNG, 1995); (MEYERS \& CHAWLA, 1999); (CALLISTER, 2000); (COUTINHO et al, 2003). O estudo das propriedades físicas e das características de processamento de qualquer tipo de polietileno requer o entendimento da influência e importância desses fatores. Brown et al (1991) apresentaram uma revisão de trabalhos realizados, nos quais foram estabelecidas relações quantitativas entre variáveis externas (tensão, temperatura), parâmetros de mecânica da fratura (fator de intensidade de tensão, $K$, Integral J), variáveis morfológicas (densidade, tamanho de cristal), variáveis moleculares e estruturais (massa molecular, densidade e distribuição de ramificações), taxa de crescimento de falhas e tempo de falha através do mecanismo de crescimento lento de trincas (BROWN et al, 1991).

O controle da massa molecular e de sua distribuição é muito usado para melhorar as propriedades mecânicas, físicas e reológicas do polietileno (WIEBECK \& HARADA, 2002). PEAD de baixa massa molecular é frágil e não forma estricção em ensaios de tração; na faixa entre 80.000 e 1.200.000, típica para o PEAD comercial, sempre ocorre a estricção (COUTINHO et al, 2003). 


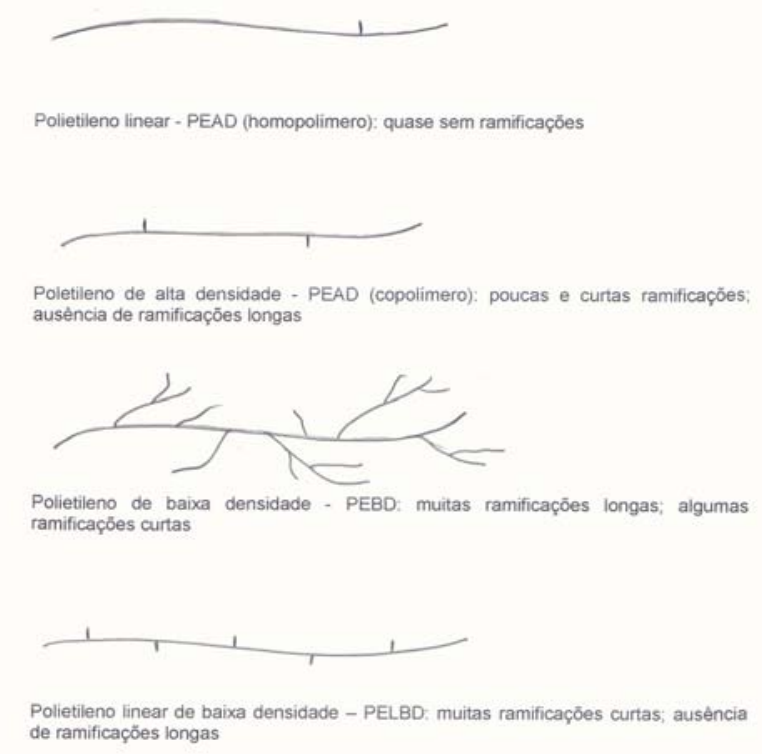

Figura 2: Exemplos de estrutura das cadeias de polietileno (Adaptado de PPI, 2003)

As propriedades mecânicas do polietileno também são influenciadas pela textura, ou seja, pela orientação das cadeias moleculares, suscetível de promover anisotropia nas suas propriedades (COUNTINHO et al, 2003); (WIEBECK \& HARADA, 2002).

Os tubos de polietileno são obtidos por extrusão, a partir de resinas na forma de pós ou grânulos. As normas brasileiras, em geral, não permitem o uso de material regranulado ou reciclado.

As condições de fabricação do tubo são muito importantes. A taxa de extrusão e a velocidade de resfriamento controlam, entre outros aspectos importantes, a orientação molecular e o grau de cristalinidade. Se o resfriamento for lento, por exemplo, haverá tempo suficiente para que um maior número de cadeias possam ser ordenadas nos cristalitos. Conseqüentemente, o grau de cristalinidade e a densidade serão maiores, com significativos reflexos sobre as propriedades que dependem desses fatores, como resistência à tração, dureza, rigidez, contração, etc. (WIEBECK \& HARADA, 2002); (LU et al, 1994).

Comercialmente, os polímeros são freqüentemente conhecidos como resinas. Assim, um composto de polietileno para tubos consiste basicamente de resina base, com adições de corantes, estabilizantes, anti-oxidantes e outros aditivos necessários para garantir e melhorar suas propriedades durante o processamento e a utilização. É 
comum o emprego do termo grade para designar os diferentes tipos de resinas e compostos. Negro-de-fumo é um aditivo geralmente empregado e, entre outros efeitos, promove proteção contra radiação ultravioleta. Na SABESP o composto de polietileno adotado é pigmentado na cor azul, tendo-se abolido o negro-de-fumo para prevenir o emprego de material reprocessado ou reciclado na fabricação dos tubos, prática que poderia não ser facilmente visualizada e percebida com o material carregado com negro-de-fumo ${ }^{1}$.

À temperatura ambiente, os polietilenos são considerados como praticamente inertes à maioria dos produtos químicos comuns, mas quando expostos a solventes em temperaturas mais elevadas pode ocorrer inchamento, dissolução parcial ou degradação do material. Apesar de altamente resistente à água e algumas soluções aquosas, inclusive a altas temperaturas, o polietileno é atacado lentamente por agentes oxidantes (OGORKIEWICZ, 1974); (COUNTINHO et al, 2003). Em especial, é importante considerar a presença de cloro na água, o qual é usado como agente desinfetante e mantido em níveis residuais a baixas concentrações e lembrar que normalmente o sistema é pressurizado (há tensões atuando no material). Bodycote Polymer AB, um laboratório de testes de tubos plásticos independente, localizado em Nyköping, Suécia, tem desenvolvido estudos sobre o efeito da água clorada sobre a vida útil de tubos plásticos, tendo verificado que pequenas quantidades de cloro provocam forte efeito oxidante sobre tubos fabricados com poliolefinas (o polietileno é uma poliolefina), com significativa redução da vida útil esperada (BODYCOTE-2003).

Observa-se em testes para avaliação de falhas prematuras de tubos de polietileno que, sob certas condições de temperatura, o tempo para ocorrência de falhas é sensível a meios hostis (agentes químicos polares e/ou oxidantes, álcoois, detergentes, halogêneos e aromáticos), mesmo estando o material submetido a tensões relativamente baixas, mas por longos períodos de tempo, sugerindo suscetibilidade dos tubos de polietileno ao environment-assisted cracking (EAC) ou environment stress cracking (ESC). Trata-se de mecanismo de crescimento subcrítico de trincas, que descreve a falha acelerada de um material devido à ação cooperativa ou combinada de exposição ao meio e à tensão (HERTZBERG, 1995).

\footnotetext{
${ }^{1}$ Informação pessoal obtida internamente na Sabesp
} 
Em condições normais, o polietileno não é tóxico, podendo inclusive ser usado em contato com produtos alimentícios e farmacêuticos, e em particular com a água.

\section{3 - Perdas físicas de água}

As falhas de materiais em sistemas de distribuição de água incorrem diretamente em perdas de água através de vazamentos.

Necessitamos de água doce para a vida humana e somente $2,5 \%$ da água do mundo é doce, sendo que a maior parte está retida nas calotas polares. De forma que somente cerca de $0,3 \%$ do volume total disponível é fácil de captar em rios, lagos e lençóis subterrâneos pouco profundos (PURA). Entretanto, para não esgotar os recursos disponíveis somente podemos utilizar a água renovável pelas chuvas, chegando a um limite de consumo de $0,002 \%$, ou cerca de $34.000 \mathrm{Km}^{3}$ anuais (QUADRADO e VERGARA, 2003). Ou seja, é um bem precioso sob ameaça de escassez, fator básico de saúde pública, causa de conflitos internacionais, exigindonos uso racional e insistente combate ao desperdício.

Elevadas perdas produzem impactos negativos de diversas naturezas, tais como: no meio ambiente (maior demanda de água, esgotamento de mananciais); nos custos (maior necessidade de investimentos em novas instalações de produção e de distribuição de água, maiores custos operacionais no tratamento); nas receitas (redução do faturamento) (REVISTA BRASILEIRA DE SANEAMENTO AMBIENTAL E MEIO AMBIENTE, 2003).

O entendimento elementar do conceito de perdas de água considera perdas nos sistema de abastecimento como a diferença entre o volume de água tratada colocado à disposição da distribuição e o volume medido nos hidrômetros dos consumidores finais, em um determinado período de tempo. Pode-se inicialmente dividir as perdas em perdas não-físicas (erros de medição, fraudes, ligações clandestinas, falhas de cadastro comercial, etc.), ou seja, água que é utilizada mas não é contabilizada pela companhia de água, e as perdas físicas (vazamentos e extravasamentos). Deve-se descontar do volume total introduzido no sistema de distribuição os chamados consumos autorizados faturados e não faturados (água exportada, combate a enchentes, uso próprio da companhia, etc.) (SABESP, 2000) 
Considerando-se o indicador percentual clássico de perdas (volume perdido / volume produzido x 100), a média brasileira de perdas de água era de cerca de 50\% em 1995, situando-se atualmente em torno de 40\% (REVISTA BRASILEIRA DE SANEAMENTO AMBIENTAL E MEIO AMBIENTE, 2003). A partir de um trabalho desenvolvido para a SABESP em 1992 pela LYSA - Lyonnaise Des Eaux Services Associés, verificou-se que as perdas totais de água na Região Metropolitana de São Paulo - RMSP - eram compostas por 50\% de perdas físicas e 50\% de perdas não-físicas. Considerando-se essa composição, as perdas físicas em 1999 eram de $17,7 \%$, equivalente a uma vazão média de $8,8 \mathrm{~m}^{3} / \mathrm{s}$ (SABESP, 2000).

O conceito de perdas varia bastante no mundo, não existindo, ainda, uma definição universalmente aceita, de forma que os indicadores de perdas podem apresentar valores e significados diferentes, dependendo de como foram apropriados e sistematizados os dados (SABESP, 2000). Conforme análise feita no Diagnóstico dos Serviços de Água e Esgotos 2001, publicado no Sistema Nacional de Informação em Saneamento (SNIS), os indicadores de perdas em percentual não são adequados para a avaliação de desempenho, uma vez que são fortemente influenciados pelo consumo, além de não expressarem os fatores principais com impacto sobre as perdas, tais como a pressão de operação, extensão de rede e a quantidade de ligações atendidas (REVISTA BRASILEIRA DE SANEAMENTO AMBIENTAL E MEIO AMBIENTE, 2003). Uma discussão mais ampla sobre os indicadores de perdas foge ao escopo do presente trabalho.

Vazamento é entendido como a água que é introduzida na rede de distribuição por uma estação de tratamento e é perdida através de fuga acidental. Tradicionalmente, tem existido recursos abundantes de água bruta e tratada, e os vazamentos eram considerados importantes somente quando eram visíveis ou causavam excessiva redução da pressão, ou ainda quando o custo para localização e reparo do vazamento era menor que o custo marginal de bombeamento e tratamento da água perdida. Sob essas condições, perdas da ordem de $50 \%$ da água introduzida na rede poderiam ser aceitáveis (SMITH et al, 2000). O aumento da demanda de água, a redução no suprimento, e a necessidade de apoiar o desenvolvimento sustentável requerem que essa prática seja revista. No cenário atual de escassez, é indispensável desenvolver estudos e adotar medidas para a prevenção de vazamentos 
e perdas de água de qualquer natureza, incluindo a identificação, a caracterização e a quantificação das causas primárias dos vazamentos em sistemas de distribuição de água. A literatura indica que há métodos disponíveis efetivos para reduzir as perdas físicas de água através da prevenção e reparos de vazamentos (SMITH et al, 2000).

Os sistemas de distribuição de água são mantidos a altas pressões tipicamente entre 140 e $700 \mathrm{KPa}$ (SMITH et al, 2000) - para garantir o suprimento aos consumidores, de forma que os vazamentos ocorrem naturalmente quando a integridade dos tubos, acessórios e outros elementos integrantes do sistema fica comprometida.

Muito esforço tem sido realizado para reduzir as perdas por vazamento e melhorar o desempenho a longo prazo das redes de distribuição de água, incluindo o desenvolvimento de indicadores de perdas, de métodos de localização e reparos de vazamentos, emprego de sistemas de redução de pressão, substituição de componentes, etc. Entretanto, algum vazamento é tido como inevitável como resultado de má seleção de materiais, problemas de instalação, sobrecargas, degradação de materiais, entre outros fatores, e seus efeitos combinados.

\section{4 - A experiência das companhias de água e os tipos de falhas encontrados na experiência operacional}

O polietileno apresenta uma série de vantagens no uso com água potável como: resistência à corrosão, baixa densidade, flexibilidade, baixo coeficiente de atrito, não é condutor elétrico, baixo custo e facilidade de instalação. Entretanto, também apresenta alguns aspectos desfavoráveis: os tubos de polietileno são sujeitos à fragilização decorrente de degradação por radiação ultravioleta e à ação de agentes oxidantes na água, incluindo cloro. Além disso, os vazamentos são mais difíceis de serem detectados em segmentos contendo tubos plásticos. A natureza viscoelástica dos plásticos tende a amortecer as vibrações, de forma que o ruído causado pelos vazamentos ou rupturas não se propaga. Apesar de atualmente serem muito empregados em sistemas de abastecimento de água, vários problemas têm sido observados com tubos de polietileno (THOMPSON et al, 1992); (SMITH et al, 2000). 
Para avaliar a extensão dos problemas observados, a AWWA (American Water Works Association) e a AWWARF (American Water Works Association Research Foundation) realizaram pesquisas na década de 1980 junto a companhias de água dos Estados Unidos (THOMPSON et al, 1992). Através de entrevistas por telefone as companhias de água que empregavam tubos de polietileno apontaram as seguintes causas de falha, em proporções mais ou menos semelhantes: fragilidade no tubo, materiais de berço e envoltória (bedding materials), procedimentos de instalação (não especificado), e falhas "frágeis" não especificadas. Verificou-se também que a data da primeira instalação e o uso de cloro como desinfetante da linha influenciavam o nível de satisfação do usuário. Em exames de laboratório observouse que nas amostras dos tubos não havia um modo predominante de falha. Entretanto foram mais comuns as falhas decorrentes de fatores relacionados à instalação: materiais da envoltória (cortes, ferimentos, arranhaduras), torcedura ou dobramento do tubo, defeitos provocados por tensões durante a instalação ou assentamento. É importante observar que os pesquisadores freqüentemente encontraram o termo “frágil" para descrever uma condição particular do tubo. Baseado na pesquisa verbal, nos exames das amostras descritas como frágeis e na literatura, os autores distinguiram dois tipos de fragilidade. No primeiro tipo o tubo apresentava uma condição "frágil como o vidro" (ou "vítrea") ou suscetível de despedaçar-se sob impacto. Esse tipo de fragilidade foi entendido como uma situação de fragilidade ou de deficiência do material. O segundo tipo de fragilidade relatada aos pesquisadores não tinha geralmente o mesmo significado. Esse segundo tipo de fragilidade foi observado em material "velho" mas que ainda mantinha alguma elasticidade. Essa situação estava freqüentemente associada com porções torcidas do tubo e pareciam estar relacionadas à instalação e não somente ao material. Muitas companhias relataram melhoria no material e na manufatura dos tubos desde o início de seu emprego em sistemas de água (final dos anos 60 e início dos anos 70), melhorando a expectativa de desempenho em serviço, com redução nas taxas de falha e melhor nível de satisfação dos usuários (THOMPSON et al, 1992); (NTSB, 1998). Nas primeiras pesquisas (início dos anos 80), fragilidade do tubo era a principal causa de insatisfação de usuários de tubos de polietileno. Nas pesquisas seguintes problemas relacionados à instalação foram causas predominantes de insatisfação. 
Nas pesquisas da AWWA e AWWARF ficou claro que as falhas de tubos de polietileno podiam decorrer de vários fatores relacionados ao material e à instalação. A idade do tubo representou uma causa primária. Nesse sentido deve-se considerar que desde o início de sua utilização em sistemas de distribuição de água, os tubos têm sido fabricados e instalados obedecendo a normas diferentes, que sofreram e vêm sofrendo aperfeiçoamentos ao longo do tempo. A evolução das formulações do material do tubo e das técnicas de manufatura tem melhorado as características operacionais e o tempo de serviço. Além disso, os instaladores vêm aprimorando sua experiência ao longo dos anos, evitando práticas como emprego de tubos de classe de pressão baixa, raios de curvatura pequenos e uso de tubos arranhados ou com cortes.

As principais conclusões da pesquisa realizada pela AWWA e pela AWWARF, conforme Thompson et al (THOMPSON et al, 1992) foram as seguintes:

- As principais causas de falhas apontadas pelas companhias de água, através de entrevista por telefone, foram tubos frágeis ou falhas frágeis (não especificadas), fratura em pontos de fixação (adaptadores de pressão) e torcedura do tubo. Causas menos freqüentes foram material do berço e da envoltória, furos e falhas de adaptadores;

- Período de tempo desde a primeira instalação foi muito importante, mostrando clara tendência de melhoria da satisfação com datas mais recentes de instalação. A idade do tubo pode afetar o grau de oxidação e além disso devem ser consideradas as normas aplicáveis e as práticas de instalação adotadas à época da instalação;

- Observações de laboratório indicaram uma maior ocorrência de torcedura de tubos do que a indicada pelas companhias. Por outro lado, as causas de falhas indicadas pelas companhias e aquelas observadas pelos pesquisadores foram bastante semelhantes. É possível que a remoção do tubo (amostras) tenha resultado em torcedura adicional do tubo;

- Análises de laboratório indicaram oxidação substancial em todas as amostras testadas, mas somente uma amostra falhou no teste de rompimento. Sugeriu-se que uma oxidação significativa poderia ocorrer antes que a integridade do tubo fosse prejudicada. Levantou-se a hipótese de que tensões relacionadas à 
instalação, tal como torcedura do tubo, poderiam causar falha prematura em tubos que demonstravam oxidação;

- Os testes indicaram que compostos antioxidantes estavam presentes em quantidades baixas ou inadequadas na maioria das amostras de tubos de polietileno testadas. Os testes apontaram a presença de oxidação na parte interna e externa dos tubos em aproximadamente iguais proporções. Os dados foram insuficientes para determinar se os compostos antioxidantes foram consumidos durante o processo de extrusão, não incorporados à resina original, ou perdidos após a produção.

Um estudo desenvolvido para a SABESP pela LYSA - Lyonnaise Des Eaux Services Associés em 1992 apontou, após análise de 808 casos de perdas, que 95\% das ocorrências ocorriam em ramais prediais, $80 \%$ destas eram em ramais de $\mathrm{PEAD}$, $49 \%$ das falhas ocorriam no tubo de PEAD e 46\% nas curvas, juntas e registros (BARRETO, 2001). Na primeira fase de um trabalho da SABESP em parceria com o Instituto de Pesquisas Tecnológicas do Estado de São Paulo S/A - IPT - no período 2000-2001, verificou-se, após estudo de 269 casos de vazamento em ramais prediais de PEAD que 51,7\% das ocorrências ocorriam no tubo de PEAD, 33,1\% eram nos adaptadores, $6,7 \%$ nos vedantes dos adaptadores, 5,6\% no registro-broca ou ferrule (tomada da rede) e 2,6\% no colar de tomada da rede (IPT, 2000). Atualmente $90 \%$ dos consertos de vazamentos executados pela SABESP na Região Metropolitana de São Paulo (cerca de 36.000 ocorrências mensais) são realizados no ramal predial, sendo que $60 \%$ ocorrem no tubo de $\mathrm{PEAD}^{2}$. Nos estudos de campo realizados pelo IPT na primeira fase do "Projeto - PEAD" foram identificados 5 tipos de falhas mais significativas em ramais prediais com tubos de PEAD, os quais representavam cerca de $80 \%$ dos casos estudados: microfissuras, furos e trincas no tubo, trinca no adaptador, vazamento em junta mecânica, vazamento em junta rosqueada e trinca em registro.

\footnotetext{
${ }^{2}$ Estimativa pessoal, a partir de informações e relatórios internos da SABESP.
} 
O trabalho apontou como principais causas e origens das falhas: má fabricação do tubo e dos acessórios, má formulação e/ou má preparação do composto de polietileno e de outros compostos plásticos empregados nos acessórios, erros de projeto de componentes, controle de qualidade ausente (ou ineficaz), instalação inadequada do ramal e respectivos compontentes, falta de treinamento dos instaladores e utilização de ferramentas impróprias (IPT, 2000); (IPT, 2001); (BARRETO, 2001).

A falha de um tubo é freqüentemente o resultado de fatores específicos locais (THOMPSON et al, 1992). A instalação de tubos tipicamente envolve atividades de abertura de valas, junção e montagem de segmentos de tubos e acessórios, e atividades de recobrimento do tubo e de preenchimento de valas. Variações nesses procedimentos depende sempre das especificações do projeto e de condições específicas do local (SMITH et al, 2000). Assim, não se deve deduzir que a falha de um certo tipo de tubo em um determinado local represente um problema geral de tubos semelhantes. A avaliação de uma falha com um tubo de polietileno deve incluir uma investigação completa da instalação, atenta observação das amostras do tubo durante a remoção, cuidadosa análise da superfície da fratura, e a execução de testes abrangentes das características e composição do material, entre outros procedimentos.

O tempo de vida útil de um tubo de polietileno depende da resistência a tensões e agentes químicos provenientes do ambiente interno e externo. As tensões podem ser internas decorrentes da pressão de trabalho, ou externas decorrentes da envoltória do tubo, dobramentos, cisalhamento e outros esforços. Essas tensões podem ainda ser constantes ou flutuantes. Gradientes de pressão interna, alterações de temperatura e cargas flutuantes como as provocadas pelo tráfego também atuam sobre o material. A resistência ao environment assisted cracking é outra característica que afeta a vida útil do tubo de polietileno.

Esforços mecânicos e mecanismos de degradação se combinam para causar uma elevada gama de possíveis modos de falha em tubos. As formas de vazamento que ocorrem variam muito de companhia para companhia e de área para área na mesma companhia devido a variações em fatores como materiais e métodos 
empregados para instalação, qualidade da água, condições do solo e intemperismo (SMITH et al, 2000)

A questão dos materiais empregados e da técnica construtiva aplicados no berço sobre o qual o tubo é depositado, na envoltória imediata do tubo e no preenchimento da vala precisa ser considerada com atenção. O tipo de berço e de recobrimento é determinado por uma série de fatores, incluindo o material do tubo e seu diâmetro, cargas de superfície e pressões de trabalho (SMITH et al, 2000). O material que imediatamente envolve o tubo e aquele sobre o qual o tubo é depositado deve ser livre de pedras e materiais pontiagudos ou abrasivos. Para tubos de polietileno, materiais do berço e da envoltória "importados" ${ }^{3}$ podem ser melhores do que o material "nativo", originalmente retirado da vala, porque o material importado pode ser mais facilmente controlado em termos de composição. Em contraste, o material nativo pode ter composição irregular, com presença de pedras pontiagudas, fragmentos de materiais e outros elementos que podem danificar a parede do tubo (THOMPSON et al, 1992)

Nas pesquisas da AWWA (THOMPSON et al, 1992), várias companhias citaram fraturas na saída de anéis de compressão (stiffeners) usados em adaptadores de pressão para tubos de polietileno. Tais fraturas surgem de movimentos de flexão na saída do anel de compressão, que provocam tensões na parede do tubo. Tais tensões podem eventualmente levar à falha circunferencial.

A pressão da coluna de solo e do tráfego aplica sobre o tubo uma força de esmagamento que produz uma tensão de compressão no tubo. Força de esmagamento excessiva tende a causar trincas longitudinais. Se o tubo não estiver apoiado, a pressão faz com que ele atue como uma viga, o que introduz tensão de flexão. Os efeitos negativos da ação de flexão são aumentados quando o tubo atravessa a borda da rua. O tráfego provoca movimentos cíclicos no segmento de tubo sob a rua, enquanto o segmento distante do leito permanece estacionário. Excessiva tensão de flexão tende a causar trincas circunferenciais (SMITH et al, 2000).

\footnotetext{
${ }^{3}$ Materiais selecionados provenientes de local distante da instalação.
} 
As propriedades físicas dos tubos plásticos são significativamente diferentes dos tubos tradicionais como os metálicos e os de concreto. Nas junções, o comportamento diferente sob carga desses materiais cria pontos de concentração de tensões que podem danificar o plástico na interface com tubos mais rígidos (SMITH et al, 2000). A indústria de tubos para condução de gás também tem acusado uma alta freqüência de falhas frágeis (brittle-like) ${ }^{4}$ em tubos de polietileno, nas junções com tubos de aço (NTSB, 1998); (NTSB, 1998b); (DOT, 1999); (SMITH et al, 2000); (DOT, 2002).

Falhas de tubos de polietileno que ocorrem em condições reais de serviço são freqüentemente trincas ou fissuras através da parede do tubo com nenhuma evidência visível de deformação plástica do material. Rupturas dúcteis são raras. A pressão de uma pedra contra o tubo plástico gera intensificação de tensão a longo prazo que conduz à formação de fratura frágil. Trincas através da parede do tubo que ocorrem durante testes de ruptura por fluência ou em condições reais de serviço, resultam da iniciação e lento crescimento de trincas e são semelhantes às fraturas frágeis de outros materiais, que ocorrem com pouca ou invisível deformação plástica. (NTSB, 1998).

A falha ou ruptura frágil é um modo de falha comum de tubos plásticos enterrados e pode causar grandes rompimentos. Uma vez iniciada a falha frágil, ela se propaga rapidamente ao longo do tubo. Essas falhas estão relacionadas à intensificação de tensões geradas por forças externas aplicadas sobre o tubo por condições como dobramento agudo durante a instalação (particularmente em acessórios), recalques (differential settlement), resultado de apoio inadequado sob o tubo, movimentos resultantes de acomodação do solo, contato com objetos pontiagudos (por exemplo, pedras no material da envoltória ou do berço), ou conexão com tubos rígidos. Falhas ou rupturas frágeis podem ser prevenidas garantindo-se que níveis críticos de pressão necessários para iniciar o modo de falha nunca sejam excedidos. A pressão crítica depende da temperatura da água e do

\footnotetext{
${ }^{4}$ Nos textos técnicos, em Inglês, é geralmente empregado o termo brittle-like para descrever as falhas frágeis, geralmente com aspecto de pequenas fissuras, designadas como slit failures (NTSB, 1998). Entendemos que é mais apropriado o termo brittle-like, com o significado em português de com aparência de frágil, em função dos mecanismos de deformação envolvidos, que serão discutidos em seção posterior. Dessa forma, a expressão falha frágil sempre será empregada neste texto com esse sentido.
} 
conteúdo de ar, do diâmetro do tubo, da espessura da parede e da tenacidade à fratura dinâmica do material. (SMITH et al, 2000). O melhor entendimento das condições que causam rupturas frágeis em tubos enterrados pode promover o desenvolvimento de métodos de projeto e de instalação que previnam as falhas.

Sob solicitação de pressão hidrostática, a pressão interna causa o aparecimento de uma tensão principal de tração na parede do tubo (SMITH et al, 2000); (OLIVEIRA, 2002), denominada tensão circunferencial, que é diretamente proporcional à pressão e ao diâmetro do tubo e inversamente proporcional à espessura da parede do tubo. Surgem ainda outras tensões principais, uma delas com direção longitudinal e cerca de duas vezes menor que a tensão cincunferencial, enquanto a outra, com direção radial, é normalmente desprezada (assume-se que o tubo trabalha sob um estado plano de tensões). Tensão circunferencial excessiva tende a causar trincas longitudinais. Pressão e fluxo atuando em curvas ou válvulas também podem introduzir tensões axiais no tubo. O nível de tensão depende da pressão e da configuração do tubo. Tensão longitudinal excessiva tende a provocar trincas cincunferenciais. Gradientes de pressão podem ocorrer devido a mudanças nas condições do fluxo. Por exemplo, quando uma válvula fecha e o fluxo é interrompido, a energia cinética da corrente de água é convertida para energia interna e resulta em súbita elevação da pressão, efeito conhecido como golpe de aríete (water hammer) (SMITH et al, 2000).

O polietileno é sujeito à progressiva oxidação e com o tempo certas áreas de fragilização podem ser desenvolvidas. Nessas áreas de fragilidade tensões relacionadas à instalação podem levar à falhas que não ocorreriam em tubos mais novos (THOMPSON et al, 1992); (NTSB, 1998).

As Figuras 3, 4, 5, 6, 7 e 8 ilustram alguns tipos de falhas típicas em tubos de polietileno: 


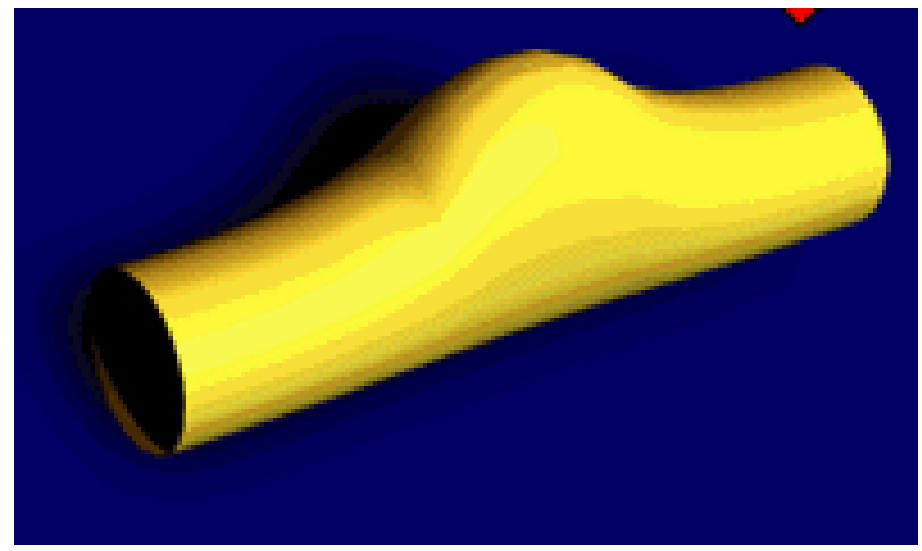

Figura 3: Falha dúctil de tubo de polietileno (abolamento)

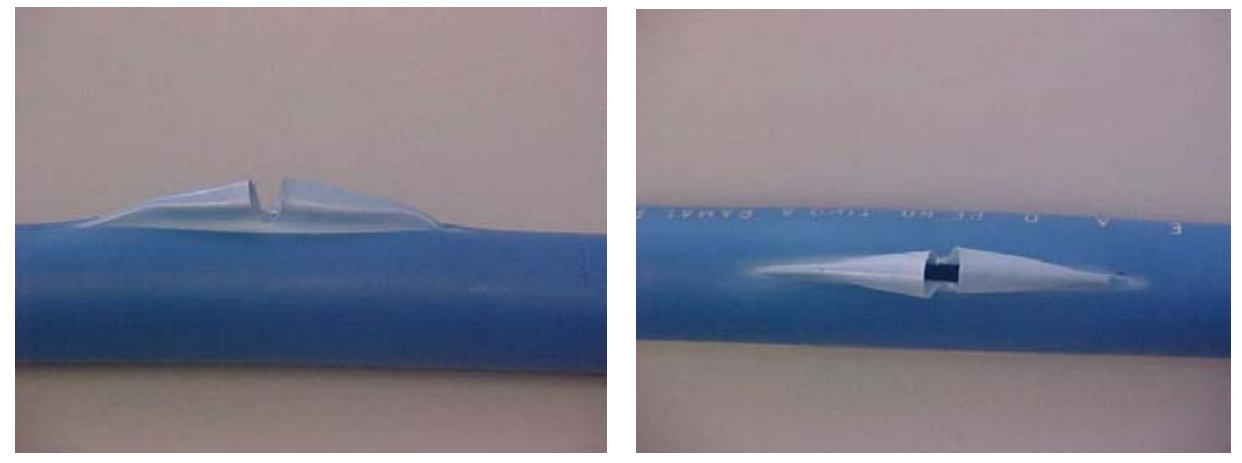

Figura 4: Falha dúctil de tubo de polietileno (abolamento seguido de ruptura dúctil)

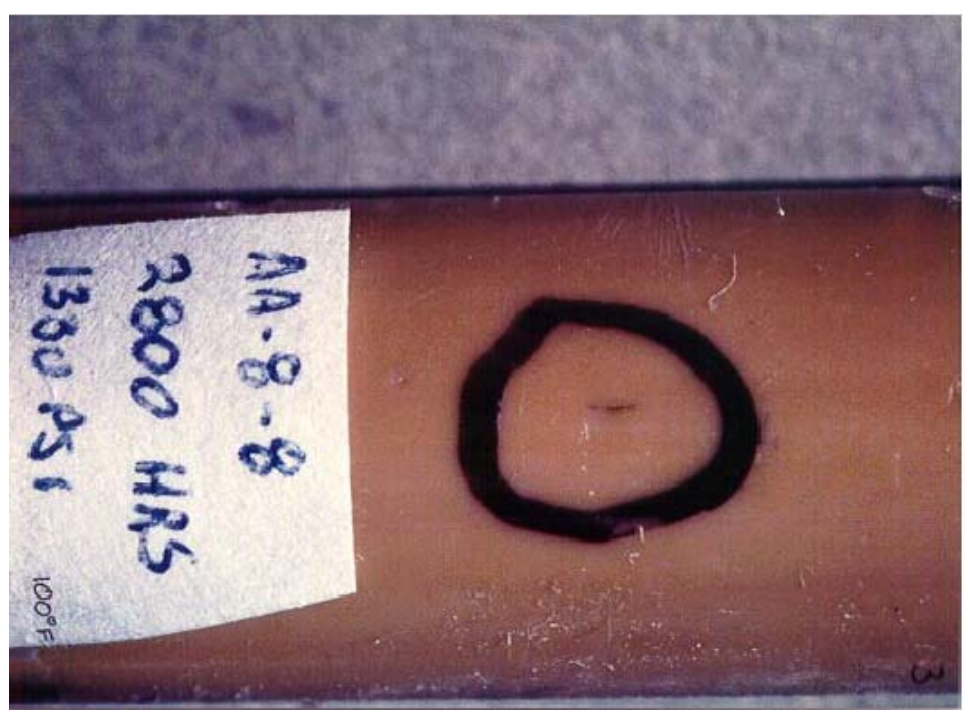

Figura 5: Falha frágil de tubo de polietileno (slit failure) (Fonte: NTSB, 1998) 


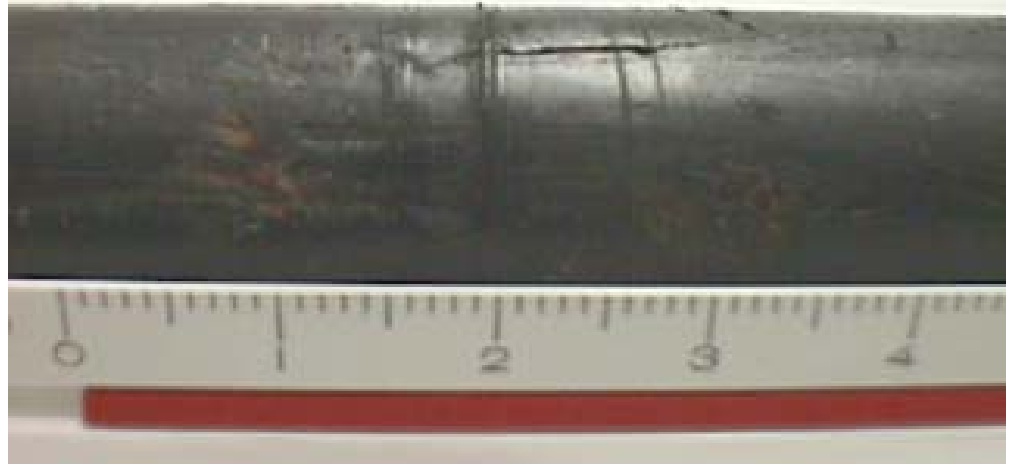

Figura 6: Falha frágil de tubo de polietileno. (Fonte: BARRETO, 2001)

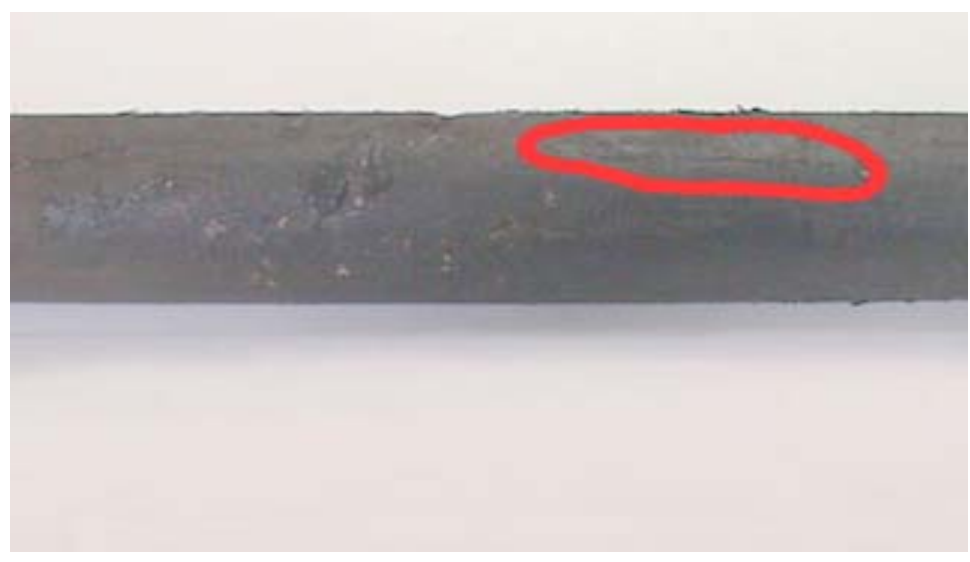

Figura 7: Falha frágil de tubo de polietileno. (Fonte: BARRETO, 2001)

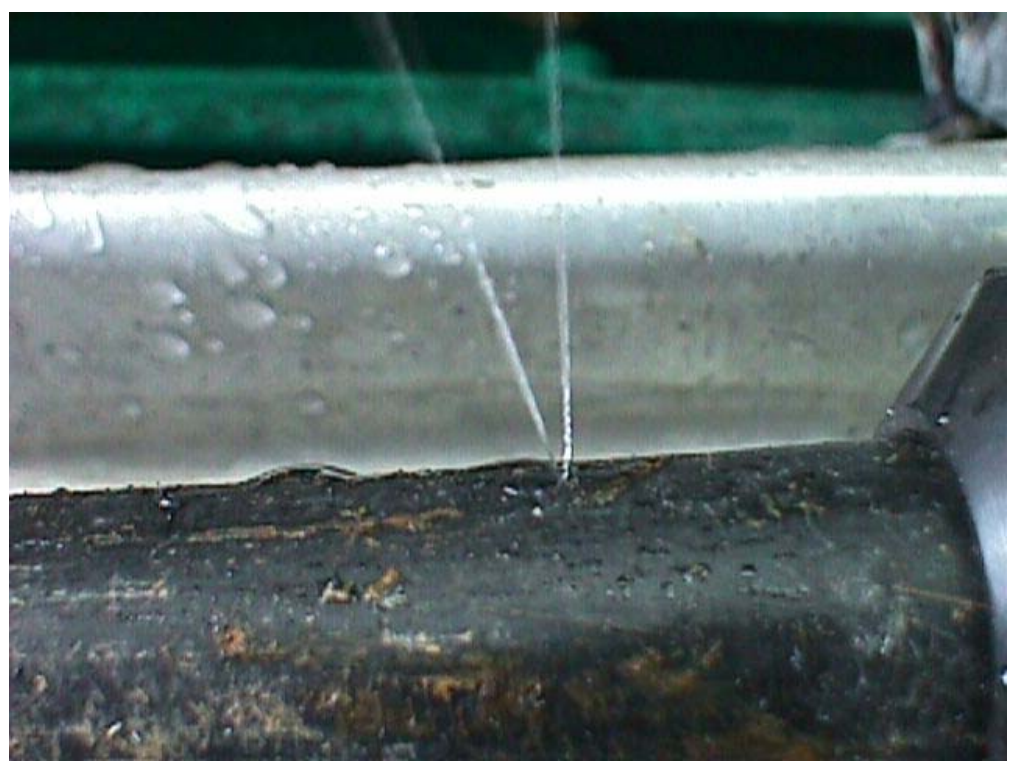

Figura 8: Vazamento a partir de uma falha frágil de tubo de polietileno. (Fonte: BARRETO, 2001 


\section{5 - A “curva de regressão" e o dimensionamento de tubos de polietileno}

Uma das mais importantes características do polietileno é sua natureza viscolelástica, ou seja, suas propriedades mecânicas são dependentes da tensão, do tempo e da temperatura. Isso se torna muito importante no projeto de componentes com função estrutural. Em condições climáticas típicas do Estado de São Paulo, os tubos de polietileno atuam expostos a altas temperaturas homólogas do material por longos períodos de tempo. Como efeito da pressão interna as paredes do tubo ficarão constantemente sob tensão e sofrerão o fenômeno de deformação por fluência (creep), no qual a deformação aumenta gradualmente com o tempo. A tensão contínua resulta no contínuo aumento da deformação com o tempo, levando à ruptura final por fluência (HAYDEN et al, 1965); (BROWN, 1988); (MORTON-JONES, 1989); (MEYERS \& CHAWLA, 1999); (DOWLING, 1999); (CALLISTER, 2000); (JANSON, 2003). Outro aspecto do comportamento viscoelástico é o fenômeno da relaxação de tensão, caracterizado pela redução gradual da tensão com o tempo se a deformação permanecer constante.

Usualmente, a vida útil dos tubos de polietileno empregados em sistemas de distribuição de água é prevista em 50 anos (MILLS, 1993); (JANSON, 2003).

Para uma dada temperatura, podemos construir curvas tensão $\mathrm{x}$ tempo de ruptura, ou ainda curvas de ruptura por fluência, submetendo o material a diversos níveis de tensão e medindo o tempo consumido até a ruptura. Observa-se à medida que a tensão é reduzida, que o tempo de ruptura aumenta. Quando lançados em gráfico, em coordenadas cartesianas, os dados obtidos dessa formam uma curva parabólica. Entretanto, quando dispostos em gráfico na forma logaritmo da tensão $\mathrm{x}$ logaritmo do tempo, ou diretamente em escala log-log, com o tempo de ruptura lançado em abscissa, os gráficos assumem um comportamento linear. Através de tratamento matemático adequado (regressão por mínimos quadrados) pode-se obter a equação de reta correspondente, permitindo projeções, por extrapolação, para tempos mais longos (PPI, 2000). A curva assim obtida é conhecida como "curva de regressão". Os ensaios são realizados em tubos de polietileno submetidos à pressão hidrostática interna, usualmente com água, mantendo-se constante a pressão até o rompimento ou falha do tubo. Geralmente os testes são conduzidos para que se obtenham dados de resistência à ruptura por fluência até pelo menos 10.000 horas - 
pouco mais de 1 ano, à temperatura ambiente - $23^{\circ} \mathrm{C}$ (ASTM D 2837) ou $20^{\circ} \mathrm{C}$ (ISO 9080). A pressão interna produz uma tensão circunferencial na parede do tubo, a qual pode ser facilmente calculada conhecendo-se a pressão e as dimensões do tubo ${ }^{5}$. A relação básica adotada é a seguinte:

$$
\sigma=\frac{p d}{2 e}
$$

onde $\sigma$ é a tensão circunferencial, $p$ é a pressão de trabalho do tubo, $d$ é o diâmetro médio, e $e$ é a espessura da parede do tubo.

Os diagramas obtidos e as curvas de regressão são usados em cálculos de projeto: dada a vida útil mínima desejada do tubo, geralmente 50 anos (JANSON, 2003), a tensão (básica) de projeto (HDB ou MRS - vide abaixo) pode ser obtida a partir da leitura da resistência à pressão hidrostática de longa duração (long-term hydrostatic strenght - LTHS) no eixo das ordenadas (Figura 9). Para obtenção da tensão de projeto são ainda aplicados coeficientes de segurança estabelecidos.

Para simplificar a classificação e facilitar a padronização, os materiais com semelhantes valores de LTHS podem ser agrupados. Considerando-se as duas principais normas existentes, as classes de tensão dos materiais dos tubos podem ser determinadas a partir da Hydrostatic Design Basis - HDB, conforme ASTM D 2837 ou da Minimum Required Strength - MRS, conforme ISO 9080. A HDB ou a MRS é a categoria de resistência à pressão hidrostática de longa duração usada para calcular a classe de tensão do material do tubo de plástico.

Ambas ASTM D 2837 e ISO 9080 analisam os dados de tensão de ruptura até 10.000 horas para estimar a resistência do material do tubo de plástico, diferindo no tratamento dos dados. Na ASTM D 2837, a HDB para o material é determinada categorizando-se o valor médio da resistência à pressão hidrostática de longa duração a 100.000 horas (cerca de 11 anos). Na ISO 9080, a MRS é determinada

\footnotetext{
${ }^{5}$ Surgem ainda outras tensões principais, uma delas com direção longitudinal e cerca de duas vezes menor que a tensão cincunferencial, enquanto a outra, com direção radial, é normalmente desprezada assumindo-se que a parede do tubo é suficientemente estreita. Dessa forma pode-se considerar que nos ensaios de resistência à pressão hidrostática interna se desenvolve um estado plano de tensão.
} 
categorizando-se o limite inferior de confiança (lower confidence limit - LCL / 97,5\%) da resistência à pressão hidrostática de longa duração a 50 anos (438.000 horas) (PPI, 2000). A partir da classificação da MRS (ISO 12162), o tipos de polietileno são designados pelas letras PE seguidas do valor (mínimo) da classe de MRS, em MPa, multiplicados por 10. Dessa forma, por exemplo, uma classe de polietilenos cujo valor de LTHS/LCL está entre 8,0 e 9,9 MPa possui a designação de PE $80(\mathrm{MRS}=8,0 \mathrm{MPa})$; uma classe de polietilenos cujo valor de LTHS/LCL é no mínimo 10,0 MPa possui a designação de PE 100 (MRS = 10,0 MPa). As normas NBR 8417 e NTS 048 estabelecem que os compostos de polietileno utilizados nos tubos de PEAD empregados em ramais prediais sejam classificados como PE 80 ou PE 100.

Os ensaios de resistência à pressão hidrostática interna de longa duração para efeito de classificação do material para a fabricação de tubos são sempre realizados com o composto de polietileno, ou seja, a resina base de polietileno mais os pigmentos e demais aditivos (PIEROZAN, 2004).

Observa-se que durante os testes de laboratório de curta duração (níveis mais altos de tensão) os tubos falham primariamente através de rupturas dúcteis, que são caracterizadas visivelmente por substancial deformação plástica, geralmente na forma de um "abolamento" (bulging or balooning) seguido de ruptura com significativa deformação plástica permanente (Figuras 3 e 4). Em tubos de polietileno submetidos a testes de ruptura por fluência prolongados (níveis mais baixos de tensão), podem surgir trincas através da parede do tubo, que se apresentam como pequenas fissuras (slit failures) geralmente com direção longitudinal, com mínima ou nenhuma deformação plástica visível (Figuras 5, 6, 7 e 8). Devido à falta de deformação permanente visível associada com essas falhas, pelo menos no nível macroscópico, elas são conhecidas como rupturas frágeis. Essa mudança do tipo de ruptura aparece na curva de regressão na forma de uma importante alteração na inclinação. O primeiro estágio da curva mantém a forma de uma linha reta de declínio gradual da tensão, ao longo do tempo, caracterizado primariamente por rupturas do tipo dúctil. O primeiro estágio gradualmente passa para o segundo estágio, onde a inclinação da curva aumenta significativamente, com um declínio mais rápido na tensão, que corresponde a uma região onde as rupturas do tipo frágil 
predominam. O tempo e a intensidade da alteração na inclinação da curva varia com o tipo de composto de polietileno empregado na fabricação do tubo (NTSB, 1998), com a temperatura e com as condições de processamento do tubo empregado nos testes (LU et al, 1994). A inflexão ou "joelho" na curva de regressão corresponde a uma mudança entre modos de falha dúctil e frágil, ou seja, a uma transição dúctilfrágil, sob o ponto de vista da falha macroscópica. Essa transição no modo de falha indica uma redução na resistência de longa duração do material, na medida em que a inclinação da curva de regressão se acentua na região frágil. Os fabricantes de resinas e tubos de polietileno têm procurado intensamente fabricar produtos que retardam a inflexão da curva de regressão.

Uma curva de regressão possui a forma geral apresentada nas Figuras 9 e 10:

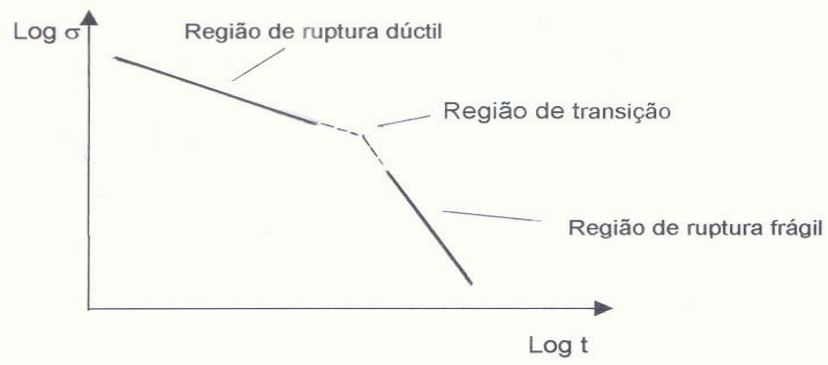

Figura 9: Forma característica da curva de regressão

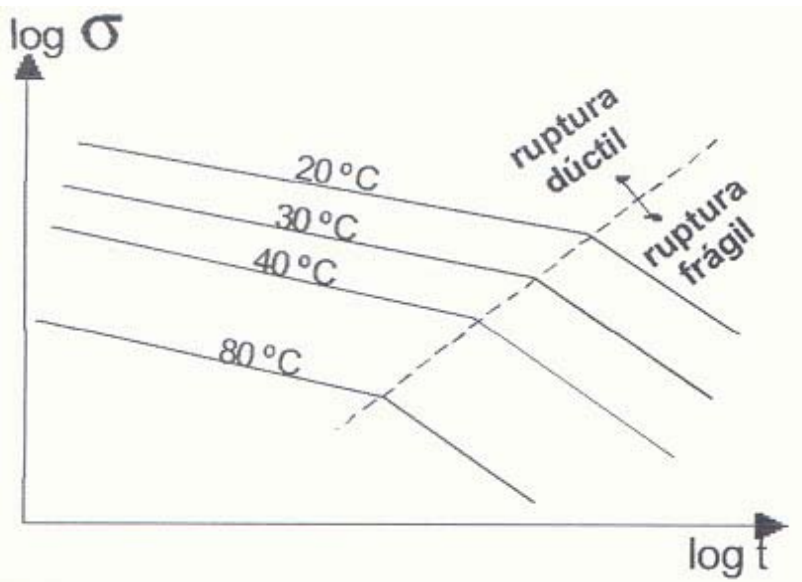

Figura 10: Forma característica da curva de regressão - influência da temperatura (Fonte: NTS 048) 
A ASTM D 2837 assume uma extrapolação linear até 100.000 horas, e então aplica um procedimento de validação para confirmar se é válida a suposição implícita no método (ou seja, de que não há inflexão antes do período extrapolado). Composições que exibem uma inflexão na "curva de regressão" antes de 100.000 horas são rejeitadas. A ISO 9080 usa uma forma de extrapolação que inclui a caracterização de uma possível inflexão na "curva de regressão" antes de 438.000 horas (PPI, 2000).

Temperaturas mais altas reduzem o tempo de falha e o tempo para a transição dúctil-frágil (Figura 10). Essa é a base da validação da LTHS (ASTM D 2837) para melhorar a confiança da linha de regressão projetada. Em outras palavras, testes a altas temperaturas pretendem mostrar se uma transição dúctil-frágil ocorre ou não no período de tempo considerado para extrapolação a temperaturas mais baixas (PPI, 2000). A Figura 11 apresenta um exemplo completo de uma "curva de regressão".

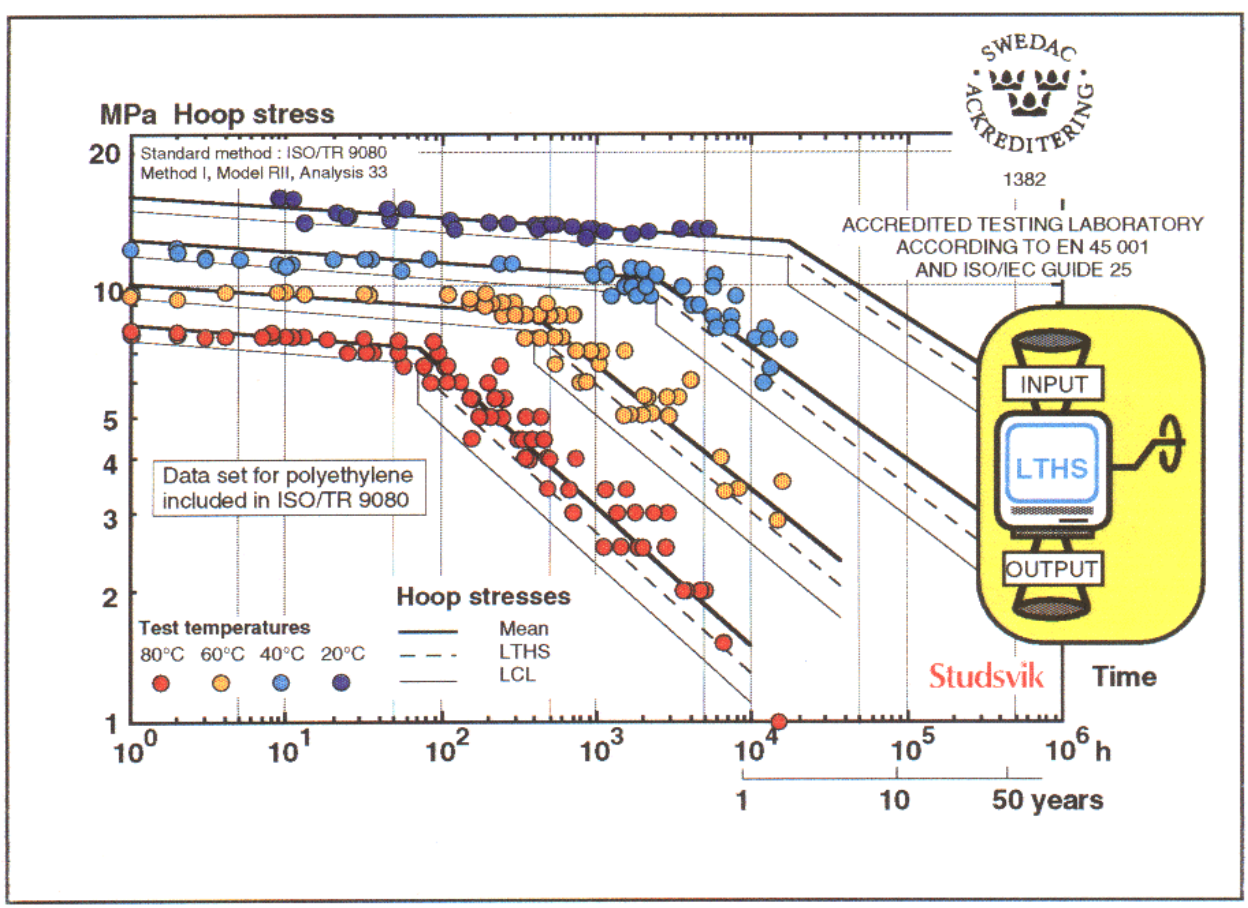

Figura 11: Exemplo de "curva de regressão" (Fonte: PIEROZAN, 2004)

A "curva de regressão" de um composto qualquer depende da resina base, dos aditivos e pigmentos incorporados, de sua história térmica e das tensões residuais e efeitos decorrentes do processamento do tubo utilizado nos ensaios. 
Segundo Ogorkiewicz (1974) e Canevarolo Jr.(2002) é importante adotar cautela na equivalência tempo-temperatura, porque dados obtidos a uma temperatura maior e usados para previsões a temperaturas mais baixas são freqüentemente obtidos em um estado bastante diferente do material. Além disso, as projeções embutem certas incertezas intrínsecas ou decorrentes de diferenças de carregamento e de solicitação do tubo entre as condições de laboratório e do tubo instalado. Dessa forma, recomenda-se que dados de fluência não sejam extrapolados mais que uma década, ou seja, o limite máximo de extrapolação de dados obtidos até 10.000 horas seria até 100.000 horas (PROGELHOF \& THRONE, 1993).

A temperatura possui um efeito inverso sobre a LTHS do polietileno, ou seja, a temperaturas mais altas, a LTHS é menor para o mesmo tempo de projeção. A ASTM 2837 não especifica a temperatura da LTHS, mas $23^{\circ} \mathrm{C}$ é tipicamente usada na caracterização da LTHS para efeito de definição da classe de pressão. A ISO 9080 especifica $20^{\circ} \mathrm{C}$ quando a LTHS é caracterizada para a definição da classe de pressão. Uma vez que a HDB ou a LTHS tenha sido validada a tensão de projeto (hydrostatic design stress - HDS) é calculada multiplicando-se a HDB por um fator de serviço (design factor $-D F)$. Esse fator é o inverso do fator de segurança. Fator típico de serviço é 0,5 para tubos de água. Da mesma forma a ISO 9080 estabelece um fator de segurança: a MRS é dividida por esse fator para determinar uma tensão máxima de operação do material. Esse fator é tipicamente 1,25 para tubos de água, mas pode ser maior, dependendo das condições de serviço e de regulamentos locais. (PPI, 2000).

\section{6 - Deformação do PEAD e a transição dúctil frágil}

Devido às suas características estruturais e à sua natureza viscoelástica, o polietileno apresenta diferentes modos de falha. A temperaturas próximas da ambiente, o material apresenta falha dúctil a altas tensões e falha frágil a baixas tensões (LU \& BROWN, 1990). Durante testes de laboratório de curta duração (níveis mais altos de tensão), ou quando submetidos a sobrecargas, os tubos falham primariamente através de rupturas dúcteis, que são caracterizadas visivelmente por substancial deformação plástica permanente (Figuras 3 e 4). Em tubos de polietileno submetidos a prolongados testes de ruptura por fluência (níveis mais baixos de tensão), ou quando em serviço, pressurizados por longos períodos de tempo, podem 
surgir trincas através da parede do tubo, com nenhuma evidência visível de deformação plástica do material (Figuras 5, 6, 7 e 8). Devido à falta de deformação visível essas falhas são conhecidas como rupturas frágeis (HERTZBERG, 1995). Essa mudança de comportamento, que caracteriza uma transição dúctil-frágil, pelo menos ao nível da fratura macroscópica, abrevia a vida útil do tubo e, portanto, precisa ser bem compreendida.

À temperatura ambiente o polietileno de alta densidade é um sólido viscoelástico não linear, ou seja, a deformação é uma função não linear do tempo e da tensão (BOENIG, 1973); (OGORKIEWICS, 1974); (BILLMEYER, 1975); (HERTZBERG, 1995); (KINLOCH \& YOUNG, 1995); (MEYERS \& CHAWLA, 1999). Os tubos de polietileno em ligações de água são pressurizados e geralmente empregados em temperaturas homólogas relativamente altas, de forma que o material sofre fluência (MEYERS \& CHAWLA, 1999). A aplicação contínua da carga resulta no contínuo aumento da deformação, cujo excesso pode levar a alterações dimensionais intoleráveis (BROWN, 1988). No estágio final do processo a deformação torna-se localizada pela formação de estricção (necking), semelhante a um ensaio de tração, ou microvazios podem formar-se no interior do material, ou ambos, e o processo leva à ruptura final por fluência. Esse estágio final pode ser devido simplesmente à redução da área da seção transversal sob carga constante, o que leva ao aumento da tensão e conseqüentemente ao aumento da taxa de deformação (HAYDEN et al, 1965); (DOWLING, 1999), mas o fator elementar na determinação do tempo de falha é a densidade de moléculas de ligação (tie molecules) (BROWN et al, 1991). Fatores como taxa de deformação e a temperatura afetam a forma das curvas tensão-deformação, com efeitos opostos, ou seja, aumentando-se a taxa de deformação (ou reduzindo-se a temperatura) níveis mais altos de tensão serão atingidos, enquanto que a deformação terá valores menores (KINLOCH \& YOUNG, 1995); (MEYERS \& CHAWLA, 1999).

A nível microscópico, a deformação de polímeros termoplásticos, como o PEAD, depende da habilidade das cadeias poliméricas se conformarem e girarem em torno das ligações moleculares, e de se movimentarem e se alinharem entre si (MEYERS \& CHAWLA, 1999), de forma que a resposta mecânica desses materiais dependente da resistência das ligações primárias covalentes, mas principalmente das 
ligações secundárias tipo forças de van der Waals (MORTON-JONES, 1989); (KINLOCH \& YOUNG, 1995).

Dada uma temperatura, em resposta à aplicação de uma tensão de cisalhamento constante as moléculas (cadeias poliméricas) deslizam continuamente umas sobre as outras através da quebra e da reconstrução de ligações intermoleculares de natureza secundária. Esse micromecanismo de fluxo viscoso é dependente do tempo, provoca um rearranjo molecular e está relacionado à difusão das moléculas através do material, provocando a deformação por fluência do mesmo. Trata-se de fenômeno termicamente ativado, podendo ser descrito por uma equação tipo Arrhenius (HAYDEN et al, 1965); (MEYERS \& CHAWLA, 1999); (DOWLING, 1999); (CALLISTER, 2000).

Induzido pela tensão e favorecido pela temperatura, o fluxo viscoso pode ser prejudicado pelo aumento da massa molecular, pelas moléculas de ligação (tie molecules), por ligações cruzadas (cross-linking) e outros fatores estruturais do polímero (BROWN et al, 1991); (KINLOCH \& YOUNG, 1995); (DOWLING, 1999).

Numa escala maior, dois mecanismos concorrentes de deformação plástica não homogênea podem ocorrer no PEAD: escoamento por cisalhamento (shear yielding), e microfibrilamento (crazing) ${ }^{6}$ (HERTZBERG, 1995); (KINLOCH \& YOUNG, 1995); (MEYERS \& CHAWLA, 1999); (ZHOU et al, 2001); (CANEVAROLO Jr., 2002). Os dois mecanismos podem ocorrer simultaneamente, mas a predominância de um ou outro em determinado modo de falha depende de fatores como nível de tensão, concentração de tensão, tempo, temperatura e meio (LU \& BROWN, 1990); (MEYERS \& CHAWLA, 1999); (ZHOU et al, 2001).

No comportamento dúctil do polímero, em níveis de tensão mais elevados, o modo de deformação dominante é o escoamento por cisalhamento enquanto que o comportamento frágil, em níveis menores e moderados de tensão, está associado com a formação de crazes; (LU \& BROWN, 1990); (HERTZBERG, 1995); (KINLOCH \& YOUNG, 1995); (MEYERS \& CHAWLA, 1999); (ZHOU et al, 2001).

\footnotetext{
${ }^{6}$ Neste texto, preferimos empregar os termos originais do Inglês crazing e craze(s), para designar respectivamente o fenômeno e a(s) microestrutura(s), assim como shear yielding. Esses termos, além de outros do Inglês eventualmente empregados, serão escritos em itálico.
} 
Na região de transição entre um e outro comportamento os dois mecanismos concorrem, e a predominância é controlada pelo acaso (ZHOU et al, 2001). Os autores têm concordado que todos os modos de fratura de polietilenos estão estreitamente relacionados com o desenvolvimento de crazes como fator precursor da fratura (OGORKIEWICZ, 1974); (KINLOCH \& YOUNG, 1995); (DUAN \& WILLIAMS, 1998); (MEYERS \& CHAWLA, 1999); (ZHOU et al, 2001); (IVANKOVIC et al, 2004).

\subsection{1 - Shear Yielding}

Shear yielding é um processo complexo, que se desenvolve sob tensões de cisalhamento, o qual envolve a quebra inicial da estrutura das regiões cristalinas e a reorientação subseqüente das cadeias poliméricas (HERTZBERG, 1995). No processo não há perda de coesão intramolecular nem alteração de volume e densidade (KINLOCH \& YOUNG, 1995); (CANEVAROLO, 2002), e provoca a deformação permanente do material. O fenômeno pode se desenvolver de forma difusa, que leva a uma deformação mais homogênea no corpo (bulk shear yielding), ou formando bandas de cisalhamento (shear bands), altamente localizadas, cuja formação é favorecida por níveis mais altos de tensão (BROWN, 1988); (KINLOCH \& YOUNG, 1995).

Sob tensão os esferulitos começam a ser destruídos, após um estágio inicial de deformação plástica. "Pacotes" de lamelas cristalinas cuja orientação é mais desfavorável em relação ao eixo da tensão são separados através da fase amorfa na região de contorno entre os cristais, enquanto outros podem girar na direção do eixo da tensão. Os cristais apresentam-se então quebrados em pequenos blocos, mas as cadeias poliméricas nas estruturas cristalinas remanescentes mantém ainda sua conformação dobrada. Segue-se um processo de orientação desses blocos na orientação do escoamento, formando feixes alinhados, juntamente com uma grande quantidade de moléculas de ligação (tie molecules) estendidas. Essas moléculas de ligação são formadas pelo desdobramento de cadeias poliméricas a partir das lamelas originais, durante a separação dos blocos cristalinos, porém permanecendo ligadas aos blocos separados e mantendo-os unidos durante o processo de escoamento e orientação, podendo pertencer a um mesmo feixe orientado ou simultaneamente a 
feixes adjacentes. Como efeito combinado de várias moléculas de ligação e da orientação dos feixes induzida pela tensão surge um rápido aumento na resistência e na rigidez (HERTZBERG, 1995). As fortes ligações primárias covalentes intramoleculares passam a dominar a resposta mecânica do material.

A Figura 12 ilustra o processo de shear yielding conforme o modelo descrito.

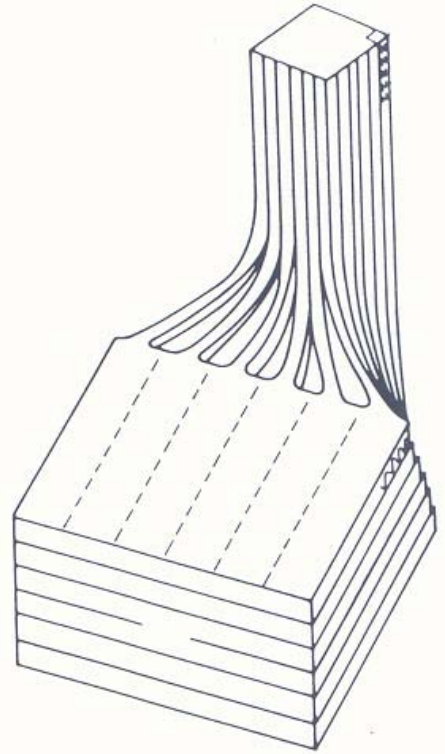

(a)

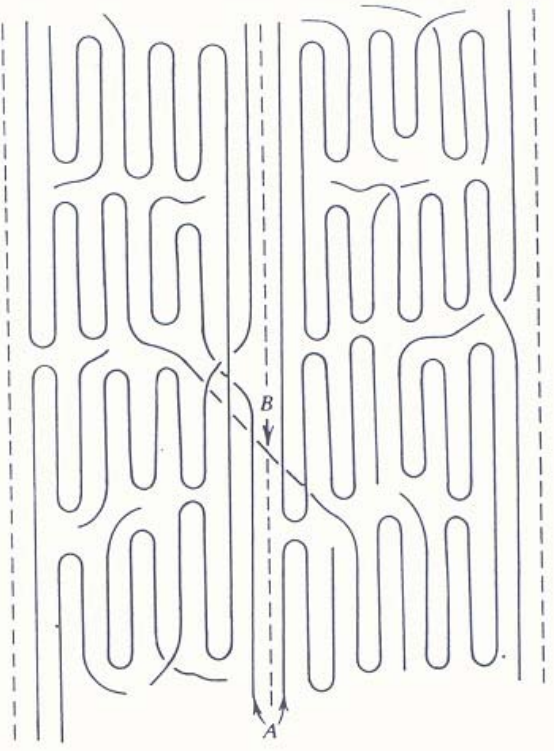

(b)

Figura 12: (a) Modelo que descreve a transformação de um "pacote" de lamelas paralelas em um "fardo" de feixes empacotados e alinhados. (b) alinhamento de blocos cristalinos em feixes. Exemplos de moléculas de ligação são mostradas em A e B. (Fonte: HERTZBERG, 1995).

O processo induzido pela tensão que envolve a ruptura da estrutura dos esferulitos, seguida da orientação molecular e das estruturas cristalinas é responsável pelo tipo de resposta tensão-deformação que será discutido adiante, particularmente pelo endurecimento por deformação (strain hardening) observado no comportamento mecânico do polietileno de alta densidade quando submetido a ensaio de tração. A continuação da deformação da estrutura orientada é dificultada devido à alta resistência dos feixes e devido às moléculas de ligação (HERTZBERG, 1995).

Em polímeros parcialmente cristalinos as bandas de cisalhamento podem ser vistas como feixes de fibras microscópicas altamente orientadas, a cerca de $30^{\circ} \mathrm{em}$ relação ao eixo da tensão principal (PROGELHOF \& THRONE, 1993), ou de $45^{\circ}$ no caso de materiais isotrópicos, segundo Kinloch \& Young (1995). 


\subsection{2 - Crazing}

Crazing é ao mesmo tempo um processo de deformação plástica localizada e um mecanismo de propagação de trinca (CANEVAROLO Jr., 2002), que ocorre sob tensão dilatacional de tração e produz significativa alteração da densidade local. $\mathrm{O}$ processo tem início em pontos de concentração de tensão, com amolecimento localizado do material (strain softening) e a formação de microcavidades. Segundo Ting et al (2004) dados experimentais recentes demonstraram que a nucleação e a subseqüente evolução de crazing é sensível a efeitos de restrição (constraint effects). A microestrutura formada, conhecida como craze, consiste de uma faixa estreita e longa de material expandido, com orientação normal ao eixo da máxima tensão principal de tração, contendo microfibrilas intercaladas com microvazios, estes por sua vez interconectados. As Figuras 13 e 14 apresentam desenhos esquemáticos de craze, segundo diferentes autores. A Figura 15 apresenta um conjunto de crazes, enquanto a Figura 16 apresenta a estrutura de um craze, a partir da ampliação de uma região da Figura 15. As imagens das Figuras 15 e 16 foram obtidas por microscopia eletrônica de varredura.
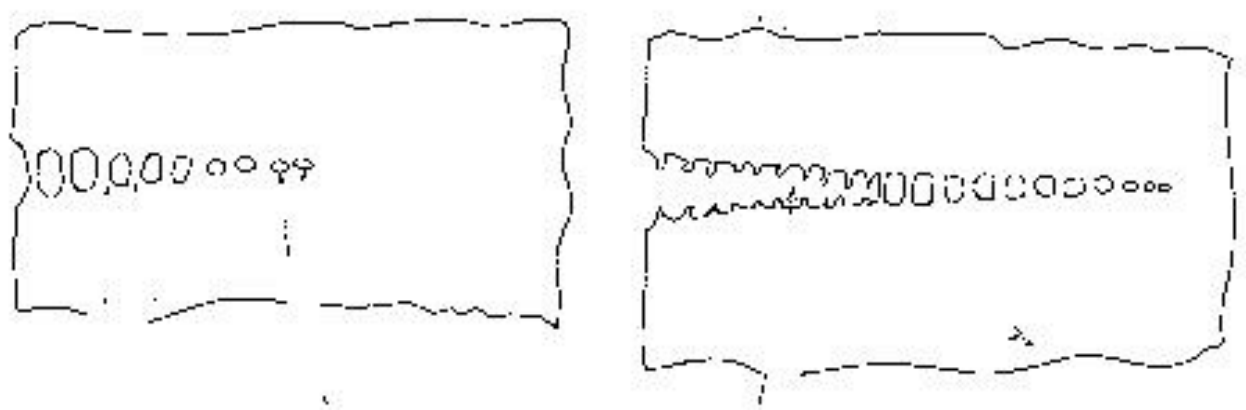

Figura 13: Desenho esquemático de um craze. (Fonte: CALLISTER, 2000) 


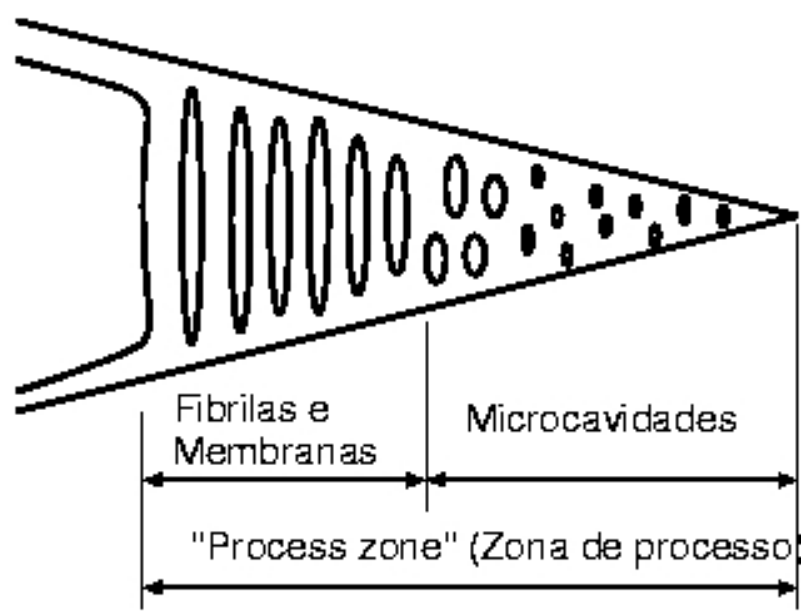

Figura 14: Desenho esquemático de craze. Chudnovsky \& Shulkin idealizaram a "zona de processo" (ou process zone - PZ) como uma região formada por uma parte cuja estrutura é a típica de crazing, como descrita acima, e uma parte composta de material com microvazios. A zona de processo integra o sistema crack layer - CL, concebido pelos autores, o qual compreende ainda a trinca. (Adaptado de CHUDNOVSKY \& SHULKIN, 1999)

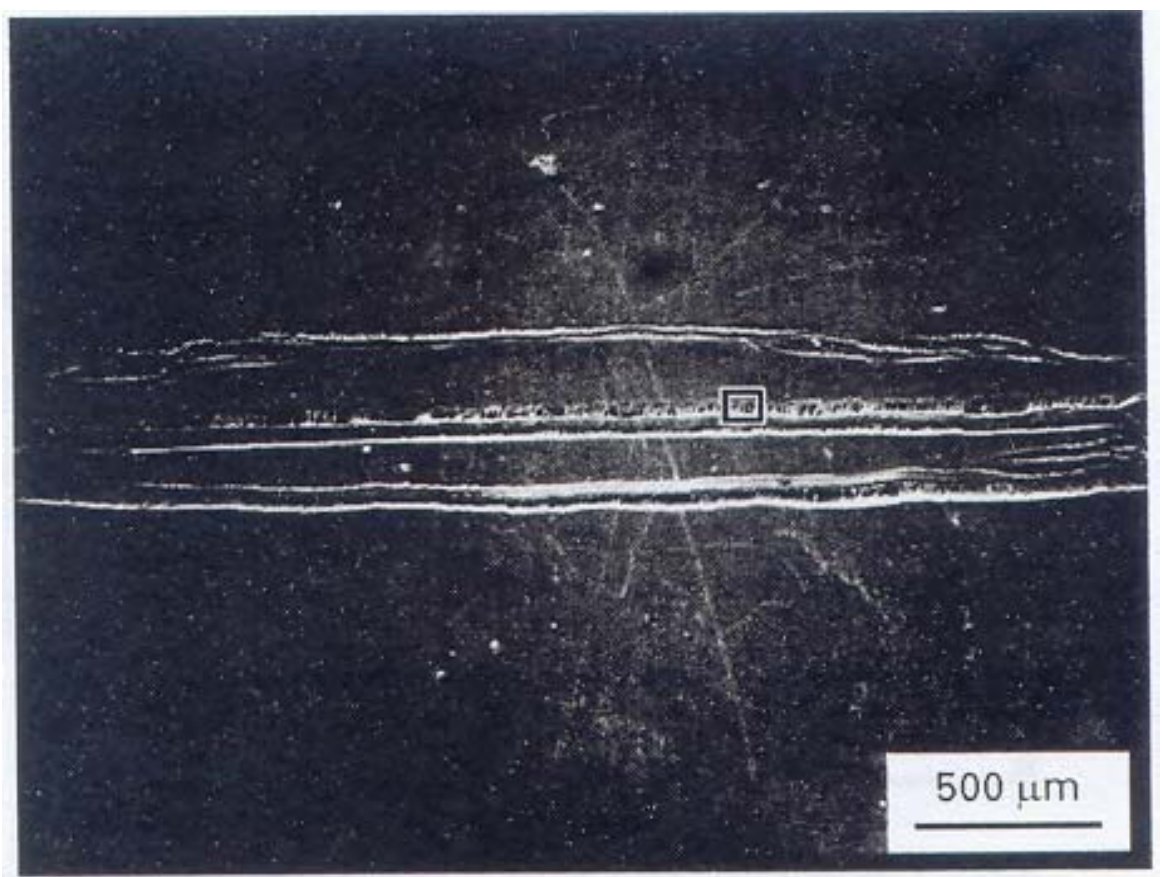

Figura 15: Conjunto de crazes em polietileno. (Fonte: DUAN \& WILLIANS, 1998) 


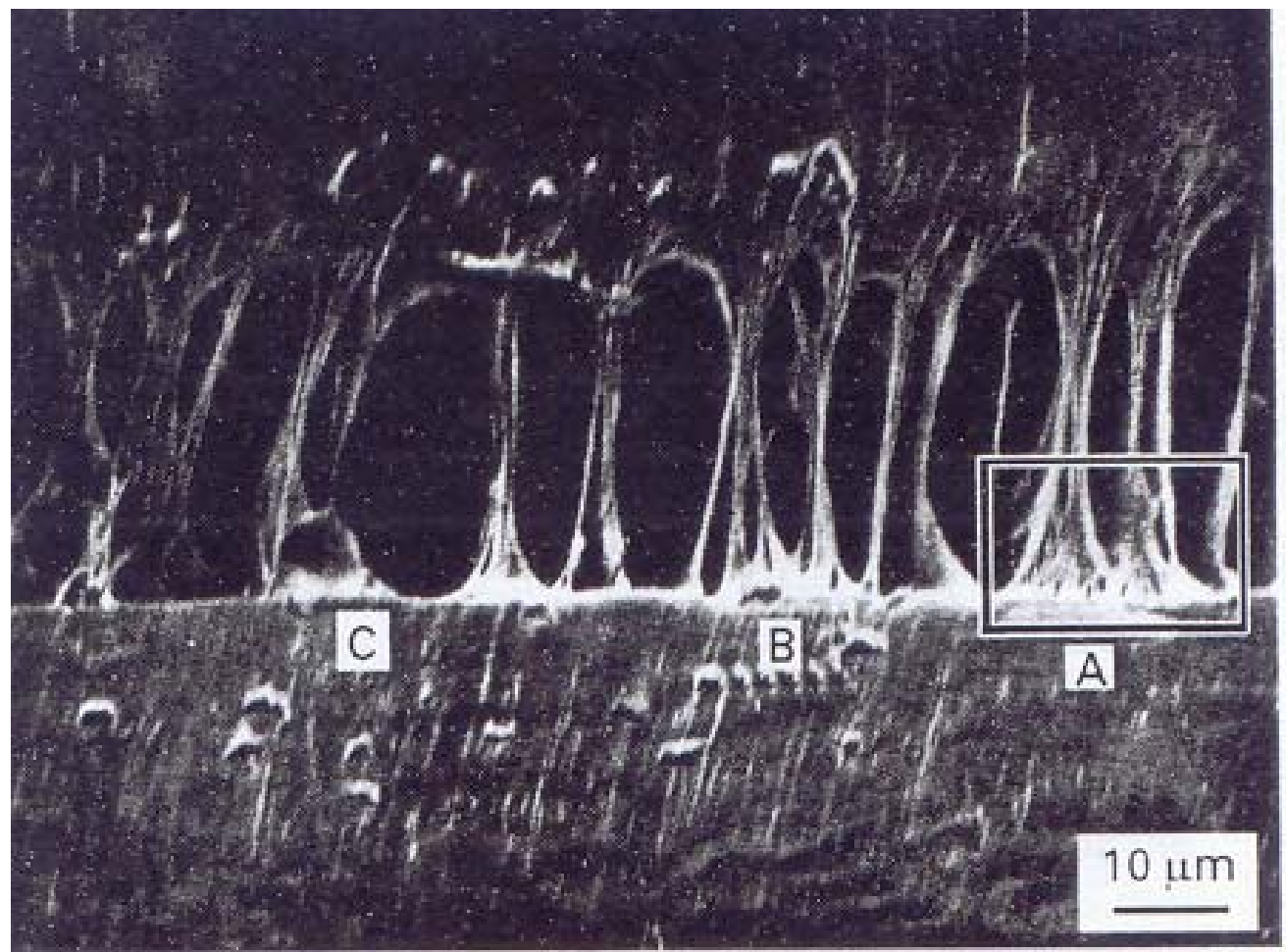

Figura 16: Estrutura do craze (ampliação da área demarcada na Figura 15). (Fonte: DUAN \& WILLIANS, 1998).

Um craze é capaz de suportar cargas de tração, sendo esta a principal diferença entre crazes e trincas verdadeiras (HERTZBERG, 1995); (KINLOCK \& YOUNG, 1995). Apesar de não formar (imediatamente) trincas verdadeiras, crazing pode levar à fragilização do polímero através da ruptura sucessiva das microfibrilas e do avanço da ponta do craze sobre a matriz do material, formando trincas cujo crescimento levará à fratura final. Esse processo, ilustrado na Figura 17, pode se desenvolver em tensões menores que aquelas necessárias para induzir bulk shear yielding e pode levar o material à ruptura frágil (KINLOCK \& YOUNG, 1995); (HERTZBERG, 1995). 


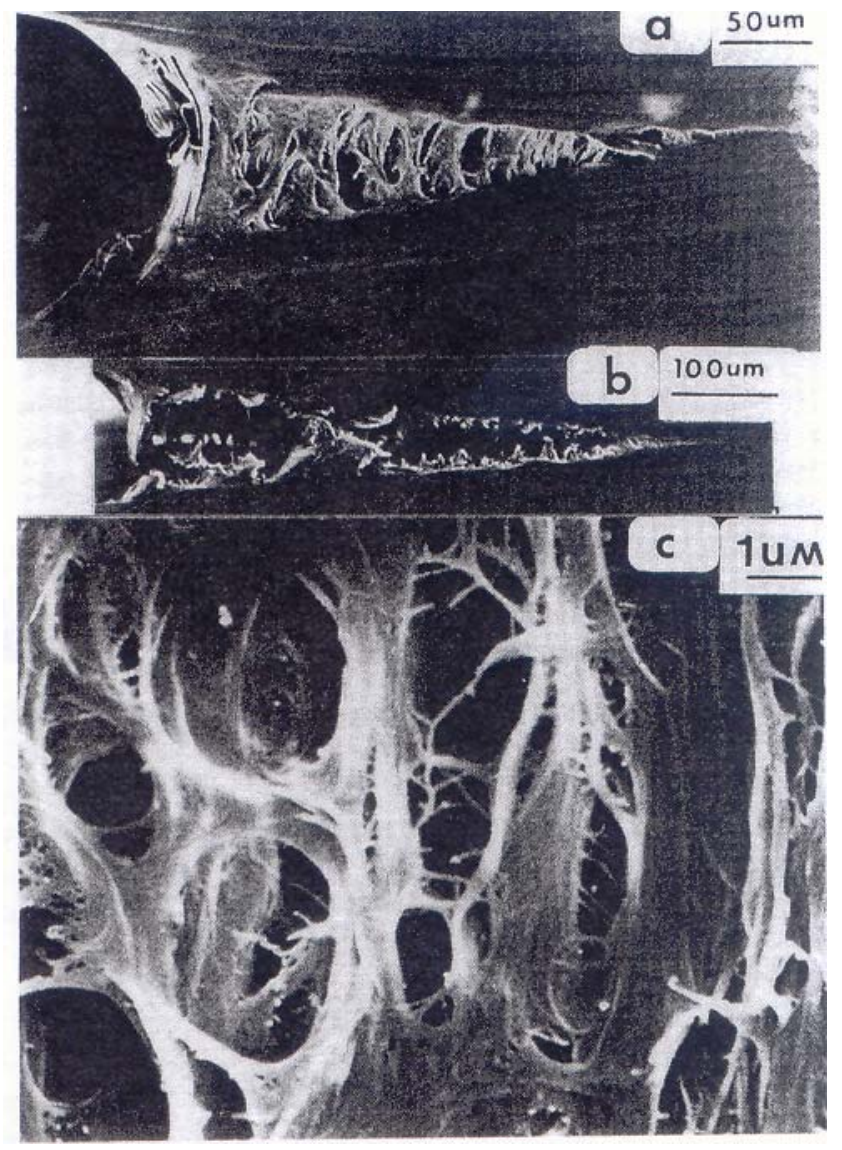

Figura 17: Morfologia da zona de processo na ponta de um entalhe. (a) iniciação da fratura; (b) após o crescimento da trinca; (c) estrutura detalhada das fibrilas. (Fonte: LU et al, 1994).

Esse mecanismo de crescimento lento de trincas através de crazes e trincas em polietileno é conhecido como slow crack growth - SCG, ou crescimento lento de trinca e se desenvolve a taxas de deformação bastante baixas. Sua descrição é bastante complexa e tem sido muito estudado por diversos autores. Segundo Qian et al (1989), sem a nucleação de um craze a fratura não ocorreria.

É importante observar que se crazes estáveis forem nucleados em um volume relativamente grande do polímero, ou seja, um mecanismo múltiplo de deformação que poderíamos chamar de múltiplo crazing, o processo pode promover tenacidade ao material e possivelmente um comportamento dúctil (NIELSEN \& LANDEL, 1994); (KINLOCH \& YOUNG, 1995).

Fatores que favorecem o crazing são principalmente altas temperaturas e altas concentrações de tensão, enquanto que fatores que previnem o fenômeno são o aumento da pressão hidrostática e fluência e outros mecanismos que sejam capazes 
de reduzir a concentração de tensões em pontos específicos (HERTZBERG, 1995); (KINLOCH \& YOUNG, 1995).

Lembrando que shear yielding e crazing são mecanismos concorrentes de deformação do polietileno, pode-se listar os seguintes fatores decisivos para a predominância de um ou outro mecanismo: estado de tensão, concentração de tensão, temperatura, tempo, meio, massa molecular do polímero e sua distribuição, densidade de moléculas de ligação, tipo e distribuição das ramificações na estrutura do polímero e cristalinidade.

Portanto, pode-se considerar que sob determinadas condições níveis moderados de tensão aplicados por longos períodos de tempo podem levar à degradação mecânica do polietileno, através de crazes e trincas, que formam um mecanismo conhecido por slow crack growth, e esta é a causa primária provável da transição dúctil-frágil observada a longo prazo, a nível macroscópico, nos modos de fratura dos tubos de polietileno submetidos à pressão hidrostática interna.

Entretanto, cabe salientar que a transição dúctil-frágil observada nas curvas de regressão (inflexão) é de natureza macroscópica, mas mesmo no modo de falha frágil a observação da superfície de fratura demonstra a ocorrência de considerável deformação plástica, sugerindo que o mecanismo microscópico é o mesmo nos dois casos (HUANG \& BROWN, 1988); (LU \& BROWN, 1990); (TRASSAERT \& SCHIRRER, 1994); (PERES \& SCHÖN, 2004).

\section{7 - Limite de escoamento (yield point) e estiramento a frio (cold-drawing)}

Escoamento (yielding) e estiramento a frio (cold-drawing) são muito importantes porque praticamente todos os polímeros tenazes e aqueles com alta resistência ao impacto apresentam esses fenômenos (NIELSEN \& LANDEL, 1994).

Consideremos a Figura 18, que representa genericamente o comportamento típico em um ensaio de tração de vários polímeros cristalinos dúcteis, como o PEAD, para a discussão que se segue. 


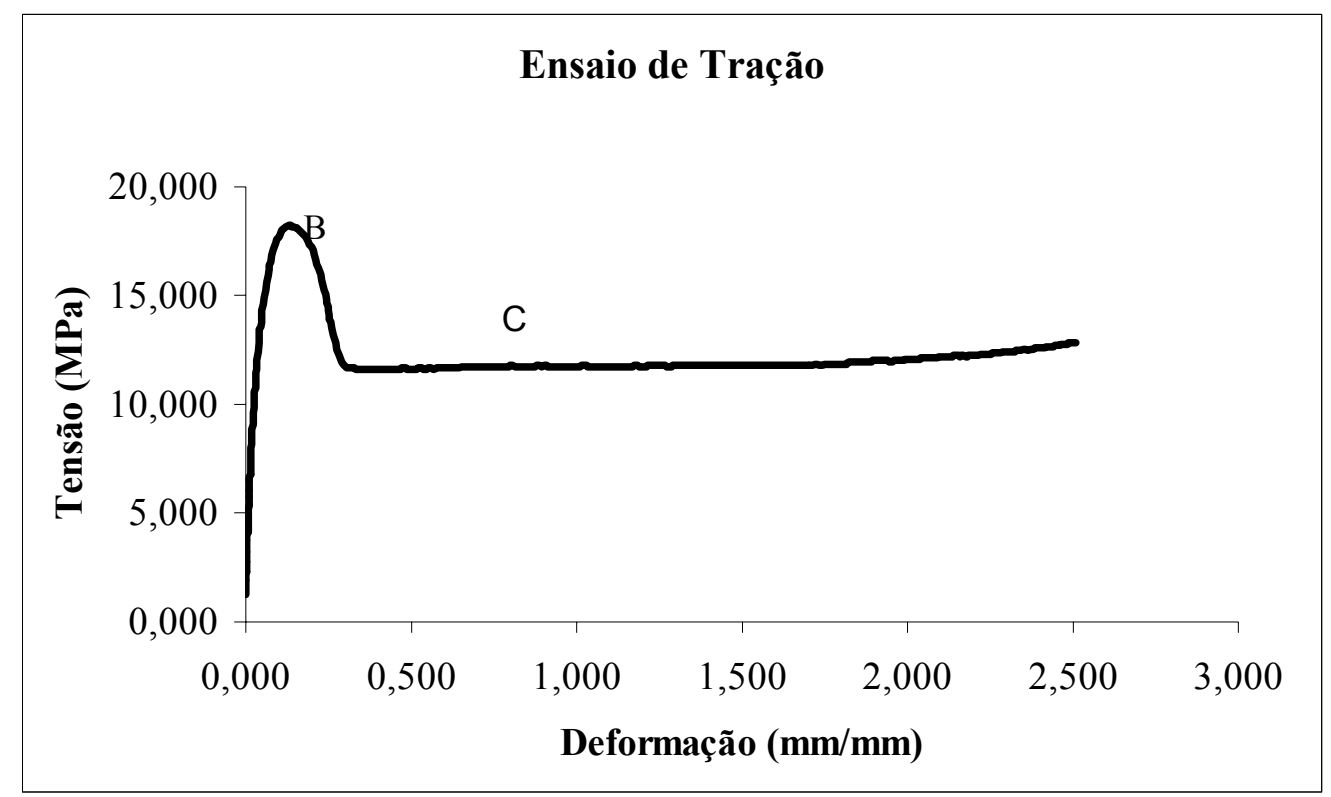

Figura 18: Curva tensão-deformação de engenharia típica de vários polímeros cristalinos. B: yield point. C: cold drawing. (Material: MDPE $8818 / 50 \mathrm{~mm} / \mathrm{min}$ )

Primeiramente, uma propriedade dos materiais muito importante obtida a partir de ensaios de tração é a resistência ao escoamento, $\sigma_{y}$, ou limite de escoamento - uma tensão relacionada ao início da deformação plástica irreversível. Como é uma quantidade difícil de ser definida, uma vez que depende da sensibilidade do equipamento de ensaio, para um grande número de materiais geralmente adota-se a tensão (engenharia) necessária para produzir uma determinada quantidade de deformação plástica. Para metais normalmente adota-se $0,2 \%$ de deformação permanente (HERTZBERG, 1995); (DOWLING, 1999). Para os polímeros dúcteis cujo comportamento é próximo daquele ilustrado na Figura 18 o limite de escoamento é tomado como o primeiro ponto de máximo na curva tensão $\mathrm{x}$ deformação (engenharia) (NIELSEN \& LANDEL, 1994); (DOWLING, 1999); (CALLISTER, 2000); (ZHOU et al, 2001); (CANEVAROLO Jr., 2002).

Após atingir o limite de escoamento, a deformação torna-se instável, podendo concentrar-se em pontos específicos, ocorrendo o fenômeno da estricção (necking), caracterizado por uma redução localizada na área da seção transversal e representada pela acentuada inflexão na curva tensão x deformação (engenharia) (HERTZBERG, 1995); (KINLOCH \& YOUNG, 1995); (DOWLING, 1999). A instabilidade da 
deformação pode ser explicada primeiramente porque a tensão e a deformação freqüentemente são maiores em um determinado ponto do corpo de prova devido, por exemplo, a pequenas variações na área da seção da transversal. Disso resulta que a tensão requerida para o escoamento plástico é atingida nesse ponto antes de qualquer outro ao longo do corpo de prova. No local onde a deformação plástica está se concentrando a área da seção transversal é preferencialmente reduzida, provocando a estricção. Uma segunda razão para a deformação plástica não homogênea é o amolecimento pela deformação, que pode ocorrer após o limite de escoamento. Essa é uma propriedade intrínseca do material tal que uma vez que o limite de escoamento é atingido a resistência à deformação plástica cai com a deformação por cisalhamento. Assim, se qualquer região localizada sofrer uma deformação ligeiramente mais elevada que o resto do material ela vai "amolecer" localmente e então vai se deformar mais facilmente e atingir um nível ainda mais alto de deformação que em qualquer outro ponto (KINLOCK \& YOUNG, 1995). Segundo Progelhof \& Throne (1993), um efeito óbvio da deformação localizada incipiente é a formação de shear bands. Schultz (1974), citado por Progelhof \& Throne (1993), descreve a estricção como a destruição das unidades cristalinas do polímero induzida pela tensão.

À medida que a estriccção se estabelece ocorre a orientação molecular e dos blocos de estruturas cristalinas remanescentes, resultando endurecimento por deformação e permitindo que a estricção se estabilize e seja estendida através da seção reduzida do corpo de prova. Esse processo é conhecido por estiramento a frio (cold-drawing). $\mathrm{O}$ comprimento da região com estricção aumenta à medida que o estiramento continua, estendendo-se por toda a região útil do corpo de prova (NIELSEN \&.LANDEL, 1994); (CHUDNOVSKY \& SHULKIN, 1999). Experimentalmente isso é observado como uma região "empescoçada" no corpo de prova, de dimensões uniformes, cujo processo de extensão resulta da contínua extração de material nas extremidades da região "empescoçada" estabilizada (PROGELHOF \& THRONE, 1993); (CHUDNOVSKY \& SHULKIN, 1999). O processo de endurecimento por deformação é uma condição necessária para o estiramento a frio, caso contrário o material sofreria ruptura na estricção (NIELSEN \& LANDEL, 1994). Cold drawing pode ser visto como um processo onde diferentes 
mecanismos competem: fluxo viscoso, quebra das estruturas cristalinas e endurecimento por deformação (NIELSEN \& LANDEL, 1994) (HERTZBERG, 1995). O processo se desenvolve até um determinado limite, estabelecido por um alongamento crítico, conhecido como taxa de estiramento natural (natural draw ratio) do material, que depende da temperatura, da orientação, da massa molecular e da velocidade de ensaio (PROGELHOF \& THRONE, 1993); (NIELSEN \& LANDEL, 1994). Com o aumento da deformação o material passa a oferecer cada vez mais resistência à deformação. Se o corpo de prova não se romper logo, a curva tensão x deformação passa a elevar-se novamente até o limite de ruptura. A Figura 19 ilustra o processo de yielding seguido de estricção e cold drawing enquanto a Figura 20 apresenta um corpo de prova de tração de polietileno de alta densidade e o mesmo corpo de prova estirado (cold drawn).

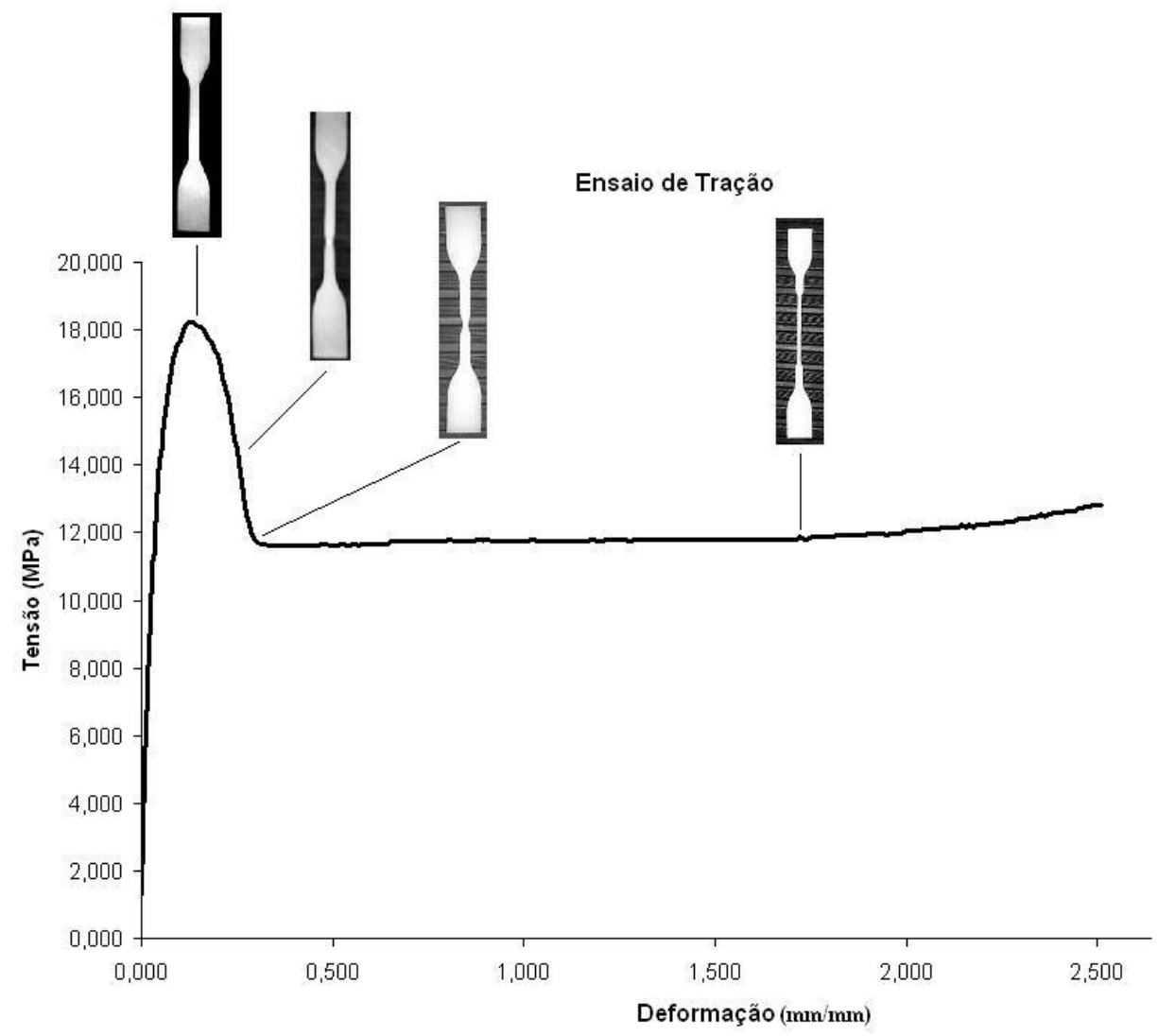

Figura 19: Yielding, estricção e cold drawing. (Material: MDPE $8818 / 50 \mathrm{~mm} / \mathrm{min}$ - Adaptado de Nimmer, 1988) 

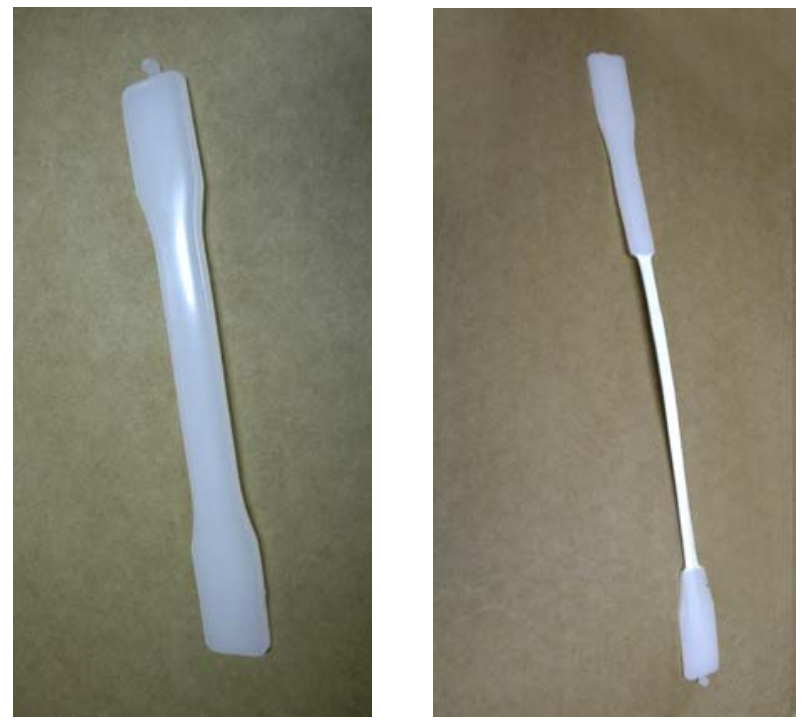

Figura 20: Corpo de prova de ensaio de tração de polietileno de alta densidade (esquerda) e o mesmo corpo de prova após estiramento (cold drawn)

Os autores têm entendido que o processo de orientação ocorre na direção do estiramento do corpo (PROGELHOF \& THRONE, 1993); (CANEVAROLO Jr., 2002).

Define-se a tensão de estiramento de engenharia, $\sigma_{d r}$, como a tensão de engenharia essencialmente constante sob a qual se desenvolve o processo de cold drawing (ZHOU et al, 2001).

As propriedades de tração do polietileno são muito dependentes da velocidade de ensaio, ou mais especificamente da taxa de deformação. O mesmo ocorre com os micromecanismos de deformação (ZHOU et al, 2001). Essa dependência será explorada com vantagens na seção 1.12 ("ramp test").

\section{8 - Processo de fratura e a fratura do polietileno de alta densidade}

A fratura é a separação, sob tensão, de um corpo sólido em duas ou mais partes (HAYDEN et al, 1965); (MEYERS \& CHAWLA, 1999); (CALLISTER, 2000).

A fratura ocorre nos materiais quando estes são solicitados acima de determinados limites de tensão. As solicitações podem ser de diversas formas: aplicação lenta de carga, aplicação rápida de carga (impacto), aplicação cíclica de carga (fadiga), deformação dependente do tempo (fluência), acúmulo de tensões 
residuais, influências do ambiente (fatores extrínsecos) (MEYERS \& SHAWLA, 1999); (SCHÖN, 2002). Entre as causas mais comuns estão incluídos processamento inadequado, má seleção de materiais, erros de projeto das peças e sua má utilização (CALLISTER, 2000).

Nos materiais de engenharia são normalmente considerados dois modos de fratura principais, dúctil e frágil, sendo que a natureza da falha depende das características do material e da sua habilidade para experimentar deformação plástica, podendo ser afetada pela natureza da tensão aplicada, pelas características geométricas da peça, pela temperatura e pela taxa de deformação. A fratura dúctil tipicamente envolve significativa deformação plástica, especialmente na vizinhança da trinca, e caracteriza-se pela propagação relativamente lenta da trinca e por uma grande absorção de energia durante o processo. Por outro lado, na fratura frágil a propagação da trinca é geralmente rápida, com pouca ou nenhuma deformação plástica e o processo requer pouca absorção de energia (HAYDEN et al, 1965); (CALLISTER, 2000). Segundo Callister (2000), na fratura dúctil o tipo de trinca que se propaga é freqüentemente chamado de estável, na medida em que sua propagação (ou seja, o aumento do seu comprimento) somente ocorre se a tensão aplicada aumentar. Além disso, normalmente a superfície de fratura apresenta evidências de deformação plástica generalizada apreciável. $\mathrm{Na}$ fratura frágil, as trincas são geralmente ditas instáveis porque uma vez que a sua propagação tenha se iniciado, o processo continua de forma catastrófica sem aumento importante da tensão aplicada. Neste caso, a direção do crescimento da trinca é aproximadamente normal ao eixo da tensão aplicada, e a falha produz superfícies relativamente planas.

A fratura é um processo de falha dominado por uma trinca, que envolve diferentes etapas importantes: acúmulo de danos, nucleação de uma ou mais trincas e propagação de trincas até a ruptura (catastrófica) final (HUANG, 1996); (MAYERS \& CHAWLA, 1999); (SCHÖN, 2002); (PERES \& SCHÖN, 2004). Cada uma dessas etapas possui uma escala de grandeza característica, de forma que o processo de fratura se desenvolve, por sua própria natureza, em múltipla escala. $\mathrm{O}$ acúmulo de danos está relacionado com as propriedades do material, que por sua vez depende da sua microestrutura e, no caso dos materiais poliméricos, da resistência das ligações intramoleculares e intermoleculares e da forma como essas ligações reagem ao 
estado de tensão aplicado (PROGELHOF \& THRONE, 1993); (MEYERS \& CHAWLA, 1999); (PERES \& SCHÖN, 2004). Quando a solicitação excede um nível crítico de resistência coesiva molecular o polímero falha, forma-se uma trinca (duas superfícies livres) e, com o aumento do carregamento, ela se propaga através da seção até a ruptura completa. Segundo Meyers \& Chawla (1999), especificamente em estruturas dúcteis podem ocorrer três estágios de fratura: arredondamento da ponta da trinca e início de propagação, crescimento lento e estável da trinca sob aplicação da carga e crescimento instável (catastrófico).

No polietileno há um processo de fratura peculiar, descontínuo, conhecido como crescimento lento de trincas (slow crack growth), que se desenvolve sob tensões e temperaturas relativamente baixas, e leva à fratura frágil (ou brittle-like). Segundo Chudnovsky \& Shulkin (1999), sob tensão e temperatura constantes, o processo de fratura do polietileno, desde a aplicação da carga até ruptura final do corpo, pode ser dividido em três etapas: um estágio inicial, que inclui um período de "incubação" que precede a nucleação da trinca e um período de crescimento lento instável de trinca; um segundo estágio de crescimento lento estável; e um terceiro estágio de transição para uma propagação rápida (dinâmica) da trinca.

De acordo com Kinloch \& Young (1995), três abordagens são geralmente adotadas para o estudo da fratura de polímeros. $\mathrm{Na}$ abordagem pela mecânica do contínuo (incluindo a mecânica da fratura) o polímero é tomado como um meio contínuo, com propriedades particulares, mas na qual a estrutura molecular é ignorada. A abordagem estatística enxerga o processo de fratura como sendo uma sucessão de eventos que podem ser previstos usando argumentos probabilísticos. A microestrutura de qualquer material tem uma grande influência no seu comportamento de fratura e assim, para se ter uma idéia completa da fratura dos polímeros sua estrutura molecular deve ser levada em conta, de forma que a abordagem molecular requer uma descrição completa do polímero: estrutura molecular, massa molecular e sua distribuição, densidade e distribuição das ramificações, densidade de moléculas de ligação, cristalinidade e assim por diante.

O evento elementar da fratura é a ruptura definitiva das ligações químicas do material na região da ponta da trinca. Para que um corpo polimérico sofra uma fratura deve ocorrer a formação de uma nova superfície, o que só é possível pelo 
rompimento de ligações primárias (covalentes) ou secundárias (tipo Van der Waals), ou de ambos os tipos. É o acúmulo dos eventos de ruptura de ligações que eventualmente leva um corpo à fratura, ou seja, a fratura ocorre quando são aplicados tensão e trabalho suficientes para romper as ligações que mantém os átomos e moléculas unidos (KINLOCH \& YOUNG, 1995); (ANDERSON, 1995). Assim sendo, a resistência à fratura de um material sólido é função das forças de coesão entre os átomos e moléculas e pode então ser estimada a partir da resistência das ligações e das forças moleculares. No caso de materiais metálicos ou cerâmicos frágeis, por exemplo, a resistência coesiva teórica foi estimada em cerca de E/10, onde E é o módulo de rigidez do material. Entretanto, tipicamente, as falhas ocorrem em níveis de tensão muito inferiores aos valores previstos teoricamente devido a presença de irregularidades e defeitos estruturais que atuam como concentradores de tensão. Entre essas imperfeições podemos citar defeitos e irregularidades microestruturais, fissuras, vazios, inclusões, partículas de impurezas, etc. (HAYDEN et al, 1965); (PROGELHOF \& THRONE, 1993); (HERTZBERG, 1995); (CALlisteR, 2000). Conforme Alfrey (1948), citado por Progelhof \& Throne (1993), as características estruturais que determinam a resistência à ruptura são fortemente afetados por pequenas diferenças fortuitas e incontroláveis nas condições de preparação. Hertzberg (1995) considera ainda que os materiais possuem baixa resistência à fratura em relação à sua capacidade teórica porque a maioria deles se deformam plasticamente em níveis de tensão muito menores e eventualmente falham em decorrência do acúmulo desse dano irreversível.

Segundo Nielsen \& Landel (1994), discutindo as teorias de yielding e colddrawing, a probabilidade de ruptura da cadeia polimérica induzida pela tensão, $\mathrm{P}_{\mathrm{b}}$, é dada pela seguinte expressão:

$$
P_{b}=w_{0} \exp \left(-\frac{\Delta H-\Lambda \sigma^{*}}{k_{B} T}\right)
$$

onde $w_{0}$ é um parâmetro de colisão, $\Delta H$ é a energia de ativação, $\Lambda$ é o volume de ativação, $\sigma^{*}$ é a tensão na cadeia do polímero (não a tensão remota, que atua sobre o corpo) e $k_{B}$ é constante de Boltzmann. 
Segundo Kinloch \& Young (1995), a partir da equação (2) pode-se demonstrar que o tempo de falha de um corpo submetido a uma tensão constante $\sigma$ pode ser expresso em termos de uma equação da forma:

$$
t_{f}=t_{0} \exp \left(\frac{\Delta G-\Lambda \sigma}{k_{B} T}\right)
$$

onde $t_{0}$ é relacionado com o recíproco da freqüência de oscilação molecular e $\Delta G$ e $\Lambda$ são a energia de ativação molar e o volume de ativação, respectivamente.

Deve-se esperar que nem todos os enlaces de cadeias sejam desfeitos durante os períodos de tempo de aplicação de tensão. Assim, a ruptura da cadeia ocorreria em algum grau, dependendo da severidade da tensão aplicada (PROGELHOF \& THRONE, 1993). A probabilidade $P_{b}$ expressa pela equação (2) é induzida pela tensão, de forma que as cadeias mais esticadas rompem-se primeiro. A tensão é então redistribuída entre as cadeias remanescentes. A relaxação da tensão em pontos de concentração de tensão pode favorecer o cold-drawing, discutido em seção anterior. Outra possibilidade é que os radicais livres formados pela ruptura de uma cadeia podem catalisar a ruptura de outras cadeias em torno dela, ativando um mecanismo de reação em cadeia, de forma que um vazio pode se desenvolver na região onde os novos finais de cadeia se contraem, à medida que a tensão sobre elas é aliviada. Esse vazio pode nuclear um crazing, que por sua vez pode levar à falha (trinca). Nielsen $\&$ Landel (1994) utilizaram este modelo para polímeros vítreos, entretanto assume-se que a descrição é aplicável também para polímeros parcialmente cristalinos. Os autores apresentam uma descrição de fenômenos em escala molecular que levam ao desenvolvimento de crazes. Os polímeros não são homogêneos em escala molecular de duas formas. Primeiramente, na escala do monômero existirão flutuações de densidade. A componente hidrostática da tensão aplicada produzirá uma dilatação que será proporcionalmente distribuída segundo algum padrão estatístico sobre essas 
regiões pré-existentes de menor módulo de volume (bulk modulus) ${ }^{7}$. Isso causará a expansão de algumas delas, a uma taxa dependente do processo de difusão. O processo passará então a ser controlado pela existência de regiões "fortes" e "fracas" no nível do segmento de cadeia. Como ilustrado na parte superior da Figura 21, estas regiões "fracas" (ou ainda, imperfeições) podem consistir, por exemplo, de agregados de finais de cadeias, regiões onde alças (loops) em diversas cadeias estão próximas, mas não emaranhadas ou "amarradas" umas às outras e regiões nas quais um agrupamento de vários segmentos de cadeia são orientados perpendicularmente à direção da tensão. Regiões fortes incluem entrelaçamentos de cadeia e regiões onde um agrupamento de segmentos de cadeia é orientado paralelamente à tensão. Embora várias cadeias orientadas paralelamente à tensão possam agir como regiões fortes, uma cadeia estirada isolada cercada por cadeias com folgas age como um ponto fraco na estrutura. Uma única cadeia retesada é facilmente rompida por uma tensão na sua direção axial, uma vez que ela suporta toda a tensão ao seu redor, e um microvazio pode se desenvolver na região rompida da cadeia, como indicado acima. Quando uma carga é aplicada a um polímero, as regiões fracas irão romper-se ou serão afastadas fisicamente (ou ambos) para formar ao nível molecular vários microvazios ou microtrincas, como ilustrado na parte central da Figura 21. Esses microvazios iniciais, isolados e achatados, crescem lateralmente e coalescem irregularmente, deixando filamentos curtos ligando as duas partes de massa de polímero. Sob influência da tensão aplicada os filamentos entre os vazios se alongam e então crescem na medida em que mais material é extraído da massa circunvizinha de material. Essa massa de material ter-se-á tornado dúctil nesta escala local, mesmo a temperaturas bem abaixo de $\mathrm{T}_{\mathrm{g}}$. A estrutura fibrilar resultante é indicada na parte inferior da Figura 21. Os microvazios podem ser detectados através de espalhamento de Raios-X de baixo ângulo e a estrutura pode ser observada diretamente por microscopia eletrônica de varredura. Essas microfibrilas estiradas molecularmente não são facilmente rompidas em função de sua alta orientação. Um craze pode então

\footnotetext{
${ }^{7}$ Módulo de volume (Bulk modulus), $B_{\text {vol }}$, é uma constante de proporcionalidade que relaciona a tensão hidrostática com a deformação volumétrica e é dada pela seguinte expressão: $B_{v o l}=\frac{E}{3(1-2 v)}$, onde $E$ é o módulo de rigidez do material e $v$ é o coeficiente de Poisson (DOWLING, 1999).
} 
avançar através do polímero sem formar uma trinca verdadeira. Entretanto, uma trinca verdadeira pode se formar a partir de um craze e se propagar através da ruptura sucessiva dos filamentos. Os filamentos em um craze e os tocos deixados após sua ruptura podem ser observados por microscopia eletrônica de varredura.

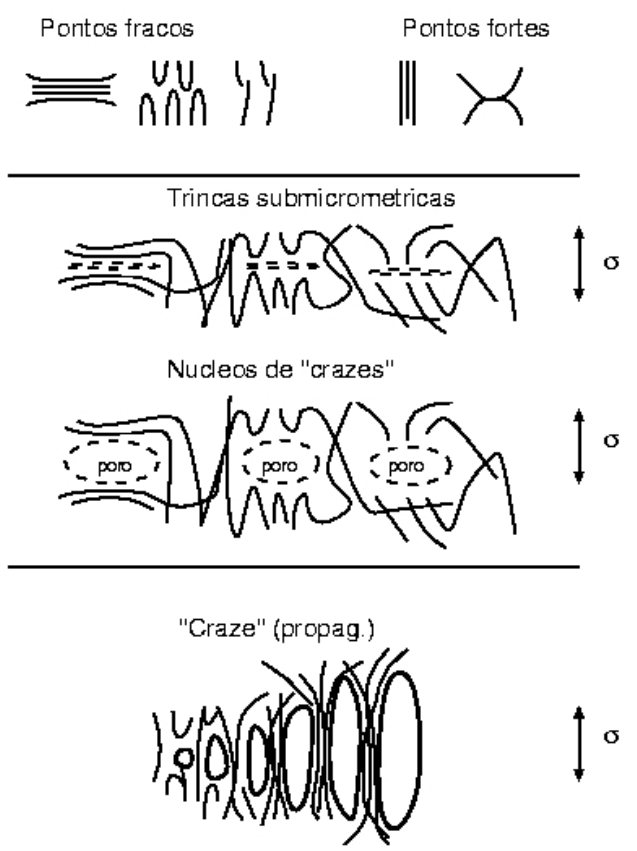

Figura 21: Superior: regiões de fragilidade e de resistência em escala molecular em um polímero, as quais parecem ser importantes na nucleação de crazes e trincas. Inferiores: Etapas sucessivas no desenvolvimento de microvazios, orientação molecular, e crazes como resultado de uma tensão de tração aplicada na direção vertical. (Adaptado de NIELSEN \& LANDEL, 1994)

Numa determinada temperatura, o processo descontínuo e lento de crescimento de trincas no polietileno, que leva à fratura frágil, ocorre dentro de uma certa faixa de tensões, acima da qual o modo de falha sofre uma transição para o modo dúctil (CHUDNOVSKY \& SHULKIN, 1999). O processo descontínuo está relacionado com o fato de que a trinca é sempre precedida por crazing. $\mathrm{O}$ avanço da trinca ocorre por um processo de degradação e ruptura por fluência das fibrilas da base do craze. Entretanto, a trinca avança e para rapidamente quando as fibrilas remanescentes são suficientemente fortes para resistir ao crescimento da trinca, ou seja, não se rompem. O tempo necessário para a ruptura das fibrilas é muito maior 
que o tempo de crescimento da trinca, após a ruptura das fibrilas mais vulneráveis. Esta seqüência de eventos consecutivos de enfraquecimento e ruptura das fibrilas seguidos do rápido e curto avanço da trinca confere ao processo de propagação da trinca sua natureza descontínua (MOSKALA, 1998); (CHUDNOVSKY \& SHULKIN, 1999).

Pelo exposto vários outros processos precisam ocorrer na seqüência da ruptura das cadeias antes que o polímero eventualmente sofra uma fratura macroscópica.

Segundo Kinloch \& Young (1995) é possível considerar um polímero sólido tanto como um corpo contínuo uniforme, o qual responde de uma forma previsível à tensão e à deformação, ou como um sólido macromolecular constituído de longas moléculas, para o qual a deformação causa uma perturbação nas ligações intermoleculares e intramoleculares.

Para muitas aplicações de engenharia a abordagem do contínuo é mais útil. Neste campo, a mecânica da fratura baseia-se na premissa de que o material que sofre a fratura pode ser considerado como um meio contínuo isotrópico. Assim, a mecânica do contínuo pode ser aplicada a sólidos na medida em que eles respondem de forma uniforme em um nível macroscópico à tensão e à deformação, mesmo que a deformação no nível atômico ou molecular possa ser significativamente não homogênea.

De fato, sabe-se que num polímero submetido à deformação algumas moléculas são muito mais tensionadas que outras e que somente uma pequena fração das moléculas estão envolvidas no evento da fratura. (NIELSEN \& LANDEL, 1994); (KINLOCH \& YOUNG, 1995).

Como a resposta mecânica de um material decorre da forma pela qual as ligações respondem à tensão, num polímero a situação é complexa porque o processo de fratura pode se desenvolver pela ruptura de ligações primárias covalentes ou de ligações secundárias, tipo van der Waals. Imagina-se que ambos os processos podem ocorrer, mas a extensão pela qual cada um se desenvolve depende do tipo de polímero e das condições de ensaio (KINLOCH \& YOUNG, 1995).

Como já discutido antes, para a maioria dos materiais a tensão de ruptura é muito menor que a resistência teórica. Por outro lado, o valor medido da energia de 
fratura é muito maior que a energia teórica requerida apenas para romper as ligações (primárias ou secundárias). Isso pode parecer um paradoxo, mas a tensão de ruptura pode ser reduzida pela presença de falhas e defeitos enquanto que a energia de fratura é aumentada pela ocorrência simultânea de outros processos que absorvem energia, como a deformação plástica, que ocorrem durante o processo de fratura.

Pelo exposto, é razoável considerar que em muitos tipos de sólidos poliméricos, como os polímeros de alta massa molecular ou muito orientados, a ruptura de ligações primárias será o principal fator de controle do processo de fratura. Em outros casos, entretanto, onde a extração (desentranhamento) das cadeias é um processo relativamente mais fácil, as forças intermoleculares podem ter um papel maior no controle do comportamento em fratura.

A distribuição de tensão nas ligações de polímeros deformados depende muito da morfologia e da estrutura do material. Essa dependência é particularmente importante porque são as ligações mais tensionadas que provavelmente serão primeiramente rompidas, nucleando crazes e trincas (NIELSEN \& LANDEL, 1994); (KINLOCH \& YOUNG, 1995).

Os detalhes do processo de fratura são altamente complexos e dependem de vários fatores tais como a estrutura do polímero, ambiente, tensão, deformação e tempo. A fratura molecular não ocorre na mesma extensão para todos os polímeros e os micromecanismos são diferentes para diferentes tipos de polímeros.

Quando um sólido polimérico é deformado as moléculas deslizam umas sobre as outras e tendem a desenrolar-se, rompendo ligações secundárias, as quais tendem a refazer-se no processo, levando a um rearranjo molecular. Eventualmente o material pode falhar por colapso plástico (fully plastic condition), na qual toda a seção resistente se reduz a um ponto. A fratura molecular decorrente da ruptura de ligações primárias ocorrerá se, por qualquer razão, o fluxo de moléculas entre si for restringido devido à natureza da estrutura do polímero. Por exemplo, em polímeros parcialmente cristalinos, como o polietileno de alta densidade, os cristais podem constituir-se em pontos de ancoragem e restringir o fluxo (KINLOCH \& YOUNG, 1995).

Vários autores têm considerado a possibilidade de trincas serem iniciadas a partir de microvazios que se formam em pontos de interseção de bandas 
cisalhamento. Nesses pontos onde o material está muito deformado, a ruptura ou o desenlace das cadeias ocorrerão prefencialmente, gerando microvazios que funcionam como pontos de nucleação de crazes e trincas.

Segundo Kinloch \& Young (1995), o papel do cisalhamento localizado na nucleação de microvazios é muito pouco conhecido.

É muito difícil modelar completamente o comportamento de fratura de um polímero diretamente de uma perspectiva molecular (PERES \& SCHÖN, 2004). A abordagem molecular oferece uma boa explicação para a fase inicial do processo de fratura, mas não é útil na descrição da etapa de propagação da trinca, principalmente em materiais que não são completamente frágeis e que são capazes de sofrer deformação inelástica ou plástica, caso do polietileno de alta densidade. Ela se presta, portanto, para complementar a abordagem do contínuo (mecânica da fratura), que se ocupa principalmente com o processo que ocorre durante a propagação da falha. Entretanto, a mecânica da fratura oferece pouca explicação para a fase de iniciação, a qual pode freqüentemente ser importante no controle da durabilidade de peças submetidas a tensão constante (KINLOCH \& YOUNG, 1995). Dessa forma, segundo os autores, para um entendimento completo do processo de fratura as três abordagens, incluindo a estatística, precisam ser seguidas simultaneamente.

\section{9 - Critérios de durabilidade e de projeto}

Um critério de projeto é uma condição crítica que precisa ser satisfeita para que determinado fenômeno ocorra e tem a função básica de prever a ocorrência do mesmo, podendo ter diferentes significados para cada situação específica (KINLOCH \& YOUNG, 1995); (MEYERS \& CHAWLA, 1999).

Os usuários de tubos de polietileno entendem que entre os testes mais importantes, senão o mais importante, está o de falha a longo prazo, sob pressão hidrostática interna constante, tanto para efeito de projeto como para efeito de classificação dos tubos. Os testes de curto prazo, geralmente de 100 e 165 horas de duração, ainda que realizados em temperaturas mais elevadas que a ambiente de forma a acelerar os resultados, não são suficientes para caracterizar o comportamento do tubo a longo prazo, servindo basicamente para controle de qualidade (OGORKIEWICZ, 1974). Além disso, eles não prescindem do ensaio de longa 
duração. Entretanto os estudos em laboratório das falhas dos tubos de PEAD submetidos a testes de resistência à pressão hidrostática interna de longa duração (ASTM 2837 e ISO 9080) são excessivamente longos e muito caros, envolvendo períodos de tempo de até 10.000 horas. Além disso, como bem observam Zhou et al (2001), os testes com tubos consomem muito material, que pode não estar disponível nas etapas iniciais de um desenvolvimento de produto. Ainda mais, podem não ser suficientemente completos, cobrindo todos os fatores existentes quando os tubos estão em serviço, e precisam ser realizados novamente a cada modificação na composição do composto (resina base, pigmentação, aditivação, etc.). Esses aspectos tornam a "curva de regressão" uma ferramenta pouco prática para efeito de controle de qualidade e desenvolvimento de produtos.

Segundo Progelhof \& Throne (1993), a extrapolação dos dados para tempos de falha mais longos deve ser feita com cuidado, não devendo exceder uma década (logarítmica), em função de certas incertezas intrínsecas embutidas nas projeções. Ou seja, as extrapolações podem ser consideradas confiáveis somente até 100.000 horas, se os testes mais longos foram conduzidos até 10.000 horas.

O próprio critério de tempo de falha é duvidoso, uma vez que o tempo de vida útil desejado para os tubos de polietileno é usualmente muito maior que aquele que pode ser verificado em serviço e as falhas em serviço geralmente são do tipo frágil, salvo em caso de acidentes, uma vez que os tubos são projetados e dimensionados para suportar as pressões internas que poderiam provocar as falhas dúcteis (PERES \& SCHÖN, 2004).

Outra consideração muito importante é que o processo de fratura a longo prazo do polietileno é consideravelmente complexo e envolve vários estágios importantes, entre eles acúmulo de danos, nucleação e propagação de trincas até a falha (catastrófica) final. Cada uma dessas etapas se desenvolve numa determinada ordem de grandeza, de forma que a modelagem do processo de fratura é, por sua própria natureza, multiescalar. Uma abordagem simplista como a da "curva de regressão" não é capaz de tratar essa complexidade e, portanto, está sujeita a erros (PERES \& SCHÖN, 2004). 
Torna-se atraente então a busca por métodos de caracterização do comportamento mecânico do material e da durabilidade dos tubos que sejam mais práticos e econômicos e, principalmente, mais eficazes e seguros.

De acordo com a ASTM, entende-se que ocorre a falha de um tubo de polietileno nos testes de resistência à pressão hidrostática interna, se houver qualquer perda contínua de pressão, com ou sem a transmissão do fluido de teste através da parede do corpo de prova sob teste. Uma falha pode ainda ser representada, de forma isolada ou combinada, pelos seguintes modos: abolamento ou inchamento, denominada falha dúctil (qualquer expansão localizada num corpo de prova pressurizado); ruptura (rompimento da parede do tubo), que se não for precedida de algum escoamento é denominada falha não dúctil (frágil ou brittle-like); exsudação (água ou fluido que passa através de trincas microscópicas na parede do tubo) (ASTM D 1598-86 e ASTM D 1599-88). Entende-se ainda como falha o rompimento, fratura, rachadura ou exsudação no tubo durante o teste (ASTM D $2837-90)^{8}$.

Estudos da transição dúctil-frágil de polietileno também consideram o tempo de falha como sendo o período de tempo decorrido até a estricção ou até a fratura final do corpo de prova (LU \& BROWN, 1990).

A prática operacional é bastante semelhante, ou seja, geralmente reconhece-se que um tubo de polietileno apresenta uma falha em serviço quando um dos modos descritos acima se manifesta, demandando ação de reparo do segmento danificado ou determinando o fim da vida útil do segmento de tubo do ramal predial.

Assim, tanto a prática como os ensaios padronizados consideram a falha macroscópica como o limite de durabilidade. Entretanto, a ruptura ou falha macroscópica não é provavelmente o critério mais apropriado de durabilidade e para fins de projeto quando existirem outros fatores ou indicadores de fratura que antecedem a falha principal que sejam considerados mais inaceitáveis pela sua criticalidade. Nestes casos, esses fatores é que devem constituir o critério de durabilidade e, portanto, de projeto (OGORKIEWICZ, 1974); (PROGELHOF \& THRONE, 1993).

\footnotetext{
${ }^{8}$ A ASTM D 2837-90 estabelece ainda determinado valor de expansão circunferencial que pode ser usado como critério para a obtenção da HDS - Hydrostatic Design Stress.
} 
Estudos de deformação e de durabilidade estão relacionados. Em particular, a falha pode ser considerada como o ponto final de um teste de fluência. Mas há diferenças de filosofias que influenciam os métodos experimentais (OGORKIEWICS, 1974). Em estudos de fluência, o objetivo principal é relacionar a deformação com a tensão aplicada como uma função do tempo, temperatura e outras variáveis. Características importantes, precursoras da falha, como deformações não homogêneas localizadas, possuem menor importância e heterogeneidades microscópicas em deformação não são consideradas. A construção das curvas de regressão, já discutidas, seguem esse princípio, nas quais os dados formam curvas $\log$ tensão $\mathrm{x} \log$ tempo para falha. Estudos de falha, entretanto, consideram qualquer fator que pode potencialmente afetar a resistência mecânica, especialmente aqueles que podem provocar uma transição dúctil-frágil no comportamento mecânico do material.

Conforme alerta Ogokiewicz (1974), nas situações onde é empregado um componente estrutural de material polimérico termoplástico, dois aspectos do comportamento mecânico a longo prazo devem ser considerados: deformação e durabilidade. Se o material permanece sempre predominantemente dúctil, os limites de projeto baseados em estudos de deformação podem ser mantidos. Mas se existirem fatores que aumentam as chances de uma transição dúctil-frágil, esses sim perigosos e problemáticos, pode ser necessário reduzir o limite de tensão.

Pela discussão desenvolvida até aqui, pode-se sugerir que deve haver um limite de tensão ou de deformação por fluência, dada uma condição de temperatura, abaixo do qual não deve ocorrer crazing, ou que ocorrendo esse mecanismo de deformação não venha a se tornar predominante no período de vida útil esperada, e esses fatores é que devem ser considerados para estabelecer o critério de durabilidade para tubos de polietileno que devem ser submetidos a pressões internas por longos períodos de tempo.

A questão filosófica sobre o critério de projeto dos tubos de polietileno submetidos a pressão interna é semelhante àquela que envolveu os projetos de componentes submetidos a cargas cíclicas, ou projetos orientados para fadiga, de forma que é oportuna uma rápida discussão sobre o assunto (SCHÜTZ, 1996); (NEWMAN JR, 1998). Para este efeito, dois conceitos adotados no desenvolvimento 
de critérios de projetos orientados para fadiga podem ser considerados: fail-safe design e damage tolerance. O primeiro, tradicional, baseado nas curvas $\sigma-\mathrm{N}$ (amplitude de tensão cíclica x número de ciclos até a ocorrência da falha), considera que a falha não deve ocorrer antes de um determinado período de tempo. Neste caso, um componente fail-safe é retirado de serviço no final de sua vida útil determinada. Sabe-se que sob solicitação cíclica há um dano crescente no material, mas esse dano é desconhecido e leva-se em conta apenas a falha final. Os resultados dos ensaios realizados em corpos de prova padronizados apresentam grande dispersão, e provocam muita incerteza na extrapolação de dados e na transferência dos dados para o projeto de componentes específicos. Como resultado são aplicados maiores coeficientes de segurança, o que concorre para um aumento do custo do componente. Por outro lado, a abordagem baseada no conceito de damage tolerance assume que o componente possui um defeito - um dano, uma trinca, por exemplo - que é inspecionado, sendo o tempo de falha determinado a partir da sua evolução. Uma importante "ferramenta de projeto" desenvolvida a partir desse conceito é a "Curva de Paris", um gráfico em escala bi-logarítmica da taxa de crescimento da trinca $(d a / d N)$ versus faixa de variação do fator de intensidade de tensão ( $\Delta K$ ) (um parâmetro da mecânica da fratura, que será visto mais adiante). Com essa filosofia, os coeficientes de segurança puderam ser reduzidos, bem como os custos.

No caso da fadiga, a mecânica da fratura mostrou-se muito valiosa ao proporcionar uma melhor compreensão do comportamento mecânico dos materiais na presença de trincas e possibilitando que a filosofia e a metodologia de projeto ficassem menos restritivas para o material.

Da mesma forma que a fadiga saltou do conceito de fail-safe para o conceito de damage-tolerance com o auxílio da mecânica da fratura, o critério de projeto de tubos de pressão feitos com polietileno de alta densidade pode avançar com a ajuda daquela disciplina de engenharia, obtendo-se melhor conhecimento do comportamento em fratura do material e assim maior segurança nos ramais prediais de sistemas de distribuição de água potável onde esses componentes são empregados. 


\subsection{0 - Fundamentos da mecânica da fratura}

A presença de trincas ou defeitos semelhantes a trincas em um componente estrutural pode enfraquecê-lo e leva-lo à fratura sob tensões menores que a resistência ao escoamento do material, quando a fratura não seria a princípio esperada (DOWLING, 1999). Como os materiais geralmente possuem trincas ou defeitos uma metodologia especial denominada mecânica da fratura foi desenvolvida visando prevenir o fenômeno da fratura.

A mecânica da fratura pode ser definida como "a disciplina de engenharia que quantifica as condições sob as quais um corpo submetido a uma carga pode falhar devido ao avanço de uma trinca dominante contida naquele corpo" (KANNINEN \& POPELAR, 1985), ou conforme Silva (1999), “é a disciplina que estuda o comportamento mecânico de materiais e estruturas na presença de trincas ou descontinuidades assemelhadas a trincas". A formação das trincas está fora do escopo da mecânica da fratura, cujo foco está somente nas fases de iniciação e propagação da fratura (HUANG, 1996).

A presença de defeitos e trincas em um corpo provoca alterações no campo de tensões na sua vizinhança (ANDERSON, 1995); (KINLOCH \& YOUNG, 1995); (DOWLING, 1999); (SCHÖN, 2002). O mais importante efeito dessas alterações é o aumento da componente de tração do estado de tensão nas proximidades dos defeitos, os quais são por esse motivo chamados "concentradores de tensão" (stress raisers). As trincas são importantes concentradores de tensão e o aumento da tensão na ponta de uma trinca irá controlar a sua propagação (SCHÖN, 2002).

Inglis (1913) apresentou uma solução para a trinca elíptica num corpo sólido linear elástico, relacionando a tensão máxima com as proporções da elipse, com o raio de curvatura da ponta da elipse e com a tensão remota (distante da trinca) uniforme. Entretanto, para o caso de trincas ou fissuras ideais muito agudas, à medida que o raio de curvatura da ponta da trinca tende a zero a tensão tende ao infinito, assim como o fator de concentração de tensão. Uma tensão infinita não pode existir num material real, de modo que nos materiais reais se a carga aplicada não for muito elevada, o material pode acomodar a presença de uma trinca inicialmente muito aguda de tal forma que a tensão infinita teórica seja reduzida a um valor finito (DOWLING, 1999); (SCHÖN, 2002). Nos materiais reais ocorrem fenômenos na 
ponta da trinca que resultam no arredondamento da ponta a um raio pequeno, mas não nulo. No caso de materiais dúcteis a intensa deformação plástica na ponta da trinca forma uma região chamada de zona plástica. A tensão muito alta que idealmente existiria próxima da ponta da trinca é redistribuída sobre uma região mais ampla. Esses fenômenos são processos dissipativos, e geralmente representam a principal fonte de absorção de energia no material (KINLOCH \& YOUNG, 1995).

O requisito fundamental para a propagação de uma trinca é que a tensão na ponta da trinca deve exceder a resistência coesiva teórica do material. Entretanto, não é fácil medir a tensão na ponta de uma trinca. Um critério equivalente, proposto por Griffith (1920), é mais útil e prevê a força que precisa ser aplicada a um corpo contendo uma trinca para a propagação da trinca. O critério de Griffith é baseado num balanço de energia e leva à definição de um importante parâmetro de mecânica da fratura, designado por $G$, que é a taxa de liberação de energia de deformação (MEYERS \& CHAWLA, 1999). $G$ caracteriza a energia por unidade de área de trinca requerida para estender a trinca, e como tal espera-se que seu valo crítico $\left(G_{c}\right)$ seja uma quantidade física fundamental que controla o comportamento da trinca (DOWLING, 1999).

Sob carga, a energia potencial de um corpo elástico linear, ou seja, que obedece à Lei de Hook, aumenta monotonicamente com o aumento da carga. Entretanto, a energia potencial no corpo não pode aumentar indefinidamente. Num determinado instante a trinca avançará, criando novas superfícies de trinca. À criação das novas superfícies está associada uma redução na energia potencial. O início do crescimento da trinca ocorre quando a energia requerida para criar as novas superfícies se iguala ao decréscimo da energia potencial, ou seja, quando $G$ se iguala à resistência do material, designada por $G_{c}$ (ou eventualmente designado por $R$ ) (KINLOCK \& YOUNG, 1995); (HUANG, 1996).

Um outro importante parâmetro da mecânica da fratura, denominado fator de intensidade de tensão, usualmente representado por $K$, caracteriza o estado de tensão próximo à ponta da trinca. É definido para materiais elásticos lineares e depende do tamanho da trinca $(a)$, da tensão remota aplicada $(\sigma)$ e de aspectos geométricos, conforme a seguinte relação: 
$K=\mathrm{Y} \sigma \sqrt{\pi a}$

onde $Y$ representa um parâmetro ou função adimensional que depende tanto dos tamanhos quanto das geometrias da trinca e do corpo, assim como da maneira da aplicação da carga (SCHÖN, 2002); (MEYERS \& CHAWLA, 1999).

Demonstra-se que o estado de tensão, $\left[\sigma_{i j}\right]$, próximo à ponta da trinca é dado em coordenadas polares, pela expressão:

$\left[\sigma_{i j}\right]=\frac{K}{\sqrt{2 \pi r}}\left[f_{i j}(\theta)\right]$

onde $r$ é a distância da ponta da trinca, $\theta$ é o ângulo medido a partir do plano da trinca e $f_{i j}$ é uma função que depende unicamente de $\theta$.

Um material pode resistir a uma trinca sem que sofra uma fratura frágil se $K$ for inferior a um valor crítico $K_{c}$, o qual é uma propriedade do material chamada tenacidade à fratura. Os valores de $K c$ são afetados pela temperatura, taxa de carregamento e pela espessura do corpo (DOWLING, 1999). Em particular, no modo de abertura (modo I) e sob domínio de um estado plano de deformação a tenacidade à fratura é indicada por $K_{I c}$.

Na definição de $K$ e de $G$ assume-se que o material é isotrópico e que apresenta comportamento elástico linear, de forma que a abordagem usada é chamada mecânica da fratura elástica linear (linear-elastic fracture mechanics LEFM).

As hipóteses da mecânica da fratura elástica linear são (SCHÖN, 2002):

- Trincas estão sempre presentes nos materiais;

- Uma trinca é uma superfície livre, plana e interna em um campo contínuo de tensões elásticas;

- O crescimento da trinca principal é controlado pela tensão normal de tração que atua sobre a trinca, ou seja, o processo é controlado por K.

Há limitações no emprego da abordagem do problema da fratura através da mecânica da fratura elástica linear, quais sejam (SCHÖN, 2002): 
- Singularidade para raio de curvatura nulo na ponta da trinca;

- O material próximo à trinca se deforma plasticamente;

- A abordagem se baseia na elasticidade linear, que é uma teoria do contínuo. A atomística na região próxima à ponta da trinca passa a ser importante, gerando contribuições anelásticas aos campos de tensões e deformações.

Se a zona plástica for suficientemente pequena, existirá uma região externa a ela onde as expressões matemáticas para o campo de tensões elásticas ainda se aplicam. Essa região é denominada região de domínio de $K$ ( $K$-dominance region) ou K-field (DOWLING, 1999). A existência dessa região é necessária para que a mecânica da fratura elástica linear seja ainda aplicável. A região de domínio de $K$ engloba e controla o comportamento da zona plástica e a área da ponta da trinca, que assim podem ser imaginadas como uma "caixa preta", não compreendida completamente. Dessa forma $K$ ainda continua a caracterizar o estado de tensão nas proximidades da ponta da trinca, apesar da ocorrência de alguma plasticidade limitada. Entretanto, se a zona plástica for extensa demais, de forma a anular o campo de domínio de $K$, então $K$ não é mais aplicável. Numa visão prática, é necessário que a zona plástica seja pequena comparada com a distância entre a ponta da trinca e qualquer extremidade ou contorno do corpo. Em dimensões planares, o seguinte critério pode ser empregado para limitar o emprego da mecânica da fratura elástica linear (DOWLING, 1999):

$a,(W-a), h \geq \frac{4}{\pi}\left(\frac{K}{\sigma_{y}}\right)^{2} \quad$ (LEFM é aplicável)

onde $a$ é o comprimento da trinca, $W$ é a largura do corpo de prova, $h$ é a altura do corpo de prova e $\sigma_{y}$ é o limite de escoamento do material.

Se a espessura do corpo de prova não for suficientemente grande comparada com a zona plástica, a contração de Poisson na direção da espessura ocorrerá livremente ao redor da ponta da trinca, resultando em escoamento em planos de 
cisalhamento inclinados através da espessura. Entretanto, para corpos espessos, a restrição geométrica limita a deformação principal na direção da espessura. Com base em observações empíricas, tem sido geralmente aceito que a condição de deformação plana é plenamente atingida quando a seguinte relação é satisfeita (DOWLING, 1999):

$B, a,(W-a), h \geq 2,5\left(\frac{K}{\sigma_{y}}\right)^{2}$ (deformação plana)

onde $B$ é a espessura do corpo de prova.

Se o critério expresso pela relação (6) não for satisfeito, então a mecânica da fratura elástica linear não é mais aplicável devido ao excessivo escoamento. Nesse caso $K$ não mais caracteriza corretamente o estado de tensão em torno da ponta da trinca e, especificamente, $K$ subestima a severidade da trinca.

Em função das limitações da mecânica da fratura elástica linear o que geralmente é adotado é seguir a análise linear elástica, e realizar alguns ajustes para considerar complicações como a deformação plástica, dentro de determinados limites muito estreitos. Assim, $K$ pode ser modificado para considerar determinada extensão da zona plástica, de forma a estender os limites da mecânica da fratura elástica linear para níveis de tensão um pouco além dos limites fixados pela expressão (6). Entretanto, situações de escoamento muito amplo não podem ser analisadas dessa forma porque as aproximações seriam muito questionáveis se as tensões aproximassem de um nível tal que pudesse ocorrer o escoamento total através do ligamento (região não fraturada) do corpo de prova. Pois neste caso o campo de tensões seria consideravelmente alterado em relação ao dado pela Equação (5).

No caso de materiais que apresentam comportamento elástico não linear as hipóteses da mecânica da fratura linear elástica são violadas, e não valem para materiais dúcteis e semi-dúcteis como o polietileno, nos quais a fratura geralmente é acompanhada de significativa deformação plástica. Nestes casos, as restrições para a zona plástica (small scale yielding) impõem sérias limitações para a caracterização da tenacidade através da LEFM (TJONG et al, 2000); (PERES \& SCHÖN, 2004). 
Em particular, no processo de fratura do polietileno de alta densidade, sempre há o desenvolvimento de crazing na ponta da trinca (DUAN \& WILLIAMNS, 1998) e o processo de crescimento lento (estável) de trincas não é abordado pela LEFM. Entretanto, apesar das limitações apontadas, importantes trabalhos foram realizados nos quais o fenômeno do crescimento lento (estável) de trincas no polietileno foi investigado com o auxílio de parâmetros da LEFM (CHAN \& WILLIAMS, 1983); (QIAN \& BROWN, 1989); (NISHIMURA \& KAWAGUCHI, 2004). O estudo de polímeros com esse comportamento é tradicionalmente desenvolvido no campo da mecânica da fratura elasto-plástica (Elastic-Plastic Fracture Mechanics - EPFM), cujas principais abordagens são Integral-J (J-Integral) e Trabalho Essencial de Fratura (Essential Work of Fracture).

$\mathrm{O}$ ensaio de integral $\mathrm{J}$ é muito interessante neste contexto, mas é bastante complexo. A Sociedade Européia de Integridade Estrutural (European Structural Integrity Society - ESIS) apresenta um protocolo completo de ensaio (HALE \& RAMSTEINER, 2001), entretanto as dificuldades de ordem prática para a sua execução não concordam com os objetivos deste trabalho que é o de desenvolver métodos práticos para a avaliação da resistência do polietileno ao crescimento lento de trincas (slow crack growth). Uma idéia surgida inicialmente foi a de observar em particular a taxa de crescimento (lento) de trincas em função de $\mathrm{J}$, tanto ao ar como em meio aquoso clorado, mas a duração do ensaio seria muito longa, recaindo no mesmo problema da "curva de regressão": tempo excessivamente longo de ensaio. Por outro lado, segundo alguns autores, o trabalho essencial de fratura em estado plano de tensão, obtido pelo método da extrapolação linear que será desenvolvido, é equivalente a $\mathrm{J}_{\mathrm{IC}}$ ( $\mathrm{J}$ crítico no estado plano de deformação) (WARD \& SWEENEY, 2004). Dessa forma, a abordagem do problema pelo método da Integral $\mathrm{J}$ foi descartada. De qualquer forma, caso o leitor esteja interessado no método, ele é apresentado no Apêndice C.

\subsection{1 - Trabalho essencial de fratura - EWF}

Através do método do trabalho essencial de fratura a energia relacionada com a fratura de um material elastoplástico pode ser dividido em duas componentes. Uma parte é específica para a fratura do material e, portanto, assume-se que seja um 
parâmetro (ou propriedade) do material. O restante da energia total de fratura está relacionada com a deformação plástica generalizada (gross ductility), governada pelo comprimento do corpo não fraturado (ligamento) e depende da geometria do corpo de prova (CLUTTON, 2001); (WILLIAMS, 2001)

O conceito dessa divisão foi originalmente sugerido por Broberg (1968, 1975), o qual propôs que a região não elástica na ponta da trinca fosse subdividida em uma região onde o processo de fratura de fato se realiza, que ele chamou de end region, e uma região que circunda a primeira, onde se desenvolve uma ductilidade volumosa, denominada outer region; (COTTERELL \& REDDEL, 1977); (SALEEMI \& NAIRN, 1990); (PEGORETTI et al, 1997); (TJONG et al, 2000); (CLUTTON, 2001); (KWON \& TRUSS, 2002). O conceito foi desenvolvido por Cotterell \& Riddel (1977) e por Mai \& Cotterell (1986) para metais e estendida para os polímeros dúcteis por uma série de autores, entre eles Saleemi \& Nairn (1990), Mai \& Powell (1991), Chan \& Williams (1994), Karger-Kocsis \& Czigany (1996), Wu \& Mai (1996), Hashemi, (1997), Marchal et al (1997), Karger-Kocsis et al (1997), Pegoretti et al (1997), Tjong et al (2000) e Bárány et al (2003).

O método do trabalho essencial de fratura é atraente porque oferece uma forma interessante e prática de se separar a energia despendida na zona de processo do trabalho gasto na zona plástica difusa. A técnica é fácil de ser aplicada e dispensa observações difíceis como a detecção do início de propagação e a medição do avanço da trinca (PARDOEN et al, 2002).

Cotterell \& Reddel (1977) chamaram o trabalho específico na ponta da trinca de Trabalho Essencial de Fratura - EWF (Essential Work of Fracture) e o trabalho realizado na região do entorno de "trabalho não essencial". Dada uma espessura de chapa, o trabalho essencial de fratura tem sido caracterizado como uma propriedade do material, independente da geometria do corpo de prova, conforme $\mathrm{Wu} \& \mathrm{Mai}$ (1996), citados por Clutton (2001). Por outro lado, o trabalho não essencial depende da forma da zona plástica circunvizinha da trinca e está relacionado à energia absorvida por unidade de volume pela deformação plástica distante da superfície de fratura, $\mathrm{w}_{\mathrm{p}}$ (HASHEMI, 1997).

O princípio da técnica é medir as energias de fratura a partir de curvas força (ou carga) x deslocamento de uma série de corpos de prova, garantindo-se que no 
ligamento (região de fratura) a plasticidade seja plenamente desenvolvida, ou seja, que toda a região do ligamento sofra deformação plástica (escoamento). Nestes casos, é possível dividir o trabalho de fratura em uma parte que se desenvolve ao longo da linha de fratura e outra que se desenvolve em um volume de material ao redor da trinca. A primeira é proporcional à área de fratura e, portanto, ao comprimento do ligamento, enquanto que a segunda é proporcional ao volume da região circunvizinha. Tanto para os metais como para os plásticos, tem sido observado que o volume da região circunvizinha é proporcional ao quadrado do comprimento do ligamento. Assim, para uma série de condições válidas qualquer, a energia total absorvida na fratura de um determinado corpo de prova, $W_{f}$, é dada pela seguinte expressão:

$$
W_{f}=w_{e} . l . t+w_{p} \beta l^{2} t
$$

onde $w_{e}$ é o trabalho essencial de fratura, $w_{p}$ é o trabalho plástico não essencial dissipado por unidade de volume do material, $l$ é o comprimento do ligamento, $t$ é a espessura da chapa e $\beta$ é um fator de forma relacionado com a dimensão da zona plástica normal à linha da trinca (CLUTTON, 2001). Normalizando por $l t$ temos:

$$
w_{f}\left(=W_{f} / l t\right)=w_{e}+\beta w_{p} l
$$

Se o ligamento estiver em um estado plano de tensão puro, $w_{e}, w_{p}$ e $\beta$ são independentes do comprimento do ligamento (PEGORETTI et al, 1997); (SALEEMI \& NAIRN, 1990); (MAI \& POWELL, 1991) e nesta condição, a expressão (9) é a equação de uma reta, cuja inclinação é $\beta w_{p}$. Nesse sentido, algumas restrições geométricas devem ser respeitadas (ligamentos suficientemente longos), de forma que todos os corpos de prova apresentem globalmente o mesmo estado de tensão através do ligamento (PARDOEN et al, 2002); (WU \& MAI, 1996); (CLUTTON, 2001).

Segundo Clutton (2001) é útil aplicar um critério de tensão aos máximos valores de tensão do método EWF de forma a garantir uma maior probabilidade de 
ocorrência da fratura sob estado plano de tensão e excluir dados onde a fratura pode ter ocorrido antes do total escoamento do ligamento.

O critério consiste em calcular um valor médio $\left(\sigma_{\mathrm{m}}\right)$ das máximas tensões $\left(\sigma_{\max }\right)$ aos quais os corpos de prova foram submetidos e rejeitar os resultados de trabalho específico para os quais a máxima tensão tenha sido superior a $1,1 \sigma_{\mathrm{m}}$ ou menor que $0,9 \sigma_{\mathrm{m}}$. Ou seja, estabelece-se uma faixa de validade em torno de $10 \%$ da média das tensões máximas para cima ou para baixo. Os pontos que estiverem situados fora dessa faixa são excluídos. O critério de tensão pode ser ilustrado graficamente na Figura 47, do Apêndice B.

$\mathrm{O}$ valor de $w_{e}$ pode ser determinado a partir de um gráfico de $w_{f} \mathrm{x} l$, por análise de regressão linear dos dados, na interseção da linha de regressão com o eixo das ordenadas. Um exemplo típico de uma curva $w_{f} \mathrm{x} l$, obtido para a resina GM 5010 T2 é apresentado na Figura 22.

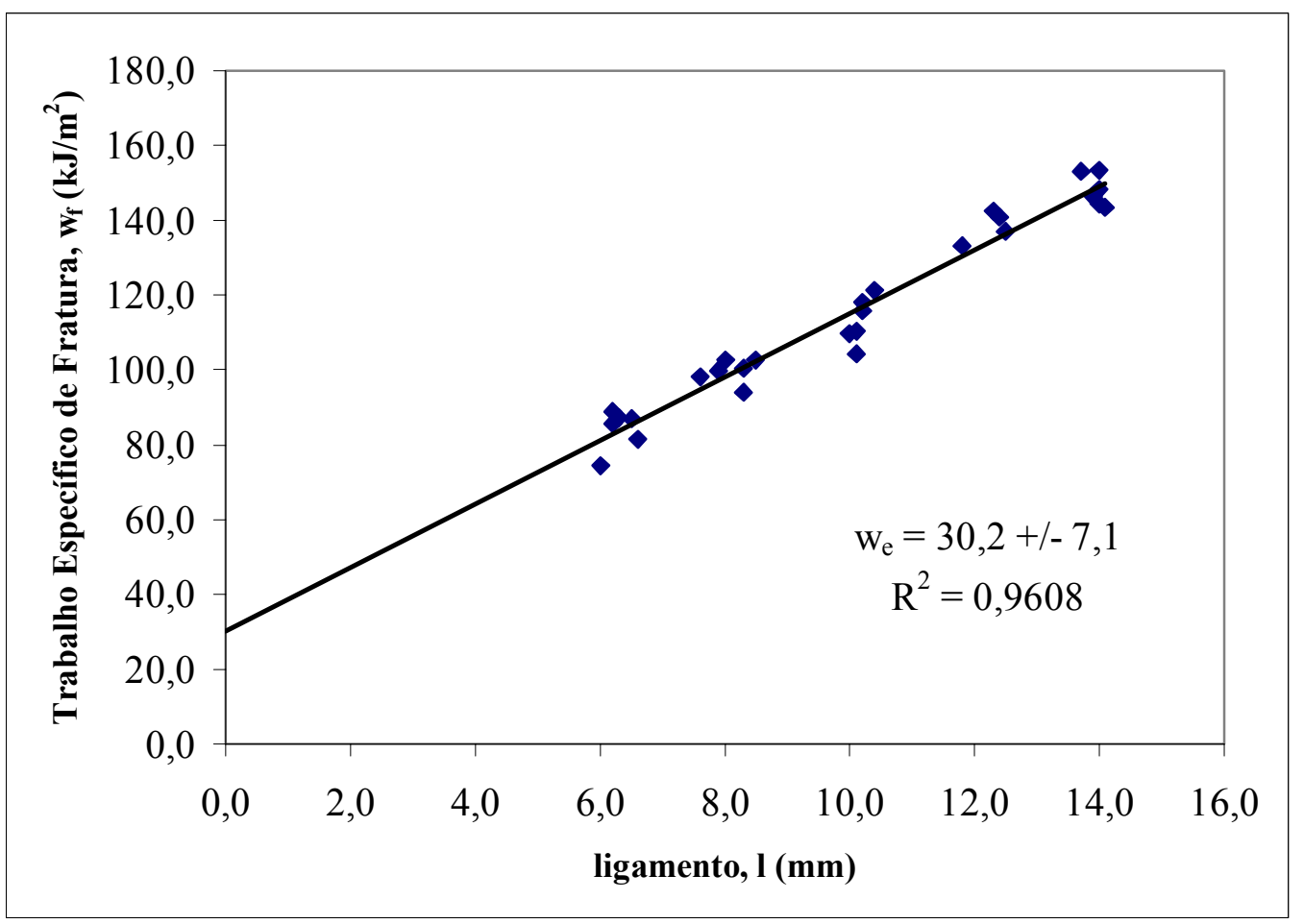

Figura 22: Gráfico típico de $\boldsymbol{w}_{\boldsymbol{f}} \mathbf{x} \boldsymbol{l}$ (Material: Resina GM 5010 T2 - perpendicular à direção de extrusão) 
Apesar de ser mais comum a obtenção de $w_{e}$ no estado plano de tensão, Saleemi \& Nairn (1990), citados por Clutton (2001) demonstraram que é possível obter um valor para o estado plano de deformação. A obtenção de um valor de estado plano de tensão implica que este seja o estado de tensão no ligamento de cada corpo de prova, o que tem implicação no tipo de corpo de prova usado e na faixa de comprimento de ligamento adotada, como discutido acima. Em função da restrição imposta pelo método, é necessário que os comprimentos dos ligamentos sejam ainda relativamente curtos de forma a garantir o total escoamento desta região, o que implica o uso de corpos de prova com entalhes profundos. O esquema do método, incluindo as restrições geométricas impostas aos corpos de prova, é ilustrado na Figura 23.

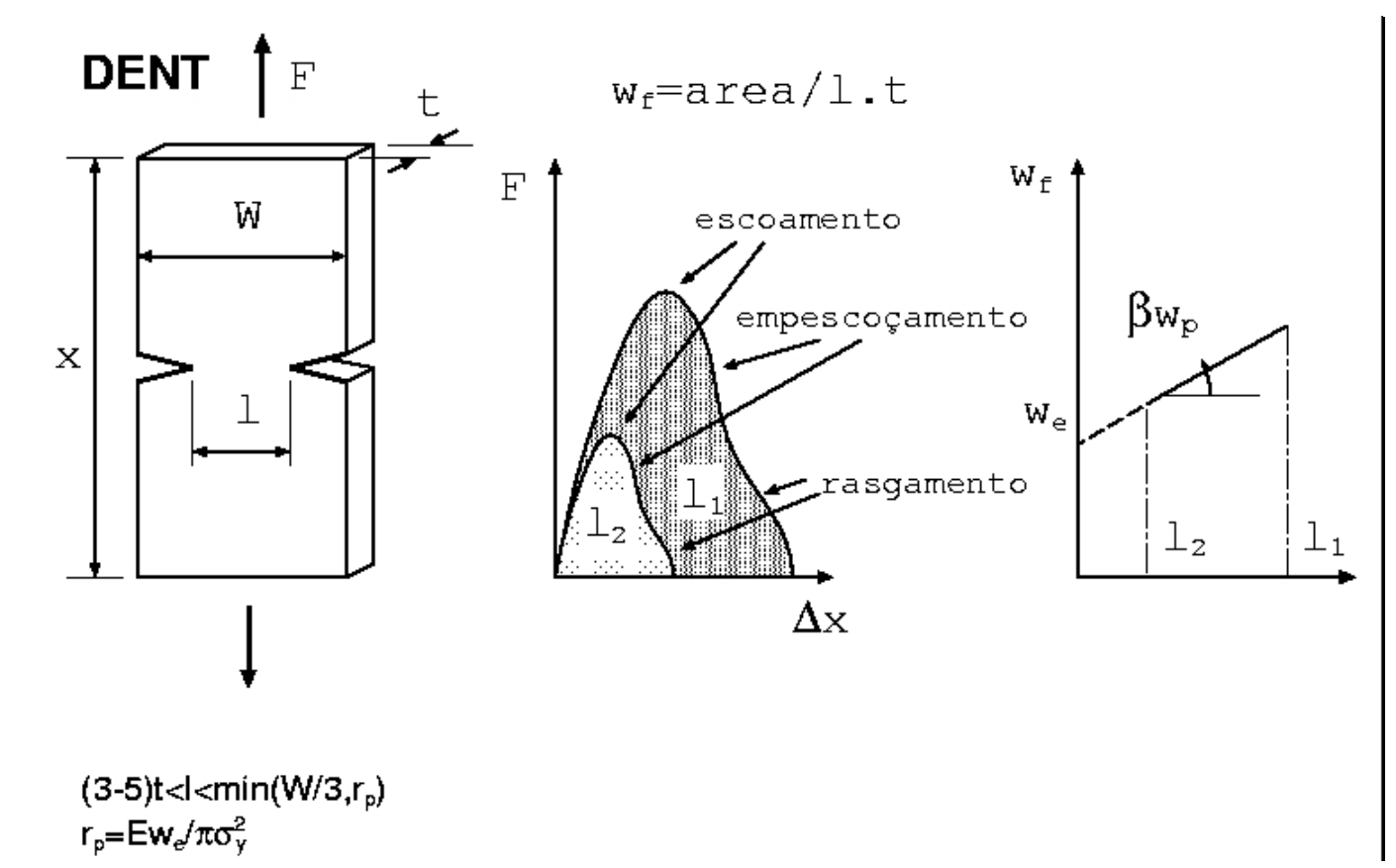

Figura 23: Esquema do método EWF (Adaptado de PERES \& SCHÖN, 2004b)

\subsection{2 - "Ramp test"}

Zhou et al (2001) estudaram a estricção do PEAD em função da taxa de deformação ("ramp test"), em ensaios de tração. Estabeleceu-se que o limite de escoamento, $\sigma_{y}$, está relacionado com a expressiva deformação e coalescência de bandas de cisalhamento, cujo processo leva à deformação localizada (estricção). A 
região de estricção do corpo de prova se propaga à tensão constante de estiramento $\sigma_{d r}$.

Como o polietileno é um sólido viscoelástico à temperatura ambiente $(+/-$ $\left.23^{\circ} \mathrm{C}\right), \sigma_{e}$ e $\sigma_{d r}$ são dependentes do tempo, e especificamente da taxa de deformação do ensaio de tração, $\dot{\varepsilon}$. Com taxas de deformação maiores obtêm-se maiores valores de $\sigma_{y}$ e $\sigma_{d r}$, enquanto que com taxas de deformação menores obtêm-se menores valores de tensão (Figura 24). Entretanto, observou-se que $\sigma_{\mathrm{dr}}$ é menos dependente da taxa de deformação, e que a diferença entre $\sigma_{y}$ e $\sigma_{d r}$ é reduzida à medida que se reduz a taxa de deformação (ZHOU et al, 2001).
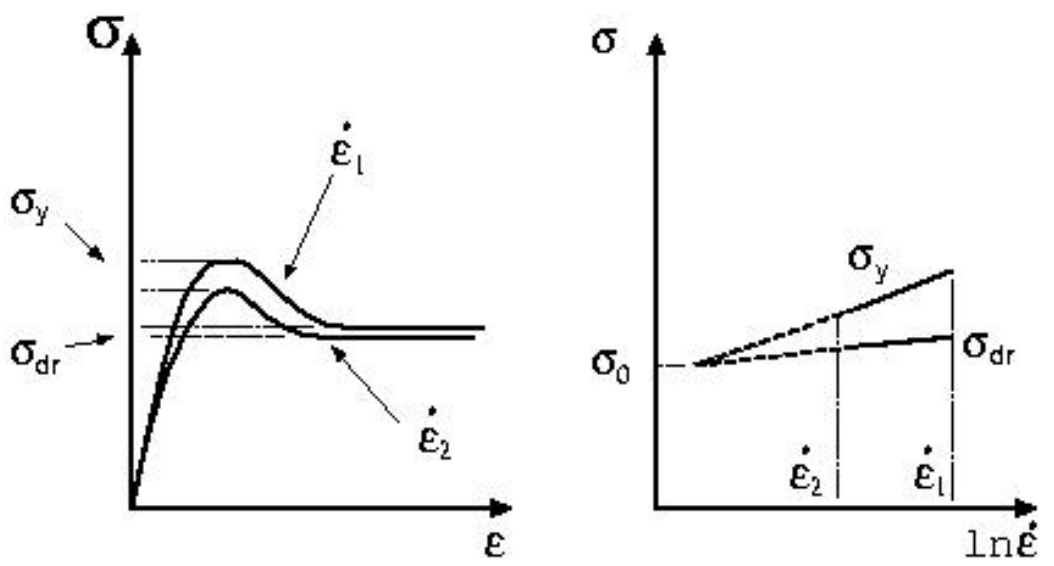

Figura 24: "ramp test". $\dot{\varepsilon}_{1}>\dot{\varepsilon}_{2}$ (Fonte: Peres \& Schön, 2004b)

Construindo-se uma curva tensão $(\sigma) \mathrm{x} \log \dot{\varepsilon}$ verificou-se que as curvas $\sigma_{\mathrm{y}} \mathrm{x}$ $\log \dot{\varepsilon}$ e $\sigma_{\mathrm{dr}} \mathrm{x} \log \dot{\varepsilon}$ possuem comportamento linear, com inclinações diferentes, conforme Figura 24. Por extrapolação pode-se identificar uma certa taxa de deformação à qual $\sigma_{e}$ e $\sigma_{d r}$ coincidem. À essa tensão comum Zhou et al (2001) denominaram tensão característica, designada por $\sigma_{0}$.

Considerando-se que $\sigma_{y}$ está relacionada com a falha dúctil, e que a falha frágil está relacionada com a formação de crazes (e com o subseqüente crescimento lento de trincas) em níveis de tensão iguais ou menores que $\sigma_{d r}$, Zhou et al (2001) 
propuseram que $\sigma_{e}=\sigma_{d r}=\sigma_{0}$ corresponde ao nível de tensão em torno do qual ocorre a transição dúctil-frágil do mecanismo de fratura, sendo predominante o mecanismo de falha dúctil acima de $\sigma_{0}$ e predominante o mecanismo de falha frágil abaixo de $\sigma_{0}$. Em níveis de tensão em torno de $\sigma_{0}$ a predominância de um ou outro mecanismo ocorre ao acaso.

Dessa forma, conhecido $\sigma_{0}$, através da "curva de regressão" pode-se estimar o tempo para ocorrência da transição dúctil-frágil, e verificar se o material estará sujeito a uma alteração no comportamento mecânico dentro do período de vida útil desejado.

Apesar de sua estrutura simples, o Ramp-Test pode ser justificado e fundamentado em escala microscópica (molecular) (PERES \& SCHÖN, 2004).

Rose et al (1994) e Cawood et al (1993) propuseram que o crescimento lento de trincas no polietileno seria controlado basicamente pela fluência das fibrilas, através da estrutura dos crazes. Por sua vez, a taxa de fluência depende da taxa de desentranhamento das fibrilas (LU et al, 1991). Foi observada uma notável correlação entre o comportamento em fluência do material estirado e o tempo de vida (tempo de ruptura), o que proporciona sustentação ao modelo idealizado. Esse modelo pode proporcionar uma nova abordagem para o estudo do fenômeno da falha, ou seja, a previsão do comportamento em fratura por um meio alternativo, que não seja através de um parâmetro de fratura (ROSE et al, 1994). Dessa forma, segundo Trassaert \& Schirrer (1983) o estudo da fratura de polímeros é na verdade o estudo da formação de crazes e a ruptura das fibrilas do craze.

Com base nos argumentos de Schirrer et. al (1984), Trassaert \& Schirrer (1983) e de Rose et al (1994), o estiramento das fibrilas pode ser visto como um processo semelhante ao estiramento a frio (cold-drawing) observado em corpos de prova de ensaio de tração de polietileno, e é igualmente acompanhado de estricção (CHUDNOVSKY \& SHULKIN, 1999). Particularmente, foram observadas evidências de que as fibrilas na base do craze (ponta da trinca verdadeira) são estiradas à mesma taxa de estiramento natural (natural draw ratio) do material e que elas estão submetidas à mesma tensão que um corpo de prova de tração quando submetido à mesma taxa de estiramento natural. 
Cawood et al (1993) e Rose et al (1994) assumiram então que a estrutura e o comportamento das fibrilas dos crazes em polietileno são idênticas àquelas de um corpo de prova de ensaio de tração orientado. Ainda, segundo Chudnovsky \& Shulkin (1999), a estrutura e o comportamento das fibrilas são semelhantes ao polietileno estirado a frio sob condições de tensão plana. Ou seja, podemos visualizar as fibrilas como uma representação microscópica de corpos de prova (macroscópicos) de tração, podendo prever o comportamento das fibrilas a partir do comportamento sob cargas de tração de corpos de prova com dimensões convencionais.

Como visto na Seção 1.7., o processo de estiramento a frio (cold-drawing) se desenvolve através da contínua extração de material original isotrópico da matriz nas extremidades da região estirada (ROSE et al, 1994). Durante esse processo, as deformações locais tanto na parte estirada como na parte não estirada permanecem constantes, de forma que a elongação do corpo de prova aumenta exclusivamente devido ao progresso da transformação do material (CHUDNOVSKY \& SHULKIN, 1999).

Segundo Chudnovsky \& Shulkin (1999), é razoável supor que a tensão requerida para causar a cavitação (voiding) do material, que é precursora da estrutura do craze, deve ser maior que a tensão necessária para manter o processo de estiramento a frio, $\sigma_{d r}$. Assumindo que o material na base do craze é polietileno estirado a frio, considera-se que a tração sobre a parte correspondente da interface entre a matriz e a denominada "zona de processo" é uniformemente distribuída e igual a $\sigma_{d r}$. Os autores demonstraram, através de simulações numéricas do crescimento descontínuo do sistema crack-layer (vide nota), que durante a maior parte do seu tempo de vida o sistema permanece em repouso e a degradação da zona de processo (mais especificamente das fibrilas) é o único processo em andamento. Sob o ponto de vista mecânico a degradação é um processo que leva à redução da resistência à fratura do material com o tempo. Isso sugere que a tensão nas fibrilas,

\footnotetext{
${ }^{9}$ Chudnovsky \& Shulkin (1999) idealizaram a "zona de processo" (ou process zone - PZ) como uma região formada por uma parte cuja estrutura é a típica de crazing, já descrita anteriormente, e uma parte composta de material com microvazios. A zona de processo integra o sistema crack layer - CL, concebido pelos autores, o qual compreende ainda a trinca - Vide Figura 14.
} 
quando o mecanismo de crescimento lento de trincas (que leva à ruptura frágil) é dominante é no máximo em torno de $\sigma_{d r}$.

Por outro lado, conforme Zhou et al (2001), a tensão de escoamento $\sigma_{y}$ está diretamente relacionada com a ruptura das unidades cristalinas e outros mecanismos de deformação plástica que predominam no modo de falha dúctil do polietileno.

Dessa forma, a tensão característica $\sigma_{0}$ é um limite inferior da tensão, em torno da qual os mecanismos que levam à fratura dúctil podem manter-se proeminentes. É um limite da tensão de estiramento, que corresponde à menor tensão necessária para o estiramento das fibrilas a partir da matriz polimérica na ponta da trinca. Em níveis menores de tensão, a extração de material da matriz é prejudicada e o crescimento da trinca passa a ser controlado pela degradação das fibrilas. Neste caso, o mecanismo de crescimento lento de trincas será predominante e o modo de falha tenderá a sofrer uma transição para o modo frágil (ou brittle-like).

Assim, realmente não é uma simples coincidência que Zhou et al (2001) tenham encontrado valores próximos para a tensão característica, $\sigma_{0}$, e a tensão crítica, $\sigma_{c}$, correspondente à região de transição dúctil-frágil dos dados da "curva de regressão" de um polietileno de alta densidade classificado como PE 100. Portanto, quando $\sigma_{y} \cong \sigma_{d r} \cong \sigma_{0}$ temos uma situação em que os mecanismos que levam à falha dúctil e à falha frágil competem entre si.

Considerando a simplicidade do RampTest, deve-se ter a cautela de não ignorar que a fratura é um processo constituído de várias etapas. Nesse sentido Rose et al (1994) advertem que a divisão do fenômeno complexo de fratura em seus processo físicos fundamentais deve proporcionar um entendimento mais profundo da falha e permitir que a influência da estrutura molecular seja mais rapidamente avaliada. 


\section{2 - MATERIAIS E MÉTODOS}

\section{1 - Materiais}

Foram estudadas as seguintes resinas, especialmente desenhadas para a produção de tubos:

- Resina GM 5010 T2: composto de polietileno, de cor preta, com teor de negro-de-fumo $2,2 \%$, lote 1263 , fabricado pela Ipiranga Petroquímica S.A, classificado como PE 80 conforme ISO 12162, destinado à fabricação por extrusão de tubos de pressão de água. É um polietileno de alta densidade, bimodal, com densidade de $0,954 \mathrm{~g} / \mathrm{cm}^{3}$ e índice de fluidez $0,53 \mathrm{~g}$ a $190^{\circ} \mathrm{C} / 5$ $\mathrm{kg} / 10$ minutos, conforme norma ISO 1133. Segundo o fabricante a resina apresenta os seguintes valores típicos de distribuição de massa molar e polidispersão, obtidos conforme norma ASTM D 3593: $\mathrm{M}_{\mathrm{n}}=12 \mathrm{~kg} / \mathrm{mol}, \mathrm{M}_{\mathrm{w}}$ $=176 \mathrm{~kg} / \mathrm{mol}, \mathrm{M}_{\mathrm{z}}=653 \mathrm{~kg} / \mathrm{mol}$, polidispersão $\left(\mathrm{M}_{\mathrm{w}} / \mathrm{M}_{\mathrm{n}}\right)=15$. Dados extraídos da "curva de regressão" (Figura 26), conforme norma ISO 9080, indicam os seguintes valores: LTHS $\left(50\right.$ anos $\left./ 20^{\circ} \mathrm{C}\right)=10,232 \mathrm{MPa}$, $\mathrm{LTHS} / \mathrm{LCL}=9,901 \mathrm{MPa}(\mathrm{MRS}=8,0 \mathrm{MPa})$;

- Resina Rigidex PC 002-50R968: composto de polietileno pigmentado, com cor azul claro, fabricado pela Solvay Indupa do Brasil S.A., classificado como PE 80 conforme ISO 12162, destinado à fabricação por extrusão de tubos de pressão de água. O material tem densidade de $0,944 \mathrm{~g} / \mathrm{cm}^{3}\left(23^{\circ}\right)$ e índice de fluidez de $0,85 \mathrm{~g}$ a $190^{\circ} \mathrm{C} / 5 \mathrm{~kg} / 10$ minutos, conforme norma ISO 1133. Dados extraídos da "curva de regressão" (Figura 28), conforme norma ISO 9080, indicam o seguintes valores: LTHS $\left(50\right.$ anos $\left./ 20^{\circ} \mathrm{C}\right)=9,38 \mathrm{MPa}$, LTHS/LCL $\left(50\right.$ anos $\left./ 20^{\circ} \mathrm{C}\right)=8,64 \mathrm{MPa}(\mathrm{MRS}=8,0 \mathrm{MPa})$;

- Resina MDPE 8818: composto de polietileno sem pigmentos, de cor natural, fabricado pela PBBPolisur S.A. (Dow Latin America), lote 1085B857, 
classificado como PE 80 conforme ISO 12162, destinado, após pigmentação, à fabricação por extrusão de tubos de pressão de água e gás natural. $\mathrm{O}$ material tem densidade de $0,940 \mathrm{~g} / \mathrm{cm}^{3}$ e índice de fluidez de $0,77 \mathrm{~g}$ a $190^{\circ} \mathrm{C} / 5 \mathrm{~kg} / 10$ minutos, conforme norma ASTM D 1238. Dados extraídos da "curva de regressão" de um composto da mesma resina na cor amarela MDPE 8818 YW (Figura 30), conforme norma ISO 9080, indicam os seguintes valores: LTHS/LCL $\left(50\right.$ anos $\left./ 23^{\circ} \mathrm{C}\right)=8,03 \mathrm{MPa}(\mathrm{MRS}=8,0 \mathrm{MPa})$;

- Resina HP-0155: composto experimental de polietileno sem pigmentos, de cor natural, fabricado pela Braskem S/A, lote 4800078I4, classificado como PE 100 conforme ISO 12162, destinado, após pigmentação, à fabricação por extrusão de tubos de pressão de água e gás natural. Com pigmento preto a resina possui índice de fluidez $0,3 \mathrm{~g}\left(190^{\circ} \mathrm{C} / 5 \mathrm{~kg} / 10\right.$ minutos $)$ e densidade $0,955 \mathrm{~g} / \mathrm{cm}^{3}$. Dados extraídos da "curva de regressão" de um composto da mesma resina na cor preta - HP 0155 Black (Figura 34), conforme norma ISO 9080, indicam os seguintes valores: LTHS $\left(50\right.$ anos $\left./ 20^{\circ} \mathrm{C}\right)=10,7 \mathrm{MPa}$, $\mathrm{LTHS} / \mathrm{LCL}\left(50 \operatorname{anos} / 20^{\circ} \mathrm{C}\right)=10,1 \mathrm{MPa}(\mathrm{MRS}=10 \mathrm{MPa})$;

- Resina MP-0240: composto experimental de polietileno sem pigmentos, de cor natural, fabricado pela Braskem S/A, lote 480082J4, classificado como PE 80 conforme ISO 12162, destinado, após pigmentação, à fabricação por extrusão de tubos de pressão de água e gás natural. Com pigmento amarelo a resina possui índice de fluidez $0,8 \mathrm{~g}\left(190^{\circ} \mathrm{C} / 5 \mathrm{~kg} / 10\right.$ minutos $)$ e densidade $0,939 \mathrm{~g} / \mathrm{cm}^{3}$. Dados extraídos da "curva de regressão" de um composto da mesma resina na cor amarela - MP 0240 Yellow (Figura 32), conforme norma ISO 9080, indicam os seguintes valores: $\operatorname{LTHS}\left(50 \operatorname{anos} / 20^{\circ} \mathrm{C}\right)=8,81$ $\mathrm{MPa}, \mathrm{LTHS} / \mathrm{LCL}\left(50 \operatorname{anos} / 20^{\circ} \mathrm{C}\right)=8,28 \mathrm{MPa}(\mathrm{MRS}=8 \mathrm{MPa})$;

Além destas, investigaram-se, para fins de controle, as seguintes resinas que não são especificamente desenhadas para a produção de tubos extrudados: 
- Resina JV060U: composto de polietileno de alta densidade, de cor natural, fabricado pela Braskem S/A, lote 3L29A, sem classificação conforme ISO 12162, densidade $0,958 \mathrm{~g} / \mathrm{cm}^{3}$, índice de fluidez $7,2 \mathrm{~g}\left(190^{\circ} \mathrm{C} / 10\right.$ minutos $)$ destinado à fabricação de peças, particularmente engradados de bebidas, por processo de injeção. É um polietileno de alta densidade, copolímero monomodal, com densidade de $0,957 \mathrm{~g} / \mathrm{cm}^{3}$ e índice de fluidez em torno de 7 g a $190^{\circ} \mathrm{C} / 2,16 \mathrm{~kg} / 10$ minutos, conforme a norma ASTM D 1238.

- Resina BS 002: composto de polietileno de alta densidade, de cor natural, fabricado pela Braskem S/A, sem classificação conforme ISO 12162, destinado à moldagem de peças por sopro, especialmente embalagens plásticas. É um polietileno de alta densidade, copolímero monomodal, com densidade de $0,954 \mathrm{~g} / \mathrm{cm}^{3}$ e índice de fluidez em torno de 0,29 $\mathrm{g}$ a $190^{\circ} \mathrm{C} / 2,16 \mathrm{~kg} / 10$ minutos, conforme a norma ASTM D 1238.

Por composto de polietileno entende-se a resina base de polietileno acrescida de antioxidantes e outros aditivos, entre os quais, quando for o caso, pigmentos.

Os materiais foram recebidos dos fabricantes na forma de grânulos (pellets) e mantidos em suas embalagens originais em sala com temperatura ambiente amena e sem umidade. A resina BS 002 não foi fornecida diretamente pelo fabricante, tendo sido oferecida pela Cromex S/A, empresa em cujos laboratórios foi feita a extrusão dos filmes para os ensaios de EWF. De qualquer forma, o material processado foi obtido também neste caso a partir da resina "virgem", na forma de grânulos.

\section{2 - "Ramp test"}

\subsection{1 - Corpos de prova}

Os corpos de prova de tração da resina JV060U, do tipo I conforme a norma ASTM D 638, foram obtidos diretamente por injeção em uma injetora Demag de procedência alemã, modelo Ergotech-pro-35-115, do PMT/EPUSP, com carga de fechamento de 12 toneladas, em molde de cavidade dupla, com temperaturas $\left({ }^{\circ} \mathrm{C}\right)$ nas zonas de alimentação, compressão e dosagem, respectivamente, 160, 170 e 175. A 
temperatura do bico de injeção foi $185^{\circ} \mathrm{C}$ e a do molde $40^{\circ} \mathrm{C}$, com tempo de resfriamento de $11 \mathrm{~s}$. Os corpos de prova dos demais materiais foram extraídos de placas moldadas por compressão. As razões para os diferentes métodos de obtenção dos corpos de prova serão discutidos no Capítulo 3 - Resultados.

Para a confecção das placas utilizou-se um molde constituído de duas chapas de aço forradas com folhas de alumínio intercaladas com uma moldura de aço de cerca de $3 \mathrm{~mm}$ de espessura. O conjunto fechado formou uma cavidade de 200 × 200 x $3 \mathrm{~mm}$. A primeira chapa de aço era colocada sobre uma superfície plana e sobre ela era posicionada a moldura. Assumindo-se uma densidade média de $0,95 \mathrm{~g} / \mathrm{cm}^{3}$ dos materiais, a cavidade era preenchida com uma quantidade de material com excesso em peso de $10 \%$. A segunda chapa de aço era então disposta sobre o material e o conjunto era posicionado entre as placas da prensa.

Foi utilizada uma prensa hidráulica marca Sirma, de procedência nacional, modelo HB-E, do PMT/EPUSP, com a regulagem da temperatura das placas ajustada para $190^{\circ} \mathrm{C}$. As placas da prensa eram aproximadas do molde e permaneciam nesta posição por 5 minutos para pré-aquecimento do material. A prensa era então acionada, aplicando-se uma pressão hidráulica de $200 \mathrm{kgf} / \mathrm{cm}^{2}$ durante 3 minutos. Após esse período a pressão era brevemente (em alguns segundos) aliviada e em seguida o molde era novamente comprimido por mais 2 minutos, totalizando 5 minutos de tempo total de prensagem. Após o período total de compressão as placas da prensa eram afastadas, o conjunto do molde era retirado e resfriado naturalmente no ambiente do laboratório (em torno de $25^{\circ} \mathrm{C}$ ). Após o resfriamento as chapas de aço do molde eram retiradas e a seguir eram extraídas as folhas de alumínio que permaneciam aderidas à placa de material moldado. As placas obtidas dessa forma apresentaram bom aspecto geral, sem irregularidades, exceto as placas da resina JV060U. Este material apresentou excessiva fluidez e significativo vazamento durante a moldagem, além de marcas superficiais decorrentes da adesão da folha de alumínio.

De forma a acelerar o processo de obtenção das placas foi tentado ainda um resfriamento rápido imediatamente após a prensagem. Apesar do aspecto bom das placas, posteriormente um ensaio de "ramp test" preliminar apresentou excessiva 
variação nos resultados. Presumindo-se que isto se deve a uma melhor homogeneidade nas placas resfriadas lentamente, optou-se pelo resfriamento natural.

Os corpos de prova foram extraídos das placas por estampagem em prensa pneumática com um estampo de aço com a geometria do tipo IV, conforme a norma ASTM D 638. Em virtude da qualidade da ferramenta empregada, muito afiada, a qualidade final dos corpos de prova foi muito boa, apresentando ótimas regularidades geométrica e dimensional.

Dessa forma, nos ensaios de "ramp test" foram empregados corpos de prova do tipo IV (ASTM D 638), extraídos de placas moldadas por compressão, para o caso de materiais projetados para processamento por extrusão e corpos de prova injetados do tipo I (ASTM D 638) para o caso do material projetado para injeção. A resina BS 002 não foi submetida ao "ramp test".

\subsection{2 - Ensaios e aplicação do método}

Os ensaios de tração dos corpos de prova foram realizados em uma máquina universal de ensaios mecânicos do PMT/EPUSP marca Kratos, modelo K 2000 MP e os resultados de carga e deslocamento da travessa móvel foram adquiridos utilizando software Tracomp-W95 (TRCU 48), calibrada em 25/05/2004, com célula de carga de $2.000 \mathrm{kgf}$.

As velocidades de ensaio inicialmente selecionadas foram $0,5,1,5,50$ e 500 $\mathrm{mm} / \mathrm{min}$, correspondendo aproximadamente a taxas de deformação entre $0,0002 \mathrm{~s}^{-1} \mathrm{e}$ $0,2 \mathrm{~s}^{-1}$ para corpos de prova do tipo IV e entre $0,0001 \mathrm{~s}^{-1}$ e $0,1 \mathrm{~s}^{-1}$ para corpos de prova do tipo I, ou seja, taxas de deformação variando entre 3 ordens de grandeza. Entretanto, os corpos de prova de alguns materiais romperam imediatamente após o limite de escoamento na maior velocidade de ensaio $(500 \mathrm{~mm} / \mathrm{min})$. Nestes casos foram adotadas velocidades inferiores, de forma a serem obtidos os valores da tensão de estiramento. Particularmente, no caso dos corpos de prova da resina JV060U, somente os resultados de limite de escoamento na velocidade de $500 \mathrm{~mm} / \mathrm{min}$ foram aproveitados. As velocidades adotadas para todos os ensaios estão listadas na tabela $1 .:$ 
Tabela 1 - Velocidades de ensaio adotadas no "ramp test"

\begin{tabular}{|c|c|c|c|c|c|c|c|c|}
\cline { 2 - 10 } \multicolumn{1}{c|}{} & \multicolumn{7}{c|}{ Velocidade da travessa móvel (mm/min) } \\
\hline MATERIAL & 0,1 & 0,5 & 1 & 5 & 10 & 50 & 100 & 500 \\
\hline GM 5010 T2 & $\mathrm{X}$ & $\mathrm{X}$ & $\mathrm{X}$ & $\mathrm{X}$ & - & $\mathrm{X}$ & - & $\mathrm{X}$ \\
\hline Rigidex PC 002-50R968 & - & $\mathrm{X}$ & $\mathrm{X}$ & $\mathrm{X}$ & - & $\mathrm{X}$ & - & $\mathrm{X}$ \\
\hline MDPE 8818 & - & $\mathrm{X}$ & $\mathrm{X}$ & $\mathrm{X}$ & - & $\mathrm{X}$ & - & $\mathrm{X}$ \\
\hline HP-0155 & - & $\mathrm{X}$ & $\mathrm{X}$ & $\mathrm{X}$ & - & $\mathrm{X}$ & $\mathrm{X}$ & - \\
\hline MP-0240 & - & $\mathrm{X}$ & $\mathrm{X}$ & $\mathrm{X}$ & - & $\mathrm{X}$ & $\mathrm{X}$ & - \\
\hline JV060U injetado & - & - & $\mathrm{X}$ & $\mathrm{X}$ & - & $\mathrm{X}$ & $\mathrm{X}$ & $\mathrm{X}$ \\
\hline JV060U moldado & - & $\mathrm{X}$ & $\mathrm{X}$ & $\mathrm{X}$ & $\mathrm{X}$ & $\mathrm{X}$ & - & - \\
\hline
\end{tabular}

Foram ensaiados 3 corpos de prova em cada velocidade acima de $1 \mathrm{~mm} / \mathrm{min}$, inclusive nesta; a $0,5 \mathrm{~mm} / \mathrm{min}$ foram ensaiados 2 corpos de prova, e a $0,1 \mathrm{~mm} / \mathrm{min}$ foi ensaiado um único corpo de prova em virtude da longa duração do ensaio - cerca de 8 horas.

Os ensaios foram realizados à temperatura de $25+/-2^{\circ} \mathrm{C}$.

A partir dos dados de carga e deslocamento capturados durante os ensaios de tração, foram calculados os limites de escoamento $\left(\sigma_{\mathrm{y}}\right)$ e as tensões de estiramento $\left(\sigma_{\mathrm{dr}}\right)$, aplicando-se nos casos cabíveis o tratamento estatístico para cálculo das médias e dos desvios padrões. O limite de escoamento foi calculado a partir do primeiro máximo valor de carga da curva carga x deslocamento. Sempre que possível a tensão de estiramento foi calculada a 100\% de deformação (engenharia). Apesar de aparentemente arbitrário este nível de deformação foi escolhido porque observou-se que na maioria dos casos o estiramento a frio apresentava-se estabilizado em torno deste ponto. Entretanto, principalmente no caso das velocidades mais altas, a ruptura do corpo de prova ocorreu eventualmente antes desse ponto. Nesses casos, adotou-se a maior valor de tensão de estiramento observada até a ruptura.

A partir dos dados calculados de limites de escoamento e tensões de estiramento para cada velocidade (taxa de deformação) foram construídas as curvas $\sigma_{\mathrm{y}} \mathrm{x} \log \dot{\varepsilon}$ e $\sigma_{\mathrm{dr}} \mathrm{x} \log \dot{\varepsilon}$. Através de análise de regressão linear simples (pelo método dos mínimos quadrados) as curvas foram extrapoladas, calculando-se o valor de $\sigma_{\mathrm{c}}-$ 
estimativa da tensão de transição dúctil-frágil na "curva de regressão" do material na intersecção entre as duas retas.

Os valores de $\sigma_{\mathrm{c}}$ foram então comparados ou situados na "curva de regressão" de cada material, exceto para os materiais não destinados à fabricação de tubos, para os quais não há "curva de regressão" disponível.

\section{3 - Trabalho essencial de fratura (EWF)}

\subsection{1 - Corpos de prova}

Tentou-se inicialmente obter por moldagem em compressão placas mais finas de cada material, algo em torno de $1 \mathrm{~mm}$ de espessura, com a mesma técnica utilizada para confecção das placas destinadas ao ramp test. As placas obtidas não tinham bom aspecto, não eram uniformes e apresentavam acentuadas marcas superficiais provocadas pelas folhas de alumínio. Optou-se então por trabalhar com filmes produzidos por extrusão e sopro.

Os filmes, com espessura média em torno de 0,20 mm foram obtidos a partir de balões com diâmetro médio de $90 \mathrm{~mm}$ produzidos por sopro em uma extrusora de laboratório pertencente à Cromex S/A, montada internamente, utilizando-se uma matriz com diâmetro de $60 \mathrm{~mm}$ e abertura de $0,8 \mathrm{~mm}$ (relação de suflamento $\cong 1,5: 1$ e relação de estiragem $\cong 4: 1$ ), regulada para temperatura do canhão $190^{\circ} \mathrm{C}$ e produção aproximada de 5,8 kg/hora. Não foi possível obter filme soprado da resina JV060U. Incluiu-se então para os ensaios de EWF a resina BS 002 como contra-tipo das resinas originalmente destinadas à extrusão de tubos.

Tiras com cerca de $130 \mathrm{~mm}$ de comprimento foram cortadas dos filmes de cada material na direção perpendicular à direção de extrusão, de forma que o futuro ligamento tivesse a mesma orientação da direção de extrusão. Presume-se que esta seja a situação mais desfavorável para a propagação da fratura (mesma orientação das falhas do tipo frágil observadas nos tubos). A largura das tiras era $32 \mathrm{~mm}$. Foram escolhidas 5 classes de comprimento de ligamento: $6 \mathrm{~mm}, 8 \mathrm{~mm}, 10 \mathrm{~mm}, 12 \mathrm{~mm}$ e $14 \mathrm{~mm}$. Para cada classe de ligamento foram inicialmente produzidos 5 corpos de prova, totalizando 25 corpos de prova para a aplicação do método. Esse procedimento foi adotado para a resina Rigidex PC 002-50R968, primeiro material 
testado. Para os demais materiais foram confeccionados 6 corpos de prova de cada classe de ligamento, totalizando 30 corpos de prova. Uma discussão sobre o número de corpos de prova será desenvolvida no Capítulo 3.

Ainda no que tange a direção do comprimento dos corpos de prova, tiras da resina GM 5010 T2 também foram extraídas na direção da extrusão dos filmes, de forma a se observar eventuais efeitos anisotrópicos. A escolha do material adotado para esta verificação foi arbitrária.

Não foram realizados entalhes laterais nos corpos de prova. As pré-trincas foram introduzidas através de cortes alinhados e igualmente espaçados das bordas das tiras, produzidos por uma lâmina afiada e pontiaguda (estilete) de aço. A operação de introdução das pré-trincas, e portanto do ligamento, foi executada manualmente com auxílio de uma régua de aço com divisões de $0,5 \mathrm{~mm}$ e de uma lupa. A discussão sobre a relevância da precisão da ponta da trinca será desenvolvida no Capítulo 3.

As dimensões dos corpos de prova, comprimento do ligamento e espessura, foram medidas com um paquímetro com divisões de $0,02 \mathrm{~mm}$ e auxílio de uma lupa e anotadas, respectivamente, com décimos de milímetro e centésimos de milímetro. As espessuras dos corpos de prova das resinas MDPE 8818 e BS 002 foram também medidas com um micrômetro com precisão de 0,01 mm. A importância do emprego de um instrumento mais preciso na medição da espessura será discutida na Seção 3.2.3.1.

\subsection{2 - Ensaios e aplicação do método}

Os ensaios de tração foram realizados em uma máquina universal de ensaios mecânicos do PMT/EPUSP marca Kratos, modelo K 2000 MP e os resultados de carga e deslocamento da travessa móvel foram adquiridos utilizando software Tracomp-W95 (TRCU 48), calibrada em 25/05/2004, com célula de carga de 50 kgf. A velocidade adotada nos ensaios foi $5 \mathrm{~mm} / \mathrm{min}$, correspondente a aproximadamente 0,2 vezes a distância inicial entre os pontos de fixação dos corpos de prova às garras da máquina, conforme sugere o protocolo de ensaio do ESIS (CLUTTON, 2001).

Os ensaios foram realizados à temperatura de $25+/-2^{\circ} \mathrm{C}$. 
A partir dos dados de carga e deslocamento capturados durante os ensaios de tração de cada corpo de prova foram calculadas a máxima tensão observada e o trabalho necessário para a ruptura do ligamento $\left(\mathrm{W}_{\mathrm{f}}\right)$, empregando-se o algoritmo do trapézio para o cálculo da área sob a curva usando a tabela de dados de carga $\mathrm{x}$ deslocamento (BARROS, 1972). Os resultados de $\mathrm{W}_{\mathrm{f}}$ de cada corpo de prova foram normalizados pela área da seção do ligamento (comprimento do ligamento $\mathrm{x}$ espessura) fornecendo os valores de trabalho específico $\left(\mathrm{w}_{\mathrm{f}}\right)$. Os dados foram submetidos ao critério de tensão, eliminando-se os pontos situados além dos limites de validade estabelecidos. Por razões que serão discutidas na Seção 3.2.3.1, os limites da faixa de validade dos resultados finais foram alterados em relação aos limites (10\%) sugeridos por Clutton (2001) e fixados em 11\% em torno da média das tensões máximas, ou seja, $1,11 \sigma_{\mathrm{m}} \mathrm{e} 0,89 \sigma_{\mathrm{m}}$. Com os resultados finais obtidos foram construídas as curvas $\mathrm{w}_{\mathrm{f}} \times 1$. Através de análise de regressão linear simples (pelo método dos mínimos quadrados) foram obtidas as equações das retas do método e a partir destas os valores do trabalho essencial de fratura do material $\left(\mathrm{w}_{\mathrm{e}}\right)$ e do fator de dissipação de trabalho plástico $\left(\beta \mathrm{w}_{\mathrm{p}}\right)$, com os respectivos intervalos de predição com 95\% de confiança (LEVINE et al, 2000).

\section{4 - Microscopia eletrônica de varredura}

A superfície de fratura de corpos de prova do "ramp test" e a região da ponta da trinca em corpos de prova do método EWF foram observadas em microscópio eletrônico de varredura do PMT/EPUSP, marca Philips, modelo XL 30, com tensão de aceleração $20 \mathrm{kV}$ e corrente no filamento entre 60 e $80 \mu \mathrm{A}$. Por não se tratar de material condutor, as amostras foram revestidas com ouro. 


\section{3 - RESULTADOS E DISCUSSÃO}

\section{1 - "Ramp test"}

\subsection{1 - Método de ensaio de "ramp test" \\ PRINCÍPIO E UTILIDADE DO MÉTODO}

O método do "ramp test" consiste na avaliação do limite de escoamento $\left(\sigma_{\mathrm{y}}\right)$ e da tensão de estiramento $\left(\sigma_{\mathrm{dr}}\right)$ a partir de corpos de prova de tração padronizados, como uma função da taxa de deformação. Ambas quantidades, quando plotadas contra o logaritmo da taxa de deformação formam linhas retas, com diferentes inclinações. A intersecção das duas retas, de acordo com a proposta original, corresponde à tensão crítica $\left(\sigma_{c}\right)$ da transição dúctil-frágil na "curva de regressão". O esquema do método é ilustrado na Figura 24. Este ensaio é especialmente útil para efeito de controle de qualidade do composto, permitindo estimar o comportamento a longo prazo, uma vez conhecida a respectiva "curva de regressão", a partir do valor de $\sigma_{\mathrm{c}}$, dispensando os ensaios mais longos de resistência à pressão hidrostática de longa duração dos tubos.

Propõe-se ainda um método mais simples alternativo à "curva de regressão" completa. O procedimento proposto consiste em realizar um número limitado de ensaios mais curtos de resistência à pressão hidrostática, a pressões mais elevadas, de forma a se determinar o posicionamento e a inclinação da região dúctil da "curva de regressão". Combinando-se esses testes com o resultado do "ramp-test" pode-se determinar o limite inferior da tensão $\left(\sigma_{\mathrm{c}}\right)$ e daí o período de tempo até a transição, ou seja, os limites até os quais a extrapolação da região dúctil seria segura.

\section{CORPOS DE PROVA}

São empregados corpos de prova padronizados, conforme a ASTM D 638: Standard Test Method for Tensile Properties of Plastic, preferencialmente obtidos a 
partir de placas moldadas por compressão, conforme a ASTM D 4703-03: Standard Practice for Compression Molding Thermoplastic Materials into Test Specimens, Plaques, or Sheets. Os corpos de prova podem ser confeccionados por estampagem direta sobre as placas, com auxílio de uma prensa e de uma matriz de aço cuja geometria obedeça fielmente aos tipos padronizados, ou em fresas próprias para essa finalidade (tipo "tensil-cut”).

Inicialmente foram injetados corpos de prova de tração, do tipo I, conforme a norma ASTM D 638. O material destinado originalmente à fabricação de peças injetadas (resina JV060U) apresentou bom desempenho no processamento; as duas cavidades do molde foram preenchidas sem dificuldade. Por outro lado, as resinas destinada à fabricação de tubos (por processo de extrusão) apresentaram problemas na injeção. Especialmente ocorreram falhas no preenchimento da $2^{\mathrm{a}}$ cavidade do molde, mesmo empregando-se condições mais severas de injeção. Em ensaios preliminares de tração verificou-se que os corpos de prova injetados com a resina JV060U apresentaram comportamento esperado, em cuja forma da curva carga $\mathrm{x}$ deslocamento pôde-se observar claramente o limite de escoamento e o estiramento a frio. Entretanto o comportamento dos corpos de prova injetados com materiais destinados à extrusão não apresentaram as curvas típicas esperadas, rompendo-se na maior parte dos casos imediatamente após o limite de escoamento. Em vista da suspeita de forte influência (negativa) do processo de injeção sobre as propriedades do material, esses corpos de prova foram descartados, optando-se então pela extração de corpos de prova a partir de placas moldadas por compressão no caso dos materiais de extrusão.

Idealmente, devem ser ensaiados pelo menos 3 corpos de prova em cada velocidade (taxa de deformação), submetendo-se os resultados à análise estatítica. Uma vez confeccionados os copos de prova devem ser medidos, com precisão, para verificação da área da seção transversal reduzida.

\section{TEMPERATURA}

As propriedades mecânicas dos polímeros são em geral muito influenciadas pela temperatura. Dessa forma, os corpos de prova devem ser pré-condicionados e os 
ensaios realizados em sala com temperatura e umidade controladas, registrando-se esses dados no relatório.

É importante observar ainda que, no caso de se adotarem taxas de deformação muito pequenas, a duração do ensaio pode estender-se por várias horas. Dessa forma, considerando-se as condições climáticas típicas do Brasil, especialmente no verão, pode haver significativa variação da temperatura durante a execução do ensaio, o que reforça a recomendação para condicionamento e execução dos ensaios em sala com ambiente controlado.

\section{MÁQUINA DE ENSAIO}

Pode ser usada qualquer máquina universal de ensaios mecânicos, devidamente calibrada e que disponha das velocidades de ensaio requeridas e dos acessórios necessários para a captura dos dados de carga e de deslocamento.

\section{VELOCIDADE DO ENSAIO}

Devem ser escolhidos pelo menos 5 valores de taxas de deformação, distribuídos entre pelo menos 3 ordens de grandeza, por exemplo entre $0,1 \mathrm{~s}^{-1} \mathrm{e}$ $0,0001 \mathrm{~s}^{-1}$. Estando disponível uma sala com ambiente controlado e existindo condições operacionais para tanto, pode-se adotar a taxa de deformação de $10^{-5} \mathrm{~s}^{-1}$. As velocidades de ensaio serão selecionadas de forma a proporcionarem as taxas de deformação adotadas, dependendo do valor do comprimento útil do corpo de prova escolhido.

As taxas de deformação escolhidas devem ser tais que o comportamento da curva carga x deformação seja típico dos polímeros cristalinos dúcteis, conforme Figura 18, de forma a apresentarem nitidamente o limite de escoamento (primeiro ponto de máximo) e o estiramento. No caso de altas velocidades de ensaio, dependendo do material, pode haver ruptura imediatamente após o limite de escoamento. Nestes casos, deve-se adotar velocidades menores, de forma a se obter suficiente número de amostras apresentando o comportamento típico. 


\section{TRATAMENTO DOS DADOS}

A partir dos dados de carga $\mathrm{x}$ deslocamento e das dimensões dos corpos de prova, calculam-se o limite de escoamento (engenharia) e a tensão de estiramento (engenharia). O limite de escoamento $\left(\sigma_{\mathrm{y}}\right)$ é calculado dividindo-se a carga do primeiro ponto de máximo da curva carga x deslocamento pela área inicial da seção reduzida do corpo de prova. Após o limite de escoamento a carga geralmente cai até determinado ponto, sofre ligeira elevação e se estabiliza à medida que o estiramento a frio se estende ao longo da seção reduzida. A tensão de estiramento $\left(\sigma_{\mathrm{dr}}\right)$ é calculada dividindo-se a carga correspondente à região estabilizada pela área inicial da seção reduzida do corpo de prova. No caso dos materiais testados a tensão de estiramento foi arbitrariamente anotada a 100\% de deformação (engenharia) do corpo de prova. Os resultados devem ser submetidos à análise estatística para obtenção das médias e verificação dos erros.

Através de análise de regressão linear simples (mínimos quadrados) obtêm-se as equações das curvas (retas) $\sigma_{\mathrm{y}} \mathrm{x} \log \mathrm{d} \varepsilon / \mathrm{dt}$ e $\sigma_{\mathrm{dr}} \mathrm{x} \log \mathrm{d} \varepsilon / \mathrm{dt}$. Igualando-as obtêm-se o valor de $\log \mathrm{d} \varepsilon / \mathrm{dt}$ correspondente ao ponto de intersecção das duas retas. Substituindo esse valor em uma das equações acima determina-se-se o valor de $\sigma_{\mathrm{c}}$.

\section{CONFECÇÃO DO RELATÓRIO DOS RESULTADOS}

Os resultados devem ser apresentados da seguinte forma:

_ Tabela de dados: de/dt, log d $\varepsilon / \mathrm{dt}, \sigma_{\mathrm{y}}$ e $\sigma_{\mathrm{dr}}$ (Vide Apêndice A);

_ Gráfico contendo as curvas $\sigma_{\mathrm{y}} \mathrm{x} \log \mathrm{d} \varepsilon / \mathrm{dt}$ e $\sigma_{\mathrm{dr}} \mathrm{x} \log \mathrm{d} \varepsilon / \mathrm{dt}$ e as correspondentes equações das retas (Vide Seção 3.1.3);

_ Destaque de $\sigma_{c}$.

\subsection{2 - Curvas carga $x$ deslocamento do "ramp test"}

As curvas carga $\mathrm{x}$ deslocamento de todos os materiais testados, nas velocidades indicadas na Tabela 1, apresentaram o comportamento esperado, típico dos polímeros parcialmente cristalinos dúcteis, conforme Figura 18. 


\subsection{3 - Resultados do "ramp test"}

Os resultados do "ramp test" serão apresentados para todos os materiais, na forma de curvas limite de escoamento x logaritmo da taxa de deformação $\left(\sigma_{\mathrm{y}} \mathrm{x} \log \right.$ $\mathrm{d} \varepsilon / \mathrm{dt})$ e tensão de estiramento $\mathrm{x}$ logaritmo da taxa de deformação $\left(\sigma_{\mathrm{dr}} \mathrm{x} \log \mathrm{d} \varepsilon / \mathrm{dt}\right)$, seguidas da indicação da tensão crítica $\left(\sigma_{c}\right)$, que corresponde à intersecção das duas retas. Os gráficos apresentam ainda a equação das retas. Em cada caso segue-se uma discussão dos valores de $\sigma_{\mathrm{c}}$ em relação às respectivas curvas de regressão fornecidas pelos fabricantes das resinas, exceto para a resina JV 060U para a qual não há "curva de regressão" disponível e para a resina BS 002, que não foi analisada.

As tabelas com os dados dos ensaios são apresentadas no Apêndice A. 


\subsubsection{1 - GM 5010 T 2}

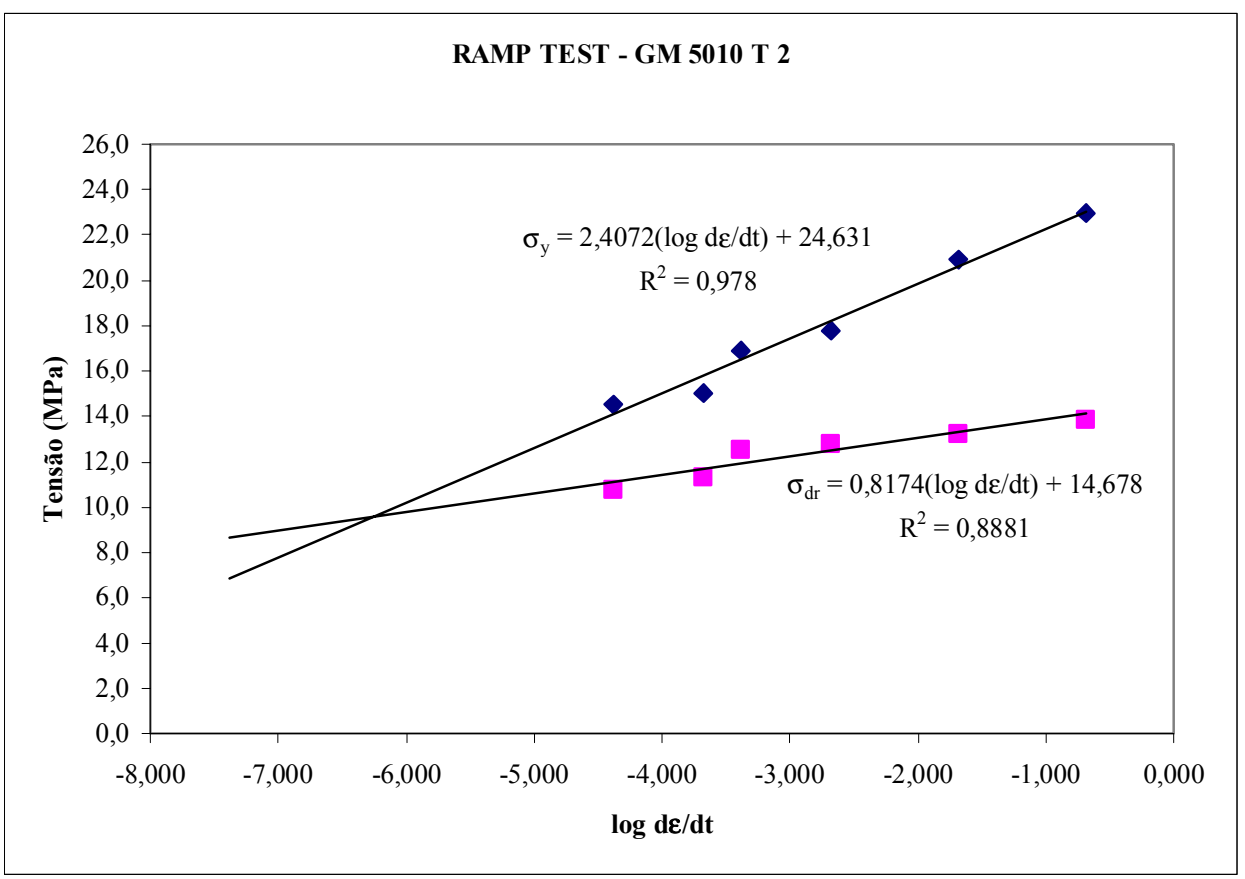

Figura 25 - Gráfico do "ramp test" da resina GM 5010 T 2

$\sigma_{\mathrm{C}}=9,6 \mathrm{MPa}$

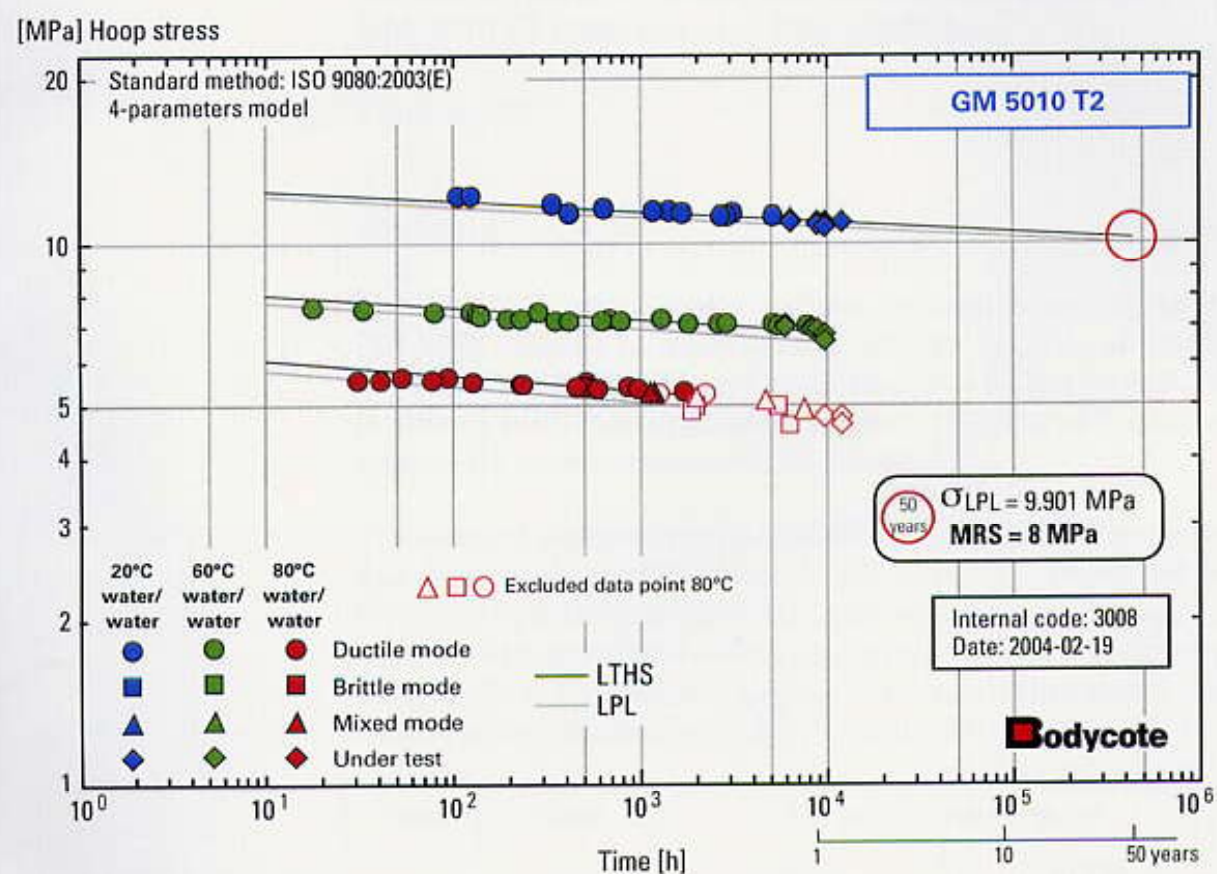

Figura 26 - "Curva de regressão" da resina GM 5010 T2 
Na Figura 26 não se observa inflexão na curva a $20^{\circ} \mathrm{C}$ até 50 anos, enquanto que o "ramp test" estima a tensão crítica em 9,6 MPa. O valor de $\sigma_{\mathrm{c}}$ estimado está bastante coerente com as posições da "curva de regressão", especialmente considerando o período de vida útil estimado para os tubos de polietileno - 50 anos. Ou seja, no nível de tensão crítica estimada a transição dúctil-frágil deverá ocorrer após 50 anos, de forma que o valor de MRS $=8 \mathrm{MPa}$ (LTHS/LCL $=9,9 \mathrm{MPa}$ ) extraído da curva por extrapolação é bastante confiável. Neste caso, há concordância entre a "curva de regressão" e o valor de $\sigma_{c}$ estimado pelo "ramp test". 


\section{$\underline{\text { 3.1.3.2 - RIGIDEX PC002-50R968 }}$}

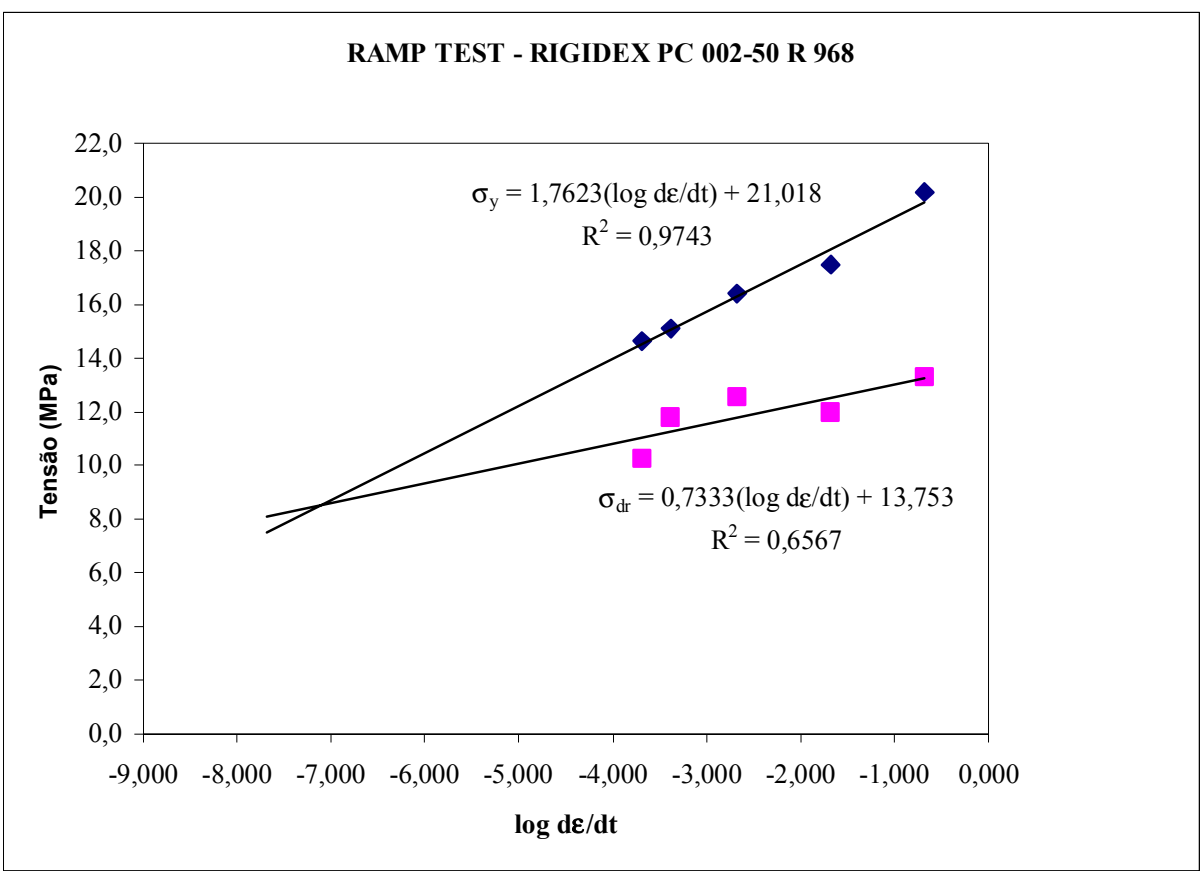

Figura 27 - Gráfico do "ramp test" da resina Rigidex PC002-50R968

$$
\sigma_{\mathrm{C}}=8,6 \mathrm{MPa}
$$

RIGIDEX BLUE MDPE

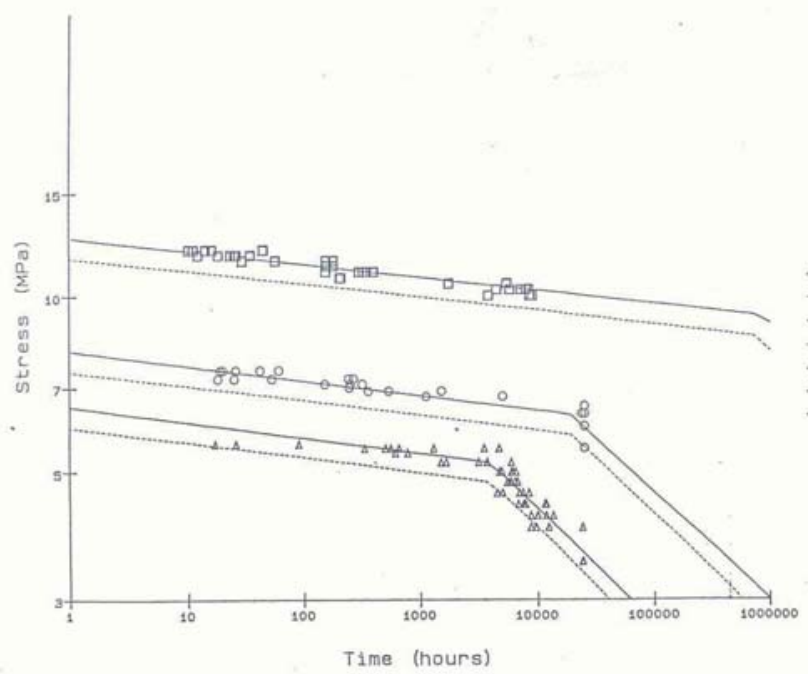

ㅁ Temperature $=20$ deg $\mathrm{C}$. Temperature $=60$ deg $\mathrm{C}$. Temperature $=80 \mathrm{deg} \mathrm{C}$

Time $=50$ years.
Temperature $=20 \mathrm{deg} C$.

(97.5\% L.C.L.)

Temperature $=60$ deg $\mathrm{C}$.

(97.5\% L.C.L.)

Temperature $=80 \mathrm{deg} \mathrm{C}$

ISO DP9080 SEM 5OYA LTHS $-9.38 \mathrm{MPa}$
LCL $-8.64 \mathrm{MPa}$

Figura 28 - “Curva de regressão" da resina Rigidex PC 002-50R968 
Na Figura 28 observa-se que o nível de tensão correspondente à inflexão na “curva de regressão" $\left(20^{\circ}\right)$ praticamente coincide com a tensão crítica estimada pelo "ramp test" e que o valor de $\sigma_{\mathrm{c}}$ estimado iguala-se ao valor de LTHS/LCL extraído da curva por extrapolação. Pode-se dizer com relativa segurança que a transição dúctil-frágil neste nível de tensão ocorre após 50 anos nos ensaios padronizados de resistência à pressão hidrostática interna de longa duração. Neste caso, há notável concordância entre a "curva de regressão" e o valor de $\sigma_{\mathrm{c}}$ estimado pelo "ramp test". 


\subsubsection{3 - MDPE 8818}

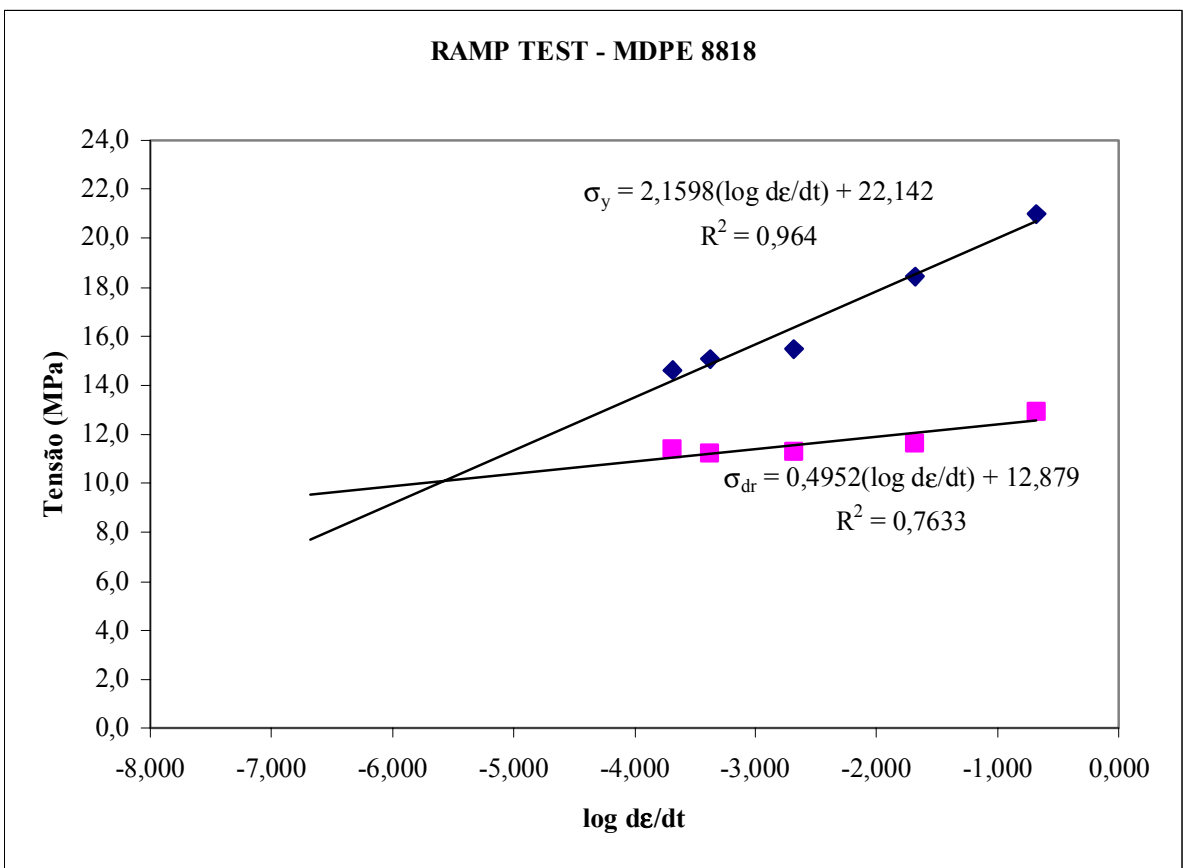

Figura 29 - Gráfico do "ramp test" da resina MDPE 8818

$$
\sigma_{\mathrm{C}}=10,1 \mathrm{MPa}
$$

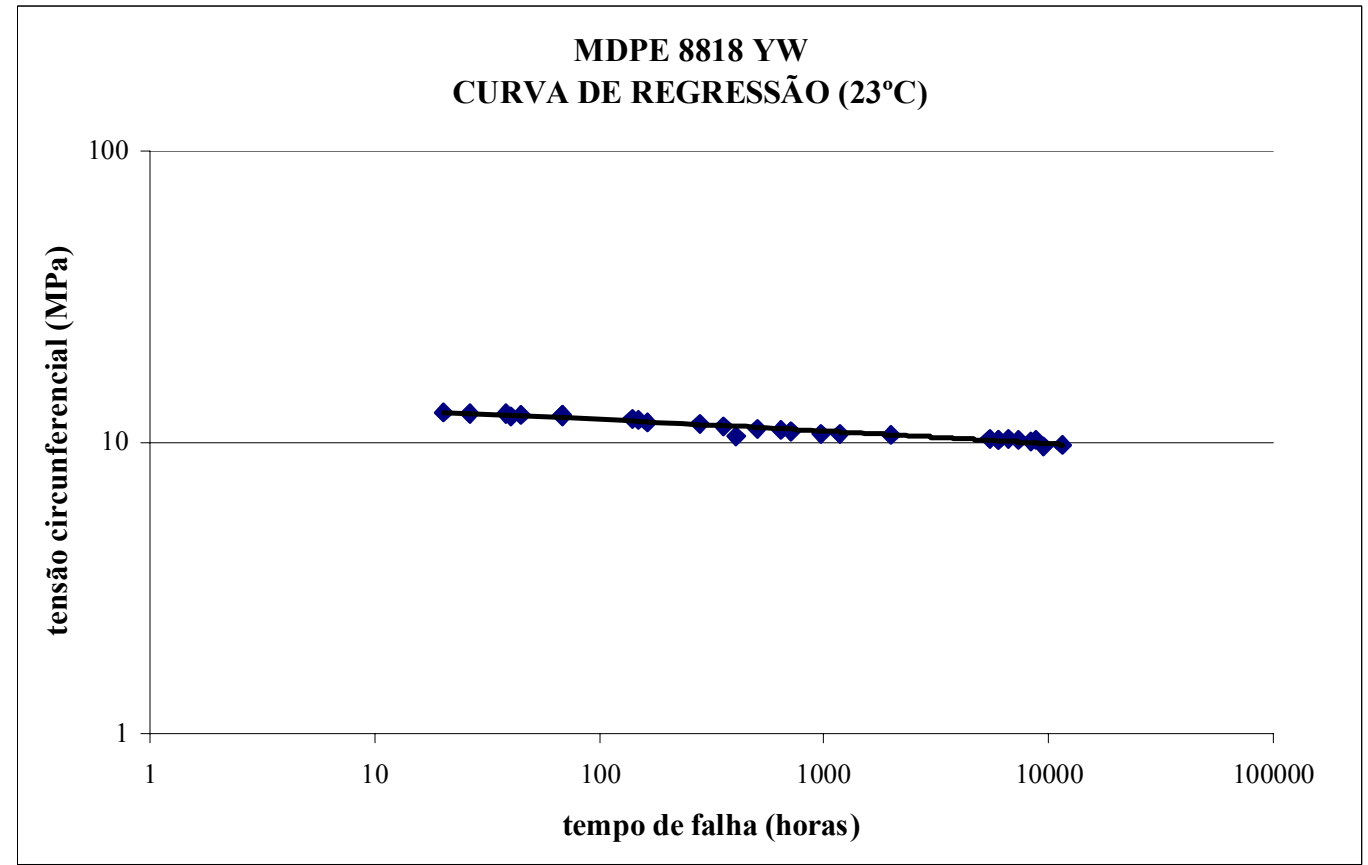

Figura 30 - "Curva de regressão" da resina MDPE 8818 YW. . A Figura é uma adaptação extraída do relatório fornecido à PBBPolisur S.A. pela Gastec N.V. - The Netherlands, referente ao material indicado na curva de regressão. 
Primeiramente deve-se observar com atenção que a "curva de regressão" fornecida pelo fabricante (Figura 30) é a de um composto da resina MDPE $8818 \mathrm{com}$ cor amarela, portanto contendo carga (no caso o pigmento), enquanto que o material testado foi um composto sem pigmentos. As partículas de pigmento podem desempenhar decisivo papel na fase de nucleação de trincas do processo de fratura por representarem pontos de concentração de tensões, podendo ter como efeito a redução das tensões de falha e/ou dos tempos de falha. É com essa ressalva que a análise da tensão crítica estimada pelo "ramp test" para o material in natura será desenvolvida.

O valor da tensão crítica da transição dúctil-frágil estimada pelo "ramp test" praticamente coincide com o nível de tensão nos limites de tempo de duração dos ensaios da "curva de regressão" - aproximadamente 10.000 horas na Figura 30. Segundo o relatório do laboratório as falhas observadas até 10.000 horas foram do tipo dúctil, tendo-se assumido o mesmo comportamento até o tempo de 438.000 horas ( $\cong 50$ anos). Sugere-se cautela na extrapolação dos dados além de 10.000 horas, ao assumir-se que a curva mantém o comportamento linear, sem inflexão, até 50 anos, porque não há dados disponíveis suficientes para oferecer segurança para tal procedimento. Por outro lado, supondo-se válido para o composto amarelo o valor de $\sigma_{\mathrm{c}}$ estimado pelo "ramp test" para o composto sem pigmento, a classificação do material na forma de tubos seria certamente inferior a PE 80 (MRS $<8 \mathrm{MPa}$ ). Observadas as considerações sobre o pigmento, pode-se supor que a "curva de regressão" do composto MDPE 8818 testado (sem pigmento) poderia estar deslocada para cima (maiores níveis de tensão) e para a direita (maiores tempos de falha) em relação à curva da Figura 30 . Neste caso, o valor de $\sigma_{\mathrm{c}}$ estimado pelo método - 10,1 MPa poderia estar bem situado e concordante com a "curva de regressão". Esta suposição somente poderia confirmar-se mediante a feitura de uma "curva de regressão" completa do composto sem pigmento. Dessa forma, fica prejudicada a verificação da concordância do resultado do "ramp test" com a "curva de regressão" fornecida. 


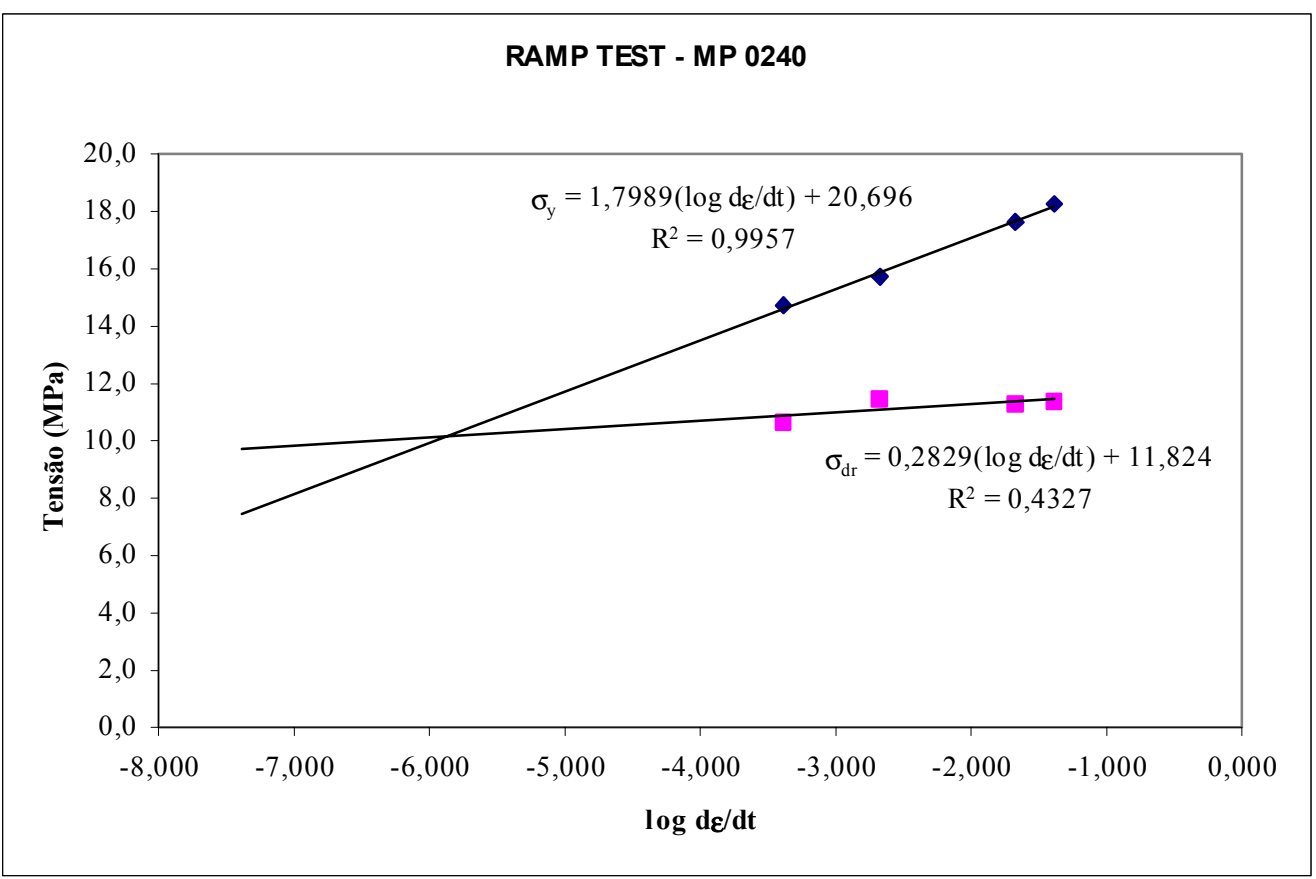

Figura 31 - Gráfico do "ramp test" da resina MP 0240

$$
\sigma_{\mathrm{C}}=10,1 \mathrm{MPa}
$$

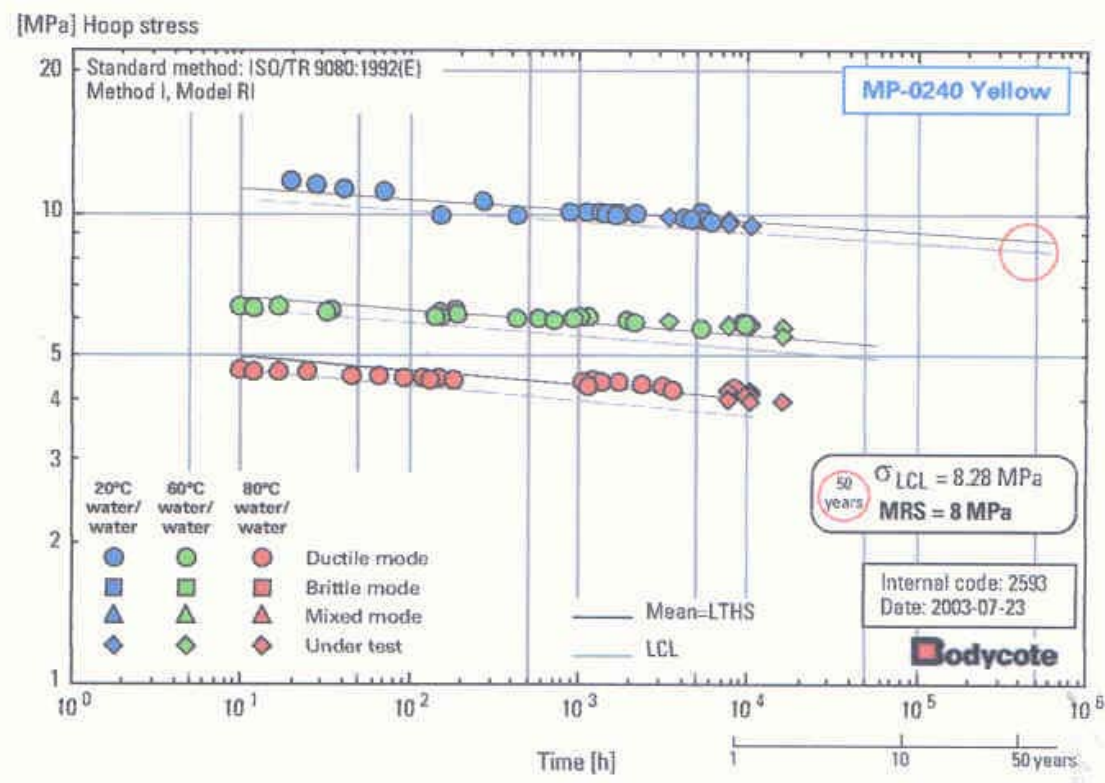

Figura 32 - “Curva de regressão" da resina MP-0240 Yellow 
A análise é a mesma do item anterior (MDPE 8818). Pode-se observar que a "curva de regressão" apresentada na Figura 32 é muito próxima da Figura 30, sendo que os valores de LTHS/LCL dos materiais extraídos das curvas - 8,28 MPa e 8,03 $\mathrm{MPa}$, respectivamente - são praticamente iguais. É oportuno ressalvar que no primeiro caso a curva correspondente à temperatura ambiente é a $20^{\circ} \mathrm{C}$ enquanto que no segundo é a $23^{\circ} \mathrm{C}$. Os valores de tensão crítica, $\sigma_{\mathrm{c}}$, estimados pelo "ramp test" para os dois compostos são também coincidentes - 10,1 MPa. Tratam-se evidentemente de materiais concorrentes na mesma aplicação (tubos amarelos), salientando-se que a resina MP 0240 é ainda, segundo o fabricante, uma resina experimental. 
$\underline{3.1 .3 .5 ~-~ H P ~} 0155$

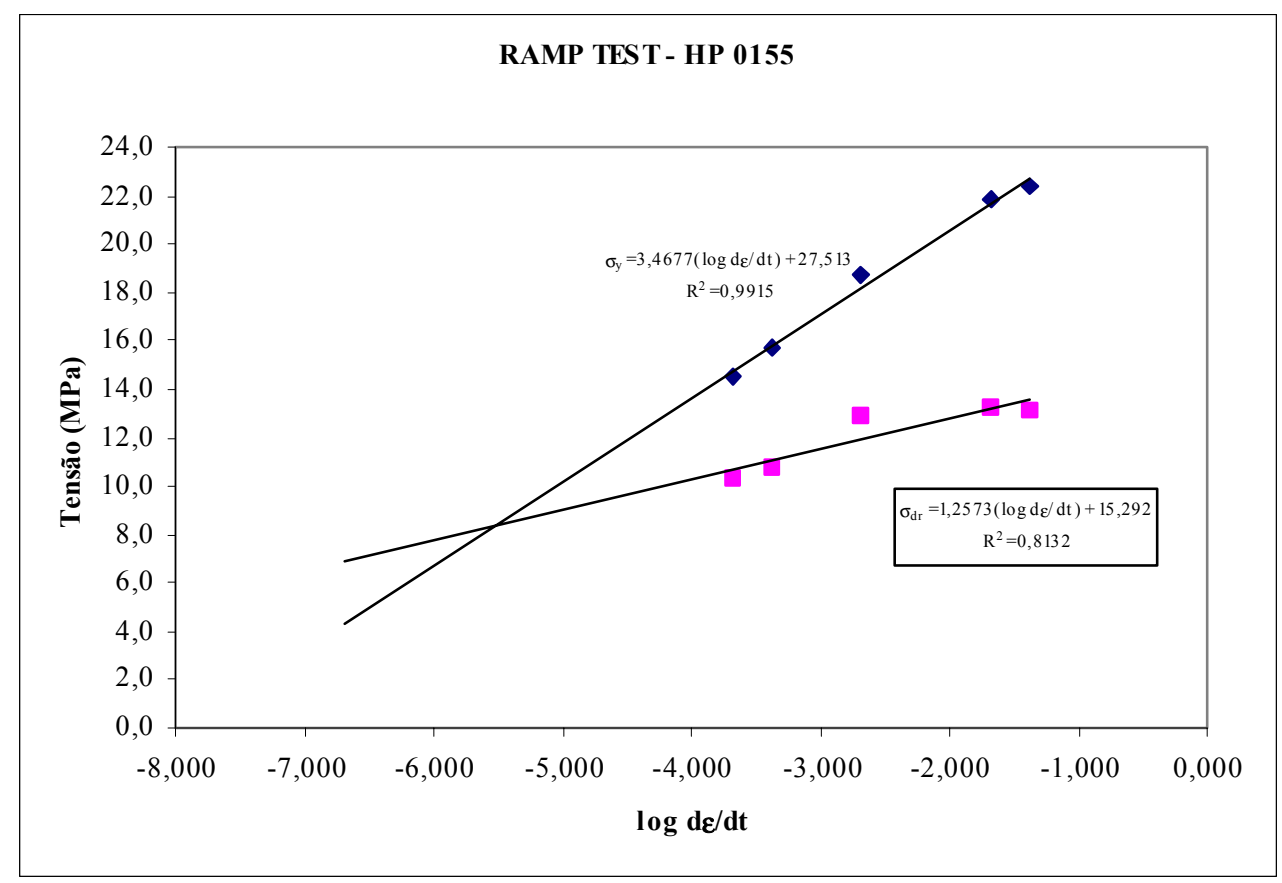

Figura 33 - Gráfico do "ramp test" da resina HP 0155

$$
\sigma_{\mathrm{C}}=8,3 \mathrm{MPa}
$$

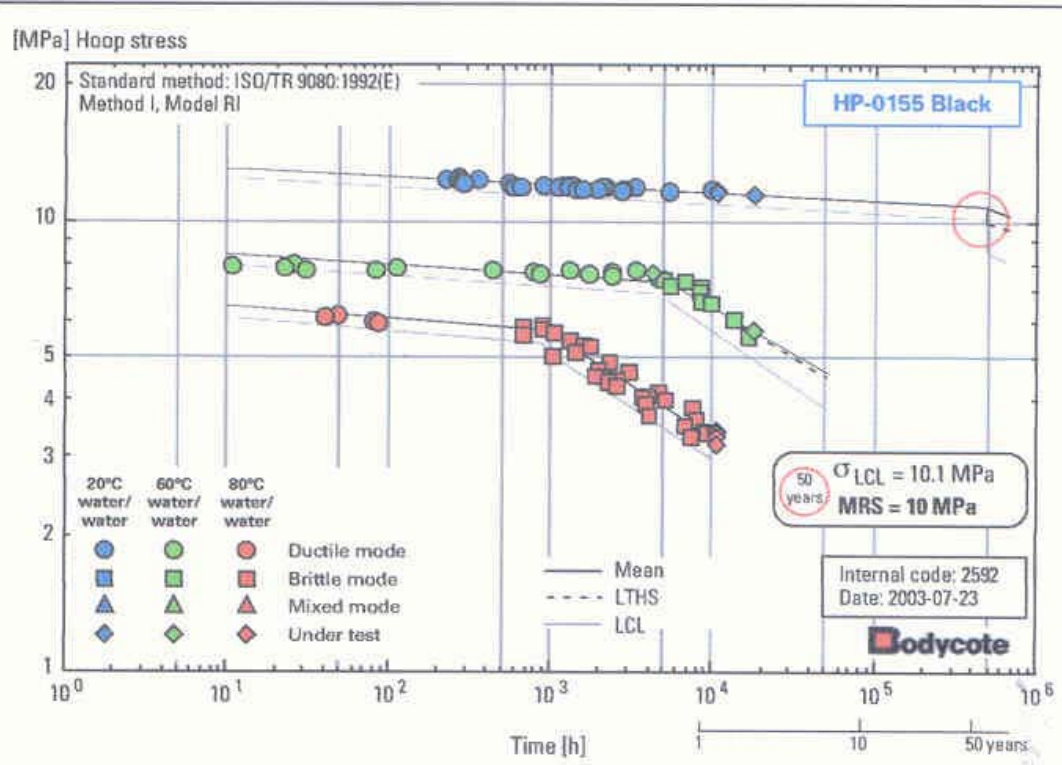

Figura 34 - "Curva de regressão" da resina HP-0155 Black 
Também neste caso é necessário observar primeiramente que o composto da “curva de regressão" (Figura 34) é de um composto na cor preta, portanto contendo pigmento (negro-de-fumo), enquanto que o material testado foi um composto sem pigmentos. O negro-de-fumo possui partículas muito pequenas e, ao menos em borrachas, aumenta a resistência à tração do composto (FISHER, 1978). Lembrando que a tensão circunferencial é uma tensão de tração é possível que o reforço proporcionado pelo negro-de-fumo eleve a posição da "curva de regressão" à temperatura ambiente (maiores tensões). Por outro lado, o composto HP 0155 Black apresenta aparentemente uma maior propensão à falha do modo frágil, demonstrada pelo comportamento das curvas a $60^{\circ} \mathrm{C}$ e $80^{\circ} \mathrm{C}$ - compare com a Figura 32, de uma resina do mesmo fabricante. Considerando-se a curva a $20^{\circ} \mathrm{C}$ da Figura 34 , de acordo com a tensão crítica estimada pelo "ramp test" - 8,3 $\mathrm{MPa}$, a transição dúctil-frágil ocorreria bem além de $10^{6}$ horas, pela projeção da curva. Entretanto os resultados dos ensaios de LTHS aparentemente sugerem uma transição justamente em torno de 50 anos - observe uma ligeira inclinação no final da reta - a uma tensão de $11 \mathrm{MPa}$. Evidentemente a correlação entre a tensão crítica estimada pelo "ramp test" para um composto sem pigmento e a "curva de regressão" do composto com negro-de-fumo fica prejudicada. É necessário produzir uma "curva de regressão" do composto sem pigmento ou realizar o "ramp test" na resina com negro-de-fumo, sendo que este material não estava disponível neste trabalho. Por fim, é necessário considerar ainda que segundo o fabricante a resina HP 0155 é um composto experimental. 


\subsubsection{6 - JV060U}

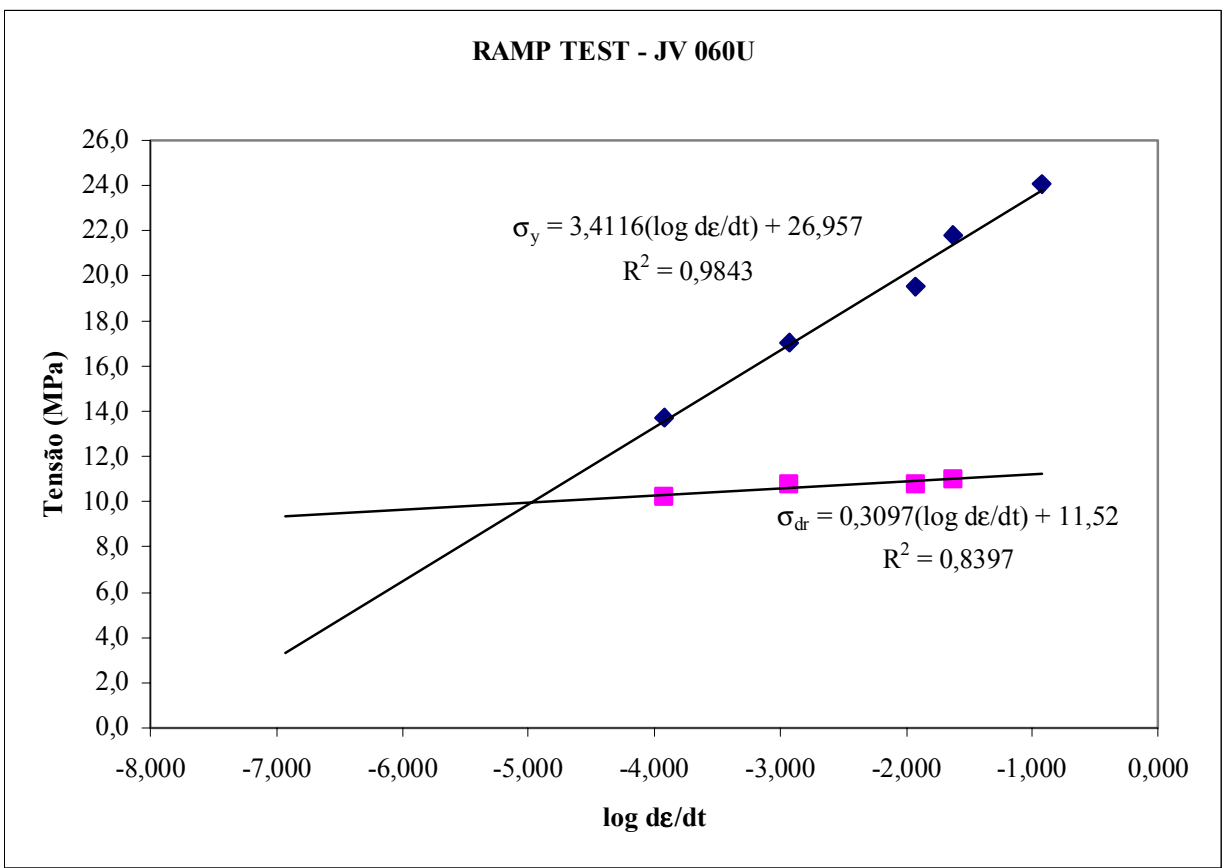

Figura 35 - Gráfico do "ramp test" da resina JV 060U

$\sigma_{\mathrm{C}}=10,0 \mathrm{MPa}$

A resina JV 060U não dispõe de curva de regressão. Ela não foi concebida para fabricação de tubos, mas sim para a fabricação de produtos injetados. De qualquer forma, o ramp test permitiu obter uma tensão crítica em torno da qual ocorreria a transição dúctil-frágil observada em uma eventual curva de regressão 10,0 MPa, da mesma ordem de grandeza das resinas MD8818 e MP 0240. Analisada isoladamente essa quantidade tem pouco significado prático. Embora o fabricante não tenha fornecido maiores detalhes estruturais do polímero, além deste ser um copolímero monomodal, pode-se presumir que se trata de um composto que, em virtude de sua aplicação, é concebido para oferecer alta resistência mecânica a curta duração em prejuízo do comportamento mecânico em fluência, enquanto que a arquitetura molecular das resinas projetadas para a fabricação de tubos de pressão é tal que proporcione alta resistência à fluência. Dessa forma, duas resinas com o mesmo valor de $\sigma_{\mathrm{c}}$, mas concebidas para aplicações diferentes poderão apresentar diferentes tempos para a transição dúctil-frágil, conforme ilustrado na Figura 36. 


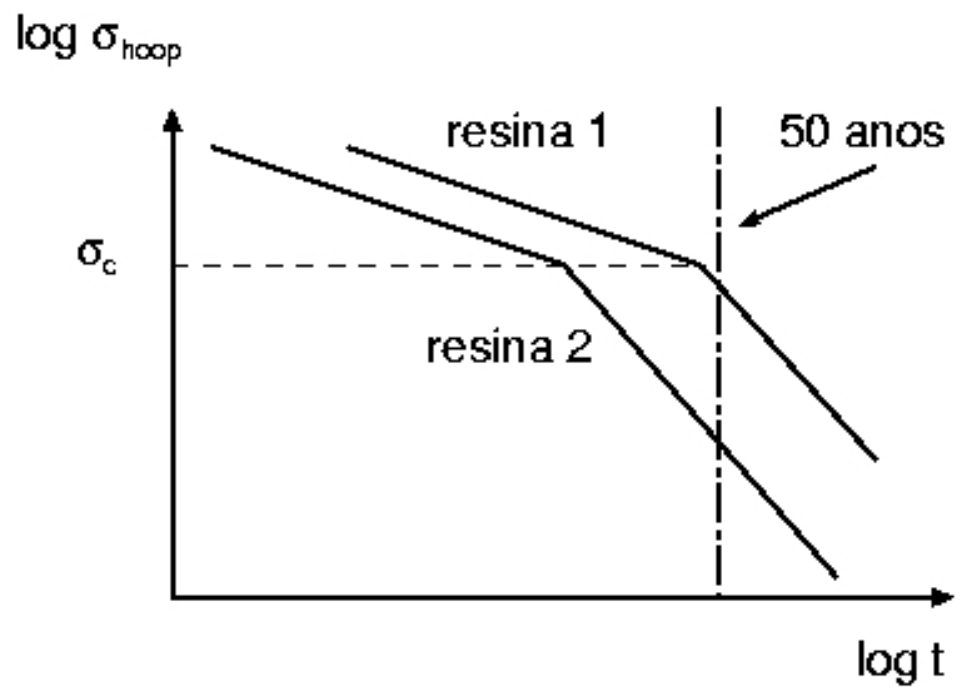

Figura 36 - Esquema de comparação entre duas resinas diferentes com o mesmo valor de $\sigma_{c}$ mas com diferentes tempos de transição dúctil-frágil

\subsection{4 - Resumo dos resultados do "ramp test"}

Tabela 2: Resumo dos resultados do "ramp test"

\begin{tabular}{|c|c|c|}
\hline RESINA & $\sigma_{\mathbf{c}}$ (MPa) & $\begin{array}{c}\text { CONCORDÂNCIA } \\
\text { COM A “CURVA DE } \\
\text { REGRESSÃO” }\end{array}$ \\
\hline GM5010T2 & 9,6 & SIM \\
\hline RIGIDEX PC002-50R968 & 8,6 & SIM \\
\hline MDPE 8818 & 10,1 & Parcialmente prejudicada $^{*}$ \\
\hline HP 0155 & 8,3 & Parcialmente prejudicada $^{*}$ \\
\hline MP 0240 & 10,1 & Parcialmente Prejudicada $^{*}$ \\
\hline JV060U & 10,0 & Prejudicada $^{* *}$ \\
\hline
\end{tabular}

* Curvas de regressão fornecidas pelos fabricantes elaboradas a partir de compostos contendo pigmentos, enquanto que os compostos testados não continham cargas.

** O material não dispõe de "curva de regressão".

Para dois dos mais tradicionais compostos de polietileno empregados na fabricação de tubos de pressão para sistemas de distribuição de água o método de 
"ramp test" mostrou-se bastante coerente e confiável, fornecendo resultados de $\sigma_{\mathrm{c}}$ concordantes com as respectivas curvas de regressão.

Para os demais materiais houve prejuízo na comparação entre os valores de tensão crítica, $\sigma_{\mathrm{c}}$, estimados pelo método do "ramp test" e as curvas de regressão porque ou as curvas foram obtidas a partir de compostos diferentes em relação àqueles que foram testados, embora baseados na mesma resina original, ou simplesmente não havia "curva de regressão" disponível.

\section{2 - Trabalho essencial de fratura - EWF}

\subsection{1 - Método do trabalho essencial de fratura}

PRINCÍPIO E UTILIDADE DO MÉTODO

O método proposto é baseado no protocolo proposto pelo Comitê Técnico 4 da Sociedade Européia de Integridade Estrutural (Technical Committee 4 of the European Structural Integrity Society - ESIS), conforme Clutton (2001).

O princípio do método é obter curvas carga $(\mathrm{P}) \mathrm{x}$ deslocamento $(\Delta)$ em tração e a partir delas calcular o trabalho (energia) de fratura, $\mathrm{W}_{\mathrm{f}}$, de uma série de corpos de prova padronizados. Desde que tenha se desenvolvido o pleno escoamento na região do ligamento, é possível separar o trabalho de fratura em duas componentes: o trabalho essencial de fratura e o trabalho não essencial de fratura. $\mathrm{W}_{\mathrm{f}}$ pode ser expressa da seguinte forma:

$$
W_{f}=\int P d \Delta=w_{e} l t+\beta w_{p} l^{2} t
$$

onde 1 é o comprimento do ligamento do ligamento (vide Figura 37) e t é a espessura do corpo de prova. O trabalho específico de fratura, $\mathrm{w}_{\mathrm{f}}$ (por unidade de seção transversal) é então expresso pela Equação 9, que é a expressão de uma reta.

A partir da equação das retas $\mathrm{w}_{\mathrm{f}} \mathrm{x} 1$ podem ser obtidos os valores do trabalho essencial de fratura, $\mathrm{w}_{\mathrm{e}}$, que corresponde ao intercepto com o eixo das ordenadas e de $\beta \mathrm{w}_{\mathrm{p}}$, que corresponde à inclinação da reta. 
O esquema do método é ilustrado na Figura 23.

O método pode revelar importantes dados sobre a resistência do material ao crescimento lento de trincas, o que não é possível na abordagem comum da "curva de regressão”. A parte essencial do trabalho de fratura está relacionada com a zona de processo (ou seja, em princípio com o avanço do processo de crazing), enquanto que a parte não essencial está relacionada com a deformação plástica em torno da zona de processo e seria, portanto, sensível à transição dúctil-frágil.

\section{CORPOS DE PROVA}

Recomenda-se o uso de corpos de prova com a geometria DENT (double edge notched tension), conforme esquema ilustrado na Figura 23. Na impossibilidade de se introduzir os entalhes em "V", opção adotada no presente trabalho, pode-se adotar a geometria esquematizada na Figura 37 abaixo.
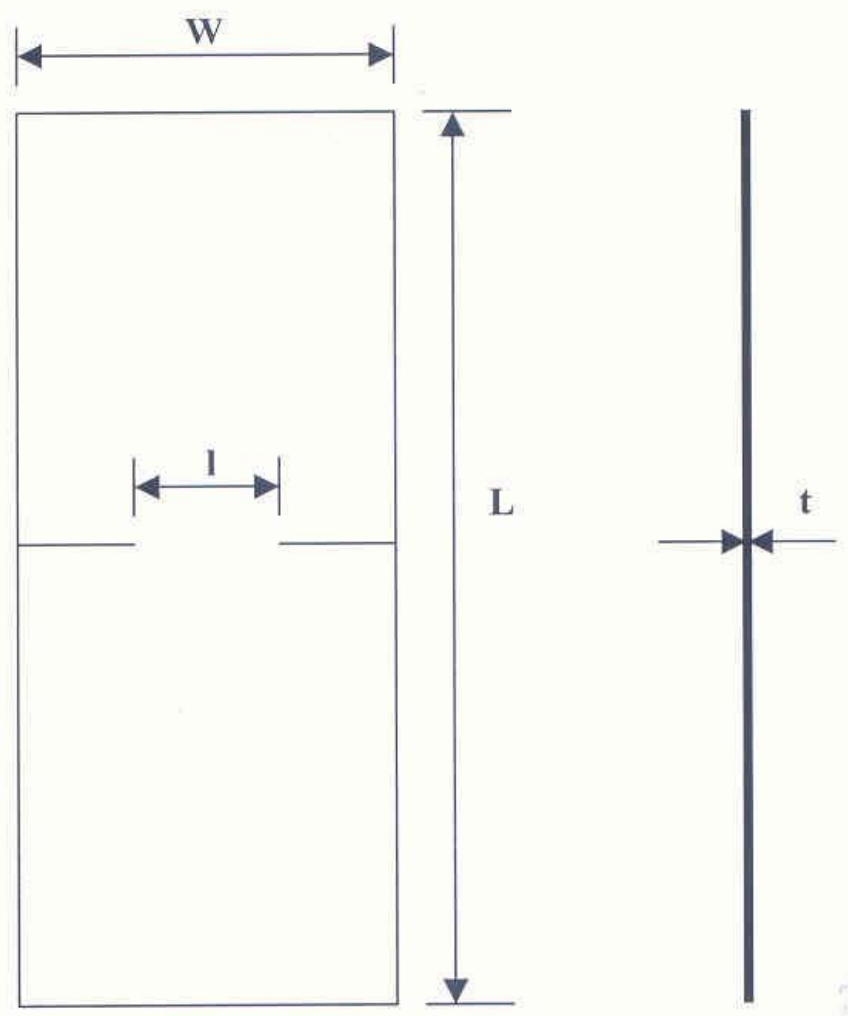

Figura 37: Corpo de prova para ensaio de EWF, sem entalhes em "V". Vista frontal (esquerda) e lateral (direita) 
Cortam-se inicialmente pedaços retangulares de largura $\mathrm{W}$ e comprimento $\mathrm{L}$ do material, que pode estar disponível a partir de chapas ou de filmes soprados, sendo a segunda opção a adotada neste trabalho.

Recomenda-se que a largura W seja pelo menos duas vezes o comprimento do maior ligamento adotado, mas isso depende da disponibilidade do material e das dimensões das garras da máquina de ensaio.

O comprimento L inclui o comprimento útil do corpo de prova e a distância requerida para fixação às garras da máquina. $\mathrm{O}$ comprimento útil do corpo de prova não é uma quantidade crítica, de forma que um comprimento total $\mathrm{L}$ de $130 \mathrm{~mm}$ mostrou-se adequado. Deve-se ter o cuidado de observar a direção do eixo principal do corpo de prova em relação à direção de extrusão no caso de filmes obtidos por sopro, como os utilizados no presente trabalho.

Segundo Clutton (2001), a precisão do método aumenta com o número de corpos de prova, sugerindo-se um mínimo de 20 pontos válidos. Com a aplicação do critério da tensão alguns pontos podem ser perdidos. Dessa forma recomenda-se que sejam ensaiados pelo menos 30 corpos de prova para que se proporcione uma precisão razoável ao método.

O comprimento máximo do ligamento deve ser $15 \mathrm{~mm}$ enquanto que o mínimo ligamento deve ser o máximo entre $3 t$ e $5 \mathrm{~mm}$. Sugere-se dividir a faixa de variação do comprimento do ligamento em 5 classes e ensaiar pelo menos 6 corpos de prova com o comprimento de ligamento nominal de cada classe.

\section{PRÉ-TRINCAS / LIGAMENTO}

As pré-trincas, no caso do tipo de material estudado neste trabalho, podem ser introduzidas utilizando-se uma lâmina de aço com a ponta afiada, por exemplo um estilete pontiagudo. As duas pré-trincas devem ser alinhadas, perpendiculares ao eixo principal do corpo de prova e de igual comprimento. Instrumentos como uma régua de aço com divisões de $0,1 \mathrm{~mm}$ e uma lupa podem ser muito úteis.

A princípio seria ideal garantir que a ponta das trincas fossem suficientemente agudas. Entretanto, observou-se durante os ensaios dos materiais estudados que as 
pontas das trincas arredondavam significativamente, da ordem de milímetros. Dessa forma, no caso desses materiais, uma discussão maior sobre o rigor da precisão da ponta trinca torna-se irrelevante. As Figuras 38 e 39 ilustram a questão, através de imagens das pontas das trincas obtidas em microscópio eletrônico de varredura MEV e por fotografia durante o ensaio, respectivamente.
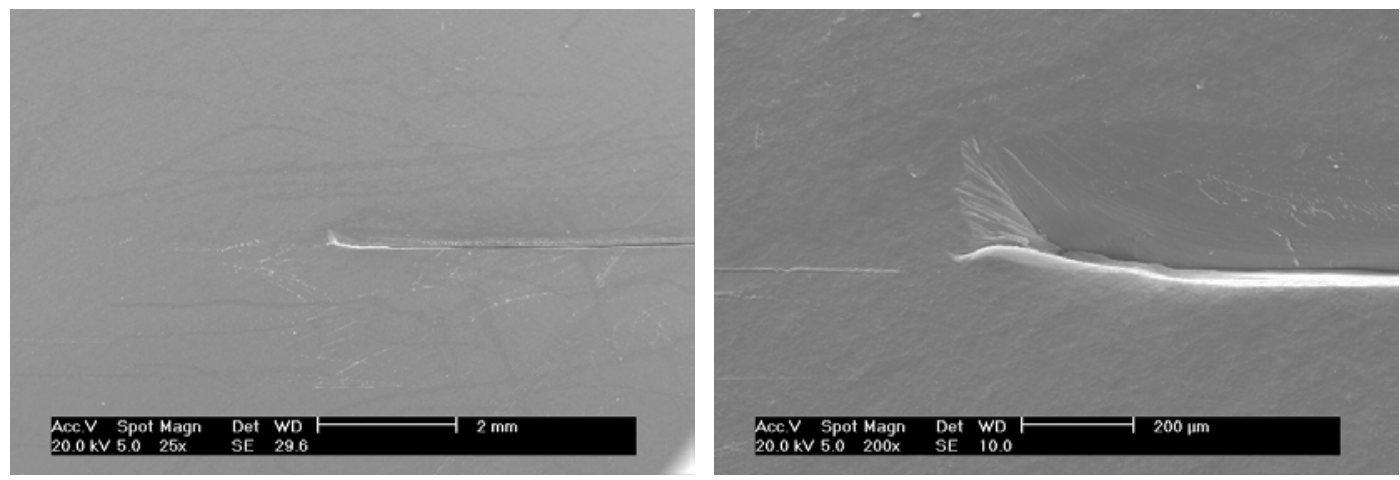

Figura 38: Imagens obtidas por MEV da ponta da trinca de corpos de prova de EWF

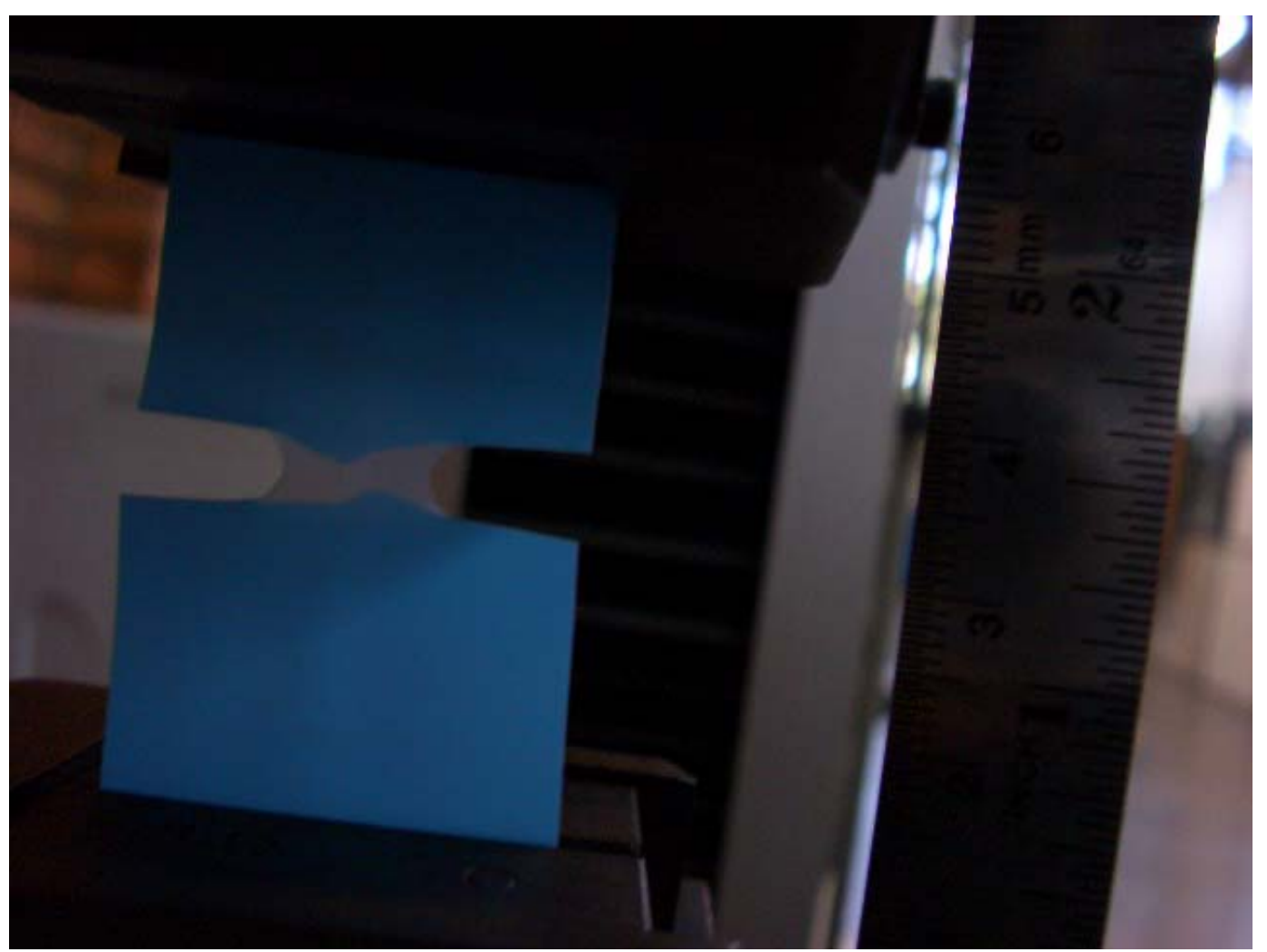

Figura 39: Fotografia da ponta da trinca durante ensaio de EWF 
TEMPERATURA

As propriedades mecânicas dos polímeros são em geral muito influenciadas pela temperatura. Dessa forma, os corpos de prova devem ser pré-condicionados e os ensaios realizados em sala com temperatura e umidade controladas, registrando-se esses dados no relatório.

\section{MEDIDA DAS DIMENSÕES DOS CORPOS DE PROVA}

O comprimento do ligamento do corpo de prova deveria ser medido com auxílio de um microscópio ótico viajante. Na falta desse equipamento pode-se usar um paquímetro com precisão de pelo menos $0,1 \mathrm{~mm}$, com auxílio de uma lente de aumento ou lupa.

Por outro lado, a espessura dos corpos de prova ao longo do ligamento deve ser realizada com cuidado no caso de filmes finos. Um micrômetro com precisão mínima de 0,01 $\mathrm{mm}$ deve ser empregado. $\mathrm{O}$ uso de um instrumento de medição menos preciso pode influenciar os resultados, como será discutido na Seção 3.2.3.1.

\section{MÁQUINA DE ENSAIO}

Os ensaios podem ser realizados em qualquer máquina universal de ensaios mecânicos, devidamente calibrada, que disponha de uma célula de carga com capacidade compatível com os níveis de força atingidos durante o ensaio e que disponha dos acessórios necessários para a captura dos dados de carga e de deslocamento.

\section{VELOCIDADE DE ENSAIO}

Deve ser dada atenção especial à velocidade do ensaio porque as propriedades dos polímeros dependem da taxa de deformação. A velocidade adotada deve ser rápida para tornar o método prático, mas suficientemente lenta para permitir o 
escoamento total do maior ligamento antes do avanço da trinca. O protocolo ESIS sugere que a velocidade de ensaio, em $\mathrm{mm} / \mathrm{min}$, seja numericamente igual a $20 \%$ do comprimento útil do corpo de prova. A velocidade de $5 \mathrm{~mm} / \mathrm{min}$ adotada nos ensaios deste trabalho proporcionou bom comportamento de todos os corpos de prova.

\section{CRITÉRIO DE TENSÃO}

Segundo Clutton (2001) é útil aplicar um critério de tensão aos máximos valores de tensão do método EWF de forma a garantir uma maior probabilidade de ocorrência da fratura sob estado plano de tensão e excluir dados onde a fratura pode ter ocorrido antes do total escoamento do ligamento.

Recomenda-se o seguinte procedimento: para cada série determina-se o valor médio $\left(\sigma_{\mathrm{m}}\right)$ das máximas tensões nos ligamentos $\left(\sigma_{\max }\right)$, excluindo-se os pontos para os quais $\sigma_{\max }>1,1 \sigma_{\mathrm{m}}$ ou $\sigma_{\max }<0,9 \sigma_{\mathrm{m}}$. Segundo Clutton (2201) o limite de $10 \% \sigma_{\mathrm{m}}$ para a faixa de validade é um tanto arbitrário, mas tem sido útil para os propósitos do critério.

\section{TRATAMENTO DOS DADOS}

Para cada corpo de prova, calcula-se a energia de fratura, $\mathrm{W}_{\mathrm{f}}$, a partir da área sob a curva carga x deslocamento, podendo ser aplicado o algoritmo do trapézio à tabela de dados (BARROS, 1972). Normalizam-se os valores de $\mathrm{W}_{\mathrm{f}}$ pela área da seção do ligamento (comprimento do ligamento x espessura do corpo de prova), obtendo-se os valores de trabalho específico, $\mathrm{w}_{\mathrm{f}}$, que devem ser plotados contra $\mathrm{o}$ comprimento do ligamento, 1. A reta do método EWF é obtida através de análise de regressão linear simples (mínimos quadrados) e a partir desta determinam-se os valores do trabalho essencial de fratura do material $\left(\mathrm{w}_{\mathrm{e}}\right)$ e do fator de dissipação de trabalho plástico $\left(\beta \mathrm{w}_{\mathrm{p}}\right)$, com os respectivos intervalos de predição com $95 \%$ de confiança (LEVINE et al, 2000). Os pontos situados além de duas vezes o desvio padrão, $S$, devem ser previamente eliminados antes dos cálculos finais de $w_{\mathrm{e}}$ e $\beta \mathrm{w}_{\mathrm{p}}$ sendo que o procedimento de rejeição de pontos deve ser aplicado uma única vez. 


\section{CONFECÇÃO DO RELATÓRIO DOS RESULTADOS}

Os resultados devem ser apresentados na forma de um relatório de ensaio contendo as seguintes informações:

_ Largura (W) e espessura (t) dos corpos de prova;

_ Velocidade e temperatura do ensaio;

_ Valores máximos e mínimos dos comprimentos dos ligamentos, 1;

_ Média das tensões máximas, $\sigma_{\mathrm{m}}$;

_ Valores de $\mathrm{w}_{\mathrm{e}}$ e $\beta \mathrm{w}_{\mathrm{p}}$ com os respectivos intervalos de predição, com 95\% de confiança;

_ Tabela de valores contendo espessura dos corpos de prova, comprimento dos ligamentos, $\sigma_{\max }, \mathrm{W}_{\mathrm{f}}$ e $\mathrm{w}_{\mathrm{f}}$, com indicação dos pontos excluídos e a razão da exclusão;

- Gráfico $\mathrm{w}_{\mathrm{f}}$ X 1 .

\subsection{2 - Curvas carga $x$ deslocamento do método EWF}

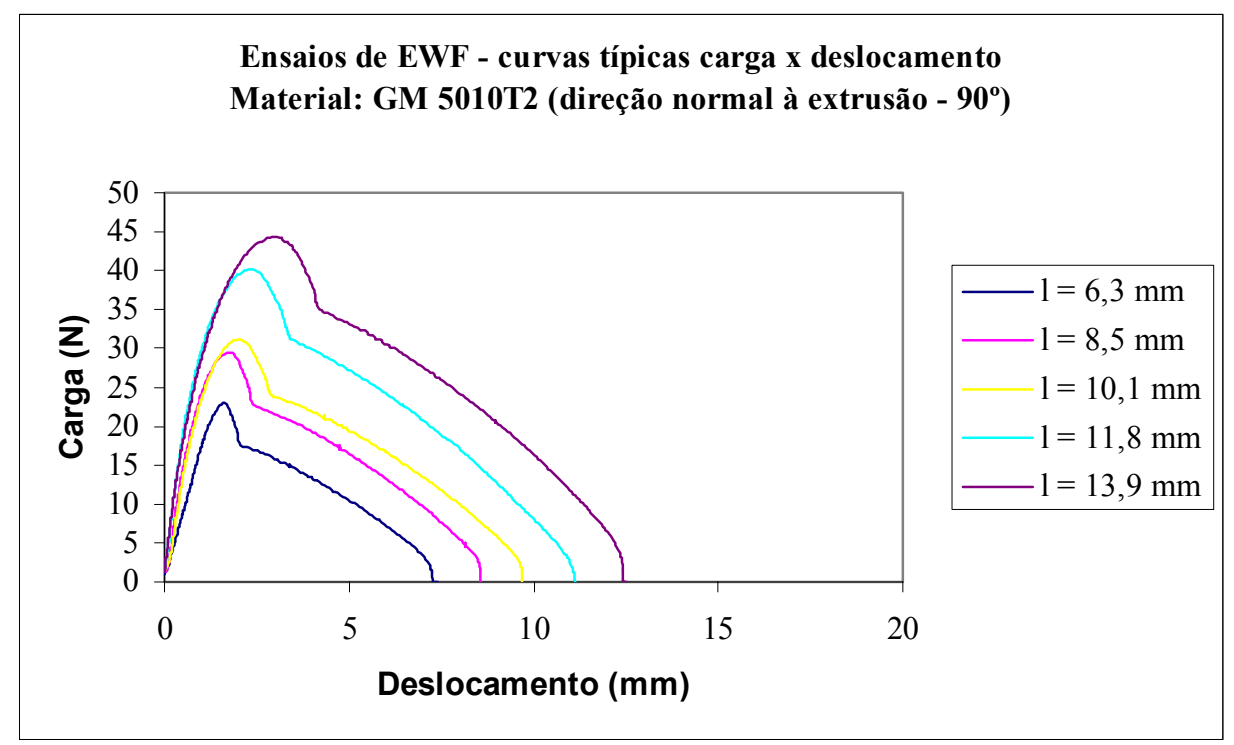

Figura 40: Conjunto de curvas típicas do método EWF (Resina GM 5010T2 - perpendicular à direção da extrusão). 


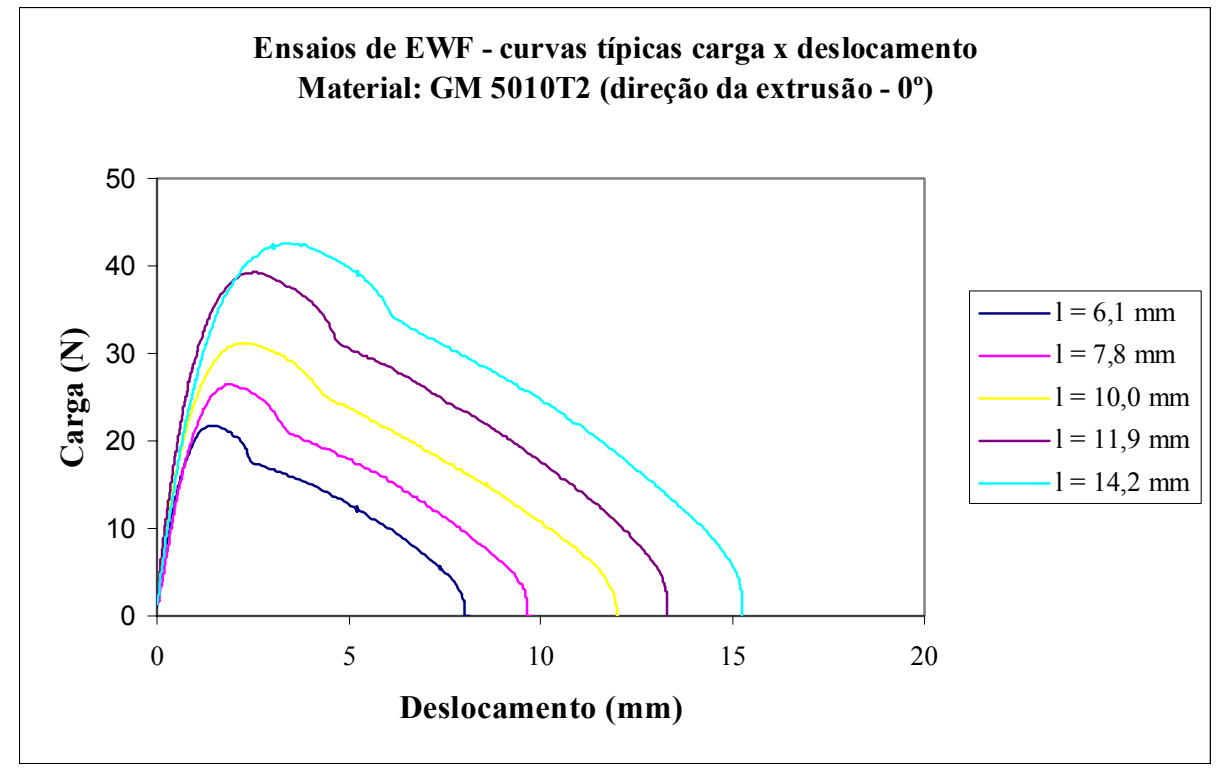

Figura 41: Conjunto de curvas típicas do método EWF (Resina GM 5010T2 - direção da extrusão).

As curvas carga $\mathrm{x}$ deslocamento nos ensaios de EWF conferem bastante com o comportamento esperado a partir da literatura (CLUTTON, 2001) e esquematizado na Figura 23. As Figuras 40 e 41 ilustram famílias de curvas típicas obtidas nos ensaios, com diferentes classes de comprimento de ligamento, em duas orientações dos corpos de prova: na direção perpendicular à direção de extrusão dos filmes (Figura 40) e na direção paralela à de extrusão (Figura 41). A diferença entre os resultados obtidos a partir de corpos de prova extraídos com a mesma orientação da extrusão dos filmes e de corpos de prova com orientação perpendicular à direção de extrusão será discutida na Seção 3.2.3.

\subsection{3 - Resultados do método EWF}

Os resultados do método EWF serão apresentados na forma de tabelas resumidas contendo as informações mais relevantes, juntamente com a discussão correspondente. Para o leitor interessado os relatórios dos ensaios, as tabelas de dados e as curvas do método são apresentadas no Apêndice B. 


\subsubsection{1 - Efeito da precisão da medida da espessura do corpo de prova}

Para a observação da relevância da precisão na medida da espessura dos corpos de prova foram escolhidos arbitrariamente os compostos MDPE 8818 eBS 002, cujos resultados são apresentados na Tabela 3.

Tabela 3: Resumo dos resultados de EWF com medições da espessura dos corpos de prova realizadas com paquímetro e com micrômetro

\begin{tabular}{|c|c|c|c|c|}
\hline RESINA & $\begin{array}{c}\text { MEDIÇÃO DA } \\
\text { ESPESSURA }\end{array}$ & $\begin{array}{c}\text { LIMITES DA } \\
\text { FAIXA DE } \\
\text { VALIDADE } \\
\text { DO CRITÉRIO } \\
\text { DE TENSÃO }\end{array}$ & $\begin{array}{c}\mathrm{w}_{\mathrm{e}} \\
\left(\mathrm{kJ} / \mathrm{m}^{2}\right)\end{array}$ & $\begin{array}{c}\beta \mathrm{w}_{\mathrm{p}} \\
\left(\mathrm{MJ} / \mathrm{m}^{3}\right)\end{array}$ \\
\hline MDPE 8818 & paquímetro & $10 \%$ & $34,0 \pm 11,9$ & $8,8 \pm 1,1$ \\
\hline MDPE 8818 & paquímetro & $11 \%$ & $34,8 \pm 12,6$ & $8,7 \pm 1,2$ \\
\hline MDPE 8818 & micrômetro & $10 \%$ & $37,6 \pm 7,6$ & $8,2 \pm 0,7$ \\
\hline MDPE 8818 & micrômetro & $11 \%$ & $37,6 \pm 7,6$ & $8,2 \pm 0,7$ \\
\hline BS 002 & paquímetro & $10 \%$ & $33,5 \pm 10,6$ & $8,1 \pm 1,0$ \\
\hline BS 002 & paquímetro & $11 \%$ & $36,7 \pm 11,8$ & $7,6 \pm 1,1$ \\
\hline BS 002 & micrômetro & $10 \%$ & $39,8 \pm 9,3$ & $7,3 \pm 0,8$ \\
\hline BS 002 & micrômetro & $11 \%$ & $40,6 \pm 8,7$ & $7,3 \pm 0,9$ \\
\hline
\end{tabular}

$\mathrm{Na}$ medição da espessura os valores foram anotados até centésimos de milímetro. Em função da precisão do paquímetro empregado (divisões de 0,02 mm), pode ter havido um erro de aproximação de até $0,01 \mathrm{~mm}$, ou seja, uma imprecisão máxima estimada em até $10 \%$ da espessura real. Essa incerteza pode ter pouca influência no cálculo do trabalho essencial de fratura "bruto", sem eliminação de pontos pelo critério de tensão, em comparação com cálculos executados a partir de medidas de espessura mais precisas, tomadas com um micrômetro com precisão de 0,01 mm. Entretanto, a precisão da medida da espessura mostrou-se relevante para o cálculo das máximas tensões observadas nos ensaios uma vez que a aplicação do 
critério de tensão pode eliminar pontos muito próximos dos limites da faixa de validade em torno da média das tensões máximas (10\% para mais ou para menos) vide, por exemplo as tabelas 15 e 17 do Anexo B. Dessa forma, após a eliminação de pontos pelo critério de tensão o valor de $\mathrm{w}_{\mathrm{e}}$ pode ser significativamente alterado. A solução possível foi expandir em 10\% os limites da faixa de validade do critério de tensão, ou seja, alterá-los de $10 \%$ para $11 \%$ para mais ou para menos. Como a faixa de $10 \%$ é até certo ponto arbitrária, conforme Clutton (2001), essa alteração não prejudica o método e previne a exclusão de pontos situados nos limites da faixa do critério de tensão em função do máximo erro estimado cometido na medição da espessura, reduzindo o erro nos cálculos do método EWF, como pode ser observado na Tabela 3.

Dessa forma, para uniformizar o tratamento dos resultados e prevenir possíveis prejuízos à análise dos demais materiais, cujos corpos de prova não foram medidos com micrômetro, os resultados finais do método EWF apresentados na próxima Seção contemplam a medição da espessura dos corpos de prova com paquímetro e limites de $11 \%$ para a faixa de validade do critério de tensão.

Entretanto, fica expressa a recomendação para que sejam utilizados no método EWF instrumentos de precisão para as medições das dimensões dos corpos de prova. 
3.2.3.2 - Resumo dos resultados do método EWF

Tabela 4: Resumo dos resultados de EWF

\begin{tabular}{|c|c|c|c|}
\hline RESINA & $\begin{array}{c}\text { DIREÇÃO DO CP EM } \\
\text { RELAÇÃO À DIREÇÃO } \\
\text { EXTRUSÃO }\end{array}$ & $\begin{array}{c}\mathrm{w}_{\mathrm{e}} \\
\left(\mathrm{kJ} / \mathrm{m}^{2}\right)\end{array}$ & $\begin{array}{c}\beta \mathrm{w}_{\mathrm{p}} \\
\left(\mathrm{MJ} / \mathrm{m}^{3}\right)\end{array}$ \\
\hline MDPE 8818 & $90^{\circ}$ & $34,8 \pm 12,6$ & $8,7 \pm 1,2$ \\
\hline BS 002 & $90^{\circ}$ & $36,7 \pm 11,8$ & $7,6 \pm 1,1$ \\
\hline RIGIDEX PC002-50R968 & $90^{\circ}$ & $37,6 \pm 15,4$ & $7,3 \pm 1,4$ \\
\hline MP 0240 & $90^{\circ}$ & $23,5 \pm 15,9$ & $9,4 \pm 1,5$ \\
\hline HP 0155 & $90^{\circ}$ & $34,4 \pm 9,8$ & $6,2 \pm 1,0$ \\
\hline GM5010T2 & $0^{\circ}$ & $30,1 \pm 12,0$ & $11,2 \pm 1,1$ \\
\hline GM5010T2 & $90^{\circ}$ & $30,2 \pm 7,1$ & $8,5 \pm 0,7$ \\
\hline
\end{tabular}

Obs: a) limites da faixa de validade do critério de tensão: $11 \% \sigma_{\mathrm{m}}$.

b) Instrumento de medição da espessura do corpo de prova: paquímetro

Os resultados do método são bastante dispersos, com reflexos no intervalo de predição ( $95 \%$ de confiança) do trabalho essencial de fratura, we, não permitindo a ordenação das resinas em termos desse parâmetro. Observa-se um valor mais reduzido de $\mathrm{w}_{\mathrm{e}}$ para a resina MP 0240 em relação às demais, cujos resultados são praticamente equivalentes.

Por outro lado, os trabalhos de Fayolle \& Verdu (2005) indicaram que o fator de dissipação de trabalho plástico, $\beta \mathrm{w}_{\mathrm{p}}$, é o parâmetro apropriado - mais apropriado do que $\mathrm{w}_{\mathrm{e}}$ - para se observar efeitos estruturais na tenacidade do polietileno. Esse parâmetro depende da velocidade de ensaio e provavelmente da geometria do corpo de prova, enquanto que os ensaios de EWF foram realizados a uma única velocidade - $5 \mathrm{~mm} / \mathrm{min}$. Entretanto, na Tabela 4 pode-se observar importante diferença entre as resinas, além dos limites de confiança (95\%) serem bem mais estreitos que para $\mathrm{w}_{\mathrm{e}}$.

Lembrando que o parâmetro $\beta \mathrm{w}_{\mathrm{p}}$ está relacionado com a plasticidade do material em torno da zona de processo, e portanto à ductilidade, pode-se fazer alguma inferência em relação às curvas de regressão. Observa-se que a resina HP 
0155 apresenta o menor valor de $\beta \mathrm{w}_{\mathrm{p}}-6,2 \pm 1,0 \mathrm{MJ} / \mathrm{m}^{3}$, o que é coerente quando a "curva de regressão" do composto - Figura 34, embora na cor preta, é comparada às curvas de regressão de outros materiais: o composto HP 0155 Black mostra nas curvas a $60^{\circ} \mathrm{C}$ e a $80^{\circ} \mathrm{C}$ uma maior propensão à fratura do tipo frágil em relação aos outros materiais, com inflexões antes de 10.000 horas. Com resultado melhor $-\beta \mathrm{w}_{\mathrm{p}}=$ $7,3 \pm 1,4 \mathrm{MJ} / \mathrm{m}^{3}$, a resina Rigidex PC 002-50R968 mostra na "curva de regressão" Figura 28 - alguma tendência à ruptura do tipo frágil antes de 10.000 horas somente na curva a $80^{\circ} \mathrm{C}$. No mesmo sentido, a resina GM 5010 T 2 apresenta um valor de $\beta \mathrm{w}_{\mathrm{p}}=8,5 \pm 0,7 \mathrm{MJ} / \mathrm{m}^{3}$ (direção perpendicular à direção de extrusão) mais elevado que a resina anterior, e uma tendência à ruptura do tipo frágil menos pronunciada, conforme pode ser observado na Figura 26. Por outro lado, a "curva de regressão" da resina MP 0240 Yellow (Figura 32), cujo valor de $\beta \mathrm{w}_{\mathrm{p}}=9,4 \pm 1,5 \mathrm{MJ} / \mathrm{m}^{3}$ é o mais elevado, não apresenta propensão à ruptura frágil antes de 10.000 horas tanto a $60^{\circ} \mathrm{C}$ como a $80^{\circ} \mathrm{C}$. A análise dos dois outros materiais fica prejudicada porque o composto BS 002 não possui "curva de regressão" e a "curva de regressão" do composto MDPE 8818 Yellow fornecida pelo fabricante está incompleta - não possui as curvas a temperaturas mais elevadas $\left(60^{\circ} \mathrm{C}\right.$ e $\left.80^{\circ} \mathrm{C}\right)$. Entretanto, pode-se esperar um bom desempenho do composto MDPE 8818 em testes de resistência à pressão hidrostática interna de longa duração em função do valor de $\beta \mathrm{w}_{\mathrm{p}}$ obtido $-8,7 \pm 1,2 \mathrm{MJ} / \mathrm{m}^{3}$. O composto BS 002 apresenta um valor moderado de $\beta \mathrm{w}_{\mathrm{p}}\left(7,6 \pm 1,1 \mathrm{MJ} / \mathrm{m}^{3}\right)$ mas não é um composto projetado a princípio para a fabricação de tubos de pressão.

Dessa forma, verifica-se que o método EWF, considerando seus dois parâmetros principais $-\mathrm{w}_{\mathrm{e}}$ e $\beta \mathrm{w}_{\mathrm{p}}$ pode proporcionar subsídios valiosos para avaliar a performance de um determinado composto em ensaios de resistência à pressão hidrostática interna de longa duração.

Outra observação interessante na Tabela 4 é que o valor de $\mathrm{w}_{\mathrm{e}}$ do composto GM 5010T2 na direção da extrusão é o mesmo que na direção perpendicular. Por outro lado, os valores de $\beta \mathrm{w}_{\mathrm{p}}$ são cerca de $30 \%$ superiores se o corpo de prova for extraído na mesma direção da extrusão. Esse resultado é bastante razoável se for considerado que o processamento pode induzir anisotropia em decorrência da esperada tendência de orientação das cadeias do polímero na direção da extrusão. No caso dos corpos de prova extraídos na direção da extrusão, a orientação do eixo do 
ligamento fica exatamente na direção perpendicular e portanto aquela que oferece maior resistência à ruptura. O método EWF demonstra-se capaz de observar diferenças de orientação molecular no polímero.

Ainda segundo Faylolle \& Verdu (2005) o entrelaçamento molecular na fase amorfa é mecanicamente ativo em tempos menores que os da transição dúctil-frágil, permitindo o estiramento das moléculas e a plasticidade macroscópica na ponta da trinca, observada nas falhas do tipo dúctil. Por outro lado, o entrelaçamento molecular é inativo além do tempo da transição dúctil-frágil devido ao desentrelaçamento (chain pull out) molecular ativado pela tensão e pela temperatura, o que, segundo os autores é favorecido a baixas velocidades de ensaio (baixas taxas de deformação) e por altas temperaturas. Sugerem ainda que o desentrelaçamento molecular é responsável pelo efeito da velocidade de ensaio nas propriedades de fratura do polietileno e que o método EWF é capaz de detectar a transição dúctilfrágil.

\section{3 - Microscopia eletrônica de varredura}

As Figuras 42, 43, 44, 45 e 46 são imagens da região de fratura de alguns corpos de prova submetidos ao "ramp test", obtidas em microscópio eletrônico de varredura - MEV.

Observa-se a presença marcante de fibrilas nos diferentes materiais, com acentuada deformação plástica permanente na região da fratura. Entretanto, para os fins do presente trabalho, as imagens não proporcionaram conclusões relevantes.

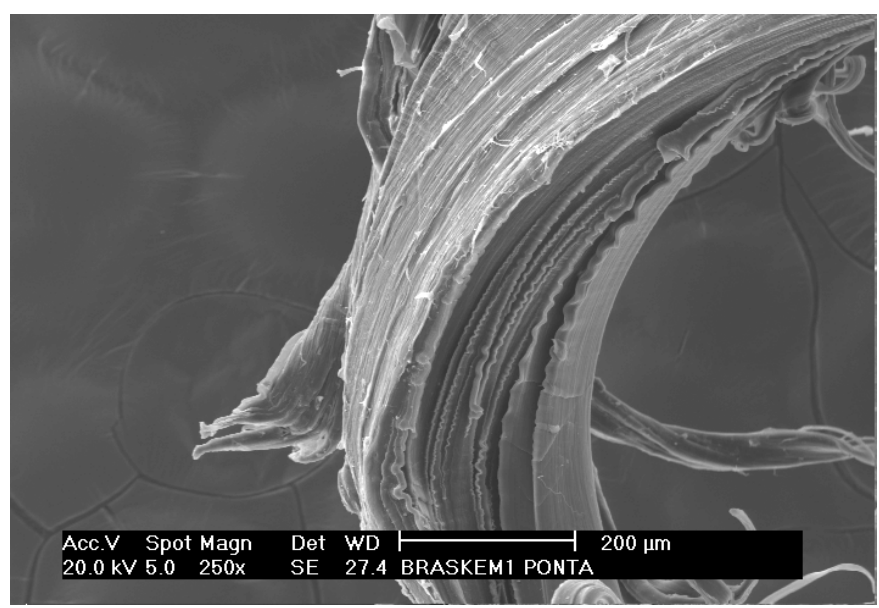

Figura 42: Imagem MEV da região de fratura do composto MP 0240 


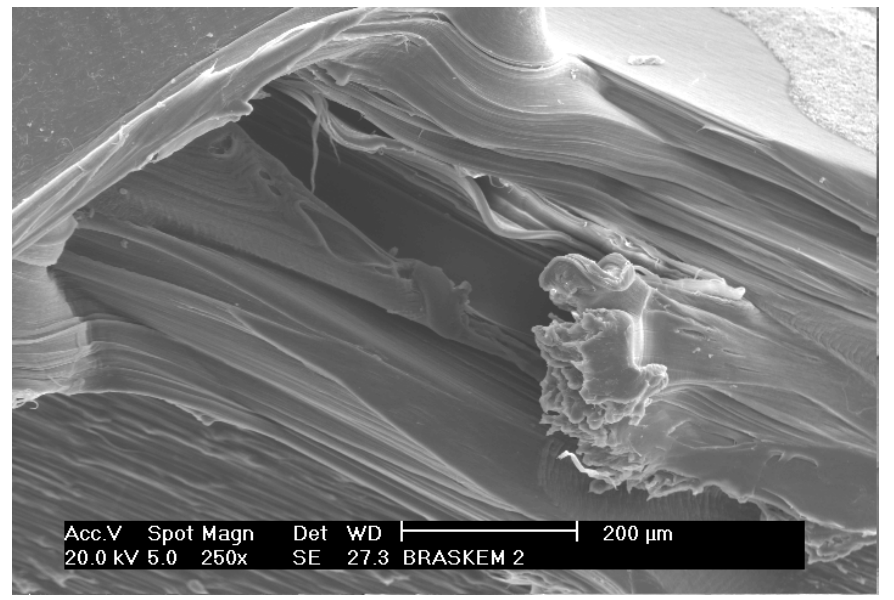

Figura 43: Imagem MEV da região de fratura do composto HP 0155

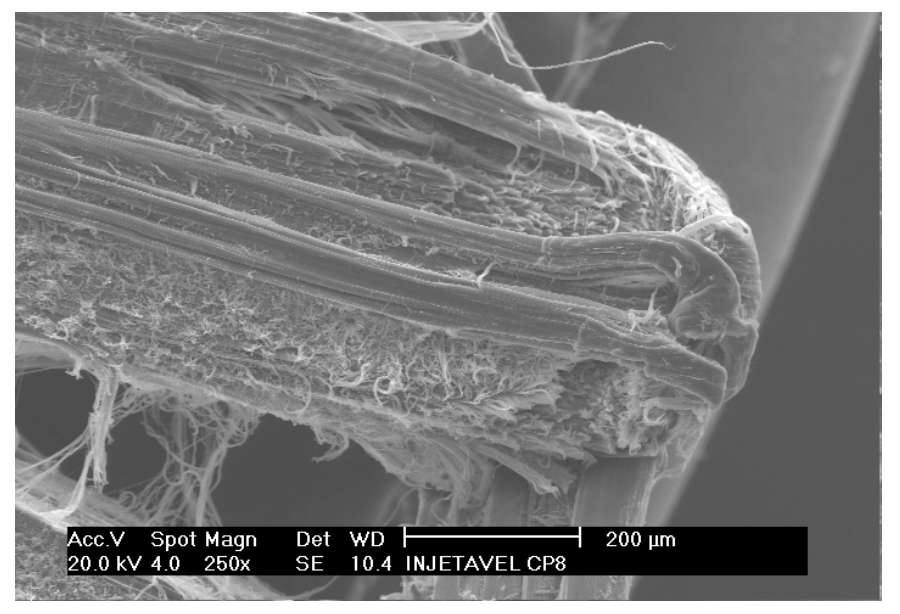

Figura 44: Imagem MEV da região de fratura do composto JV 060U

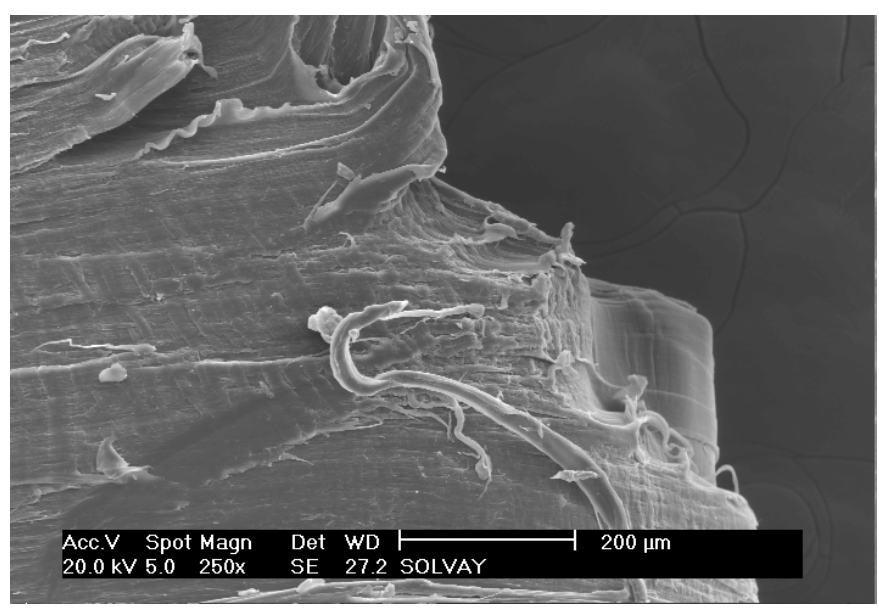

Figura 45: Imagem MEV da região de fratura do composto Rigidex PC 002-50R968 


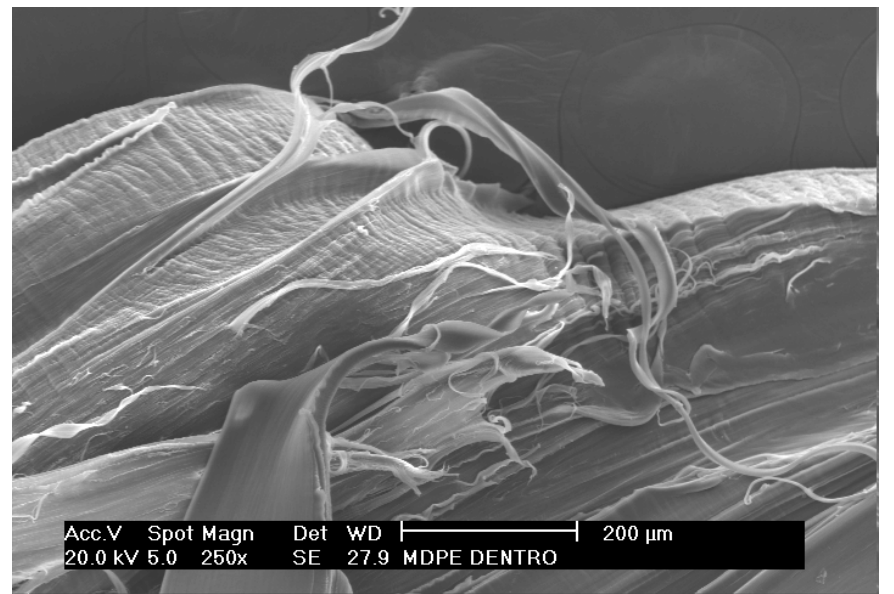

Figura 46: Imagem MEV da região de fratura do composto MDPE 8818 


\section{4 - CONCLUSÕES}

Foram desenvolvidas as metodologias de ensaios de "ramp test" e de trabalho essencial de fratura (EWF) para aplicação à análise da resistência de resinas de polietileno à fratura por fluência. As metodologias desenvolvidas são suficientemente simples para aplicação industrial.

Ambos ensaios permitem caracterizar completamente uma dada resina de polietileno em um intervalo de tempo consideravelmente menor que o necessário para a aplicação do ensaio de resistência à pressão hidrostática interna de longa duração ("curva de regressão"). Em particular o ensaio de "ramp test" pode ser executado em poucos dias, enquanto que a determinação de uma "curva de regressão" completa requer vários ensaios com durações da ordem de até 10.000 horas.

O "ramp test" deve ser executado no mesmo material (composto) destinado à fabricação dos tubos de água, incluindo os pigmentos.

Pela análise global dos resultados conclui-se que o ensaio de EWF é insensível à metodologia de preparação da pré-trinca, ao menos nos materiais investigados, porém os resultados são afetados pela precisão dos instrumentos de medida utilizados na caracterização das dimensões do corpo de prova.

O "ramp test" permite estimar a tensão crítica correspondente à inflexão da curva de regressão, dispensando os testes de resistência à pressão hidrostática interna mais demorados (LTHS). A combinação dos resultados de ensaios mais curtos de resistência à pressão hidrostática interna com os resultados do "ramp test" (tensão critica) representa uma alternativa viável para os ensaios completos de LTHS.

O método EWF permite comparar e ordenar o comportamento esperado de diferentes resinas em ensaios de LTHS completos. A parcela não essencial do trabalho específico de fratura, ou fator de dissipação de trabalho plástico $\left(\beta \mathrm{w}_{\mathrm{p}}\right)$ é o melhor parâmetro do método para realizar esta diferenciação.

A parcela essencial do trabalho específico de fratura $\left(\mathrm{w}_{\mathrm{e}}\right)$ é praticamente equivalente para os materiais estudados, variando entre 30,2 e $37,6 \mathrm{~kJ} / \mathrm{m}^{2}$, exceto para a resina MP 0240 , cujo resultado foi menor $-23,5 \mathrm{~kJ} / \mathrm{m}^{2}$. 
A parcela não essencial do trabalho específico de fratura permite dispor em ordem crescente as resinas estudadas, em termos de suscetibilidade à fratura frágil, da seguinte forma: MP 0240, MDPE 8818, GM 5010 T 2, BS 002, RIGIDEX PC 002-50R968 e HP 0155. 


\section{APÊNDICE A - TABELAS DE DADOS DO "RAMP TEST"}

\section{A.1 - GM 5010 T 2}

Tabela 5 - Resultados do "ramp test" da resina GM 5010 T 2

\begin{tabular}{|c|c|c|c|}
\hline $\mathbf{d} \varepsilon / \mathbf{d t}\left(\mathbf{s}^{-\mathbf{1}}\right)$ & $\log \mathbf{d} \varepsilon / \mathbf{d t}$ & $\sigma_{\mathbf{y}}(\mathbf{M P a})$ & $\sigma_{\mathbf{d r}}$ (Mpa) \\
\hline $4,17 \mathrm{E}-05$ & $-4,380$ & 14,5 & 10,7 \\
\hline $2,08 \mathrm{E}-04$ & $-3,681$ & 15,0 & 11,3 \\
\hline $4,17 \mathrm{E}-04$ & $-3,380$ & 16,9 & 12,5 \\
\hline $2,08 \mathrm{E}-03$ & $-2,681$ & 17,8 & 12,8 \\
\hline $2,08 \mathrm{E}-02$ & $-1,681$ & 20,9 & 13,3 \\
\hline $2,08 \mathrm{E}-01$ & $-0,681$ & 23,0 & 13,9 \\
\hline \multicolumn{3}{|c|}{$\sigma_{\mathbf{C}}=\mathbf{9 , 6} \mathbf{~ M P a}$} \\
\hline
\end{tabular}

Obs: coeficientes de variação de Pearson ${ }^{10}$ menores que $4 \%$

\section{A.2 - RIGIDEX PC002-50R968}

Tabela 6 - Resultados do "ramp test" da resina Rigidex PC002-50R968

\begin{tabular}{|c|c|c|c|}
\hline $\mathbf{d} \varepsilon / \mathbf{d t}^{\left(\mathbf{s}^{-1}\right)}$ & $\log \mathbf{d} \varepsilon / \mathbf{d t}$ & $\sigma_{\mathbf{y}}(\mathbf{M P a})$ & $\sigma_{\mathbf{d r}}(\mathbf{M P a})$ \\
\hline $2,08 \mathrm{E}-04$ & $-3,681$ & 14,6 & 10,3 \\
\hline $4,17 \mathrm{E}-04$ & $-3,380$ & 15,1 & 11,8 \\
\hline $2,08 \mathrm{E}-03$ & $-2,681$ & 16,4 & 12,5 \\
\hline $2,08 \mathrm{E}-02$ & $-1,681$ & 17,5 & 12,0 \\
\hline $2,08 \mathrm{E}-01$ & $-0,681$ & 20,2 & 13,3 \\
\hline \multicolumn{3}{|c|}{$\sigma_{\mathbf{C}}=\mathbf{8 , 6} \mathbf{~ M P a}$} \\
\hline
\end{tabular}

Obs: coeficientes de variação de Pearson menores que 6\%

${ }^{10}$ Coeficiente de variação de Pearson: uma medida da variabilidade dos dados em relação ao seu valor médio (razão entre o desvio padrão e a média referentes a dados de uma mesma série), expresso em termos percentuais (MARTINS, 2002). 


\section{A.3 - MDPE 8818}

Tabela 7 - Resultados do "ramp test" da resina MDPE 8818

\begin{tabular}{|c|c|c|c|}
\hline $\mathbf{d} \varepsilon / \mathbf{d t}\left(\mathbf{s}^{-\mathbf{1}}\right)$ & $\log \mathbf{d} \varepsilon / \mathbf{d t}$ & $\sigma_{\mathbf{y}}(\mathbf{M P a})$ & $\sigma_{\mathbf{d r}}(\mathbf{M P a})$ \\
\hline $2,08 \mathrm{E}-04$ & $-3,681$ & 14,6 & 11,4 \\
\hline $4,17 \mathrm{E}-04$ & $-3,380$ & 15,1 & 11,2 \\
\hline $2,08 \mathrm{E}-03$ & $-2,681$ & 15,5 & 11,3 \\
\hline $2,08 \mathrm{E}-02$ & $-1,681$ & 18,4 & 11,6 \\
\hline $2,08 \mathrm{E}-01$ & $-0,681$ & 21,0 & 12,9 \\
\hline \multicolumn{3}{|c|}{$\sigma_{\mathbf{C}}=\mathbf{1 0 , 1} \mathbf{M P a}$} \\
\hline
\end{tabular}

Obs: coeficientes de variação de Pearson menores que 3\%

\section{A.4 - HP 0155}

Tabela 8 - Resultados do "ramp test" da resina HP 0155

\begin{tabular}{|c|c|c|c|}
\hline $\mathbf{d} \varepsilon / \mathbf{d t}^{\left(\mathbf{s}^{-1}\right)}$ & $\log \mathbf{d} \varepsilon / \mathbf{d t}$ & $\sigma_{\mathbf{y}}(\mathbf{M P a})$ & $\sigma_{\mathbf{d r}}(\mathbf{M P a})$ \\
\hline $2,08 \mathrm{E}-04$ & $-3,681$ & 14,5 & 10,3 \\
\hline $4,17 \mathrm{E}-04$ & $-3,380$ & 15,7 & 10,7 \\
\hline $2,08 \mathrm{E}-03$ & $-2,681$ & 18,7 & 13,0 \\
\hline $2,08 \mathrm{E}-02$ & $-1,681$ & 21,8 & 13,2 \\
\hline $4,17 \mathrm{E}-02$ & $-1,380$ & 22,4 & 13,1 \\
\hline \multicolumn{4}{|c|}{$\sigma_{\mathbf{C}}=\mathbf{8 , 3} \mathbf{M P a}$} \\
\hline
\end{tabular}

Obs: coeficientes de variação de Pearson menores que 5\% 


\section{A.5 - MP 0240}

Tabela 9 - Resultados do "ramp test" da resina MP 0240

\begin{tabular}{|c|c|c|c|}
\hline $\mathbf{d} \varepsilon / \mathbf{d t}\left(\mathbf{s}^{-\mathbf{1}}\right)$ & $\log \mathbf{d} \varepsilon / \mathbf{d t}$ & $\sigma_{\mathbf{y}}(\mathbf{M P a})$ & $\sigma_{\mathbf{d r}}(\mathbf{M P a})$ \\
\hline $2,08 \mathrm{E}-04$ & $-3,681$ & $16,425^{*}$ & $12,0^{*}$ \\
\hline $4,17 \mathrm{E}-04$ & $-3,380$ & 14,7 & 10,6 \\
\hline $2,08 \mathrm{E}-03$ & $-2,681$ & 15,7 & 11,5 \\
\hline $2,08 \mathrm{E}-02$ & $-1,681$ & 17,6 & 11,3 \\
\hline $4,17 \mathrm{E}-02$ & $-1,380$ & 18,3 & 11,4 \\
\hline \multicolumn{4}{|c}{$\sigma_{\mathrm{C}}=\mathbf{1 0 , 1} \mathbf{M P a}$} \\
\hline
\end{tabular}

* Valor excluído

Obs: coeficientes de variação de Pearson menores que 7\%

\section{A.6 - JV060U}

Tabela 10 - Resultados do "ramp test" da resina JV060U

\begin{tabular}{|c|c|c|c|}
\hline $\mathbf{D} \varepsilon / \mathbf{d t}\left(\mathbf{s}^{-\mathbf{1}}\right)$ & $\mathbf{L o g} \mathbf{d} \varepsilon / \mathbf{d t}$ & $\sigma_{\mathbf{y}}(\mathbf{M P a})$ & $\sigma_{\mathbf{d r}}(\mathbf{M P a})$ \\
\hline $1,19 \mathrm{E}-04$ & $-3,924$ & 13,7 & 10,2 \\
\hline $1,19 \mathrm{E}-03$ & $-2,924$ & 17,0 & 10,8 \\
\hline $1,19 \mathrm{E}-02$ & $-1,924$ & 19,5 & 10,8 \\
\hline $2,38 \mathrm{E}-02$ & $-1,623$ & 21,8 & 11,0 \\
\hline $1,19 \mathrm{E}-01$ & $-0,924$ & 24,1 & - \\
\hline \multicolumn{4}{|c|}{$\sigma_{\mathbf{C}}=\mathbf{1 0 , 0}$ MPa } \\
\hline
\end{tabular}

Obs: coeficientes de variação de Pearson menores que 3\%. 


\section{APÊNDICE B - RELATÓRIOS DE ENSAIOS, TABELAS DE DADOS E CURVAS DO MÉTODO EWF}

\section{B.1 - MDPE 8818}

\section{B.1.1 - Espessura do corpo de prova medida com paquímetro}

B.1.1.1 - Critério de tensão com limites da faixa de validade de $10 \% \sigma_{\underline{m}}$.

\section{CONDIÇÕES DE ENSAIO}

LARGURA DO CORPO DE PROVA (mm): 132

ESPESSURA NOMINAL DO CORPO DE PROVA (mm): 0,20 - paquímetro

VELOCIDADE DO ENSAIO ( $\mathrm{mm} / \mathrm{min}): 5$

TEMPERATURA DE ENSAIO $\left({ }^{\circ} \mathrm{C}\right): 25 \pm 2$

ORIENTAÇÃO DO CORPO DE PROVA: direção perpendicular à extrusão $\left(90^{\circ}\right)$

LIGAMENTO MÁXIMO (mm): 14,1

LIGAMENTO MÍNIMO (mm): 6,0

DADOS DE TRABALHO ESPECÍFICO

VALOR MÉDIO DAS MÁXIMAS TENSÕES, $\sigma_{\mathrm{m}}(\mathrm{MPa}):$ 20,7

TRABALHO ESSENCIAL DE FRATURA, $\mathrm{w}_{\mathrm{e}}\left(\mathrm{kJ} / \mathrm{m}^{2}\right): 34,0 \pm 11,9$ ( $95 \%$ confiança na predição)

FATOR DE DISSIPAÇÃO DE TRABALHO PLÁSTICO, $\beta \mathrm{w}_{\mathrm{p}}\left(\mathrm{MJ} / \mathrm{m}^{3}\right): 8,8 \pm 1,1$ (inclinação da curva energia específica $\left(\mathrm{w}_{\mathrm{f}}\right) \mathrm{x}$ ligamento $(\mathrm{l})$ ( $95 \%$ confiança na predição) 
Tabela 11 - Dados EWF MDPE 8818/paquímetro/10\% $\sigma_{\mathrm{m}}$.

\begin{tabular}{|c|c|c|c|c|c|}
\hline $\begin{array}{c}\mathbf{L} \\
\mathbf{( m m})\end{array}$ & $\begin{array}{c}\mathbf{t} \\
\mathbf{( m m )}\end{array}$ & $\begin{array}{c}\boldsymbol{\sigma}_{\mathbf{m a x}} \\
\mathbf{( M P a )}\end{array}$ & $\begin{array}{c}\mathbf{W}_{\mathbf{f}} \\
\mathbf{( m J )}\end{array}$ & $\begin{array}{c}\mathbf{w}_{\mathbf{f}} \\
\mathbf{( k J / \mathbf { m } ^ { 2 }} \mathbf{)}\end{array}$ & $\begin{array}{c}\text { Dados } \\
\text { Inválidos }\end{array}$ \\
\hline 6,0 & 0,20 & 21,9 & 103,4 & 86,2 & \\
\hline 6,0 & 0,20 & 23,2 & 114,7 & 95,6 & $*$ tensão \\
\hline 6,0 & 0,20 & 23,3 & 115,6 & 96,3 & $*$ tensão \\
\hline 6,2 & 0,20 & 22,4 & 115,5 & 93,2 & \\
\hline 6,3 & 0,20 & 21,4 & 109,6 & 87,0 & \\
\hline 6,3 & 0,20 & 21,0 & 106,0 & 84,1 & \\
\hline 8,0 & 0,20 & 21,6 & 171,1 & 106,9 & \\
\hline 8,0 & 0,20 & 20,1 & 156,2 & 97,6 & \\
\hline 8,1 & 0,20 & 22,3 & 186,2 & 114,9 & \\
\hline 8,2 & 0,20 & 20,8 & 169,5 & 103,4 & \\
\hline 8,2 & 0,20 & 20,9 & 172,9 & 105,4 & \\
\hline 8,4 & 0,20 & 21,9 & 193,2 & 115,0 & \\
\hline 9,7 & 0,20 & 19,0 & 213,3 & 109,9 & \\
\hline 9,9 & 0,20 & 19,9 & 221,7 & 112,0 & \\
\hline 10,0 & 0,20 & 21,8 & 264,6 & 132,3 & \\
\hline 10,0 & 0,20 & 20,6 & 240,2 & 120,1 & \\
\hline 10,0 & 0,20 & 21,6 & 260,0 & 130,0 & \\
\hline 10,0 & 0,20 & 20,7 & 249,3 & 124,6 & \\
\hline 11,9 & 0,20 & 19,3 & 307,3 & 129,1 & \\
\hline 12,0 & 0,20 & 21,2 & 354,6 & 147,8 & \\
\hline 12,0 & 0,20 & 18,6 & 296,4 & 123,5 & $*$ tensão \\
\hline 12,1 & 0,20 & 20,0 & 337,4 & 139,4 & \\
\hline 12,2 & 0,20 & 20,7 & 356,6 & 146,1 & \\
\hline 12,3 & 0,20 & 19,2 & 324,1 & 131,7 & \\
\hline 13,7 & 0,20 & 20,0 & 403,6 & 147,3 & \\
\hline 13,8 & 0,20 & 21,4 & 465,3 & 168,6 & \\
\hline 13,9 & 0,20 & 20,6 & 456,3 & 164,2 & \\
\hline 14,0 & 0,20 & 19,0 & 403,8 & 144,2 & \\
\hline 14,1 & 0,20 & 19,9 & 437,0 & 155,0 & \\
\hline 14,1 & 0,20 & 20,9 & 465,3 & 165,0 & \\
\hline
\end{tabular}




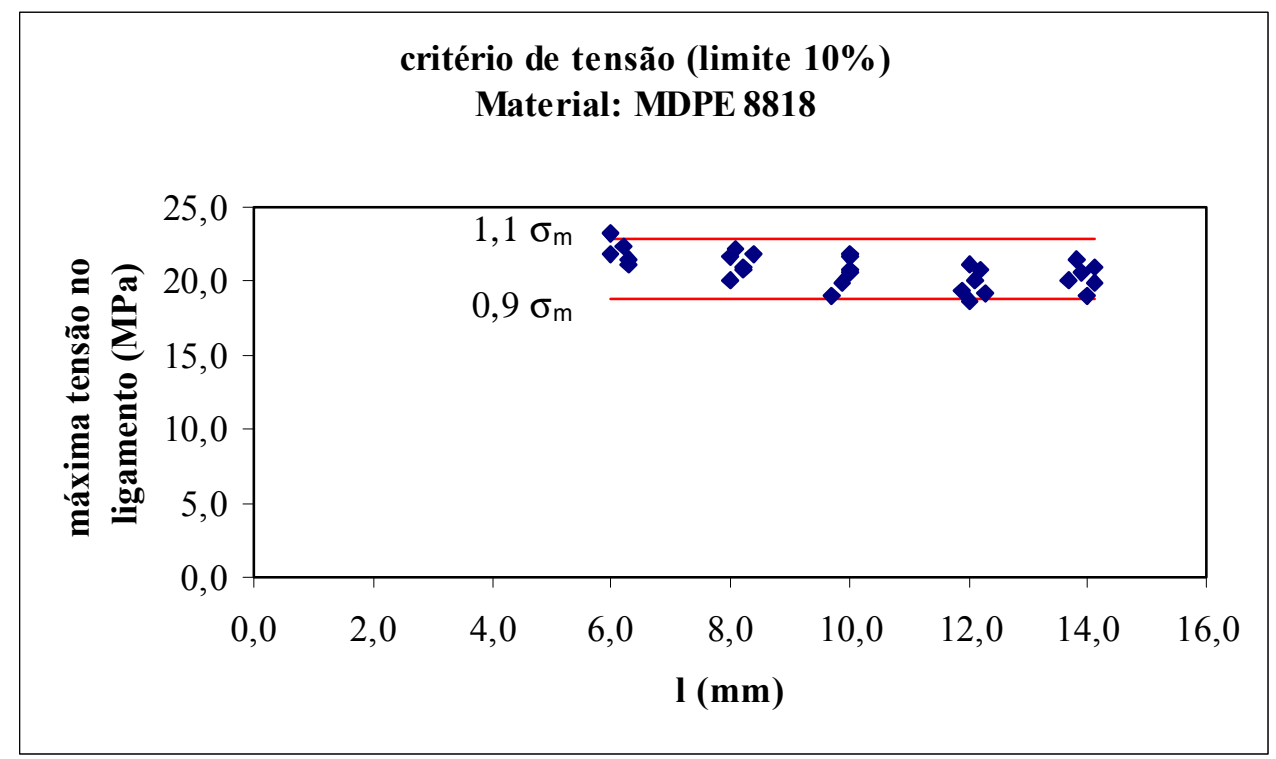

Figura 47: Critério de tensão - MDPE 8818/paquímetro/10\% $\sigma_{\mathrm{m}}$.

A Figura 47 ilustra graficamente o critério de tensão. O valor médio das máximas tensões é informado no relatório de ensaio enquanto que as máximas tensões de ligamento e os pontos eventualmente excluídos são informados na tabela de dados EWF. Com essas informações o leitor já dispõe dos dados referentes ao critério de tensão, de forma que nos próximos resultados do método EWF o esquema gráfico do critério de tensão será omitido.

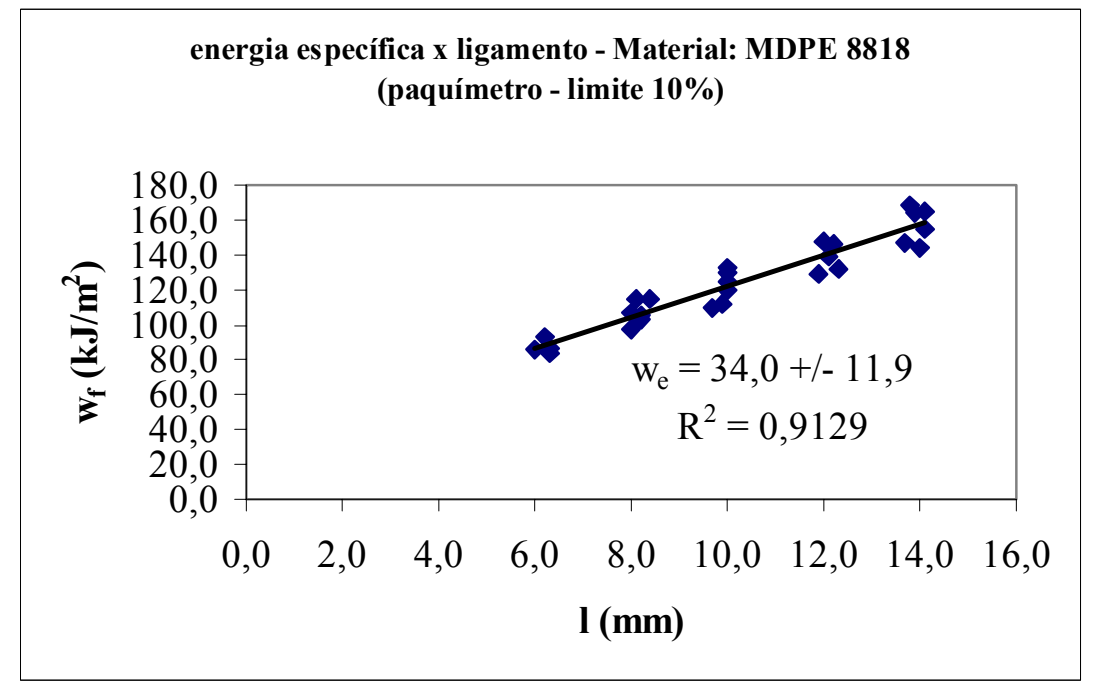

Figura 48: Curva do método EWF - MDPE 8818/paquímetro/10\% $\sigma_{\mathrm{m}}$. 
$\underline{\text { B.1.1.2 - Critério de tensão com limites da faixa de validade de } 11 \% \sigma_{\underline{m}}}$.

\section{CONDIÇÕES DE ENSAIO}

LARGURA DO CORPO DE PROVA (mm): 132

ESPESSURA NOMINAL DO CORPO DE PROVA (mm): 0,20 - paquímetro

VELOCIDADE DO ENSAIO ( $\mathrm{mm} / \mathrm{min}): 5$

TEMPERATURA DE ENSAIO $\left({ }^{\circ} \mathrm{C}\right): 25 \pm 2$

ORIENTAÇÃO DO CORPO DE PROVA: direção perpendicular à extrusão $\left(90^{\circ}\right)$

LIGAMENTO MÁXIMO (mm): 14,1

LIGAMENTO MÍNIMO (mm): 6,0

DADOS DE TRABALHO ESPECÍFICO

VALOR MÉDIO DAS MÁXIMAS TENSÕES, $\sigma_{\mathrm{m}}(\mathrm{MPa}):$ 20,8

TRABALHO ESSENCIAL DE FRATURA, $\mathrm{w}_{\mathrm{e}}\left(\mathrm{kJ} / \mathrm{m}^{2}\right): 34,8 \pm 12,6$

(95\% confiança na predição)

FATOR DE DISSIPAÇÃO DE TRABALHO PLÁSTICO, $\beta \mathrm{w}_{\mathrm{p}}\left(\mathrm{MJ} / \mathrm{m}^{3}\right): 8,7 \pm 1,2$ (inclinação da curva energia específica $\left(\mathrm{w}_{\mathrm{f}}\right) \mathrm{x}$ ligamento (l) (95\% confiança na predição)

TABELA DE DADOS E GRÁFICO EWF: vide Tabela 12 e Figura 49. 
Tabela 12: Dados EWF MDPE 8818/paquímetro/11\% $\sigma_{\mathrm{m}}$.

\begin{tabular}{|c|c|c|c|c|c|}
\hline $\begin{array}{c}\mathbf{I} \\
\mathbf{( m m})\end{array}$ & $\begin{array}{c}\mathbf{t} \\
\mathbf{( m m})\end{array}$ & $\begin{array}{c}\boldsymbol{\sigma}_{\mathbf{m a x}} \\
\mathbf{( M P a )}\end{array}$ & $\begin{array}{c}\mathbf{W}_{\mathbf{f}} \\
\mathbf{( m J )}\end{array}$ & $\begin{array}{c}\mathbf{w}_{\mathbf{f}} \\
\left.\mathbf{( k J} / \mathbf{m}^{\mathbf{2}}\right)\end{array}$ & $\begin{array}{c}\text { Dados } \\
\text { inválidos }\end{array}$ \\
\hline 6,0 & 0,20 & 21,9 & 103,4 & 86,2 & \\
\hline 6,0 & 0,20 & 23,2 & 114,7 & 95,6 & $*$ tensão \\
\hline 6,0 & 0,20 & 23,3 & 115,6 & 96,3 & $*$ tensão \\
\hline 6,2 & 0,20 & 22,4 & 115,5 & 93,2 & \\
\hline 6,3 & 0,20 & 21,4 & 109,6 & 87,0 & \\
\hline 6,3 & 0,20 & 21,0 & 106,0 & 84,1 & \\
\hline 8,0 & 0,20 & 21,6 & 171,1 & 106,9 & \\
\hline 8,0 & 0,20 & 20,1 & 156,2 & 97,6 & \\
\hline 8,1 & 0,20 & 22,3 & 186,2 & 114,9 & \\
\hline 8,2 & 0,20 & 20,8 & 169,5 & 103,4 & \\
\hline 8,2 & 0,20 & 20,9 & 172,9 & 105,4 & \\
\hline 8,4 & 0,20 & 21,9 & 193,2 & 115,0 & \\
\hline 9,7 & 0,20 & 19,0 & 213,3 & 109,9 & \\
\hline 9,9 & 0,20 & 19,9 & 221,7 & 112,0 & \\
\hline 10,0 & 0,20 & 21,8 & 264,6 & 132,3 & \\
\hline 10,0 & 0,20 & 20,6 & 240,2 & 120,1 & \\
\hline 10,0 & 0,20 & 21,6 & 260,0 & 130,0 & \\
\hline 10,0 & 0,20 & 20,7 & 249,3 & 124,6 & \\
\hline 11,9 & 0,20 & 19,3 & 307,3 & 129,1 & \\
\hline 12,0 & 0,20 & 21,2 & 354,6 & 147,8 & \\
\hline 12,0 & 0,20 & 18,6 & 296,4 & 123,5 & \\
\hline 12,1 & 0,20 & 20,0 & 337,4 & 139,4 & \\
\hline 12,2 & 0,20 & 20,7 & 356,6 & 146,1 & \\
\hline 12,3 & 0,20 & 19,2 & 324,1 & 131,7 & \\
\hline 13,7 & 0,20 & 20,0 & 403,6 & 147,3 & \\
\hline 13,8 & 0,20 & 21,4 & 465,3 & 168,6 & \\
\hline 13,9 & 0,20 & 20,6 & 456,3 & 164,2 & \\
\hline 14,0 & 0,20 & 19,0 & 403,8 & 144,2 & \\
\hline 14,1 & 0,20 & 19,9 & 437,0 & 155,0 & \\
\hline 14,1 & 0,20 & 20,9 & 465,3 & 165,0 & \\
\hline
\end{tabular}


energia específica $x$ ligamento - Mate rial: MDPE 8818 (paquíme tro - limite 11\%)

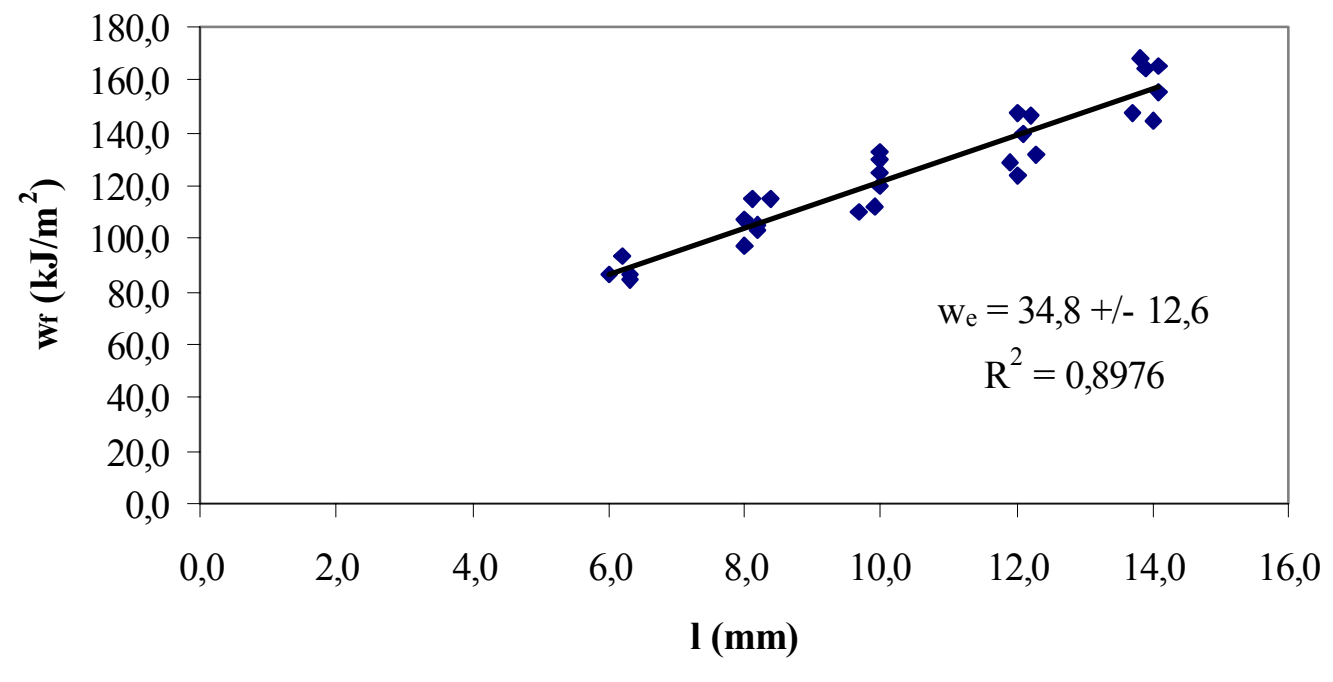

Figura 49: Curva do método EWF - MDPE 8818/paquímetro/11\% $\sigma_{\mathrm{m}}$. 


\section{B.1.2. Espessura do corpo de prova medida com micrômetro}

$\underline{\text { B.1.2.1 - Critério de tensão com limites da faixa de validade de } 10 \% \sigma_{\underline{m}}}$.

CONDIÇÕES DE ENSAIO

LARGURA DO CORPO DE PROVA (mm): 132

ESPESSURA NOMINAL DO CORPO DE PROVA (mm): 0,20 - micrômetro

VELOCIDADE DO ENSAIO ( $\mathrm{mm} / \mathrm{min}): 5$

TEMPERATURA DE ENSAIO $\left({ }^{\circ} \mathrm{C}\right): 25 \pm 2$

ORIENTAÇÃO DO CORPO DE PROVA: direção perpendicular à extrusão $\left(90^{\circ}\right)$

LIGAMENTO MÁXIMO (mm): 14,1

LIGAMENTO MÍNIMO (mm): 6,0

DADOS DE TRABALHO ESPECÍFICO

VALOR MÉDIO DAS MÁXIMAS TENSÕES, $\sigma_{\mathrm{m}}(\mathrm{MPa}): 20,5$

TRABALHO ESSENCIAL DE FRATURA, $\mathrm{w}_{\mathrm{e}}\left(\mathrm{kJ} / \mathrm{m}^{2}\right): 37,6 \pm 7,6$

(95\% confiança na predição)

FATOR DE DISSIPAÇÃO DE TRABALHO PLÁSTICO, $\beta \mathrm{w}_{\mathrm{p}}\left(\mathrm{MJ} / \mathrm{m}^{3}\right): 8,2 \pm 0,7$ (inclinação da curva energia específica $\left(\mathrm{w}_{\mathrm{f}}\right) \mathrm{x}$ ligamento (l) ( $95 \%$ confiança na predição)

TABELA DE DADOS E GRÁFICO EWF: vide Tabela 13 e Figura 50. 
Tabela 13: Dados EWF MDPE 8818/micrômetro/10\% $\sigma_{\mathrm{m}}$.

\begin{tabular}{|c|c|c|c|c|c|}
\hline $\begin{array}{c}\mathrm{l} \\
(\mathrm{mm})\end{array}$ & $\begin{array}{c}\mathrm{t} \\
(\mathrm{mm})\end{array}$ & $\begin{array}{c}\sigma_{\max } \\
\text { (Mpa) }\end{array}$ & $\begin{array}{c}\mathbf{W}_{\mathrm{f}} \\
(\mathrm{mJ})\end{array}$ & $\begin{array}{c}\mathbf{w}_{\mathrm{f}} \\
\left(\mathrm{kJ} / \mathrm{m}^{2}\right)\end{array}$ & $\begin{array}{c}\text { dados } \\
\text { inválidos }\end{array}$ \\
\hline 6,0 & 0,19 & 23,0 & 103,4 & 90,7 & * tensão \\
\hline 6,0 & 0,20 & 23,2 & 114,7 & 95,6 & * tensão \\
\hline 6,0 & 0,21 & 22,2 & 115,6 & 91,7 & \\
\hline 6,2 & 0,20 & 22,4 & 115,5 & 93,2 & \\
\hline 6,3 & 0,20 & 21,4 & 109,6 & 87,0 & \\
\hline 6,3 & 0,20 & 21,0 & 106,0 & 84,1 & \\
\hline 8,0 & 0,21 & 20,6 & 171,1 & 101,8 & \\
\hline 8,0 & 0,19 & 21,2 & 156,2 & 102,8 & \\
\hline 8,1 & 0,21 & 21,2 & 186,2 & 109,4 & \\
\hline 8,2 & 0,20 & 20,8 & 169,5 & 103,4 & \\
\hline 8,2 & 0,21 & 19,9 & 172,9 & 100,4 & \\
\hline 8,4 & 0,21 & 20,8 & 193,2 & 109,5 & \\
\hline 9,7 & 0,19 & 20,0 & 213,3 & 115,7 & \\
\hline 9,9 & 0,20 & 19,9 & 221,7 & 112,0 & \\
\hline 10,0 & 0,21 & 20,7 & 264,6 & 126,0 & \\
\hline 10,0 & 0,20 & 20,6 & 240,2 & 120,1 & \\
\hline 10,0 & 0,21 & 20,6 & 260,0 & 123,8 & \\
\hline 10,0 & 0,21 & 19,7 & 249,3 & 118,7 & \\
\hline 11,9 & 0,20 & 19,3 & 307,3 & 129,1 & \\
\hline 12,0 & 0,21 & 20,2 & 354,6 & 140,7 & \\
\hline 12,0 & 0,20 & 18,6 & 296,4 & 123,5 & $* 2 \mathrm{~S}$ \\
\hline 12,1 & 0,21 & 19,1 & 337,4 & 132,8 & \\
\hline 12,2 & 0,21 & 19,8 & 356,6 & 139,2 & \\
\hline 12,3 & 0,20 & 19,2 & 324,1 & 131,7 & \\
\hline 13,7 & 0,20 & 20,0 & 403,6 & 147,3 & \\
\hline 13,8 & 0,21 & 20,4 & 465,3 & 160,5 & \\
\hline 13,9 & 0,21 & 19,6 & 456,3 & 156,3 & \\
\hline 14,0 & 0,20 & 19,0 & 403,8 & 144,2 & \\
\hline 14,1 & 0,20 & 19,9 & 437,0 & 155,0 & \\
\hline 14,1 & 0,21 & 19,9 & 465,3 & 157,1 & \\
\hline
\end{tabular}




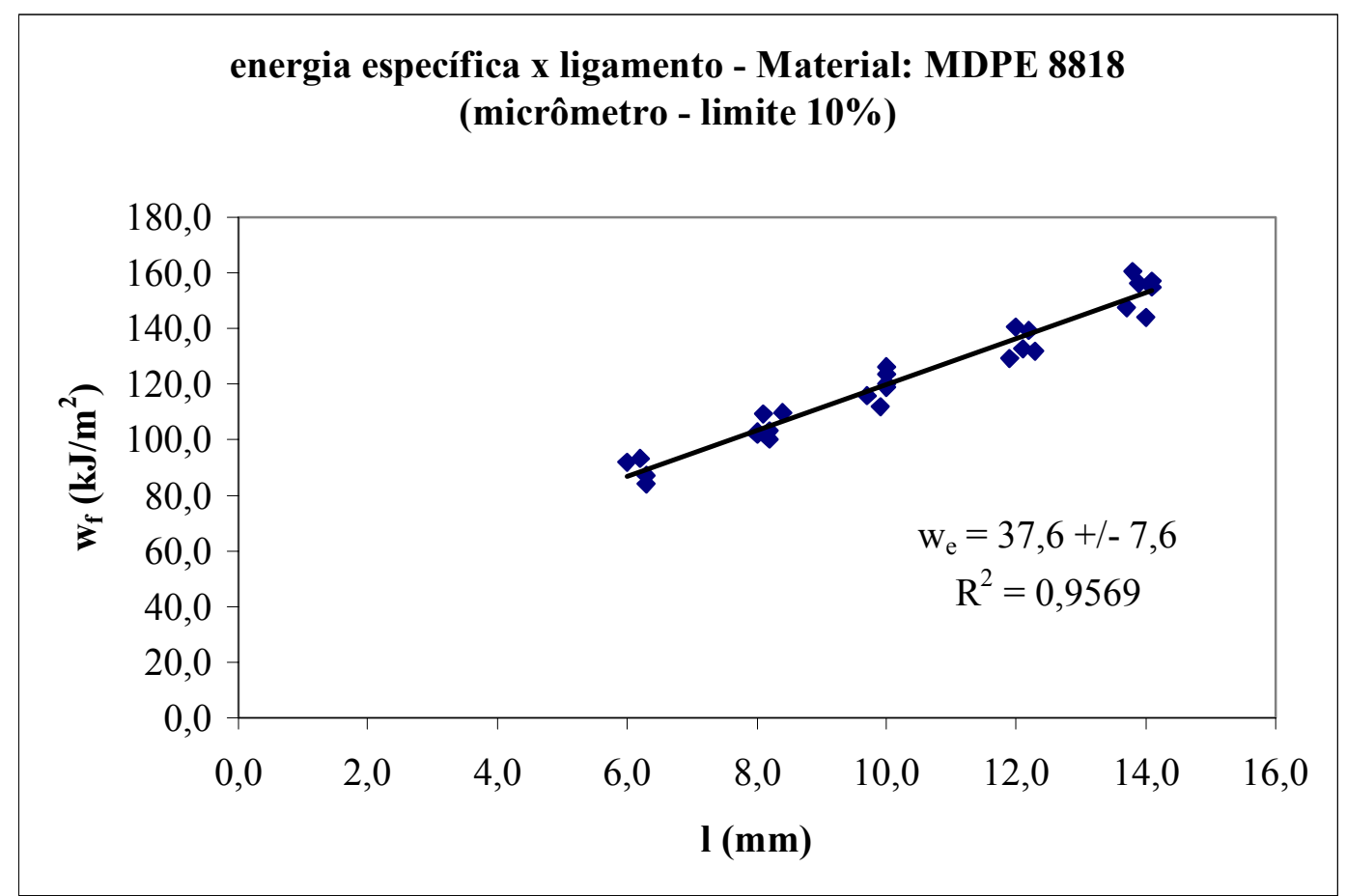

Figura 50: Curva do método EWF - MDPE 8818/micrômetro/10\% $\sigma_{\mathrm{m}}$. 
B.1.2.2 - Critério de tensão com limites da faixa de validade de $11 \% \sigma_{\underline{m}}$.

\section{$\underline{\text { CONDIÇÕES DE ENSAIO }}$}

LARGURA DO CORPO DE PROVA (mm): 132

ESPESSURA NOMINAL DO CORPO DE PROVA (mm): 0,20 - micrômetro

VELOCIDADE DO ENSAIO (mm/min): 5

TEMPERATURA DE ENSAIO $\left({ }^{\circ} \mathrm{C}\right): 25 \pm 2$

ORIENTAÇÃO DO CORPO DE PROVA: direção perpendicular à extrusão $\left(90^{\circ}\right)$

LIGAMENTO MÁXIMO (mm): 14,1

LIGAMENTO MÍNIMO (mm): 6,0

$\underline{\text { DADOS DE TRABALHO ESPECÍFICO }}$

VALOR MÉDIO DAS MÁXIMAS TENSÕES, $\sigma_{\mathrm{m}}(\mathrm{MPa}):$ 20,5

TRABALHO ESSENCIAL DE FRATURA, $\mathrm{w}_{\mathrm{e}}\left(\mathrm{kJ} / \mathrm{m}^{2}\right): 37,6 \pm 7,6$

(95\% confiança na predição)

FATOR DE DISSIPAÇÃO DE TRABALHO PLÁSTICO, $\beta \mathrm{w}_{\mathrm{p}}\left(\mathrm{MJ} / \mathrm{m}^{3}\right): 8,2 \pm 0,7$ (inclinação da curva energia específica $\left(\mathrm{w}_{\mathrm{f}}\right) \mathrm{x}$ ligamento (l) (95\% confiança na predição)

TABELA DE DADOS E GRÁFICO EWF: vide Tabela 14 e Figura 51. 
Tabela 14: Dados EWF MDPE 8818/micrômetro/11\% $\sigma_{\mathrm{m}}$.

\begin{tabular}{|c|c|c|c|c|c|}
\hline $\begin{array}{c}\mathbf{I} \\
\mathbf{( m m})\end{array}$ & $\begin{array}{c}\mathbf{t} \\
\mathbf{( m m})\end{array}$ & $\begin{array}{c}\boldsymbol{\sigma}_{\mathbf{m a x}} \\
\mathbf{( M P a )}\end{array}$ & $\begin{array}{c}\mathbf{W}_{\mathbf{f}} \\
\mathbf{( m J )}\end{array}$ & $\begin{array}{c}\mathbf{w}_{\mathbf{f}} \\
\left.\mathbf{( k J} / \mathbf{m}^{\mathbf{2}}\right)\end{array}$ & $\begin{array}{c}\text { dados } \\
\text { inválidos }\end{array}$ \\
\hline 6,0 & 0,19 & 23,0 & 103,4 & 90,7 & $*$ tensão \\
\hline 6,0 & 0,20 & 23,2 & 114,7 & 95,6 & $*$ tensão \\
\hline 6,0 & 0,21 & 22,2 & 115,6 & 91,7 & \\
\hline 6,2 & 0,20 & 22,4 & 115,5 & 93,2 & \\
\hline 6,3 & 0,20 & 21,4 & 109,6 & 87,0 & \\
\hline 6,3 & 0,20 & 21,0 & 106,0 & 84,1 & \\
\hline 8,0 & 0,21 & 20,6 & 171,1 & 101,8 & \\
\hline 8,0 & 0,19 & 21,2 & 156,2 & 102,8 & \\
\hline 8,1 & 0,21 & 21,2 & 186,2 & 109,4 & \\
\hline 8,2 & 0,20 & 20,8 & 169,5 & 103,4 & \\
\hline 8,2 & 0,21 & 19,9 & 172,9 & 100,4 & \\
\hline 8,4 & 0,21 & 20,8 & 193,2 & 109,5 & \\
\hline 9,7 & 0,19 & 20,0 & 213,3 & 115,7 & \\
\hline 9,9 & 0,20 & 19,9 & 221,7 & 112,0 & \\
\hline 10,0 & 0,21 & 20,7 & 264,6 & 126,0 & \\
\hline 10,0 & 0,20 & 20,6 & 240,2 & 120,1 & \\
\hline 10,0 & 0,21 & 20,6 & 260,0 & 123,8 & \\
\hline 10,0 & 0,21 & 19,7 & 249,3 & 118,7 & \\
\hline 11,9 & 0,20 & 19,3 & 307,3 & 129,1 & \\
\hline 12,0 & 0,21 & 20,2 & 354,6 & 140,7 & \\
\hline 12,0 & 0,20 & 18,6 & 296,4 & 123,5 & $* 2 \mathrm{~S}$ \\
\hline 12,1 & 0,21 & 19,1 & 337,4 & 132,8 & \\
\hline 12,2 & 0,21 & 19,8 & 356,6 & 139,2 & \\
\hline 12,3 & 0,20 & 19,2 & 324,1 & 131,7 & \\
\hline 13,7 & 0,20 & 20,0 & 403,6 & 147,3 & \\
\hline 13,8 & 0,21 & 20,4 & 465,3 & 160,5 & \\
\hline 13,9 & 0,21 & 19,6 & 456,3 & 156,3 & \\
\hline 14,0 & 0,20 & 19,0 & 403,8 & 144,2 & \\
\hline 14,1 & 0,20 & 19,9 & 437,0 & 155,0 & \\
\hline 14,1 & 0,21 & 19,9 & 465,3 & 157,1 & \\
\hline
\end{tabular}




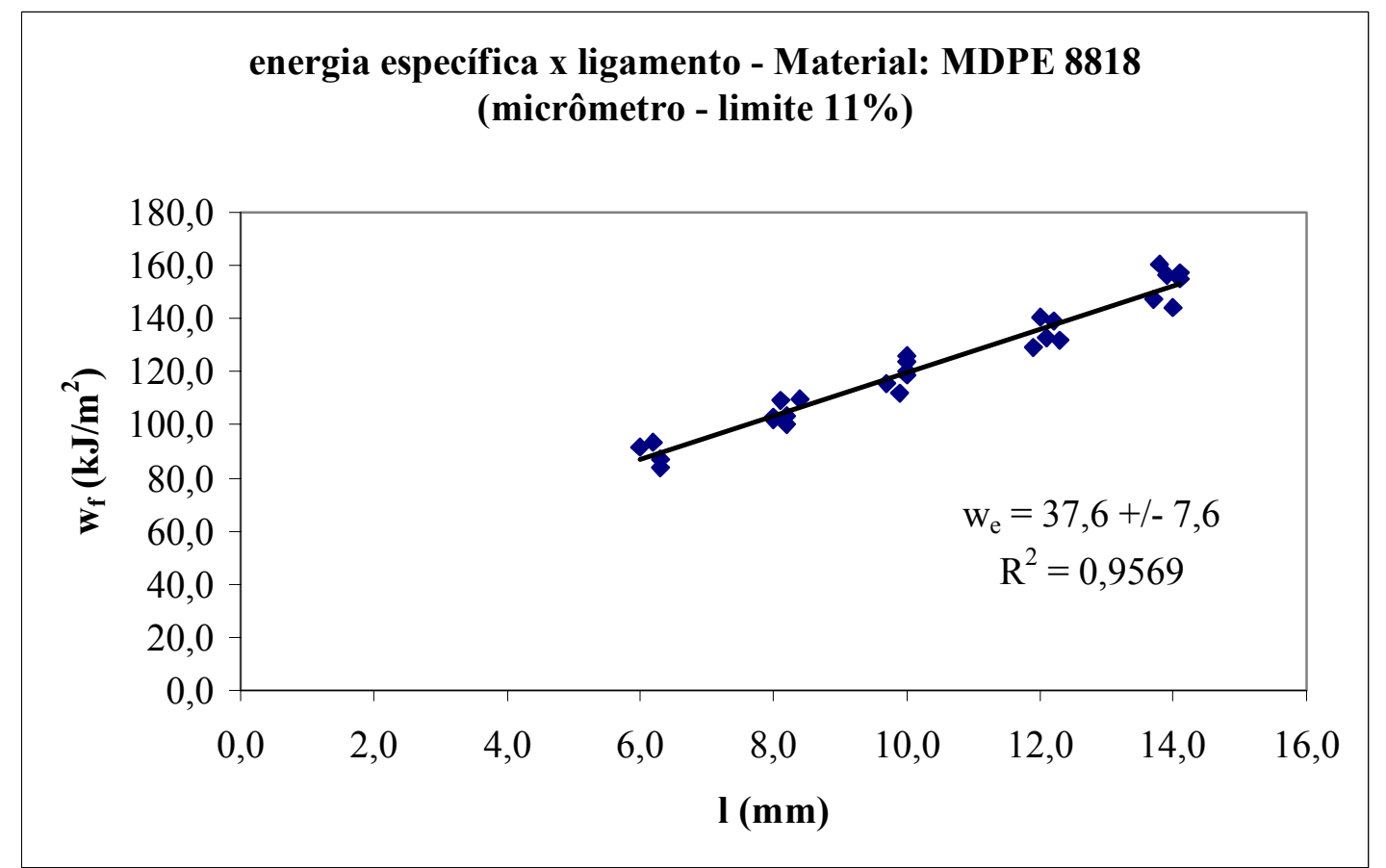

Figura 51: Curva do método EWF - MDPE 8818/micrômetro/11\% $\sigma_{\mathrm{m}}$. 


\section{B.2 - BS 002}

\section{B.2.1 - Espessura do corpo de prova medida com paquímetro}

$\underline{\text { B.2.1.1. Critério de tensão com limites da faixa de validade de } 10 \% \sigma_{m}}$.

\section{CONDIÇÕES DE ENSAIO}

LARGURA DO CORPO DE PROVA (mm): 132

ESPESSURA NOMINAL DO CORPO DE PROVA (mm): 0,20 - paquímetro VELOCIDADE DO ENSAIO ( $\mathrm{mm} / \mathrm{min}): 5$

TEMPERATURA DE ENSAIO $\left({ }^{\circ} \mathrm{C}\right): 25 \pm 2$

ORIENTAÇÃO DO CORPO DE PROVA: direção perpendicular à extrusão $\left(90^{\circ}\right)$ LIGAMENTO MÁXIMO (mm): 14,1

LIGAMENTO MÍNIMO (mm): 5,9

\section{DADOS DE TRABALHO ESPECÍFICO}

VALOR MÉDIO DAS MÁXIMAS TENSÕES, $\sigma_{\mathrm{m}}(\mathrm{MPa}):$ 20,2

TRABALHO ESSENCIAL DE FRATURA, $\mathrm{w}_{\mathrm{e}}\left(\mathrm{kJ} / \mathrm{m}^{2}\right): 33,5 \pm 10,6$ ( $95 \%$ confiança na predição)

FATOR DE DISSIPAÇÃO DE TRABALHO PLÁSTICO, $\beta \mathrm{w}_{\mathrm{p}}\left(\mathrm{MJ} / \mathrm{m}^{3}\right): 8,1 \pm 1,0$ (inclinação da curva energia específica $\left(\mathrm{w}_{\mathrm{f}}\right) \mathrm{x}$ ligamento (l) ( $95 \%$ confiança na predição)

TABELA DE DADOS E GRÁFICO EWF: vide Tabela 15 e Figura 52. 
Tabela 15: Dados EWF BS 002/paquímetro/10\% $\sigma_{\mathrm{m}}$.

\begin{tabular}{|c|c|c|c|c|c|}
\hline $\begin{array}{c}\mathbf{I} \\
\mathbf{( m m})\end{array}$ & $\begin{array}{c}\mathbf{t} \\
\mathbf{( m m})\end{array}$ & $\begin{array}{c}\boldsymbol{\sigma}_{\mathbf{m a x}} \\
\mathbf{( M P a )}\end{array}$ & $\begin{array}{c}\mathbf{W}_{\mathbf{f}} \\
\mathbf{( m J )}\end{array}$ & $\begin{array}{c}\mathbf{w}_{\mathbf{f}} \\
\mathbf{( k J / \mathbf { m } ^ { 2 }} \mathbf{)}\end{array}$ & $\begin{array}{c}\text { dados } \\
\text { inválidos }\end{array}$ \\
\hline 5,9 & 0,20 & 22,2 & 104,8 & 88,8 & \\
\hline 6,0 & 0,20 & 21,9 & 101,2 & 84,3 & \\
\hline 6,0 & 0,20 & 21,4 & 103,2 & 86,0 & \\
\hline 6,1 & 0,20 & 22,6 & 110,3 & 90,4 & $*$ tensão \\
\hline 6,1 & 0,20 & 19,9 & 93,3 & 76,5 & \\
\hline 6,2 & 0,20 & 22,4 & 110,7 & 89,2 & $*$ tensão \\
\hline 7,6 & 0,20 & 24,2 & 178,9 & 117,7 & $*$ tensão \\
\hline 7,9 & 0,20 & 21,4 & 158,5 & 100,3 & \\
\hline 7,9 & 0,20 & 20,0 & 147,9 & 93,6 & \\
\hline 8,0 & 0,20 & 21,0 & 156,2 & 97,6 & \\
\hline 8,0 & 0,20 & 19,9 & 147,8 & 92,4 & \\
\hline 8,2 & 0,20 & 21,3 & 176,0 & 107,3 & \\
\hline 10,0 & 0,20 & 20,4 & 244,1 & 122,1 & \\
\hline 10,0 & 0,20 & 19,1 & 215,3 & 107,7 & \\
\hline 10,0 & 0,20 & 18,9 & 214,7 & 107,4 & \\
\hline 10,1 & 0,20 & 18,5 & 208,4 & 103,2 & \\
\hline 10,1 & 0,20 & 22,1 & 275,0 & 136,2 & $* 2 \mathrm{~S}$ \\
\hline 10,3 & 0,20 & 19,6 & 234,3 & 113,8 & \\
\hline 11,8 & 0,20 & 19,8 & 314,9 & 133,4 & \\
\hline 11,9 & 0,20 & 18,2 & 267,3 & 112,3 & $*$ tensão \\
\hline 12,0 & 0,20 & 19,5 & 314,4 & 131,0 & \\
\hline 12,0 & 0,20 & 18,1 & 272,1 & 113,4 & $*$ tensão \\
\hline 12,0 & 0,20 & 19,0 & 304,3 & 126,8 & \\
\hline 12,2 & 0,20 & 19,7 & 327,3 & 134,1 & \\
\hline 13,9 & 0,20 & 19,5 & 409,3 & 147,2 & \\
\hline 13,9 & 0,20 & 20,8 & 447,4 & 160,9 & \\
\hline 13,9 & 0,20 & 19,3 & 410,9 & 147,8 & \\
\hline 14,0 & 0,20 & 18,6 & 387,9 & 138,5 & \\
\hline 14,1 & 0,20 & 18,0 & 383,2 & 135,9 & $*$ tensão \\
\hline 14,1 & 0,20 & 19,3 & 405,2 & 143,7 & \\
\hline
\end{tabular}




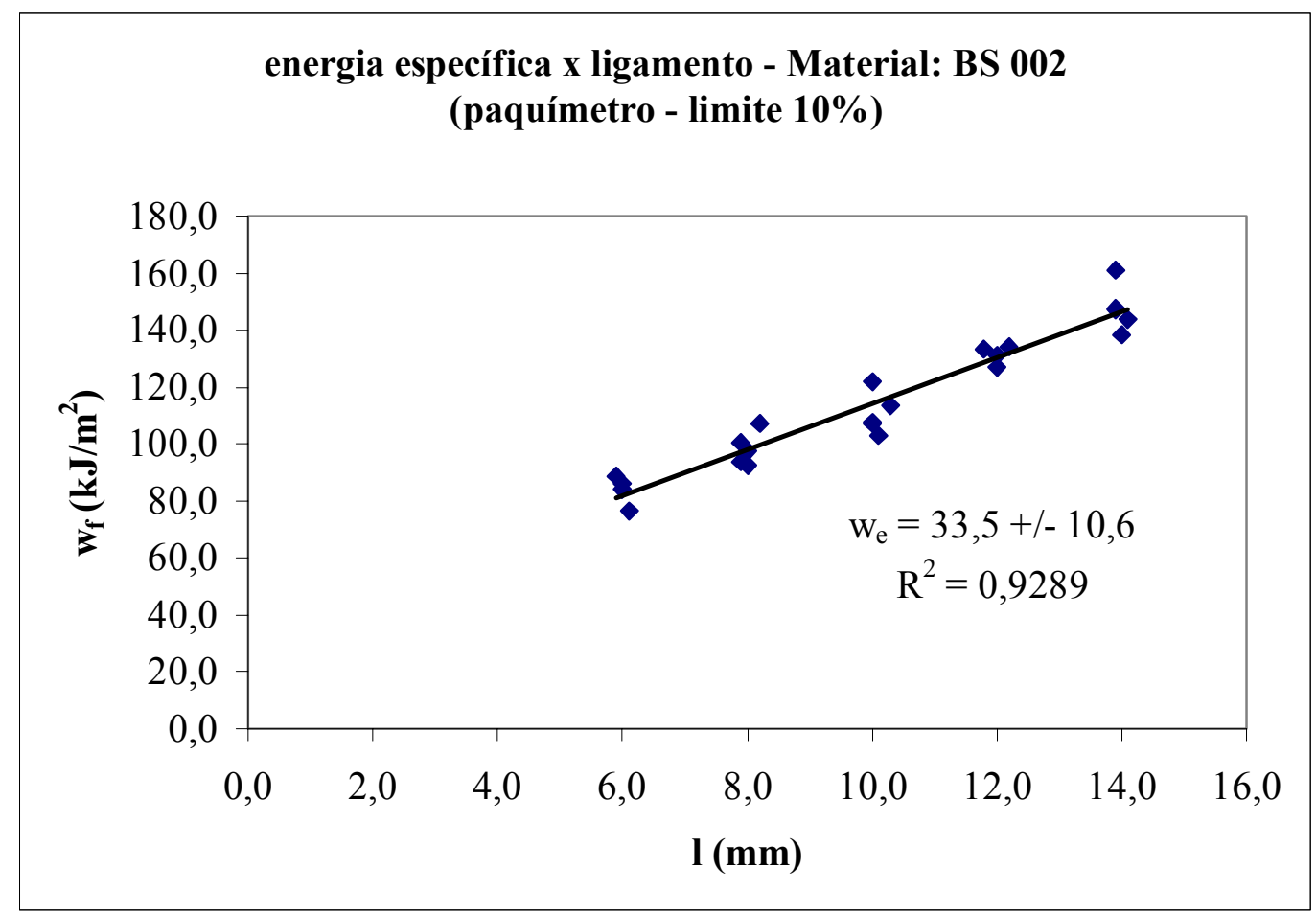

Figura 52: Curva do método EWF - BS 002/paquímetro/10\% $\sigma_{\mathrm{m}}$. 
$\underline{\text { B.2.1.2 - Critério de tensão com limites da faixa de validade de } 11 \% \sigma_{\underline{m}}}$.

\section{CONDIÇÕES DE ENSAIO}

LARGURA DO CORPO DE PROVA (mm): 132

ESPESSURA NOMINAL DO CORPO DE PROVA (mm): 0,20 - paquímetro

VELOCIDADE DO ENSAIO ( $\mathrm{mm} / \mathrm{min}): 5$

TEMPERATURA DE ENSAIO $\left({ }^{\circ} \mathrm{C}\right): 25 \pm 2$

ORIENTAÇÃO DO CORPO DE PROVA: direção perpendicular à extrusão $\left(90^{\circ}\right)$

LIGAMENTO MÁXIMO (mm): 14,1

LIGAMENTO MÍNIMO (mm): 5,9

$\underline{\text { DADOS DE TRABALHO ESPECÍFICO }}$

VALOR MÉDIO DAS MÁXIMAS TENSÕES, $\sigma_{\mathrm{m}}(\mathrm{MPa}):$ 20,2

TRABALHO ESSENCIAL DE FRATURA, $\mathrm{w}_{\mathrm{e}}\left(\mathrm{kJ} / \mathrm{m}^{2}\right): 36,7 \pm 11,8$ (95\% confiança na predição)

FATOR DE DISSIPAÇÃO DE TRABALHO PLÁSTICO, $\beta \mathrm{w}_{\mathrm{p}}\left(\mathrm{MJ} / \mathrm{m}^{3}\right): 7,6 \pm 1,1$ (inclinação da curva energia específica $\left(\mathrm{w}_{\mathrm{f}}\right) \mathrm{x}$ ligamento (l) (95\% confiança na predição)

TABELA DE DADOS E GRÁFICO EWF: vide Tabela 16 e Figura 53. 
Tabela 16: Dados EWF BS 002/paquímetro/11\% $\sigma_{\mathrm{m}}$.

\begin{tabular}{|c|c|c|c|c|c|}
\hline $\begin{array}{c}\mathrm{l} \\
(\mathrm{mm})\end{array}$ & $\begin{array}{c}\mathrm{t} \\
(\mathrm{mm})\end{array}$ & $\begin{array}{c}\sigma_{\max } \\
\text { (Mpa) }\end{array}$ & $\begin{array}{c}\mathbf{W}_{\mathrm{f}} \\
(\mathrm{mJ})\end{array}$ & $\begin{array}{c}\mathbf{W}_{\mathrm{f}} \\
\left(\mathrm{kJ} / \mathrm{m}^{2}\right)\end{array}$ & $\begin{array}{c}\text { Dados } \\
\text { inválidos }\end{array}$ \\
\hline 5,9 & 0,20 & 22,2 & 104,8 & 88,8 & \\
\hline 6,0 & 0,20 & 21,9 & 101,2 & 84,3 & \\
\hline 6,0 & 0,20 & 21,4 & 103,2 & 86,0 & \\
\hline 6,1 & 0,20 & 22,6 & 110,3 & 90,4 & * tensão \\
\hline 6,1 & 0,20 & 19,9 & 93,3 & 76,5 & \\
\hline 6,2 & 0,20 & 22,4 & 110,7 & 89,2 & \\
\hline 7,6 & 0,20 & 24,2 & 178,9 & 117,7 & * tensão \\
\hline 7,9 & 0,20 & 21,4 & 158,5 & 100,3 & \\
\hline 7,9 & 0,20 & 20,0 & 147,9 & 93,6 & \\
\hline 8,0 & 0,20 & 21,0 & 156,2 & 97,6 & \\
\hline 8,0 & 0,20 & 19,9 & 147,8 & 92,4 & \\
\hline 8,2 & 0,20 & 21,3 & 176,0 & 107,3 & \\
\hline 10,0 & 0,20 & 20,4 & 244,1 & 122,1 & \\
\hline 10,0 & 0,20 & 19,1 & 215,3 & 107,7 & \\
\hline 10,0 & 0,20 & 18,9 & 214,7 & 107,4 & \\
\hline 10,1 & 0,20 & 18,5 & 208,4 & 103,2 & \\
\hline 10,1 & 0,20 & 22,1 & 275,0 & 136,2 & $* 2 \mathrm{~S}$ \\
\hline 10,3 & 0,20 & 19,6 & 234,3 & 113,8 & \\
\hline 11,8 & 0,20 & 19,8 & 314,9 & 133,4 & \\
\hline 11,9 & 0,20 & 18,2 & 267,3 & 112,3 & \\
\hline 12,0 & 0,20 & 19,5 & 314,4 & 131,0 & \\
\hline 12,0 & 0,20 & 18,1 & 272,1 & 113,4 & \\
\hline 12,0 & 0,20 & 19,0 & 304,3 & 126,8 & \\
\hline 12,2 & 0,20 & 19,7 & 327,3 & 134,1 & \\
\hline 13,9 & 0,20 & 19,5 & 409,3 & 147,2 & \\
\hline 13,9 & 0,20 & 20,8 & 447,4 & 160,9 & \\
\hline 13,9 & 0,20 & 19,3 & 410,9 & 147,8 & \\
\hline 14,0 & 0,20 & 18,6 & 387,9 & 138,5 & \\
\hline 14,1 & 0,20 & 18,0 & 383,2 & 135,9 & * tensão \\
\hline 14,1 & 0,20 & 19,3 & 405,2 & 143,7 & \\
\hline
\end{tabular}




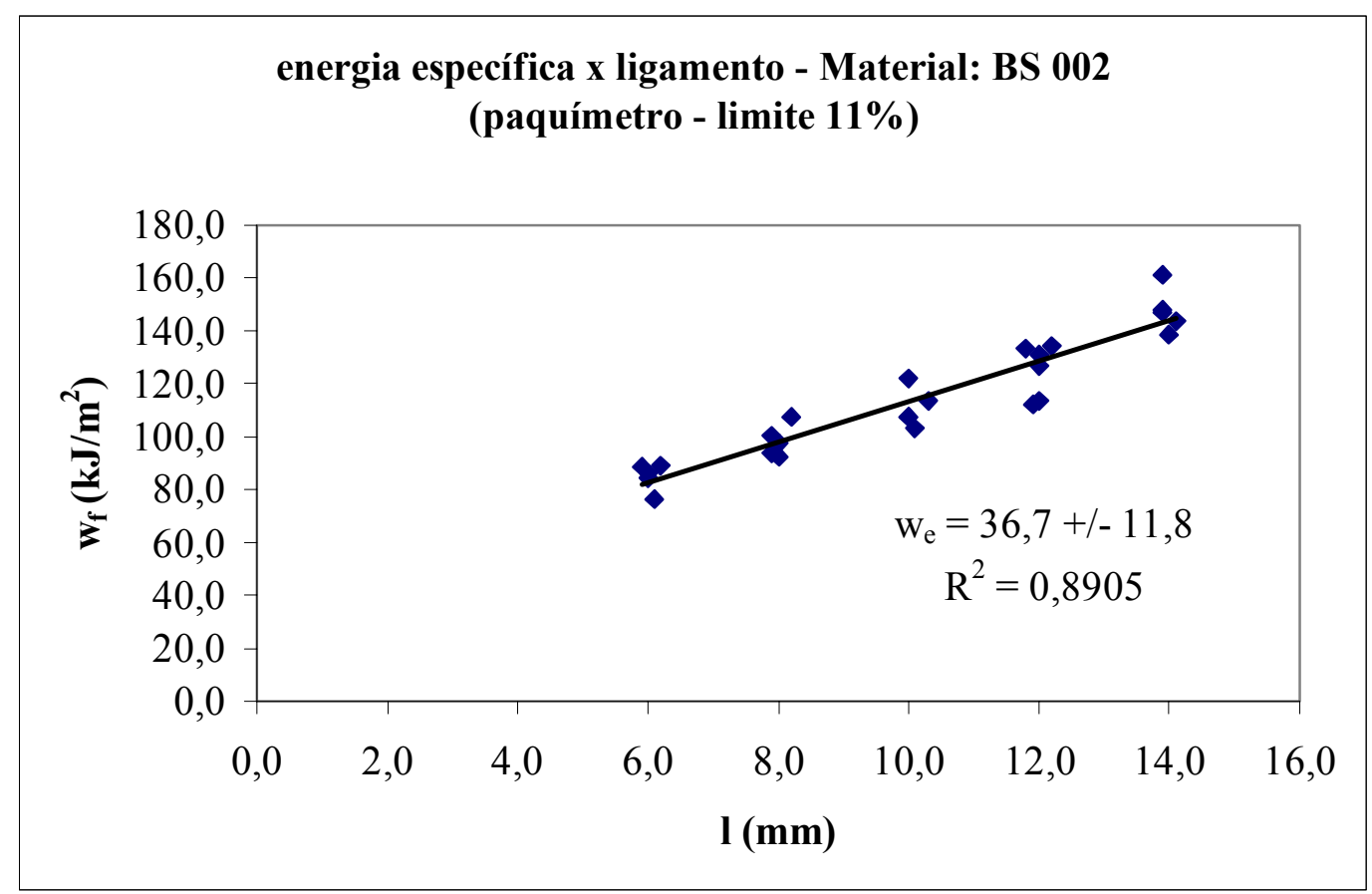

Figura 53: Curva do método EWF - BS 002/paquímetro/11\% $\sigma_{\mathrm{m}}$. 


\section{B.2.2 - Espessura do corpo de prova medida com micrômetro}

$\underline{\text { B.2.2.1 - Critério de tensão com limites da faixa de validade de } 10 \% \sigma_{\underline{m}}}$.

CONDIÇÕES DE ENSAIO

LARGURA DO CORPO DE PROVA (mm): 132

ESPESSURA NOMINAL DO CORPO DE PROVA (mm): 0,20 - micrômetro

VELOCIDADE DO ENSAIO ( $\mathrm{mm} / \mathrm{min}): 5$

TEMPERATURA DE ENSAIO $\left({ }^{\circ} \mathrm{C}\right): 25 \pm 2$

ORIENTAÇÃO DO CORPO DE PROVA: direção perpendicular à extrusão $\left(90^{\circ}\right)$

LIGAMENTO MÁXIMO (mm): 14,1

LIGAMENTO MÍNIMO (mm): 5,9

DADOS DE TRABALHO ESPECÍFICO

VALOR MÉDIO DAS MÁXIMAS TENSÕES, $\sigma_{\mathrm{m}}(\mathrm{MPa}): 20,2$

TRABALHO ESSENCIAL DE FRATURA, $\mathrm{w}_{\mathrm{e}}\left(\mathrm{kJ} / \mathrm{m}^{2}\right): 39,8 \pm 9,3$

(95\% confiança na predição)

FATOR DE DISSIPAÇÃO DE TRABALHO PLÁSTICO, $\beta \mathrm{w}_{\mathrm{p}}\left(\mathrm{MJ} / \mathrm{m}^{3}\right): 7,3 \pm 0,8$ (inclinação da curva energia específica $\left(\mathrm{w}_{\mathrm{f}}\right) \mathrm{x}$ ligamento (l) ( $95 \%$ confiança na predição)

TABELA DE DADOS E GRÁFICO EWF: vide Tabela 17 e Figura 54. 
Tabela 17: Dados EWF BS 002/micrômetro/10\% $\sigma_{\mathrm{m}}$.

\begin{tabular}{|c|c|c|c|c|c|}
\hline $\begin{array}{c}\mathrm{l} \\
(\mathrm{mm})\end{array}$ & $\begin{array}{c}\mathrm{t} \\
(\mathrm{mm})\end{array}$ & $\begin{array}{c}\sigma_{\max } \\
(\mathrm{MPa})\end{array}$ & $\begin{array}{c}\mathbf{W}_{\mathrm{f}} \\
(\mathrm{mJ})\end{array}$ & $\begin{array}{c}\mathbf{W}_{\mathrm{f}} \\
\left(\mathrm{kJ} / \mathrm{m}^{2}\right)\end{array}$ & $\begin{array}{c}\text { Dados } \\
\text { inválidos }\end{array}$ \\
\hline 5,9 & 0,20 & 22,2 & 104,8 & 88,8 & \\
\hline 6,0 & 0,20 & 21,9 & 101,2 & 84,3 & \\
\hline 6,0 & 0,20 & 21,4 & 103,2 & 86,0 & \\
\hline 6,1 & 0,21 & 21,5 & 110,3 & 86,1 & \\
\hline 6,1 & 0,19 & 21,0 & 93,3 & 80,5 & \\
\hline 6,2 & 0,20 & 22,4 & 110,7 & 89,2 & * tensão \\
\hline 7,6 & 0,21 & 23,1 & 178,9 & 112,1 & * tensão \\
\hline 7,9 & 0,20 & 21,4 & 158,5 & 100,3 & \\
\hline 7,9 & 0,19 & 21,1 & 147,9 & 98,6 & \\
\hline 8,0 & 0,20 & 21,0 & 156,2 & 97,6 & \\
\hline 8,0 & 0,20 & 19,9 & 147,8 & 92,4 & \\
\hline 8,2 & 0,20 & 21,3 & 176,0 & 107,3 & \\
\hline 10,0 & 0,20 & 20,4 & 244,1 & 122,1 & \\
\hline 10,0 & 0,20 & 19,1 & 215,3 & 107,7 & \\
\hline 10,0 & 0,20 & 18,9 & 214,7 & 107,4 & \\
\hline 10,1 & 0,20 & 18,5 & 208,4 & 103,2 & \\
\hline 10,1 & 0,21 & 21,0 & 275,0 & 129,7 & $* 2 \mathrm{~S}$ \\
\hline 10,3 & 0,20 & 19,6 & 234,3 & 113,8 & \\
\hline 11,8 & 0,20 & 19,8 & 314,9 & 133,4 & \\
\hline 11,9 & 0,20 & 18,2 & 267,3 & 112,3 & \\
\hline 12,0 & 0,20 & 19,5 & 314,4 & 131,0 & \\
\hline 12,0 & 0,19 & 19,1 & 272,1 & 119,3 & \\
\hline 12,0 & 0,20 & 19,0 & 304,3 & 126,8 & \\
\hline 12,2 & 0,20 & 19,7 & 327,3 & 134,1 & \\
\hline 13,9 & 0,21 & 18,6 & 409,3 & 140,2 & \\
\hline 13,9 & 0,21 & 19,8 & 447,4 & 153,3 & \\
\hline 13,9 & 0,20 & 19,3 & 410,9 & 147,8 & \\
\hline 14,0 & 0,20 & 18,6 & 387,9 & 138,5 & \\
\hline 14,1 & 0,19 & 18,9 & 383,2 & 143,0 & \\
\hline 14,1 & 0,20 & 19,3 & 405,2 & 143,7 & \\
\hline
\end{tabular}




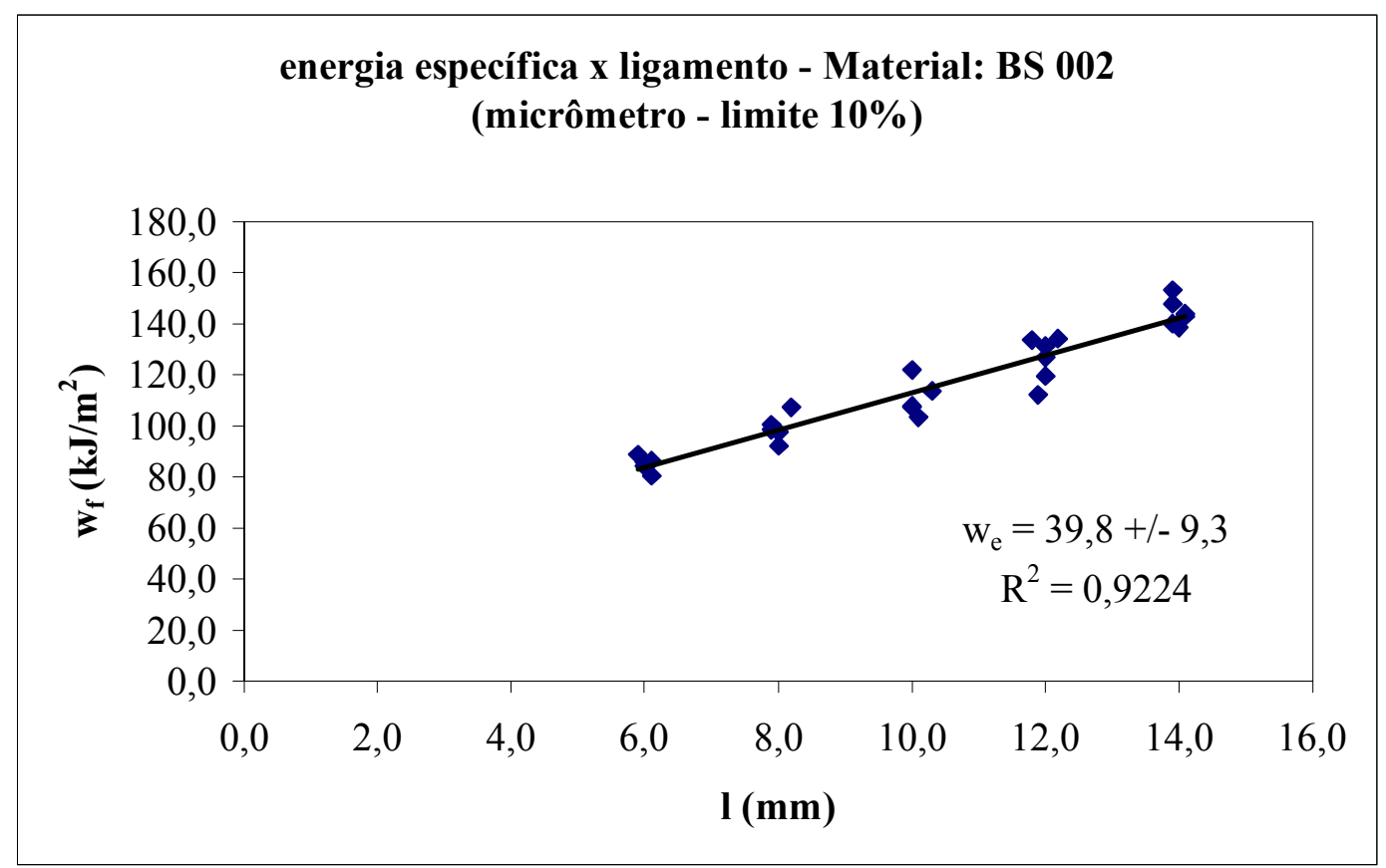

Figura 54: Curva do método EWF - BS 002/micrômetro/10\% $\sigma_{\mathrm{m}}$. 
$\underline{\text { B.2.2.2 - Critério de tensão com limites da faixa de validade de } 11 \% \sigma_{\underline{m}}}$.

\section{CONDIÇÕES DE ENSAIO}

LARGURA DO CORPO DE PROVA (mm): 132

ESPESSURA NOMINAL DO CORPO DE PROVA (mm): 0,20 - micrômetro

VELOCIDADE DO ENSAIO ( $\mathrm{mm} / \mathrm{min}): 5$

TEMPERATURA DE ENSAIO $\left({ }^{\circ} \mathrm{C}\right): 25 \pm 2$

ORIENTAÇÃO DO CORPO DE PROVA: direção perpendicular à extrusão $\left(90^{\circ}\right)$

LIGAMENTO MÁXIMO (mm): 14,1

LIGAMENTO MÍNIMO (mm): 5,9

$\underline{\text { DADOS DE TRABALHO ESPECÍFICO }}$

VALOR MÉDIO DAS MÁXIMAS TENSÕES, $\sigma_{\mathrm{m}}(\mathrm{MPa}): 20,2$

TRABALHO ESSENCIAL DE FRATURA, $\mathrm{w}_{\mathrm{e}}\left(\mathrm{kJ} / \mathrm{m}^{2}\right): 40,6 \pm 8,7$

(95\% confiança na predição)

FATOR DE DISSIPAÇÃO DE TRABALHO PLÁSTICO, $\beta \mathrm{w}_{\mathrm{p}}\left(\mathrm{MJ} / \mathrm{m}^{3}\right): 7,3 \pm 0,9$ (inclinação da curva energia específica $\left(\mathrm{w}_{\mathrm{f}}\right) \mathrm{x}$ ligamento (l) (95\% confiança na predição)

TABELA DE DADOS E GRÁFICO EWF: vide Tabela 18 e Figura 55. 
Tabela 18: Dados EWF BS 002/micrômetro/11\% $\sigma_{\mathrm{m}}$.

\begin{tabular}{|c|c|c|c|c|c|}
\hline $\begin{array}{c}\mathrm{l} \\
(\mathrm{mm})\end{array}$ & $\begin{array}{c}\mathrm{t} \\
(\mathrm{mm})\end{array}$ & $\begin{array}{c}\sigma_{\max } \\
(\mathbf{M P a})\end{array}$ & $\begin{array}{c}\mathbf{W}_{\mathrm{f}} \\
(\mathrm{mJ})\end{array}$ & $\begin{array}{c}\mathrm{w}_{\mathrm{f}} \\
\left(\mathrm{kJJ} / \mathrm{m}^{2}\right)\end{array}$ & $\begin{array}{c}\text { dados } \\
\text { inválidos }\end{array}$ \\
\hline 5,9 & 0,20 & 22,2 & 104,8 & 88,8 & \\
\hline 6,0 & 0,20 & 21,9 & 101,2 & 84,3 & \\
\hline 6,0 & 0,20 & 21,4 & 103,2 & 86,0 & \\
\hline 6,1 & 0,21 & 21,5 & 110,3 & 86,1 & \\
\hline 6,1 & 0,19 & 21,0 & 93,3 & 80,5 & \\
\hline 6,2 & 0,20 & 22,4 & 110,7 & 89,2 & \\
\hline 7,6 & 0,21 & 23,1 & 178,9 & 112,1 & * tensão \\
\hline 7,9 & 0,20 & 21,4 & 158,5 & 100,3 & \\
\hline 7,9 & 0,19 & 21,1 & 147,9 & 98,6 & \\
\hline 8,0 & 0,20 & 21,0 & 156,2 & 97,6 & \\
\hline 8,0 & 0,20 & 19,9 & 147,8 & 92,4 & \\
\hline 8,2 & 0,20 & 21,3 & 176,0 & 107,3 & \\
\hline 10,0 & 0,20 & 20,4 & 244,1 & 122,1 & \\
\hline 10,0 & 0,20 & 19,1 & 215,3 & 107,7 & \\
\hline 10,0 & 0,20 & 18,9 & 214,7 & 107,4 & \\
\hline 10,1 & 0,20 & 18,5 & 208,4 & 103,2 & \\
\hline 10,1 & 0,21 & 21,0 & 275,0 & 129,7 & $* 2 \mathrm{~S}$ \\
\hline 10,3 & 0,20 & 19,6 & 234,3 & 113,8 & \\
\hline 11,8 & 0,20 & 19,8 & 314,9 & 133,4 & \\
\hline 11,9 & 0,20 & 18,2 & 267,3 & 112,3 & \\
\hline 12,0 & 0,20 & 19,5 & 314,4 & 131,0 & \\
\hline 12,0 & 0,19 & 19,1 & 272,1 & 119,3 & \\
\hline 12,0 & 0,20 & 19,0 & 304,3 & 126,8 & \\
\hline 12,2 & 0,20 & 19,7 & 327,3 & 134,1 & \\
\hline 13,9 & 0,21 & 18,6 & 409,3 & 140,2 & \\
\hline 13,9 & 0,21 & 19,8 & 447,4 & 153,3 & \\
\hline 13,9 & 0,20 & 19,3 & 410,9 & 147,8 & \\
\hline 14,0 & 0,20 & 18,6 & 387,9 & 138,5 & \\
\hline 14,1 & 0,19 & 18,9 & 383,2 & 143,0 & \\
\hline 14,1 & 0,20 & 19,3 & 405,2 & 143,7 & \\
\hline
\end{tabular}




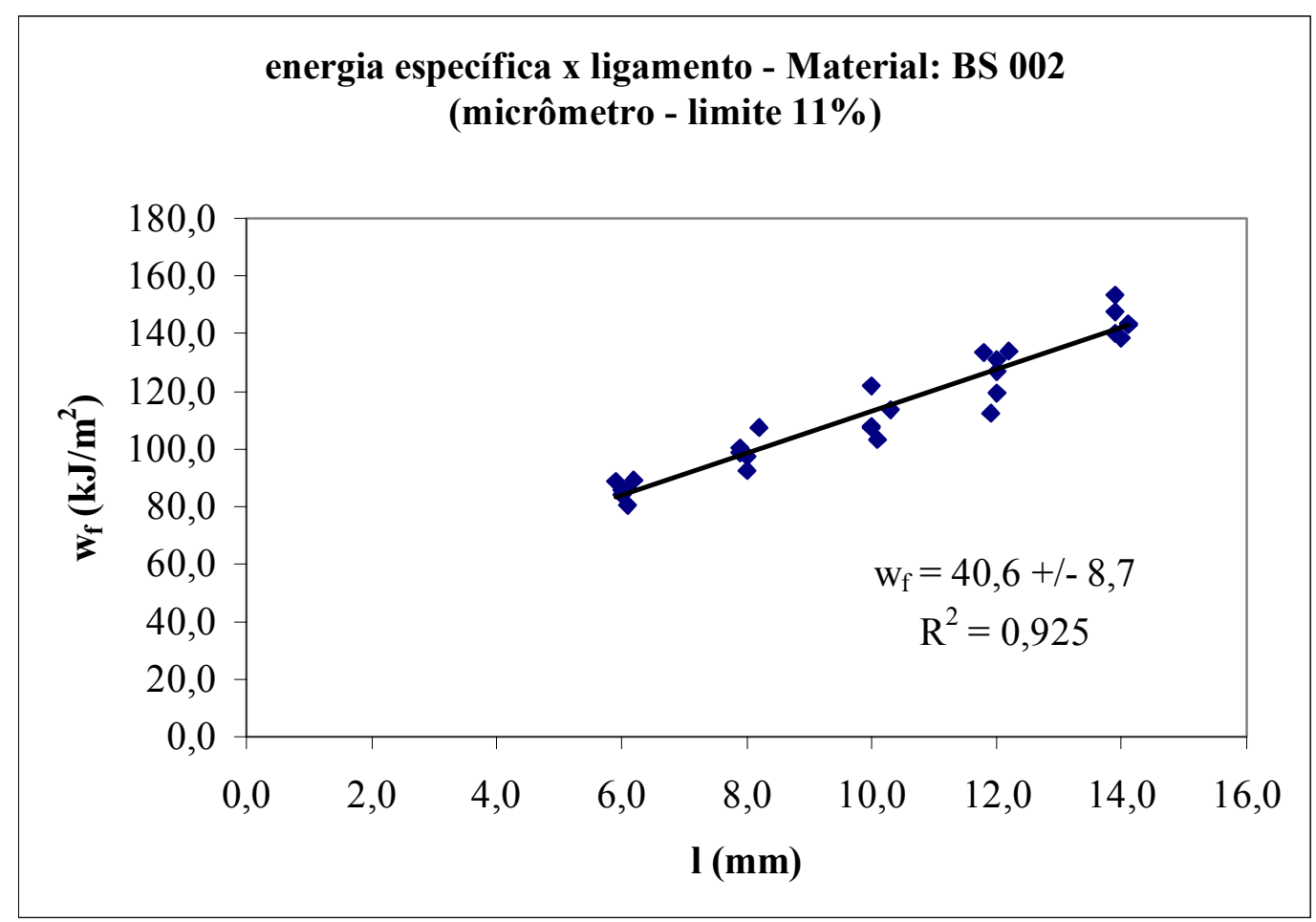

Figura 55: Curva do método EWF - BS 002/micrômetro/11\% $\sigma_{\mathrm{m}}$. 


\section{B.3 - RIGIDEX PC 002-50R968}

CONDIÇÕES DE ENSAIO

LARGURA DO CORPO DE PROVA (mm): 132

ESPESSURA NOMINAL DO CORPO DE PROVA (mm): 0,20

VELOCIDADE DO ENSAIO ( $\mathrm{mm} / \mathrm{min}): 5$

TEMPERATURA DE ENSAIO $\left({ }^{\circ} \mathrm{C}\right): 25 \pm 2$

ORIENTAÇÃO DO CORPO DE PROVA: direção perpendicular à extrusão $\left(90^{\circ}\right)$

LIGAMENTO MÁXIMO (mm): 14,4

LIGAMENTO MÍNIMO (mm): 6,3

DADOS DE TRABALHO ESPECÍFICO

VALOR MÉDIO DAS MÁXIMAS TENSÕES, $\sigma_{\mathrm{m}}(\mathrm{MPa}): 17,8$

TRABALHO ESSENCIAL DE FRATURA, $\mathrm{w}_{\mathrm{e}}\left(\mathrm{kJ} / \mathrm{m}^{2}\right): 37,6 \pm 15,4$ (95\% confiança na predição)

FATOR DE DISSIPAÇÃO DE TRABALHO PLÁSTICO, $\beta \mathrm{w}_{\mathrm{p}}\left(\mathrm{MJ} / \mathrm{m}^{3}\right): 7,3 \pm 1,4$ (inclinação da curva energia específica $\left(\mathrm{w}_{\mathrm{f}}\right) \mathrm{x}$ ligamento (l) (95\% confiança na predição)

TABELA DE DADOS E GRÁFICO EWF: vide Tabela 19 e Figura 56. 
Tabela 19: Dados EWF Rigidex PC 002-50R968

\begin{tabular}{|c|c|c|c|c|c|}
\hline $\begin{array}{c}\text { l } \\
(\mathrm{mm})\end{array}$ & $\begin{array}{c}\mathrm{t} \\
(\mathrm{mm})\end{array}$ & $\begin{array}{c}\sigma_{\max } \\
(\mathbf{M P a})\end{array}$ & $\begin{array}{c}W_{f} \\
(m J)\end{array}$ & $\begin{array}{c}\mathbf{W}_{\mathrm{f}} \\
\left(\mathrm{kJ} / \mathrm{m}^{2}\right)\end{array}$ & \begin{tabular}{|c} 
dados \\
inválidos
\end{tabular} \\
\hline 5,5 & 0,20 & 20,6 & 99,6 & 90,6 & * tensão \\
\hline 6,0 & 0,20 & 21,3 & 116,8 & 97,3 & * tensão \\
\hline 6,3 & 0,20 & 19,8 & 113,2 & 89,8 & * tensão \\
\hline 6,3 & 0,20 & 19,1 & 112,9 & 89,6 & \\
\hline 6,3 & 0,20 & 18,3 & 106,8 & 84,8 & \\
\hline 8,0 & 0,20 & 16,9 & 143,6 & 89,7 & \\
\hline 8,1 & 0,20 & 18,3 & 172,6 & 106,6 & \\
\hline 8,2 & 0,20 & 17,0 & 148,6 & 90,6 & \\
\hline 8,3 & 0,20 & 17,9 & 164,6 & 99,2 & \\
\hline 8,3 & 0,20 & 17,9 & 172,8 & 104,1 & \\
\hline 9,7 & 0,20 & 19,2 & 230,1 & 118,6 & \\
\hline 10,0 & 0,20 & 16,8 & 202,9 & 101,4 & \\
\hline 10,2 & 0,20 & 17,1 & 211,8 & 103,8 & \\
\hline 10,2 & 0,20 & 18,2 & 235,2 & 115,3 & \\
\hline 10,3 & 0,20 & 16,4 & 210,0 & 101,9 & \\
\hline 12,0 & 0,20 & 17,9 & 311,1 & 130,2 & \\
\hline 12,1 & 0,20 & 17,2 & 305,9 & 126,4 & \\
\hline 12,2 & 0,20 & 19,4 & 377,7 & 154,8 & $* 2 \mathrm{~S}$ \\
\hline 12,3 & 0,20 & 16,9 & 298,2 & 121,2 & \\
\hline 12,5 & 0,20 & 16,2 & 302,9 & 121,2 & \\
\hline 13,9 & 0,20 & 16,2 & 377,5 & 135,8 & \\
\hline 14,1 & 0,20 & 15,4 & 354,1 & 125,6 & * tensão \\
\hline 14,1 & 0,20 & 15,7 & 355,8 & 126,2 & * tensão \\
\hline 14,3 & 0,20 & 17,3 & 432,3 & 151,2 & \\
\hline 14,4 & 0,20 & 17,1 & 435,3 & 151,1 & \\
\hline
\end{tabular}




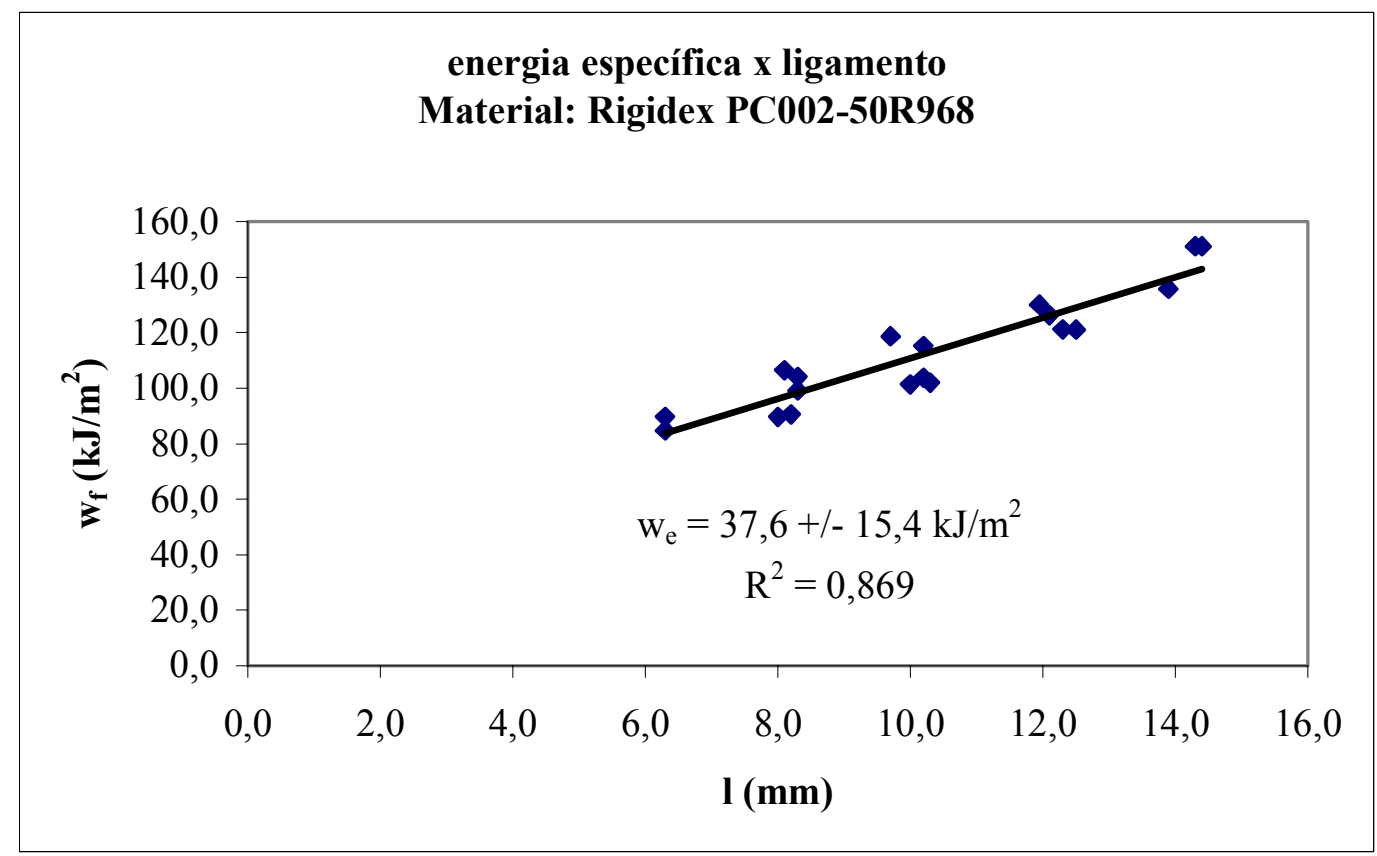

Figura 56: Curva do método EWF - Rigidex PC 002 - 50 R968 


\section{B.4 - MP 0240}

\section{CONDIÇÕES DE ENSAIO}

LARGURA DO CORPO DE PROVA (mm): 132

ESPESSURA NOMINAL DO CORPO DE PROVA (mm): 0,20

VELOCIDADE DO ENSAIO ( $\mathrm{mm} / \mathrm{min}): 5$

TEMPERATURA DE ENSAIO $\left({ }^{\circ} \mathrm{C}\right): 25 \pm 2$

ORIENTAÇÃO DO CORPO DE PROVA: direção perpendicular à extrusão $\left(90^{\circ}\right)$

LIGAMENTO MÁXIMO (mm): 14,1

LIGAMENTO MÍNIMO (mm): 6,0

\section{$\underline{\text { DADOS DE TRABALHO ESPECÍFICO }}$}

VALOR MÉDIO DAS MÁXIMAS TENSÕES, $\sigma_{\mathrm{m}}(\mathrm{MPa}):$ 19,9

TRABALHO ESSENCIAL DE FRATURA, $\mathrm{w}_{\mathrm{e}}\left(\mathrm{kJ} / \mathrm{m}^{2}\right): 23,5 \pm 15,9$

(95\% confiança na predição)

FATOR DE DISSIPAÇÃO DE TRABALHO PLÁSTICO, $\beta \mathrm{w}_{\mathrm{p}}\left(\mathrm{MJ} / \mathrm{m}^{3}\right): 9,4 \pm 1,5$ (inclinação da curva energia específica $\left(\mathrm{w}_{\mathrm{f}}\right) \mathrm{x}$ ligamento (l) ( $95 \%$ confiança na predição)

TABELA DE DADOS E GRÁFICO EWF: vide Tabela 20 e Figura 57. 
Tabela 20: Dados EWF MP 0240.

\begin{tabular}{|c|c|c|c|c|c|}
\hline $\begin{array}{c}\mathrm{I} \\
(\mathrm{mm})\end{array}$ & $\begin{array}{c}\mathbf{t} \\
(\mathrm{mm})\end{array}$ & $\begin{array}{c}\sigma_{\max } \\
(\mathrm{MPa})\end{array}$ & $\begin{array}{c}\mathbf{W}_{\mathrm{f}} \\
(\mathrm{mJ})\end{array}$ & $\begin{array}{c}\mathbf{W}_{\mathrm{f}} \\
\left(\mathrm{kJ} / \mathrm{m}^{2}\right)\end{array}$ & $\begin{array}{c}\text { dados } \\
\text { inválidos }\end{array}$ \\
\hline 6,0 & 0,20 & 18,3 & 85,4 & 71,2 & \\
\hline 6,1 & 0,18 & 23,9 & 109,2 & 99,5 & * tensão \\
\hline 6,2 & 0,18 & 20,6 & 97,1 & 87,0 & \\
\hline 6,3 & 0,20 & 18,6 & 89,8 & 71,3 & \\
\hline 6,4 & 0,20 & 18,8 & 97,7 & 76,3 & \\
\hline 6,5 & 0,20 & 19,9 & 108,8 & 83,7 & \\
\hline 7,9 & 0,18 & 22,0 & 160,7 & 113,0 & \\
\hline 8,0 & 0,18 & 21,6 & 160,2 & 111,3 & \\
\hline 8,0 & 0,18 & 21,2 & 154,3 & 107,1 & \\
\hline 8,1 & 0,18 & 22,7 & 172,1 & 118,0 & * tensão \\
\hline 8,3 & 0,18 & 18,7 & 129,1 & 86,4 & \\
\hline 8,4 & 0,18 & 20,1 & 154,8 & 102,4 & \\
\hline 9,7 & 0,20 & 19,1 & 214,3 & 110,5 & \\
\hline 9,8 & 0,18 & 21,6 & 231,4 & 131,2 & \\
\hline 9,9 & 0,18 & 19,8 & 201,3 & 113,0 & \\
\hline 10,0 & 0,18 & 21,6 & 232,0 & 128,9 & \\
\hline 10,0 & 0,18 & 19,6 & 201,4 & 111,9 & \\
\hline 10,1 & 0,18 & 19,2 & 202,8 & 111,5 & \\
\hline 11,9 & 0,18 & 18,8 & 264,9 & 123,7 & \\
\hline 12,0 & 0,18 & 19,0 & 273,6 & 126,7 & \\
\hline 12,0 & 0,18 & 19,5 & 288,8 & 133,7 & \\
\hline 12,1 & 0,18 & 21,4 & 338,1 & 155,2 & \\
\hline 12,3 & 0,18 & 20,9 & 337,8 & 152,6 & \\
\hline 12,5 & 0,20 & 16,6 & 284,9 & 113,9 & * tensão \\
\hline 13,8 & 0,18 & 19,8 & 373,6 & 150,4 & \\
\hline 13,9 & 0,18 & 20,3 & 399,0 & 159,5 & \\
\hline 13,9 & 0,20 & 16,9 & 348,8 & 125,5 & * tensão \\
\hline 14,0 & 0,20 & 18,6 & 404,7 & 144,5 & \\
\hline 14,1 & 0,20 & 18,4 & 448,1 & 158,9 & \\
\hline 14,1 & 0,20 & 18,0 & 412,3 & 146,2 & \\
\hline
\end{tabular}




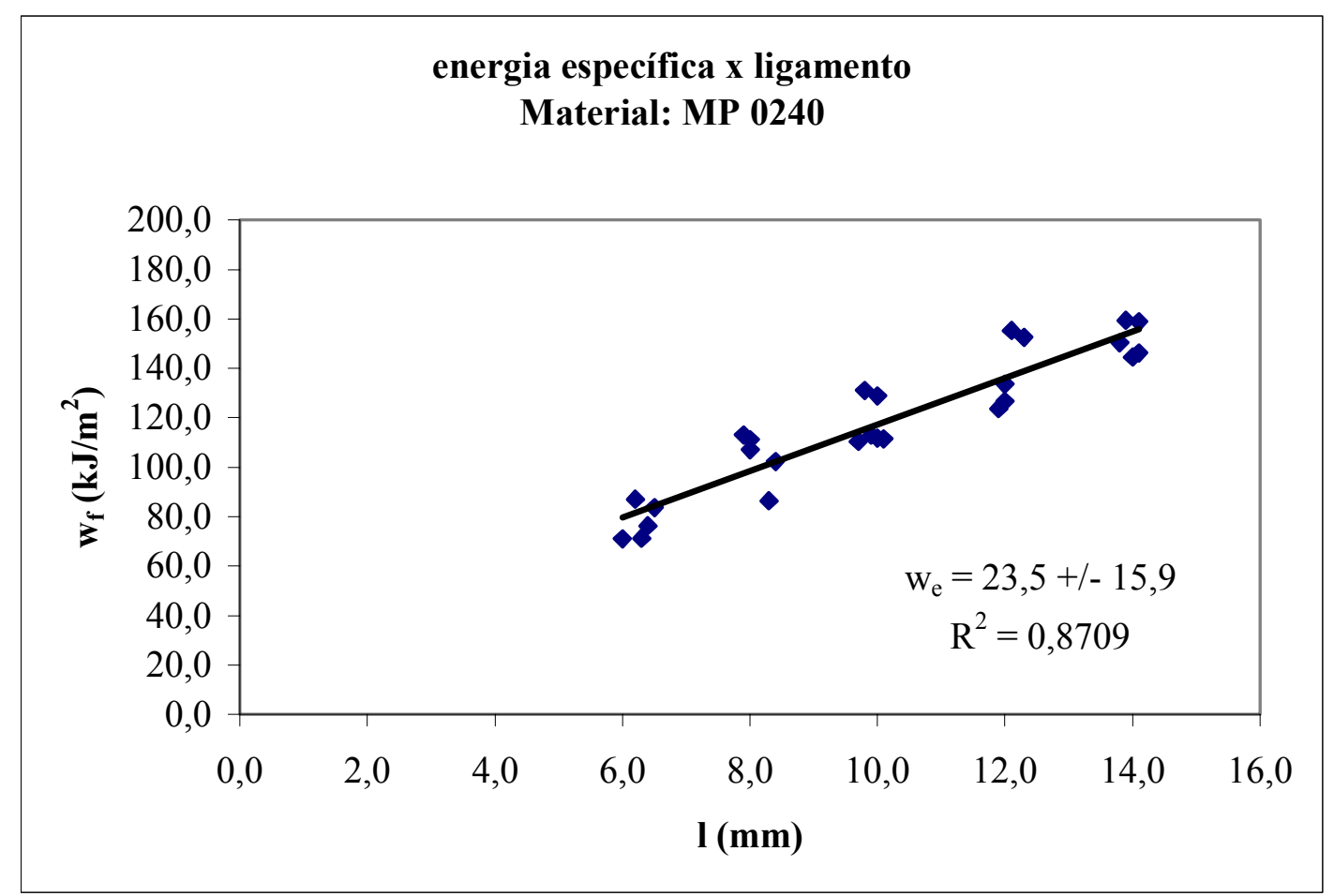

Figura 57: Curva do método EWF - MP 0240. 


\section{B.5 - HP 0155}

\section{CONDIÇÕES DE ENSAIO}

LARGURA DO CORPO DE PROVA (mm): 132

ESPESSURA NOMINAL DO CORPO DE PROVA (mm): 0,20

VELOCIDADE DO ENSAIO ( $\mathrm{mm} / \mathrm{min}): 5$

TEMPERATURA DE ENSAIO $\left({ }^{\circ} \mathrm{C}\right): 25 \pm 2$

ORIENTAÇÃO DO CORPO DE PROVA: direção perpendicular à extrusão $\left(90^{\circ}\right)$

LIGAMENTO MÁXIMO (mm): 14,1

LIGAMENTO MÍNIMO (mm): 6,0

\section{$\underline{\text { DADOS DE TRABALHO ESPECÍFICO }}$}

VALOR MÉDIO DAS MÁXIMAS TENSÕES, $\sigma_{\mathrm{m}}(\mathrm{MPa}):$ 20,4

TRABALHO ESSENCIAL DE FRATURA, $\mathrm{w}_{\mathrm{e}}\left(\mathrm{kJ} / \mathrm{m}^{2}\right): 34,4 \pm 9,8$ ( $95 \%$ confiança na predição)

FATOR DE DISSIPAÇÃO DE TRABALHO PLÁSTICO, $\beta \mathrm{w}_{\mathrm{p}}\left(\mathrm{MJ} / \mathrm{m}^{3}\right): 6,2 \pm 1,0$ (inclinação da curva energia específica $\left(\mathrm{w}_{\mathrm{f}}\right) \mathrm{x}$ ligamento (l) ( $95 \%$ confiança na predição)

TABELA DE DADOS E GRÁFICO EWF: vide Tabela 21 e Figura 58. 
Tabela 21: Dados EWF HP 0155.

\begin{tabular}{|c|c|c|c|c|c|}
\hline $\begin{array}{c}\text { l } \\
(\mathrm{mm})\end{array}$ & $\begin{array}{c}\mathrm{t} \\
(\mathrm{mm})\end{array}$ & $\begin{array}{c}\sigma_{\max } \\
(\mathrm{MPa})\end{array}$ & $\begin{array}{c}\mathbf{W}_{\mathrm{f}} \\
(\mathbf{m J})\end{array}$ & $\begin{array}{c}\mathbf{w}_{\mathrm{f}} \\
\left(\mathrm{kJ} / \mathrm{m}^{2}\right)\end{array}$ & $\begin{array}{c}\text { dados } \\
\text { inválidos }\end{array}$ \\
\hline 6,0 & 0,18 & 23,3 & 82,0 & 75,9 & * tensão \\
\hline 6,2 & 0,20 & 21,1 & 91,0 & 73,4 & \\
\hline 6,3 & 0,20 & 22,1 & 96,2 & 76,3 & \\
\hline 6,3 & 0,20 & 22,1 & 94,9 & 75,3 & \\
\hline 6,3 & 0,20 & 21,7 & 95,9 & 76,1 & \\
\hline 6,4 & 0,20 & 19,8 & 82,7 & 64,6 & \\
\hline 7,9 & 0,20 & 19,5 & 113,7 & 72,0 & \\
\hline 7,9 & 0,18 & 22,0 & 119,1 & 83,7 & \\
\hline 7,9 & 0,20 & 21,9 & 147,4 & 93,3 & \\
\hline 8,1 & 0,20 & 20,7 & 145,7 & 89,9 & \\
\hline 8,3 & 0,18 & 20,6 & 123,2 & 82,5 & \\
\hline 8,4 & 0,20 & 19,8 & 144,1 & 85,8 & \\
\hline 9,9 & 0,18 & 21,1 & 181,4 & 101,8 & \\
\hline 9,9 & 0,20 & 18,1 & 176,6 & 89,2 & \\
\hline 10,0 & 0,20 & 20,0 & 185,6 & 92,8 & \\
\hline 10,2 & 0,20 & 20,2 & 202,1 & 99,0 & \\
\hline 10,2 & 0,18 & 22,1 & 206,7 & 112,6 & $* 2 \mathrm{~S}$ \\
\hline 10,5 & 0,20 & 19,1 & 197,0 & 93,8 & \\
\hline 11,7 & 0,20 & 20,4 & 269,2 & 115,1 & \\
\hline 11,7 & 0,20 & 18,4 & 221,2 & 94,5 & \\
\hline 11,9 & 0,18 & 21,1 & 257,1 & 120,0 & \\
\hline 12,0 & 0,18 & 20,5 & 235,0 & 108,8 & \\
\hline 12,2 & 0,18 & 21,0 & 237,7 & 108,2 & \\
\hline 12,2 & 0,18 & 21,4 & 240,4 & 109,5 & \\
\hline 13,5 & 0,20 & 18,5 & 313,8 & 116,2 & \\
\hline 13,7 & 0,18 & 19,9 & 293,3 & 118,9 & \\
\hline 13,8 & 0,18 & 19,7 & 290,0 & 116,7 & \\
\hline 13,9 & 0,20 & 17,9 & 310,1 & 111,5 & * tensão \\
\hline 13,9 & 0,20 & 19,9 & 338,1 & 121,6 & \\
\hline 14,1 & 0,20 & 17,0 & 287,3 & 101,9 & * tensão \\
\hline
\end{tabular}




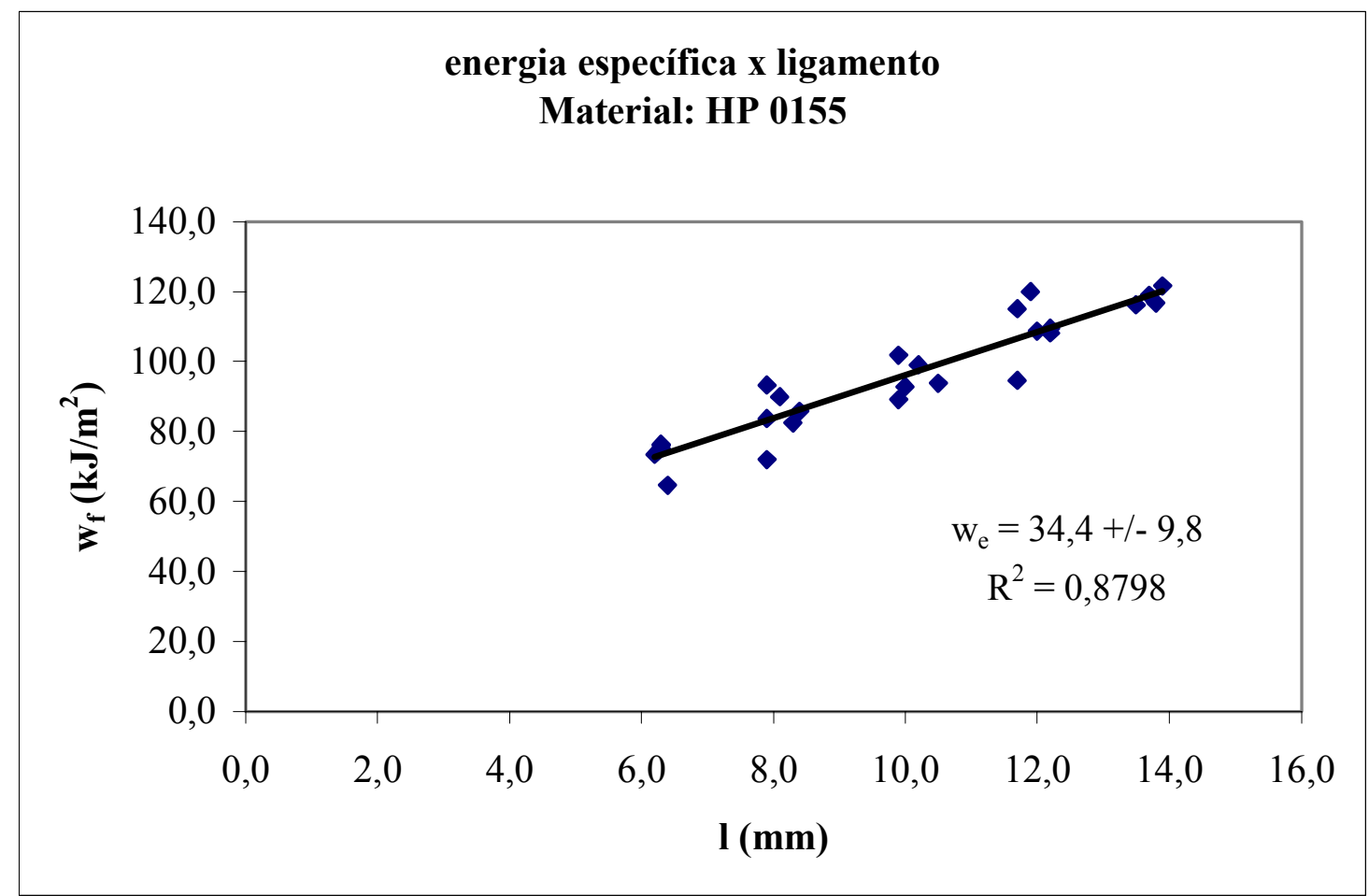

Figura 58: Curva do método EWF - HP 0155 
B.6 - GM 5010 T 2

B.6.1 - Corpos de prova na direção da extrusão $\left(0^{\circ}\right)$

CONDIÇÕES DE ENSAIO

LARGURA DO CORPO DE PROVA (mm): 132

ESPESSURA NOMINAL DO CORPO DE PROVA (mm): 0,16

VELOCIDADE DO ENSAIO ( $\mathrm{mm} / \mathrm{min}): 5$

TEMPERATURA DE ENSAIO $\left({ }^{\circ} \mathrm{C}\right): 25 \pm 2$

ORIENTAÇÃO DO CORPO DE PROVA: direção da extrusão $\left(0^{\circ}\right)$

LIGAMENTO MÁXIMO (mm): 14,3

LIGAMENTO MÍNIMO (mm): 5,9

DADOS DE TRABALHO ESPECÍFICO

VALOR MÉDIO DAS MÁXIMAS TENSÕES, $\sigma_{\mathrm{m}}(\mathrm{MPa}):$ 20,1

TRABALHO ESSENCIAL DE FRATURA, $\mathrm{w}_{\mathrm{e}}\left(\mathrm{kJ} / \mathrm{m}^{2}\right): 30,1 \pm 12,0$

( $95 \%$ confiança na predição)

FATOR DE DISSIPAÇÃO DE TRABALHO PLÁSTICO, $\beta \mathrm{w}_{\mathrm{p}}\left(\mathrm{MJ} / \mathrm{m}^{3}\right): 11,2 \pm 1,1$ (inclinação da curva energia específica $\left(\mathrm{w}_{\mathrm{f}}\right) \mathrm{x}$ ligamento (l) ( $95 \%$ confiança na predição)

TABELA DE DADOS E GRÁFICO EWF: vide Tabela 22 e Figura 59. 
Tabela 22: Dados EWF GM 5010 T 2 - direção da extrusão.

\begin{tabular}{|c|c|c|c|c|c|}
\hline $\begin{array}{c}\text { l } \\
(\mathbf{m m})\end{array}$ & $\underset{(\mathbf{m m})}{\mathbf{t}}$ & $\begin{array}{c}\sigma_{\max } \\
(\mathbf{M P a})\end{array}$ & $\begin{array}{c}W_{f} \\
(m J)\end{array}$ & $\begin{array}{c}\mathbf{w}_{\mathrm{f}} \\
\left(\mathrm{kJ} / \mathrm{m}^{2}\right)\end{array}$ & \begin{tabular}{|c|} 
Dados \\
Inválidos
\end{tabular} \\
\hline 5,9 & 0,16 & 19,8 & 89,2 & 94,4 & \\
\hline 5,9 & 0,16 & 22,3 & 103,8 & 110,0 & * tensão \\
\hline 6,1 & 0,16 & 22,3 & 106,7 & 109,3 & * tensão \\
\hline 6,1 & 0,16 & 20,2 & 95,0 & 97,3 & \\
\hline 6,1 & 0,16 & 20,1 & 92,2 & 94,5 & \\
\hline 6,2 & 0,16 & 21,5 & 106,0 & 106,9 & \\
\hline 7,3 & 0,16 & 20,1 & 125,9 & 107,8 & \\
\hline 7,8 & 0,16 & 21,2 & 155,2 & 124,3 & \\
\hline 7,9 & 0,16 & 20,5 & 155,6 & 123,1 & \\
\hline 8,2 & 0,16 & 18,0 & 140,9 & 107,4 & \\
\hline 8,2 & 0,16 & 22,4 & 184,2 & 140,4 & * tensão \\
\hline 8,2 & 0,16 & 20,3 & 164,4 & 125,3 & \\
\hline 9,8 & 0,16 & 20,5 & 228,6 & 145,8 & \\
\hline 9,9 & 0,16 & 19,2 & 221,4 & 139,8 & \\
\hline 10,0 & 0,16 & 19,5 & 230,6 & 144,1 & \\
\hline 10,0 & 0,16 & 19,1 & 212,6 & 132,8 & \\
\hline 10,0 & 0,16 & 19,6 & 217,5 & 136,0 & \\
\hline 10,2 & 0,16 & 20,5 & 244,4 & 149,7 & \\
\hline 11,9 & 0,16 & 22,8 & 366,5 & 192,5 & * tensão \\
\hline 11,9 & 0,16 & 20,6 & 322,9 & 169,6 & \\
\hline 11,9 & 0,16 & 19,1 & 298,7 & 156,9 & \\
\hline 12,0 & 0,16 & 20,8 & 335,6 & 174,8 & \\
\hline 12,1 & 0,16 & 19,9 & 319,3 & 164,9 & \\
\hline 12,3 & 0,16 & 21,3 & 358,9 & 182,4 & \\
\hline 14,1 & 0,16 & 19,4 & 429,5 & 190,4 & \\
\hline 14,2 & 0,16 & 17,2 & 369,2 & 162,5 & * tensão \\
\hline 14,2 & 0,16 & 18,7 & 412,1 & 181,4 & \\
\hline 14,2 & 0,16 & 19,8 & 440,9 & 194,1 & \\
\hline 14,2 & 0,16 & 16,7 & 377,0 & 165,9 & * tensão \\
\hline 14,3 & 0,16 & 18,6 & 408,2 & 178,4 & \\
\hline
\end{tabular}




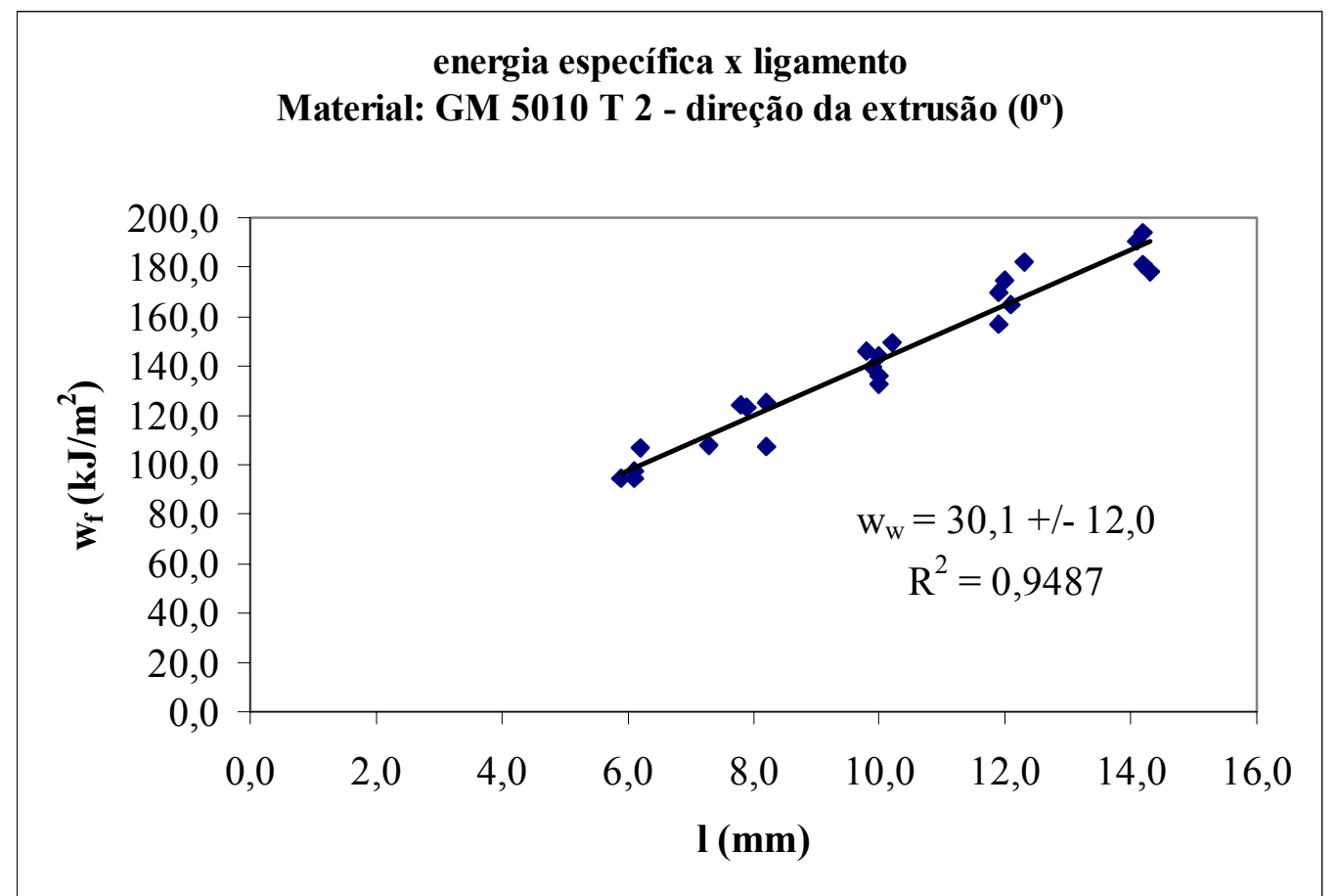

Figura 59: Curva do método EWF - GM 5010 T 2 - direção da extrusão 
B.6.2 - Corpos de prova na direção perpendicular à extrusão $\left(90^{\circ}\right)$

CONDIÇÕES DE ENSAIO

LARGURA DO CORPO DE PROVA (mm): 132

ESPESSURA NOMINAL DO CORPO DE PROVA (mm): 0,16

VELOCIDADE DO ENSAIO ( $\mathrm{mm} / \mathrm{min}): 5$

TEMPERATURA DE ENSAIO $\left({ }^{\circ} \mathrm{C}\right): 25 \pm 2$

ORIENTAÇÃO DO CORPO DE PROVA: direção perpendicular à extrusão $\left(90^{\circ}\right)$

LIGAMENTO MÁXIMO (mm): 14,1

LIGAMENTO MÍNIMO (mm): 6,0

DADOS DE TRABALHO ESPECÍFICO

VALOR MÉDIO DAS MÁXIMAS TENSÕES, $\sigma_{\mathrm{m}}(\mathrm{MPa}): 21,0$

TRABALHO ESSENCIAL DE FRATURA, $\mathrm{w}_{\mathrm{e}}\left(\mathrm{kJ} / \mathrm{m}^{2}\right): 30,2 \pm 7,1$

(95\% confiança na predição)

FATOR DE DISSIPAÇÃO DE TRABALHO PLÁSTICO, $\beta \mathrm{w}_{\mathrm{p}}\left(\mathrm{MJ} / \mathrm{m}^{3}\right): 8,5 \pm 0,7$ (inclinação da curva energia específica $\left(\mathrm{w}_{\mathrm{f}}\right) \mathrm{x}$ ligamento (l) ( $95 \%$ confiança na predição)

TABELA DE DADOS E GRÁFICO EWF: vide Tabela 23 e Figura 60. 
Tabela 23: Dados EWF GM 5010 T 2 - perpendicular à direção de extrusão.

\begin{tabular}{|c|c|c|c|c|c|}
\hline $\begin{array}{c}\text { l } \\
(\mathrm{mm})\end{array}$ & $\begin{array}{c}\mathrm{t} \\
(\mathrm{mm})\end{array}$ & $\begin{array}{c}\sigma_{\max } \\
(\mathbf{M P a})\end{array}$ & $\begin{array}{c}W_{f} \\
(m J)\end{array}$ & $\begin{array}{c}\mathbf{w}_{\mathrm{f}} \\
\left(\mathrm{kJ} / \mathrm{m}^{2}\right)\end{array}$ & $\begin{array}{c}\text { dados } \\
\text { inválidos }\end{array}$ \\
\hline 6,0 & 0,16 & 20,7 & 71,5 & 74,5 & \\
\hline 6,2 & 0,16 & 22,5 & 85,1 & 85,8 & \\
\hline 6,2 & 0,16 & 22,0 & 88,1 & 88,9 & \\
\hline 6,3 & 0,16 & 22,9 & 88,1 & 87,4 & \\
\hline 6,5 & 0,16 & 22,0 & 90,5 & 87,0 & \\
\hline 6,6 & 0,16 & 20,5 & 86,2 & 81,6 & \\
\hline 7,6 & 0,16 & 22,0 & 119,3 & 98,1 & \\
\hline 7,9 & 0,16 & 21,8 & 126,1 & 99,8 & \\
\hline 8,0 & 0,16 & 22,5 & 131,5 & 102,7 & \\
\hline 8,3 & 0,16 & 20,5 & 124,9 & 94,1 & \\
\hline 8,3 & 0,16 & 21,6 & 133,5 & 100,5 & \\
\hline 8,5 & 0,16 & 21,7 & 139,5 & 102,6 & \\
\hline 10,0 & 0,16 & 20,5 & 175,8 & 109,9 & \\
\hline 10,1 & 0,16 & 19,3 & 168,3 & 104,1 & \\
\hline 10,1 & 0,16 & 20,3 & 178,1 & 110,2 & \\
\hline 10,2 & 0,16 & 20,8 & 189,2 & 116,0 & \\
\hline 10,2 & 0,16 & 20,9 & 192,8 & 118,1 & \\
\hline 10,4 & 0,16 & 21,4 & 201,9 & 121,3 & \\
\hline 11,8 & 0,16 & 21,3 & 251,1 & 133,0 & \\
\hline 12,0 & 0,16 & 20,2 & 207,3 & 107,9 & $* 2 \mathrm{~S}$ \\
\hline 12,3 & 0,16 & 21,2 & 280,3 & 142,4 & \\
\hline 12,4 & 0,16 & 20,8 & 279,2 & 140,7 & \\
\hline 12,5 & 0,16 & 20,6 & 274,3 & 137,2 & \\
\hline 13,0 & 0,16 & 18,9 & 255,3 & 122,7 & $* 2 \mathrm{~S}$ \\
\hline 13,7 & 0,16 & 21,6 & 335,6 & 153,1 & \\
\hline 13,9 & 0,16 & 19,9 & 325,4 & 146,3 & \\
\hline 14,0 & 0,16 & 20,0 & 323,5 & 144,4 & \\
\hline 14,0 & 0,16 & 21,4 & 331,9 & 148,1 & \\
\hline 14,0 & 0,16 & 20,3 & 343,5 & 153,3 & \\
\hline 14,1 & 0,16 & 20,3 & 323,9 & 143,6 & \\
\hline
\end{tabular}




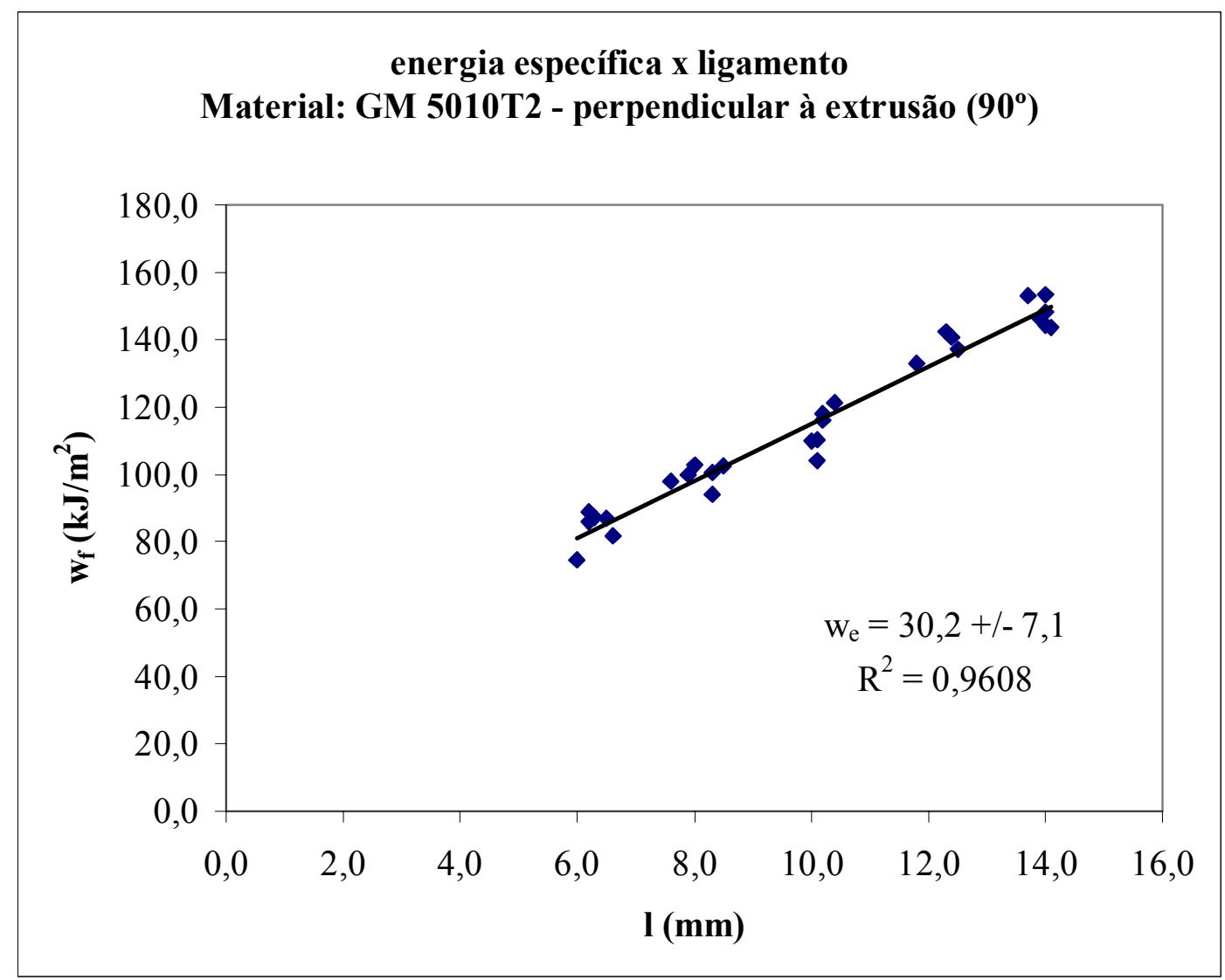

Figura 60: Curva do método EWF - GM 5010 T 2 - perpendicular à extrusão 


\section{APÊNDICE C - MÉTODO DA INTEGRAL J}

Rice (1968), citado por Kinloch \& Young (1995), Hale \& Ramsteiner (2001), Anderson (1995), Meyers \& Chawla (1999), Schön (2002), demonstrou que uma certa integral conhecida como Integral $\mathrm{J}$, descrevia o fluxo de energia na região da ponta de trinca e que o termo dominante na descrição das singularidades de tensão e deformação na ponta da trinca também poderia ser escrito em termos de $J$ (KINLOCH \& YOUNG, 1995). Assim, para caracterizar a instabilidade de trincas e $\mathrm{o}$ crescimento de trincas em materiais elásticos não lineares Rice introduziu o método da Intergal J (HALE \& RAMSTEINER, 2001). Ele demonstrou que a diferença entre o trabalho externo e a variação na energia potencial interna na área circunscrita por uma linha de integração (ou contorno) $\Gamma$, em torno da ponta de uma trinca (Figura 61), pode ser expressa pela integral de linha ao longo desse contorno, através da expressão (C1) (ANDERSON, 1995); (MEYERS \& CHAWLA, 1999); (HALE \& RAMSTEINER, 2001); (SCHÖN, 2002).

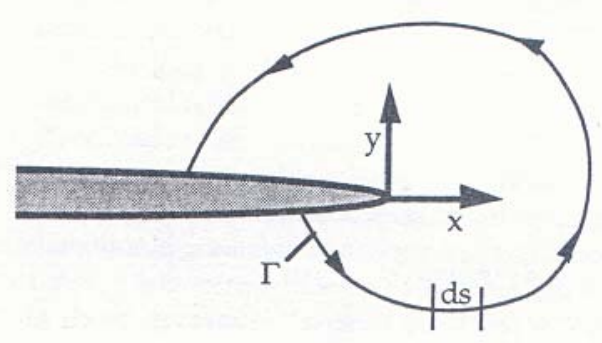

Figura 61: Contorno arbitrário em torno da ponta de uma trinca (Fonte: ANDERSON, 1999).

$J=\int_{\Gamma} w d y-\int_{\Gamma} T \frac{d u}{d x} d s$

onde

$\Gamma: \quad$ caminho da integral ao redor da trinca

w: densidade de energia de deformação (ou energia de deformação por unidade de volume) 
$T: \quad$ vetor de tensão (tração), perpendicular a $\Gamma$ e apontando para fora do contorno, ao longo do caminho de integração $\Gamma$

$u$ : deslocamento (do corpo)

$x, y: \quad$ coordenadas

$s: \quad$ comprimento do arco ao longo da linha de integração

$T \frac{d u}{d x} d s:$ taxa de trabalho na área circunscrita por $\Gamma$

A densidade de energia de deformação $w$ é dada por:

$$
w=\int_{0}^{\varepsilon_{i j}} \sigma_{i j} d \varepsilon_{i j}
$$

Rice demonstrou que o valor de $J$ era independente do caminho de integração. $\mathrm{Na}$ medida em que não há dissipação de energia na área circunscrita por $\Gamma$, o valor da Integral $J$ é zero (ANDERSON, 1995) (MEYERS \& CHAWLA, 1999); (HALE \& RAMSTEINER, 2001); (SCHÖN, 2002). Qualquer trabalho externo aplicado é armazenado elasticamente no material. Entretanto, se a linha de integração incluir uma trinca se propagando, o valor de $J$ leva em conta o trabalho realizado por unidade de crescimento de trinca. Considere a Figura (62), que representa esquematicamente as curvas de carregamento (não lineares) correspondentes a amostras com comprimento de trinca $a$ e $(a+\partial a)$, sob condições de deslocamento controlado.

Com base nesse modelo $J$ pode ser simplesmente definido em termos de energia como a taxa de decréscimo da energia potencial em um corpo elástico não linear, $U$, com o comprimento da trinca (KINLOCH \& YOUNG, 1995), ou ainda, $J$ representa a diferença de energia potencial entre dois corpos idênticos contendo trincas de comprimento $a$ e $(a+\partial a)$. Na Figura 62 a área demarcada representa a variação da energia $J B \partial a$, e assim:

$$
J=-\frac{1}{B}\left(\frac{\partial U}{\partial a}\right)
$$


onde $B$ é a espessura da amostra.

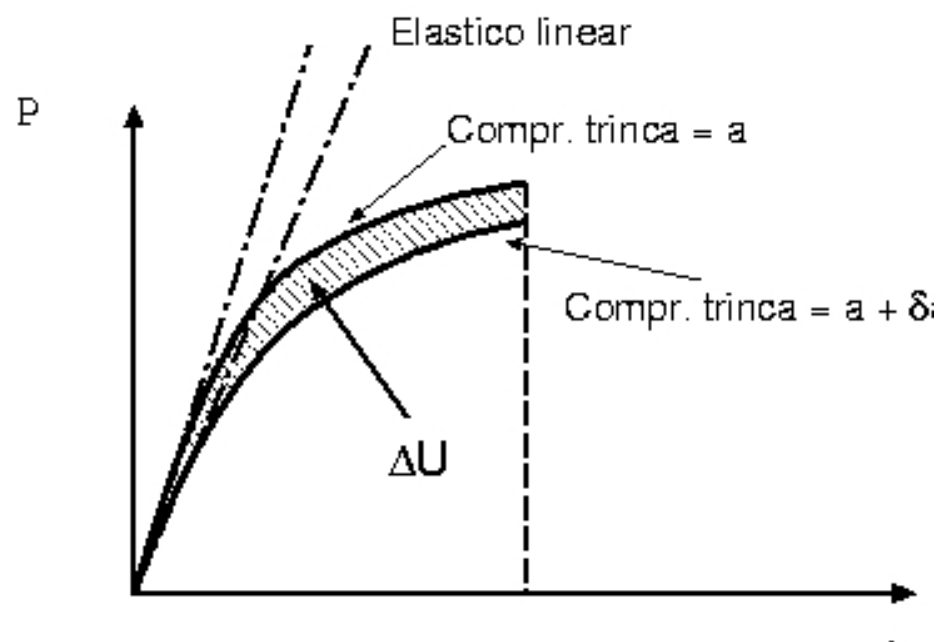

$\Delta$

Figura 62: A Integral J (deslocamento controlado). (Adaptado de Kinloch \& Young, 1995).

$J$ pode ser visto tanto como um parâmetro de energia como um parâmetro de intensidade de tensão (ANDERSON, 1995), ou seja, também como um parâmetro de campo.

É importante considerar que a derivação de $J$ é estritamente válida somente para materiais elásticos lineares e não-lineares, nos quais o descarregamento ocorre segundo o mesmo caminho inicial de carregamento. Nos materiais reais, após a deformação plástica, o descarregamento segue um caminho diferente. Para materiais elasto-plásticos, $J$ perde sua interpretação física relacionada à energia potencial, mas conserva seu significado como uma medida da intensidade dos campos de tensão e deformação elasto-plástica ao redor da ponta da trinca (DOWLING, 1999). $\mathrm{Na}$ prática, $J$ é muito empregado para materiais com comportamento elasto-plástico. (BROBERG, 1982); (KINLOCH \& YOUNG, 1995); (ANDERSON, 1995); (HALE \& RAMSTEINER, 2001); (WILLIAMS, 2001).

O critério para o crescimento da trinca é:

$$
J \geq J_{c}
$$


Ou seja, se $J$ atinge um valor crítico, $J_{c}$, a trinca avança. Idealmente $J_{c}$ é uma propriedade do material independente do comprimento da trinca e da geometria do corpo de prova. Em particular, no modo de abertura (modo I) e no estado plano de deformação este é designado por $J_{I C}$.

$\mathrm{Na}$ determinação experimental de $J_{c}$, certas restrições geométricas dos corpos de prova precisam ser respeitadas, conforme o seguinte critério de validação (TJONG et al, 2000); (WILLIAMS, 2001):

$$
B, W, W-a \geq 25\left(\frac{J_{c}}{\sigma_{y}}\right)
$$

$J$ é um caso mais geral da taxa de liberação de energia, $G$. No caso especial de um material elástico linear, $J_{c}=G_{c}$.

Uma forma de se determinar $J$ é aplicar a definição da integral de linha, conforme Equação $(\mathrm{C} 1)$, para a configuração de interesse, entretanto, o método do contorno não é prático na maioria das vezes (ANDERSON, 1999).

$\mathrm{Na}$ prática é preferível usar o conceito de taxa de liberação de energia, conforme a Equação (C3). Neste caso, $J$ pode ser calculado a partir da energia dissipada usando a seguinte expressão (WILLIAMS, 2001); (HALE \& RAMSTEINER, 2001):

$$
J=\eta \frac{U_{t}}{B(W-a)}
$$

onde $U_{t}$ é a energia total aplicada, $\eta$ é um fator de calibração, $B$ é a espessura do corpo de prova, $W$ é a profundidade (ou largura) do corpo de prova e $a$ é o comprimento da trinca.

Para as configurações dos corpos de prova sugeridas pelo protocolo de ensaio do European Structural Integrity Society - ESIS, Figura (63), o fator de calibração $\eta$ é dado da seguinte forma (HALE \& RAMSTEINER, 2001):

$$
\eta=2+0,522(1-\mathrm{a} / W) \quad(\text { corpo de prova compacto de tração) }
$$




$$
\eta=2
$$

(SENB - flexão de três pontos)

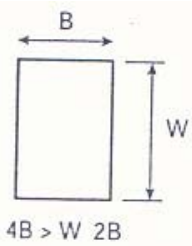

(a)
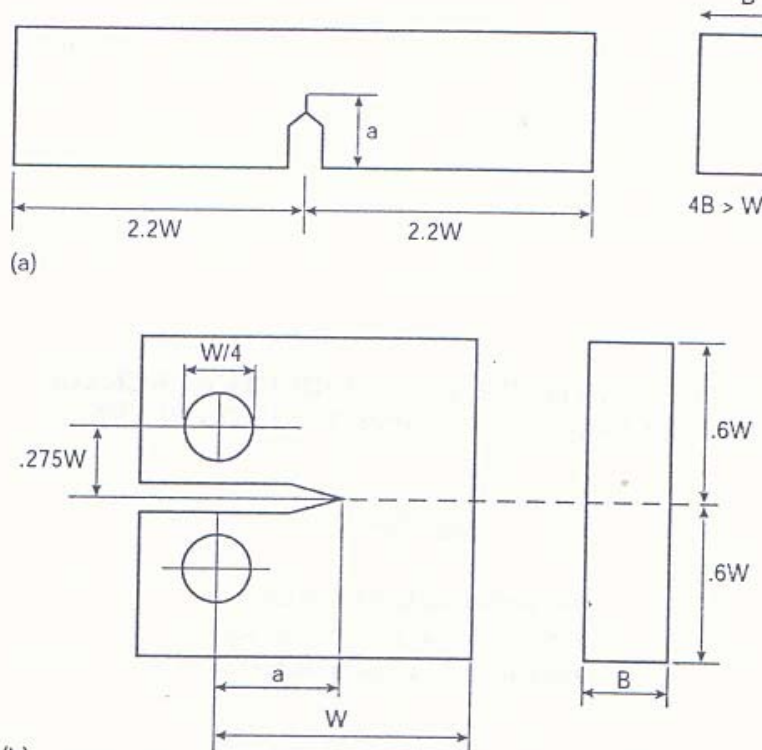

$4 \mathrm{~B}>\mathrm{W} 2 \mathrm{~B}$

(b)

Figura 63: Configurações dos corpos de prova conforme protocolo de ensaio do ESIS. (a) flexão de três pontos (SENB); (b) corpo de prova compacto. (Fonte: HALE \& RAMSTEINER, 2001).

Uma série de corpos de prova nominalmente idênticos são carregados para apresentarem diferentes quantidades de crescimento estável de trinca, $\Delta a$. A energia absorvida em cada caso é medida através do cálculo da área sob a curva carga $(P) \mathrm{x}$ deslocamento ( $\Delta$ ), e $J$ é determinado conforme a Equação (C6). Com os dados calculados de $J$, constrói-se então uma curva $J$ x $\Delta a$, conhecida como Curva J-R.

Entretanto, no caso de materiais muito dúcteis, como o polietileno de alta densidade, ocorre o arredondamento acentuado da ponta da trinca. Nestes casos é necessária uma correção, construindo-se uma outra curva denominada "blunting line", indicada por $J_{b}$, que obedece à seguinte relação:

$J_{b}=2 . \sigma_{y} . \Delta a_{b}$

onde $\Delta a_{b}$ decorre do arredondamento da ponta da trinca. 
Assumindo-se, a princípio, um comportamento linear da curva J-R (obtendose uma "best line" através dos pontos), com inclinação menor que a "blunting line", o valor de $J_{c}$, que corresponde então ao real início de crescimento da trinca, pode ser obtido a partir da interseção da curva J-R com a "blunting line" (MEYERS \& CHAWLA, 1999); (WILLIAMS, 2001).

A inclinação da curva $J-R$, dada uma certa extensão da trinca, fornece uma noção da relativa estabilidade do crescimento da trinca. Um material cuja inclinação é mais acentuada é menos suscetível a uma propagação instável da trinca (ANDERSON, 1995). Para materiais muito frágeis a curva tem inclinação praticamente nula (WILLIAMS, 2001).

Esse esquema pode funcionar bem para materiais moderadamente tenazes, para os quais há uma nítida diferença entre as inclinações das duas linhas. No caso de polímeros muito tenazes, como os polietilenos empregados em tubos, a diferença não é tão acentuada, tornando difícil distinguir entre crescimento de trinca e arredondamento da ponta da trinca, de forma que a definição de $J_{c}$ é problemática. Por exemplo, a Figura 64 mostra que o polietileno de alta densidade exibe arredondamento da ponta trinca à temperatura ambiente, enquanto que à $-20^{\circ} \mathrm{C}$ a trinca se propaga através de crazing (HALE \& RAMSTEINER, 2001).
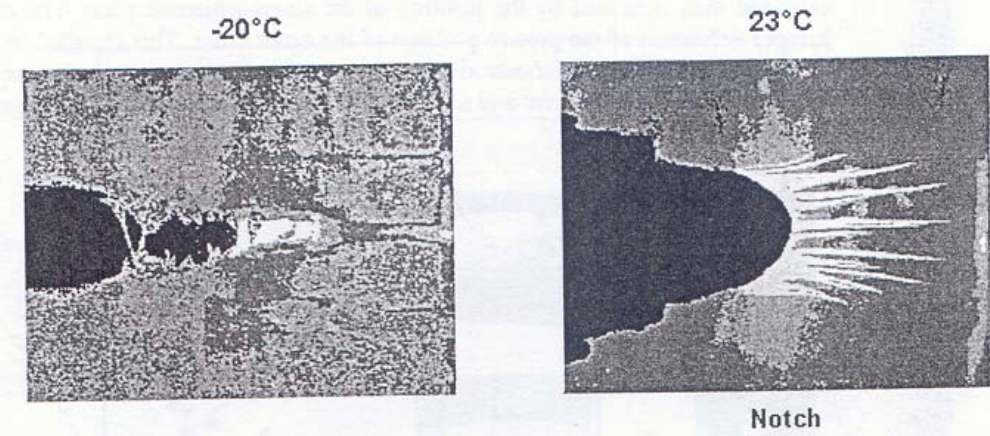

Figura 64: Ponta da trinca em um corpo de prova compacto de tração de polietileno de alta densidade (vista lateral) após deformação a $-\mathbf{2 0}^{\circ} \mathrm{C}$ (crazing) e $23^{\circ} \mathrm{C}$ (blunting) (Fonte: HALE \& RAMSTEINER, 2001).

A solução adotada nesses casos é abandonar a noção de arredondamento e do verdadeiro início de crescimento e caracterizar o material através de uma relação de potência, ou seja: 


$$
J=A(\Delta a)^{N}
$$

estabelecendo um valor $J_{0,2}$ de "início de crescimento" quando $\Delta a_{0}=0,2 \mathrm{~mm}$. Tratase de um valor arbitrário, que é pequeno e próximo do limite inferior de resolução de $\Delta a$ nas situações reais, tornando-se assim uma definição prática sensível do início de crescimento da trinca, uma vez que é mais fácil de ser definida que a intersecção das duas linhas (WILLIAMS, 2001); (HALE \& RAMSTEINER, 2001).

A equação (C10) pode ser reescrita para o caso de um crescimento de trinca real:

$$
J=A\left(\Delta a_{0,2}+\Delta a\right)^{N}
$$

e o valor da iniciação é $J=A\left(\Delta a_{0,2}\right)^{N}$ (aqui dessa forma considerado quando $\Delta a=0$ ).

Dessa forma, para pequenos valores de $N$ e/ou $\Delta a<<\Delta a_{0,2}$ temos:

$$
J=J_{0,2}+N J_{0,2} \frac{\Delta a}{\Delta a_{0,2}}
$$

Atualmente é reconhecido que as curvas J-R dependem do tamanho do corpo de prova e dessa forma não representam propriedades fundamentais do material (WILLIAMS, 2001) e para materiais poliméricos que possuem baixos valores de limite de escoamento $\left(\sigma_{y}\right)$, como o polipropileno e o polietileno, as limitações geométricas podem apresentar algumas dificuldades práticas (TJONG, et al, 2000). Além disso, como já discutido, o avanço da trinca pode não ser tão evidente e o método da Integral J foi desenvolvido para crescimento estável (contínuo) de trincas enquanto que o mecanismo de crescimento lento de trincas (SCG) no polietileno de alta densidade é descontínuo (nucleação e crescimento de crazes $\rightarrow$ degradação e ruptura das fibrilas $\rightarrow$ avanço da trinca) - por sua própria natureza é um processo mesoscópico (PERES \& SCHÖN, 2004). Apesar dessas considerações, as curvas J-R 
podem ser úteis para a comparação de materiais e, em particular, para o desenvolvimento de estudos sobre a taxa de crescimento (sub-crítico) de trincas em polietileno. 


\section{REFERÊNCIAS}

ALFREY JR, T. Mechanical Behavior of High Polymers. New York: Interscience, 1948.

ALLMANN, J. Polyethylene - a proven material in the practical application. Plastic-Pipes XII - Proceedings. Milão, [1 CD-ROM], 2004.

ANDERSON, T.L. Fracture mechanics: fundamentals and applications. Boca Raton: CRC Press, $2^{\text {nd }}$ Ed., 1995, 688p.

ASTM D 638-91: Standard Test method for tensile properties of plastics.

ASTM D 2837-90: Standard test method for obtaining hydrostatic design basis for thermoplastic pipe materials.

ASTM D 4703-03: Standard practice for compression molding thermoplastic materials into test specimens, plaques, or sheets.

BÁRÁNY, T.; CZIGANY, T.; KARGER-KOCSIS, J. Essential work of fracture concept in polymers. Periodica Polytechnica Ser. Mech. Eng., Vol. 47, no 2, pp. 91102, 2003. Disponível em http://www.pp.bme.hu/me/2003_2/pdf/me2003_2_01.pdf.

BARRETO, D. Projeto - PEAD. São Paulo. Instituto de Pesquisas Tecnológicas do Estado de São Paulo, 2000. Notas de apresentação.

BARROS, I.Q. Introdução ao cálculo numérico. São Paulo: Edgard Blücher, 1972.

BILLMEYER, F.W. Textbook of polymer science. 2.ed. New York: WileyInterscience, 1971, 598p.

BODYCOTE POLYMER AB. Lifetime of hot and cold water pipes exposed to chlorinated water. Disponível em <http://www.bodycotepolymer.com/downloads. Acesso em 08/08/2003.

BOENIG, H.V. Structure and properties of polymers. Stuttgart: Georg Thieme, 1973. 283p.

BROBERG, K.B. Critical review of some theories in fracture mechanics. International Journal of Fracture Mechanics, 4, pp. 11-18, 1868.

BROBERG, K.B. On the stable crack growth. Journal of the Mechanics and Physics of Solids, Vol. 23, pp. 215-237, 1975. 
BROBERG, K.B. The foundations of fracture mechanics. Engineering Fracture Mechanics, Vol. 16, nº 4, pp. 497-515, 1982.

BROWN, N. Creep, stress relaxation and yielding, in Engineered Materials Handbook - Vol.2: Engineering Plastics. ASM - The American Society for Metals, Ed, pp. 728-733, 1988.

BROWN, N; LU, X; HUANG, Y-L; QIAN, R. Slow crack growth in polyethylene - a review. Makromol. Chem, Macromol. Symp, Vol. 41, pp. 55-67, 1991.

CALLISTER JR, W.D. Materials science and engineering: an introduction. 5.ed..New York: John Wiley \& Sons, 2000.

CANEVAROLO JR, S.V. Ciência dos polímeros: um texto básico para tecnólogos e engenheiros. São Paulo: Artliber, 2002, 183p.

CAWOOD, M.J.; CHANNELL, A.D.; CAPACCIO, G. Crack initiation and fibre creep in polyethylene. Polymer, Vol. 34, nº 2, pp. 423-425, 1993.

CHAN, M.K.V; WILLIAMS, J.G. Slow stable crack growth in high density polyethylenes. Polymer, Vol. 24, pp. 234-244, 1983.

CHAN, W.Y.F.; WILLIAMS, J.G. Determination of the fracture toughness of polymeric films by the essential work method. Polymer, Vol. $35, \mathrm{n}^{\circ} 8$, pp. 16661672, 1994.

CHUDNOVSKY, A.; SHULKIN, Y. Application of the crack layer theory to modeling of slow crack growth in polyethylene. International Journal of Fracture, Vol. 97, pp. 83-102, 1999.

CLUTTON, E.. Essential work of fracture, in MOORE, D.R; PAVAN, A.; WILLIAMS, J.G. - Editors: Fracture mechanics testing methods for polymers, adhesives and composites. Amsterdam: Elsevier, ESIS Publication 28, 2001.

COTTERELL, B.; REDDEL, J.K. The essential work of plane stress ductile fracture. International Journal of Fracture, Vol. 13, nº 3, pp. 267-277, 1977.

COUTINHO, M.B.; MELLO, I.L.; SANTA MARIA, L.C. Polietileno: principais tipos, propriedades e aplicações. Polímeros: Ciência e Tecnologia, Vol.13, $\mathrm{n}^{\mathrm{o}} 1$, pp.1-13, 2003.

DOT - DEPARTMENT OF TRANSPORTATION. DOT ADVISORY 09/12/2002. Premature brittle-like cracking of older plastic pipe.

Disponível em $<$ http://ops.dot.gov $>$. Acesso em 26/06/2003.

DOT - DEPARTMENT OF TRANSPORTATION. ADB99-01: Potential failure due to brittle-like cracking certain polyethylene plastic pipe manufactured by Century Utility Products Inc. 1999. 
Disponível em <http://ops.dot.gov/foia/adb9901.htm>. Acesso em 18/06/2003.

DOWLING, N.E. Mechanical behavior of materials - engineering methods for deformation, fracture, and fatigue. New Jersey: Prentice-Hall, $2^{\text {nd }}$ Ed., 1999, 830p.

DUAN, D.M.; WILLIAMS, J.G. Craze testing for tough polyethylene. Journal of Materials Science, 33, pp.625-638, 1998.

FAYOLE, B; VERDU, J. EWF method to study long term fracture properties of cross-linked polyethylene. Polymer Engineering and Science, Vol.45, n ${ }^{\circ} 3$, pp. 424431, 2005.

FISHER, W.F. em BABBIT, R.O., ed. The Vanderbilt rubber handbook. Norwalk: R.T. Vanderbilt Company, 1978.

GRIFFITH, A.A. The phenomena of rupture and flow in solids. Philosophical Transactions, Series A, Vol. 221, pp. 163-198, 1920.

HALE, G.E.; RAMSTEINER, F.. J-Fracture toughness of polymers at slow speed, in MOORE, D.R.; PAVAN, A.; WILLIAMS, J.G. - Editors: Fracture mechanics testing methods for polymers, adhesives and composites. Amsterdam: Elsevier, ESIS Publication 28, 2001.

HASHEMI, S. Fracture toughness evaluation of ductile polymeric films. Journal of Materials Science, Vol. 32, no 6, pp. 1563-1573, 1997.

HAYDEN, W; MOFFATT, W.G.; WULFF, J. Structure and Properties of Materials - Mechanical Behavior. New York: John Wiley \& Sons, 1965.

HERTZBERG, R.W. Deformation and fracture mechanics of engineering materials. John Wiley \& Sons, 4.ed, 1995, 786p.

HUANG, D.D. The application of fracture mechanics to materials selection. Polymer Engineering and Science, Vol. 36, n 18, pp. 2270-2274, 1996.

HUANG, Y-L; BROWN, N. The effect of molecular weight on slow crack growth in linear polyethylene homopolymers. Journal of Materials Science, Vol.23, p.3648, 1988.

INGLIS, C.E. Stresses in a plate due to the presence of cracks and sharp corners. Transactions of the Institute of Naval Architects, Vol. 55, pp. 219-241, 1913.

IPT - INSTITUTO DE PESQUISAS TECNOLÓGICAS DO ESTADO DE SÃO PAULO S.A. Relatório técnico no 49.118. 13/12/2000.

IPT - INSTITUTO DE PESQUISAS TECNOLÓGICAS DO ESTADO DE SÃO PAULO S.A. Relatório técnico $\mathbf{n}^{\mathbf{0}}$ 49.552. 15/01/2001. 
ISO 9080: Plastic-piping and ducting systems - Determination of the long-term hydrostatic strength of thermoplastics materials in pipe form by extrapolation.

ISO 12162: Thermoplastics materials for pipes and fittings for pressure applications - Classification and designation - Overall service (design) coefficient.

IVANKOVIC, A.; PANDYA, K.C.; WILLIAMS, J.G. Crack growth predictions in polyethylene using measured traction-separation curves. Engineering Fracture Mechanics, Vol. 71, pp 657-668, 2004.

JANSON, L-E. Plastic pipes for water supply and sewage disposal. Stockholm: VBB/SWECO INTERNATIONAL, 2003. 404p.

KANNINEN, M.F.; POPELAR, C.H. Advanced fracture mechanics. New York: Oxford University Press, 1985, 563p.

KARGER-KOCSIS, J; CZIGÁNY, T.; MOSKALA, E.J. Thickness dependence of work of fracture parameters of an amorphous copolyester. Polymer, Vol. 38, $\mathrm{n}^{\mathrm{o}}$ 18, pp. 4587-4593, 1997.

KINLOCH, A.J.; YOUNG, R.J. Fracture behaviour of polymers. London: Chapman \& Hall, 1995. 496p.

KWON, J.A; TRUSS, R.W. The work of fracture in uniaxial and biaxial oriented unplasticised polyvinylchloride pipes. Engineering Fracture Mechanics, Vol. 69, pp.605-616, 2002.

LEVINE, D; BERENSON, M.L.; STEPHAN, D. Estatística: teoria e aplicação. Rio de Janeiro: Livros Técnicos e Científicos, 2000.

LJUNGBERG, L.Y. Materials selection and design for structural polymers. Materials and design, Vol. 24, nº 5, pp. 383-390, 2003.

LU, X.; BROWN, N. The ductile-brittle transition in a polyethylene copolymer. Journal of Materials Science, 25, p.29-34, 1990a.

LU, X.; BROWN, N. The transition from ductile to slow crack growth failure in a copolymer of polyethylene. Journal of Materials Science, 25, p.411-416, 1990b.

LU, X; QIAN, R.; BROWN, N. Discontinuous crack growth in polyethylene under a constant load. Journal of Materials Science, Vol. 26, pp. 917-924, 1991.

LU, X; ZHOU, Z.; BROWN, N. The anisotropy of slow crack growth in polyethylene pipes. Polymer Engineering and Science, Vol. 34, nº 2, 1994. 
MAI, Y-W; POWELL, P. Essential work of fracture and J-Integral measurements for ductile polymers. Journal of Polymer Science: Part B: Polymer Physics, Vol. 29, pp. 785-793, 1991.

MARCHAL, Y.; WALHIN, J., DELANNAY, F. Statistical procedure for improving the precision of the measurement of the essential work of fracture of thin sheets. International Journal of Fracture, Vol. 87, pp. 189-199, 1997.

MARTINS, G.A. Estatística Geral e Aplicada. São Paulo: Atlas, 2a Ed., 2002, $424 p$.

MEYERS, M.A.; CHAWLA, K.K. Mechanical behavior of materials. John Wiley \& Sons, 1999.

MILLS, N.J. Plastics: microestructure \& engineering applications. London: Edward Arnold, $2^{\text {nd }}$ ed., 1993, 377 p.

MOORE, D.R.; PAVAN, A.; WILLIAMS, J.G. - Editors. Fracture mechanics testing methods for polymers, adhesives and composites. Amsterdam: Elsevier, ESIS Publication 28, 2001, 375p.

MORTON-JONES, D.H. Polymer Processing. London: Chapman and Hall, 1989. 260p.

MOSKALA, E.J. A fracture mechanics approach to environmental stress cracking in poly(ethyleneterephthalate). Polymer, Vol. 39, $\mathrm{n}^{\circ} 3$, pp. 675-680, 1998.

NEWMAN JR, J.C. The merging of fatigue and fracture mechanics concepts: a historical perspective. Progress in Aerospace Sciences, Vol. 34, pp. 347-390, 1998.

NIELSEN, L.E.; LANDEL, R.F. Mechanical properties of polymers and composites. New York: Marcel Dekker, $2^{\text {nd }}$ ed., 1994, 557p.

NIMMER, R. Impact loading. in Engineered Materials Handbook - Vol.2: Engineering Plastics. ASM - The American Society for Metals, Ed, pp. 728-733, 1988.

NISHIMURA, H; KAWAGUCHI, T. Evaluation method of slow crack growth on polyethylene pipes for gas distribution. Plastic-Pipes XII - Proceendings. Milão, [1 CD-ROM], 2004

NTS 048: Norma Técnica Interna SABESP - Tubos de polietileno para ramais prediais de água - Especificação.

NTSB - NATIONAL TRANSPORTATION SAFETY BOARD. NTSB/SIR-98/01: Special investigation report: brittle-like cracking in plastic pipe for gas service. 1998. Disponível em <http://www.ntsb.gov/publictn>. Acesso em 18/06/2003. 
NTSB - NATIONAL TRANSPORTATION SAFETY BOARD. Pipeline accident brief. 1998. Disponível em <http://www.ntsb.gov/publictn/1998/PAB9802.pdf $>$. Acesso em 18/06/2003.

OGORKIEWICZ, R.M. Thermoplastics: properties and design. London: John Wiley \& Sons, 1974. 248p.

OLIVEIRA, P.A.O. Análise da distribuição de tensões em um cilindro circular de parede espessa submetido a pressões uniformes nas superfícies interna e externa. Trabalho da disciplina Introdução à Mecânica do Contínuo, curso de PósGraduação em Métodos Numéricos em Engenharia, Universidade Federal do Paraná. Disponível em $<$ http://www.ceses.ufpr.br/ p p_alex/_private/Mecanica.htm $>$. Acesso em: 07/10/2002.

PARDOEN, T; MARCHAL, Y.; DELANNAY, F. Essential work of fracture compared to fracture mechanics - towards a thickness independent plane stress toughness. Engineering Fracture Mechanics, Vol. 69, pp. 617-631, 2002.

PEGORETTI, A.; MARCHI, A.; RICCOे, T. Determination of the fracture toughness of thermoformed polypropylene cups by the essential work method. Polymer Engineering and Science, Vol. 37, nº 6, pp. 1045-1052, 1997.

PERES, F.M.; SCHÖN, C.G. Application of fracture mechanics to failure of high density polyethylene pipes used in service line of water distribution systems. Proceedings of PPS-2004 Americas Regional Meeting, The Polymer Processing Society, Florianópolis, [1 CD-ROM], 2004.

PERES, F.M.; SCHÖN, C.G. Application of fracture mechanics to failure of high density polyethylene pipes used in service line of water distribution systems. Slides of oral presentation at PPS-2004 Americas Regional Meeting, The Polymer Processing Society, Florianópolis, 2004b.

PIEROZAN, R.S. Redes de PEAD para distribuição de água: alta eficiência no combate às perdas. Engenharia, ${ }^{\circ}$ 563, pp. 58-61, 2004.

PPI - THE PLASTIC PIPE INSTITUTE. TN-7/2000: nature of hydrostatic stress rupture curves. 2000. Disponível em $<$ http://www.plasticpipe.org $>$. Acesso em $18 / 06 / 2003$.

PPI - THE PLASTIC PIPE INSTITUTE. Engineering properties of polyethylene. Disponível em $<$ http://www.plasticpipe.org $>$. Acesso em 18/06/2003.

PROGElHOF, R.C.; THRONE, J.L. Polymer Engineering Principles. Munich: Hanser, 1993, 918p.

PURA-PROGRAMA DE USO RACIONAL DA ÁGUA. Por que economizar água?. Disponível em $<$ http://www.pura.poli.usp.br $>$. Acesso em 15/08/2003. 
QIAN, R.; LU, X.; BROWN, N. Investigating the existence of a threshold stress intensity for slow crack growth in high-density polyethylene. Journal of Materials Science, 24, pp. 2467-2472, 1989.

QUADRADO, A.; VERGARA, R. Vai faltar água? Super Interessante, $\mathrm{n}^{\circ} 189$, p.42-46, Junho/2003.

RICE, J.R. A path independent integral and the approximate analysis of strain concentration by notches and cracks. Journal of Applied Mechanics, Vol. 35, pp. 379-386, 1968.

REVISTA BRASILEIRA DE SANEAMENTO AMBIENTAL E MEIO AMBIENTE. Combate às Perdas. Abril/Junho 2003, Caderno Especial, p. 39 a 49.

ROSE, L.J.; CHANNELL, A.D.; FRYE, C.J.; CAPACCIO, G. Slow crack growth in polyethylene: a novel predictive model based on the creep of craze fibrils. Journal of Applied Polymer Science, Vol. 54, pp. 2119-2124, 1994.

SABESP - COMPANHIA DE SANEAMENTO BÁSICO DO ESTADO DE SÃO PAULO. Vice-Presidência Metropolitana de Distribuição. Pesquisa sobre perdas nos ramais prediais. 1998 (documento interno).

SABESP - COMPANHIA DE SANEAMENTO BÁSICO DO ESTADO DE SÃO PAULO. Vice-Presidência Metropolitana de Distribuição. Redução e controle de perdas na RMSP - documento de referência. 2000 (documento interno).

SALEEMI, A.S.; NAIRN, J.A. The plain-strain essential work of fracture as a measure of the fracture toughness of ductile polymers. Polymer Engineering and Science, Vol. 30, no 4, p. 211, 1990.

SANDSTRUM, S.D. High Density Polyethylene (HDPE) Water Distribution Systems. Proceedings of Plastic-Pipes XII. Milan, 2004. [1 CD-ROM].

SCHULTZ, J.M. Polymer Materials Science. Englewood Cliffs: Prentice-Hall, 1974.

SCHÖN, C.G. Noções de mecânica da fratura. Escola Politécnica da Universidade de São Paulo (apostila), 2002.

SCHIRRER, R.; LE MASSON, J.; TOMATIS, B.; LANG, R. The disentanglement time of the craze fibrils under cyclic loading. Polymer Engineering and Science, Vol. 24, pp. 820-824, 1984.

SCHÜTZ, W. A history of fatigue. Engineering Fracture Mechanics, Vol. 54, $\mathrm{n}^{\mathrm{o}} 2$, pp.263-300, 1996. 
SILVA, P.S.C.P. Comportamento mecânico e fratura de componentes e estruturas metálicas. Universidade Federal do Paraná (apostila), Caps 7 e 8, 1999.

SMITH, L.A. et al. Options for leak and break detection and repair for drinking water systems. 1.ed. Columbus: Battelle Press, 2000, 163p.

THOMPSON, D.M.; WEDDLE, S.A.; MADDAUS, W.O. Water utility experience with plastic service lines. Denver, Colo.: AWWARF and AWWA, 1992.

TING, S.K.M.; WILLIAMNS, J.G.; IVANKOVIC, A. Damage evolution and failure mechanisms in polyethylene. Plastic-Pipes XII - Proceendings. Milão, [1 CD-ROM], 2004.

TJONG, S.C.; XU, S.A.; LI, R.K.Y. Work of fracture of polystyrene/high density polyethylene blends compatibilized by triblock copolymer. Journal of Applied Polymer Science, Vol. 77, pp. 2074-2081, 2000.

TRASSAERT, P.; SCHIRRER, R. The disentanglement time of the craze fibrils in polymethylmethacrylate. Journal of Materials Science, Vol. 18, pp. 3004-3010, 1983.

TSUTIYA, M.T. Abastecimento de água. São Paulo: Departamento de Engenharia Hidráulica e Sanitária da Escola Politécnica da Universidade de São Paulo, 2004, $643 p$.

WARD, I.M; SWEENEY, J. An introduction to the mechanical properties of solid polymers. London: John Wiley \& Sons, $2^{\text {nd }}$ ed., 2004.

WIEBEK, H.; HARADA, J. Tecnologia do processo de injeção do plástico módulo avançado. (Apostila). São Paulo: Projeto Atual-Tec/USP. 2002.

WILLIAMS, J.G. Introduction to elastic-plastic fracture mechanics, in MOORE, D.R.; PAVAN, A.; WILLIAMS, J.G. - Editors: Fracture mechanics testing methods for polymers, adhesives and composites. Amsterdam: Elsevier, ESIS Publication 28, 2001.

WU, J; MAI, Y.W. The essential fracture work concept for toughness measurement of ductile polymers. Polymer Engineering and Science, Vol. 36, $\mathrm{n}^{\mathbf{0}}$ 18, p.2275, 1996.

ZHOU, W. et al em MOALLI, J, ed. Plastic failure analysis and prevention. William Andrew Publishing/Plastic Design Library, 400 p., 2001. 